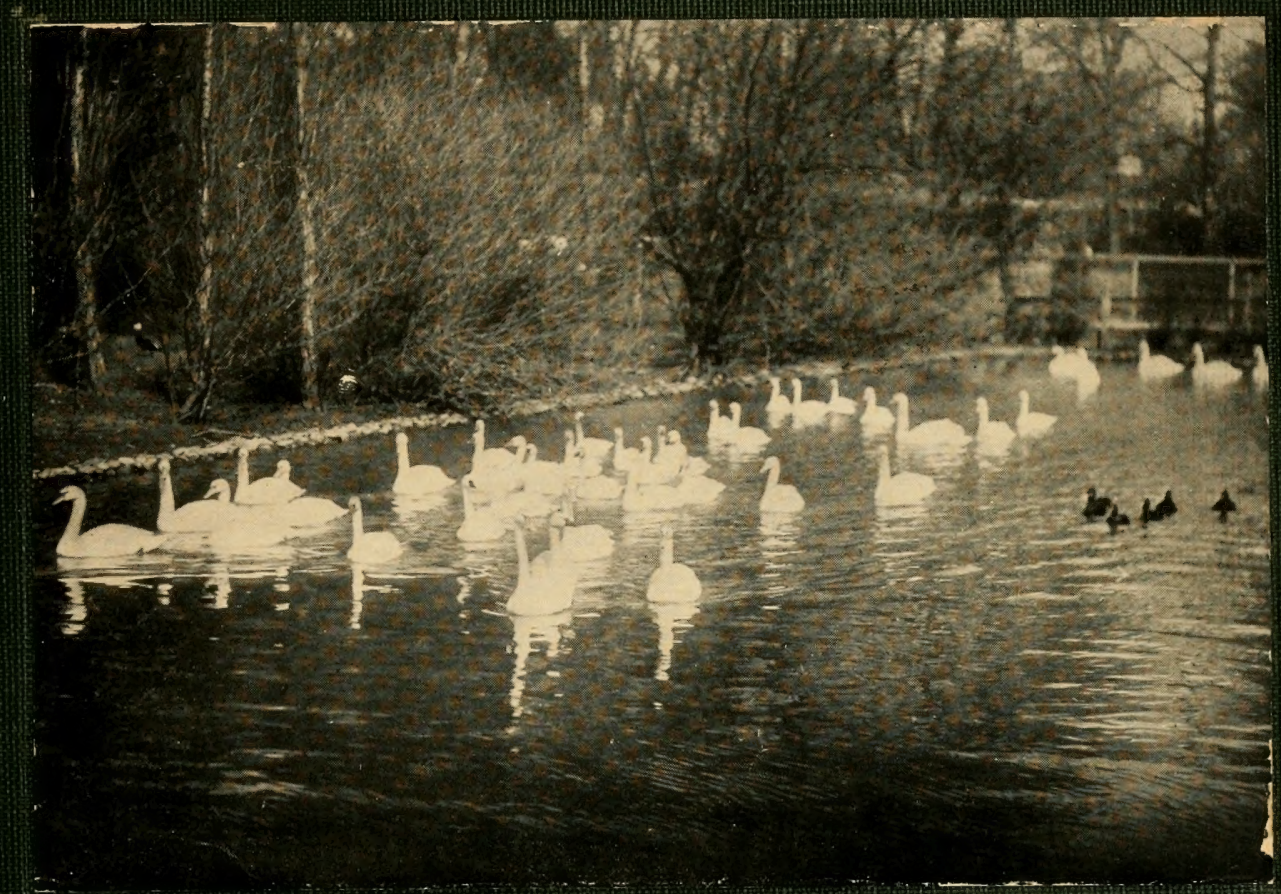

\title{
PROPAGATION OF WILD BIRDS
}

HERBERT K. JOB 


\section{Smithsonian Institution $\checkmark$ Sibraries}

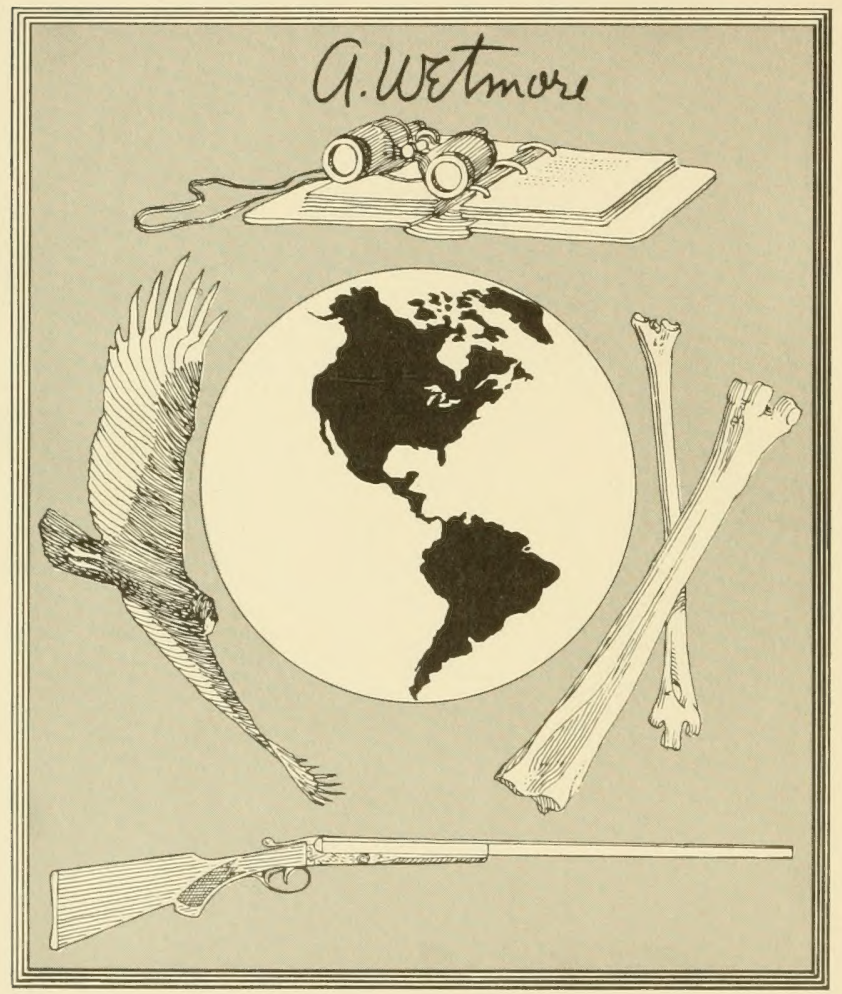

Alexander Wetmore 1946 SixtbSecretary 1953 (2) 
appil 27,1916.

$z^{-}$ 

PROPAGATION OF WILD BIRDS 


\section{ILLUSTRATED BOOKS BY THE SAME AUTHOR}

\section{AMONG THE WATER-FOWL}

Observation, adventure, photography. One hundred photographs. \$r.35, net. Doubleday, Page \& Co., Garden City, N. Y.

\section{WILD WINGS}

Adventures of a camera hunter among the larger wild birds of North America on sea and land. With an introductory letter by ex-President Roosevelt. One hundred and sixty photographs. $\$ 3.00$, net. The Houghton Mifflin Co., Boston.

\section{THE SPORT OF BIRD STUDY}

A book for young or active people. Telling how a man and boy friend had fun learning the birds of a country town. One hundred and thirty-four photographs. \$1.50, net. The Outing Publishing Company, New York City.

\section{HOW TO STUDY BIRDS}

A practical guide for amateur bird lovers and camera hunters. A companion book to the preceding. Fifty-seven photographs. \$1.50,net. The Outing Publishing Company, New York.

\section{THE BLUE GOOSE CHASE}

A camera hunting adventure in Louisiana. A story for boys. Illustrated. $\$ 1.25$, net. Doubleday, Page \& Co., Garden City, N. Y. 



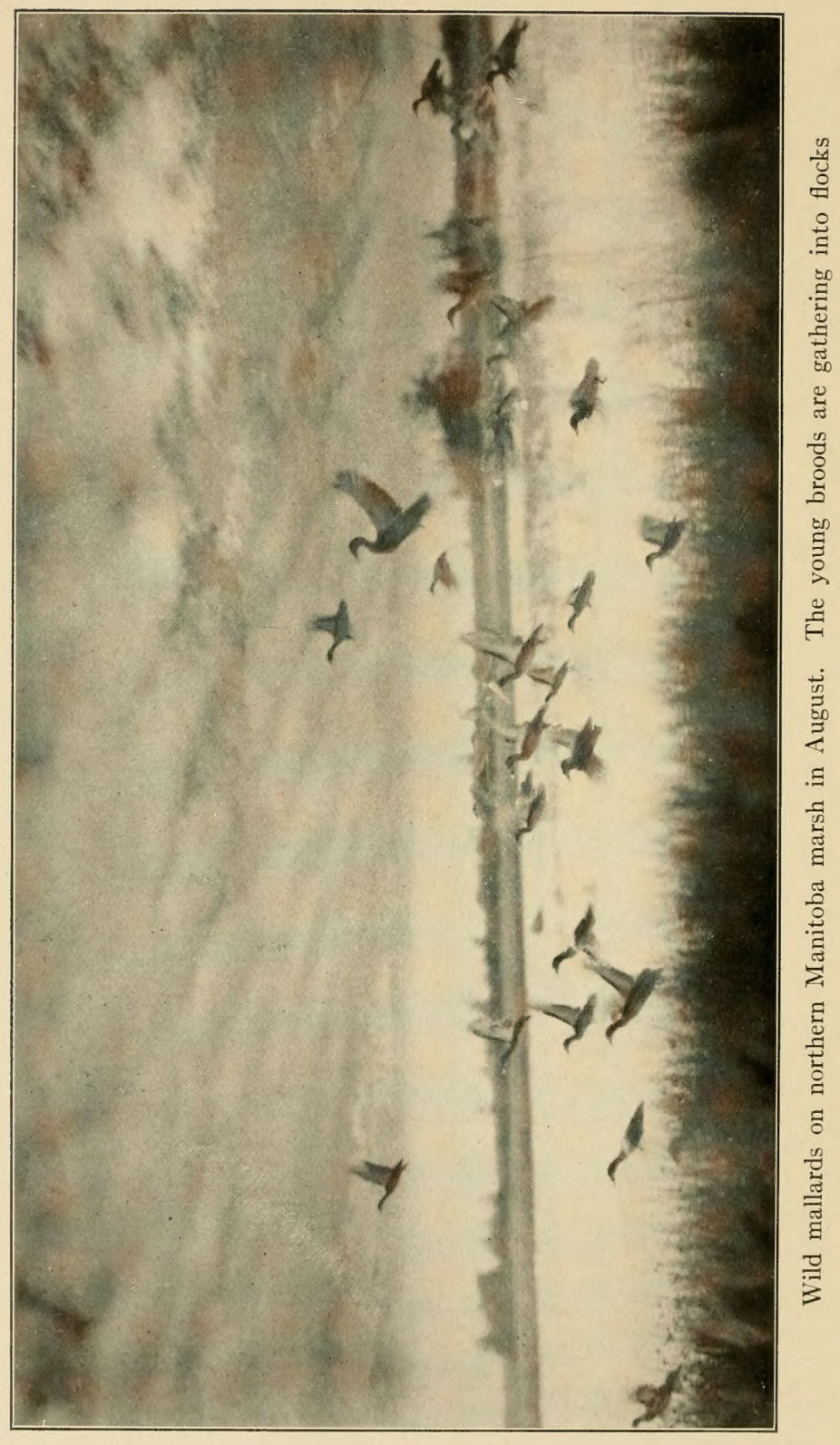




\section{PROPAGATION OF WILD BIRDS, \\ A Manual of Applied Ornithology}

TREATING OF PRACTICAL METHODS OF PROPAGATION OF QUAILS, GROUSE, WILD TURKEY, PHEASANTS, PARTRIDGES, PIGEONS AND

DOVES, AND WATERFOWL, IN AMER-

ICA, AND OF ATTRACTING AND INCREASING WILD BIRDS IN GENERAL, INCLUDING SONG-BIRDS

\section{By HERBERT K. JOB}

Economic Ornithologist in Charge of the Department of Applied Ornithology of the National Association of Audubon Societies, Member of the American Ornithologists' Union, Formerly State Ornithologist of Connecticut, E'c.

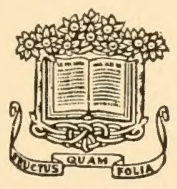

Illustrated from photographs Thostly by the Author

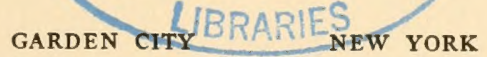
DOUBLEDAY, PAGE \& COMPANY I9I 5 
Copyright, 191 5, by Doubleday, Page \& Company All rights reserved, including that of translation into foreign languages, including the Scandinavian 
TO THE FOUNDERS OF THE DEPARTMENT OF APPLIED ORNITHOLOGY OF THE NATIONAL ASSOCIATION OF AUDUBON SOCIETIES,

FRIENDS AND FELLOW-WORKERS IN THE GREAT CAUSE OF THE CONSERVATION OF THE WILD BIRD LIFE OF AMERICA,

I DEDICATE THIS FIRST MANUAL OF APPLIED ORNITHOLOGY 



\section{A PREFATORY NOTE}

There has grown up in the United States, within the past ten years, a widespread interest in birds, the extent of which has never been equalled in this or any other country. Along with the desire to acquire more knowledge regarding the habits and activities of these feathered denizens of the great Outside has arisen a sense of personal obligation to aid all movements that tend toward safeguarding their lives and prolonging their usefulness. As a result, the popular support for the enactment of important State and Federal laws for the conservation of wild birds and animals has given profound astonishment to those benighted persons whose custom it has been to accumulate wealth by the destruction of wild creatures for the markets offered by the game-dealer and the millinery feathermerchant. This was well illustrated in I9Io, when the people of New York State arose almost in mass and demanded of the Legislature that it pass the Audubon Society's bill to prohibit the sale of birds' feathers; and again in 1913, when there was pending in the Tariff Bill the proviso to prohibit the importation of the feathers of wild birds. More than two hundred thousand letters and telegrams of approval poured in upon the desks of the Senators and Congressmen in Washington.

The enactment of the Federal Migratory Bird Bill, also in I9I3, would not have been possible a few years before, as numerous unsuccessful attempts had demonstrated.

As a natural consequence of these manifestations of vii 
interest on the part of the public, there has appeared an increased desire to have birds come about the home in greater numbers. People are wanting more robins on the lawn, more wrens in the garden, and more bluebirds, thrashers, and woodpeckers in the neighbourhood.

To encourage the birds to become more familiar thousands of persons in every State are now erecting nestingboxes for the birds in spring and providing food for them in winter. Others favourably situated for larger experiments wish to engage in the rearing of wild ducks, or of quails, grouse, pheasants, and other upland game-birds.

I recall that less than ten years ago I spent much time in an effort to induce a certain man to begin the manufacture and sale of nesting-boxes for birds and similar apparatus, with the view of supplying a demand which I felt was certain to come. It was with very great difficulty that he was induced to go into this business. To-day there are more than twenty well-known manufacturers of bird-boxes and other bird-attracting apparatus in the eastern part of the United States alone.

It has not been a great many years since an estate on which pheasants and wild ducks were reared was a curiosity and occasioned much local comment. To-day hundreds of persons are engaging in this pleasant and profitable occupation. Naturally much well-meant effort in this direction has been ill-directed; and it has become evident that there is great need of some one highly skilled in the matter of artificial propagation of birds to give counsel to those desiring to undertake an enterprise of this character.

It was to meet this demand and provide expert advice for those desiring to begin the raising of game-birds, or to make bird-sanctuaries of their groves and fields, that I arranged for the National Association of Audubon Socicties 
to establish, in I9I4, its "Department of Applied Ornithology."

After looking over the entire field I felt that the best man to conduct this important branch of the association's activities was Herbert K. Job, a well-known naturalist, and at that time State Ornithologist of Connecticut. Since his connection with the association, as well as before, he has had unusual facilities for investigating the methods of successful game-breeders throughout the country; and the broad knowledge thus gained, added to his many years of practical experience in the hand-raising of upland gamebirds and waterfowl, has qualified him in a most unusual degree for undertaking the preparation of this "Manual" which undoubtedly will be the standard authority on game propagation for many years to come.

I have read the pages of the manuscript with great pleasure and profit, and my opinion of its excellence is shared by Senator George P. McLean, F. C. Walcott, Wallace Evans, Dwight W. Huntington, and other gentlemen of experience, who have also read it critically and given it their approval.

T. Gilbert Pearson. 



\section{CONTENTS}

INTRODUCTORY. The New Ornithology . . . xvii

PART I. METHODS WITH GALLINACEOUS BIRDS, AND OTHERS

CHAPTER

PAGB

I. General Methods . . . . . . . . . 3

II. Quail Propagation Methods as a Basis • I3

III. The Grouse Famly • • • • • • • • 55

IV. The Wild Turkey. • . . . . . • . 67

V. Pheasant Rearing . . . . . . . . . 75

VI. Other Foreign Gallinaceous Species • • 9 I

VII. Pigeons and Doves • . . . . . . • 100

VIII. Control of Vermin . . . . . . . IO3

PART II. THE PROPAGATION OF WILD

WATERFOWL

IX. Wild Ducks . • • • • • • • •

X. Wild Geese . • • • • • • • , • I84

$\mathrm{XI}$. Swans. • • • • • • • • • • •

XII. WADING-BIRDS • • • • • • • • • . 194

XIII. Refuges and Protected Colonies . • . 199 
PART III. METHODS WITH THE SMALLER LAND-BIRDS

CHAPTER

XIV. Preliminary Matters. . . . . . 203 XV. Aids to Nesting . . . . • . . • . 2 II

a. Nesting-boxes . . . . . . . . 2 II

b. Supplying Nesting Material • . • 233

XVI. Making Surroundings Attractive . • . 236

a. Attractive Vegetation . . . . . 236

b. Water Supply . . . . . . . 246

c. Suppression of Enemies . . . . . 248

XVII. Artificial Feeding . • . • • • • 255

Addenda . . . . . . . . . . 267

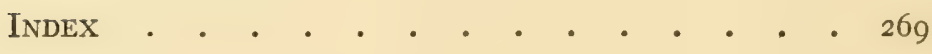




\section{ILLUSTRATIONS}

Wild mallards flying from Manitoba marsh . Frontispiece

FACING PAGE

Ring-neck pheasants on Evans' Game Farm . . . . . . I6

Hatching-coops, State Game Farm, Sherburne, New York. I7

Breeding-pen for pair of quails, Storrs, Connecticut. . . I I7

Typical hatching and rearing coop, Sherburne, New York . I7

Bob-white breeding-stock before pairing. . . . . . 32

Group of young bob-whites feeding . . . . . . . 32

Main holding-pen for quails, Storrs, Connecticut . . . 33

Quail rearing-field, with covered corral in near corner . . 33

Buckwheat left standing for birds . . . . . . . . 33

Nest with twenty-four eggs of bob-white in a coop . . . 36

Day-old quails and empty egg-shell . . . . . . . 36

Young quail watching a fly . . . . . . . . . 37

Bantam with quail chicks . . . . . . . . 37

Muriel, daughter of author, feeding little bob-whites . . 44

Bob-white stock of T. A. Howell in winter quarters . . . 44

Ruth, daughter of Supt. Dirks, with California or valley quails . . . . . . . . . . . . 45

Scaled or "blue" quails . . . . . . . . . 45

Young ruffed grouse strutting. . . . . . . . . . 48

Tame ruffed grouse, captured wild . . . . . . . 48

F. N. Manross and young ruffed grouse which he raised 49

U. S. Senator George P. McLean feeding his young ruffed grouse . . . . . . . . . . 49

Ruffed grouse chicks . . . . . . . . . . 64

Young ruffed grouse three weeks old . . . . . . 64

Sharp-tailed grouse on nest . . . . . . . . 65

Rearing-field and shelter-house for wild turkeys . . . 65 
Wild turkey breeding-stock in enclosure . . . . . . 68

Pheasant breeding-pens, Evans' Game Farm . 69

Single pheasant breeding-pen, Sherburne, New York . . 69

Pheasant rearing-field . . . . . . . . . . 76

Breeding-field for pheasants, Clove Valley Club, New York $\quad 76$

Fence of pheasant rearing-field and vermin-traps . . . 77

Hatching-house. Putting out hens to feed . . . . . 77

Golden and silver pheasants . . . . . . . . . 80

Feeding young pheasants, Clove Valley Club . . . . 8 I

Breeding harem of pheasants . . . . . . . . . SI

Young pheasants caught for shipment . . . . . 8 I

Tinamou, the South American species bred by William Rockefeller . . . . . . . . . . . . . 96

Gray or "Hungarian" partridges . . . . . . . . . 96

Mourning dove . . . . . . . . . . . . 97

Crows shot by a farmer. . . . . . . . . . . . 97

Box trap for vermin . . . . . . . . . 98

Four predatory cats . . . . . . . . . . . 98

Skunk in trap . . . . . . . . . . . . . . . . 99

Gray fox caught by front paw . . . . . . . . . . 99

Wild ducks in Texas . . . . . . . . . . . . II 8

Swans keeping open a hole in the ice . . . . . . . IIS

Mallards at feeding time . . . . . . . . . . . . II9

Young mallards raised at Clove Valley Club. . . . . . . II9

Mallards and black ducks raised on Evans' Game Farm . I22

Henry Cook feeding some of his wild ducks . . . . . 123

Mallards raised by a farmer in Connecticut . . . . . . 123

Rearing-field for mallards, Clove Valley Club . . . . I2S

Our "duck farm" in Manitoba wilderness . . . . . I2S

Canvasbacks in artificial pool . . . . . . . . . 129

Wild ducks in winter quarters . . . . . . . . . 129

Mr. Heywood's method of wintering waterfowl . . . . I32

Canvasbacks at Branchport, New York . . . . . . I33

Wild black ducks on Lanier preserve . . . . . . . . I33

Son of author feeding "wild" ducklings, gadwalls, etc. . . $\quad 140$ 
Author feeding young wild ducks .

Evans' method of rearing young wood ducks.

Ducklings in fenced marsh, Evans' Game Farm . . . . I4I

Female lesser scaup duck fluttering from nest . . . . I44

Gadwall flushing from nest in prairie grass . . . . . 144

Nest of canvasback, seldom seen by white men . . . . 145

Nest of lesser scaup duck ten feet back from shore . . . I45

Young canvasbacks, about two weeks old . . . . . I48

Young canvasbacks, well grown . . . . . . . 148

Young redheads, Manitoba expedition . . . . . . 149

Brood of young gadwalls . . . . . . . . . . . I49

Young shovellers or spoonbills . . . . . . . . ${ }_{5} 56$

Young pintails . . . . . . . . . . . ${ }^{2} 56$

Young white-winged scoter or "sea-coot" . . . . . I57

Young golden-eyes or "whistlers" . . . . . . . I57

Young ruddy duck . . . . . . . . . . . I60

Pair of adult ruddy ducks near nest . . . . . . . I60

Lesser scaups or "broadbills" under protection from shooting. . . . . . . . . . . . . I6I

Wild geese on Evans' Game Farm. . . . . . . . I70

Great flock of blue geese . . . . . . . . . 177

Brants in captivity . . . . . . . . . . . 177

Family party of domesticated Canada geese . . . . I80

Canada goose incubating on Connecticut farm . . . . I8o

Swans at George D. Tilley's aviary . . . . . . . I8I

Cranes at aviary of George D. Tilley . . . . . . . ISI

Black swans nesting on Evans' Game Farm . . . . . IS8

Young coots or "mud-hens" raised from incubator . . . I88

Mrs. Bath and her pet coots . . . . . . . . . I 89

Flock of pintails on Louisiana marsh . . . . . . . 196

Black skimmers on Government reservation. . . . . 197

Breeding royal terns under protection . . . . . . 197

Von Berlepsch-model nesting-box. . . . . . . . 204

Suet basket in position . . . . . . . . . . 204

Warc-model "swallow box" occupied by bluebirds . . . 205 
FACING PAGE

The same bluebird entering . . . . . . . 205

Natural nesting of tree swallow . . . . . . . . 208

Tree swallow occupying Ware-model "bluebird box" . . 208

Natural nesting of flicker . . . . . . . . . . 209

Flicker using Ware-model nesting-box . . . . . . 209

Purple martins nesting in gourds . . . . . . . . 224

An occupied martin house . . . . . . . . . . . 224

Pair of purple martins nesting. . . . . . . . . 225

Protected nesting-box on Henry Ford farm . . . . . 225

House wren nesting in a tin can . . . . . . . . 228

Thorn shrubbery on Ford farm where birds like to nest. $\quad 228$

Food-houses and Henry Ford's bungalow . . . . 229

Grackles and sparrow bathing on sidewalk . . . . . 236

Birds' drinking fountain and bathing pool . . . . 236

Starlings going to roost in steeple . . . . . . . . 237

European starling entering stolen woodpecker's nest . . 237

Female scarlet tanager touched by author . . . . . 240

Blue-headed vireo being handled on nest by author. . . 240

Black-throated green warbler feeding young in lap of girl . $24 \mathrm{I}$

Chickadee feeding young on author's arm . . . . 24I

White-breasted nuthatch feeding on window-sill . . 256

Tree sparrows at lunch-counter . . . . . . 256

Chickadec feeding . . . . . . . . . . 257

Downy woodpecker eating suet . . . . . . . 257

Red-headed woodpecker at lunch-counter . . . . . 260

Blue-jay at lunch-counter . . . . . . . . 260

Junco or snow-bird eating seed sprinkled on snow . . . $26 \mathrm{I}$

Magpies on food-shelf . . . . . . . . . 26 I 


\section{INTRODUCTORY}

\section{THE NEW ORNITHOLOGY}

Applied ornithology may be defined broadly as the application of our knowledge of bird life to human welfare. For our present purpose it may be regarded as the discovery and explanation of practical methods for the increase of wild birds, based upon a knowledge of their habits and capabilities acquired by observation and experiment. It will include also methods of bringing wild birds into closer proximity with man, since the sight and observation of wild life has become an important source of pleasure and education. The topics to be considered in this Manual, therefore, are the best practical methods for attracting, protecting, propagating, and generally increasing wild bird life within the limits of each reader's place and circumstances.

Applied ornithology is directly in line with modern progress and with the spirit of the times. Although any science or knowledge is worth while for its own sake, there is at present a general feeling that mere learning should not normally be considered the finality, but that it should lead to some real benefit to mankind. Hence the phrase "applied science" has become familiar, and special usages of it havealready appeared - " applied entomology," for example, designating the service entomological science renders to agriculture, forestry, etc.

It was very natural, then, that the term "Applied Ornithology" should be given by T. Gilbert Pearson, the Secretary of the National Association of Audubon Societies, to 
this new branch of science, when the association purposed to organize a department to prosecute it.

Up to about I875 birds of all sorts were slaughtered for food, or sport, or their plumage, with almost utter unconcern. Then it began to dawn upon thoughtful minds that bird life had economic value, and that, unless the slaughter was stopped, there soon would be no birds.

A great and successful warfare has been waged for the protection of bird life, and now public sentiment strongly demands its restoration to normal abundance. This has resulted in great good, and the wild bird population of the whole country has gained in numbers; but much remains to be done, and more and more persons are conscientiously trying to advance the beneficent movement.

One of the most interesting developments in public sentiment is that an increasing number of persons are discovering that it affords them pleasure to see wild birds multiply, particularly as the result of their own efforts; to have them settled on their own land or home-spot; to see new kinds; and to have intimate personal contact with these pretty pensioners.

Louis Agassiz Fuertes, the artist of bird life, once asked the writer whether he ever felt a sort of rapturous thrill when in close proximity to a wild bird, especially with a rare or unusual one. Bless his artistic soul! A thousand times, yes! It is one of the most entrancing emotions; and the person is fortunate indeed who knows it from frequent experience.

Recently I sat for more than an hour on the shore of a small pond close to several species of wild ducks in all the glory of their nuptial plumage. The previous season out in the wilds of northern Manitoba I had hatched these ducklings in an incubator, raised them by hand, and had brought 
them under my personal care more than two thousand miles to the spot where I sat. The wonderful canvasbacks were diving and eating the succulent roots which they brought to the surface. The light glanced resplendent from their delicately pencilled backs and gleamed in the fiery eyes of the males. Was it tedious to sit there so long in the cold April wind? Nay, rather in my delight I was oblivious to the passing of time.

Much the same feeling may be kindled when a pair of bluebirds, wrens, or chickadees accept our hospitality and raise a brood or two in one of our nesting-boxes; or when the chipping sparrows and phœbes use the building material we have put out for them, and nest in the woodbine or under the porch by our very door.

There are also many who, besides enjoying the sight and presence of wild birds, will utilize the methods hereafter described to increase or propagate certain species for purposes of food, financial profit, or hunting. These demands properly met need not diminish the supply of wild birds, but may serve to increase them. The old adage is becoming popular, "For every bird you take, put back two."

The best type of sportsman is not a person greedy for slaughter. He loves the whole experience of a day afield, the exhilarating exercise, the matching of his wits with the keen instincts of the wild creatures. A mere taste of the game on the table is enough, and he forbears to kill more. He feeds the game in winter and takes measures to propagate or protect it from natural enemies and dangers. On many a hunt, when he secures no game, he enjoys the experience to the full. Such a man saves more than he destroys, and is a real friend of wild bird life, standing for strict protective laws and the rigid enforcement of them.

The actual propagation of edible species for purposes of 
food or financial profit is receiving a great impetus these days, and is becoming an important industry. Wild ducks and pheasants are raised in large numbers for the market. Farmers and youths are beginning to propagate "game" as a side line for profit, and in some cases add neat sums to their incomes. To supply the wide demand for breedingstock people here and there are beginning to experiment with various species, often with considerable success. Such efforts will also help to extend the range and increase the numbers of these birds. Farmers can make it a source of revenue to protect or propagate game on their land either for purposes of sale or to lease out the hunting privilege.

The propagation by human industry of wild birds for food is precisely as legitimate as the farming of domestic poultry. All the domesticated species came originally from wild stock, though modified by hybridization and selection. They have thus been saved from extermination, and have become of immense value to mankind. The question becomes largely one of conscrvation, of keeping up the supply. It is now impracticable to allow the sale of wild game, because modern commercial methods would speedily exterminate it. But if it can be multiplied by industry, there is every reason to encourage such undertakings, and permit the sale of birds so raised under proper restrictions.

Already there is a considerable demand for men skilled in the propagation of game-birds and wildfowl, for employment on game preserves or private estates. Besides raising game, their work is to protect and feed birds and game, and to exterminate the vermin that preys upon them.

On some estates the owner allows no shooting, but breeds game for the pleasure of seeing it about, and also attracts and protects bird life in general. For such positions men of 
all-round familiarity with birds and game, and versed in modern methods as defined in this Manual, are desired.

As a result of the protection of migratory birds by the Federal Government, under authority of the Weeks-McLean law, men are being employed as Federal wardens under civil service regulations, and I am informed that preference will be given to those who understand the methods of propagation of game and other practical methods described hereafter, and can teach them in their districts. Municipalities also are beginning to employ "bird wardens," to protect, attract, and care for wild bird life. No doubt State authorities would be glad to employ game wardens of this calibre, could they be found.

These various demands will provide congenial outdoor employment for many young men who love such things. One frequent complaint that I hear about game-keepers is that some are addicted to liquor, are unreliable at critical times, and are illiterate and unprogressive. It is an honourable and important profession, coming rapidly to the fore, and there is a growing demand in this work for young men who abstain from liquor, have sufficient education to carry out experiments and keep proper records, and who know their business. The number of game preserves and large estates whose owners propagate or protect game and wild life is already large, and is constantly increasing. Most of these either employ game-keepers, or, in employing superintendents or assistants, give preference to men who understand these methods of "applied ornithology." This is bound to become an important profession.

The many kindly persons who dislike the idea of shooting wild birds, whether for food or for any other purpose, and might be inclined to look askance upon their propagation for food or sport, may feel assured of an interesting 
tendency which is working out. Many a man who has begun the propagation of "game-birds" with the idea of securing better shooting has found so much satisfaction in such work, and has become so much attached to his "feathered children" that he becomes disinclined to shoot them. Humane sentiment is spreading wonderfully, and we can well afford to leave it to the individual what he will do with the birds which he raises. At any rate, the result is bound to be the increase of bird life.

I shall be very glad if applied ornithology serves to broaden popular sentiment in all classes of bird life. It has always seemed illogical to me that so many people should take no interest in any but the common local "song-birds," and know nothing about others. The fact that it has now become possible to breed certain species of gallinaceous birds, and of wild ducks and geese, and have them free on one's own premises under easy observation, should tend to arouse general interest in them and make them almost as familiar as robins and swallows.

I cannot help feeling that the term "game-bird" is often overworked and made to imply too much, as if such birds as quails and grouse, lawfully regarded as game, were owned only by those who shoot, whereas they are property of all the people, and there are other legitimate uses for them than for shooting.

The term "game-birds," moreover, is loose and unscientific. What birds are game-birds changes from time to time under varying laws. The mourning dove, for instance, formerly legal game in all States, is now protected by law almost everywhere. Likewise the wood duck, and many kinds of shore birds, now protected by Federal enactment, are no longer "game-birds." Even the crow is known to be eaten in construction camps. The term is convenient where refer- 
ence is made to birds that are eaten. To the lover of wild life a bird is a bird, irrespective of whether or not it is edible. I feel like putting on record here a kindly and well-meant plea to the public not to be narrow in their sympathies, but to take a broad interest in all wild life.

Speaking of "game-birds" calls up a point in nomenclature. Among the hunters it is quite common to use the singular form for the plural in referring to birds of this class. One says he saw twenty "quail" or a covey of "partridge." But it would sound ridiculous to say a flock of sparrow, a raft of gull, or a wavy line of goose. So, when I write quails, it is not exactly through ignorance!

Applied ornithology is so new a field that its development necessarily remains incomplete. There is no thought of finality in mind in penning these pages and chapters. I consider this Manual as merely preliminary, and shall hope from time to time to revise it, adding discoveries and improvements, dropping what may have become superseded, and trying to keep the matter up to date.

That there is a real demand for such practical information has been made very apparent by the many letters which have come to me for several years from all over the United States and Canada, asking for information, and especially for literature-hitherto lacking-on these practical subjects.

Owing to this widespread interest, The National Association of Audubon Societies has asked me to conduct under their auspices a Department of Applied Ornithology. This new department will try to serve as a bureau for practical advice and assistance to all who desire help in attracting, propagating, or increasing bird life; and it will provide bulletins or other helpful publications. I shall be glad to hear at any time from such persons in care of the National Asso- 
ciation of Audubon Societies, New York City. It will be of real service if those who are trying practical measures to increase, attract, or propagate wild birds will acquaint me with the details of their work, whether successful or otherwise. Many phases of the subject are yet in the experimental stage, and by comparison of methods a great deal may be learned.

I feel myself under deep obligation to many fellowenthusiasts who in various ways have assisted, encouraged, or inspired me in the prosecution of these studies and in the preparation of this volume. To these various friends, whose names follow, my sincere thanks and appreciation are extended:

The Okeetee Club contributed liberally to the carrying on of my experimental work at a time when such help was particularly needed, and the results are in no small degree due to its generosity. Others who have made it possible for me to carry out important lines of experiment and research are Frederic C. Walcott, S. W. Childs, William Rockefeller, Edmund C. Converse, H. O. Havemeyer, T. A. Howell, F. F. Brewster, United States Senator George P. McLean, T. Gilbert Pearson, and the donors of the fund for The Department of Applied Ornithology, whose names are listed in The National Association of Audubon Societies, "Bulletin Number 2," to whom I would add the the name of my Harvard classmate, Philip Dexter. For these this expression of thanks seems utterly inadequate.

From the following I have received detailed, practical information of great value, of ten representing the results of years of observation and research. Let this mention of their names, in alphabetical order, be the assurance of my appreciation and grateful remembrance: E. Aubry, E. H. Austin, O. R. Austin, A. M. Barnes, C. William Beebe, A. C. Bent, 
Dr. L. B. Bishop, William Brewster, Henry P. Bridges, Neil Clark, Henry Cook, John A. Cox, L. S. Crandall, Samuel Evans, Wallace Evans, Dr. George W. Field, William L. Finley, Dr. A. K. Fisher, Edward H. Forbush, Henry Ford, A. N. Frey, Amos E. George, John Heywood, Dr. C. F. Hodge, Frank Hopkins, Dr. William T. Hornaday, F. H. Kennard, Charles D. Lanier, Rev. William R. Lord, A. G. MacVicar, F. N. Manross, W. L. McAtee, E. A. McIlhenny, Mrs. George H. Mellen, Arthur Merrill, Dr. John C. Phillips, Harry T. Rogers, Adam Scott, Ludwig Seidler, C. A. Shaw, Dr. A. F. Warren, Ernest A. Watts, William P. Wharton, Dr. J. W. Whealton, William Whisker. If I have inadvertently omitted other kind helpers, I am no less grateful to them also. The skilled and patient bacteriological researches of Dr. L. F. Rettger, of Yale University, with whom I have been delightfully associated in the investigation of gallinaceous birds, have proved of great value in the solution of important problems.

Also I would thank most heartily for the use of photographs for this volume the following: Wallace Evans, Thorn L. German, Edward H. Forbush, Henry Ford, John Heywood, William B. Hoot, Verdi Burtch, W. N. Dirks, F. N. Manross, George H. Graham, Henry P. Bridges, Harry T. Rogers, John Winters, Arthur W. Brokway, Francis Harper, G. Curtiss Job, and the National Association of Audubon Societies.

In addition to the above I would mention Dwight W. Huntington, who has for years been a recognized pioneer in this movement, and has long coöperated with me. His magazine, The Game Breeder, New York City, is valuable for all who undertake these methods of propagation. Another valued ally in this movement is The American Game Protective and Propagation Association, whose president, 
John B. Burnham, has shown me many courtesies, likewise L. A. Quarles, one of its vice-presidents, and all its officers.

In connection with the scientific expeditions to Manitoba, I am also deeply grateful to Hon. George Lawrence, Minister of Agriculture of the Province of Manitoba, and the others of the Ministry who granted the permits: to Charles Barber, the chief game guardian; to Samuel Spence, Dr. Gordon Bell, Dr. R. M. Simpson, Dr. F. B. Cadham, and E. W. Darbey, of Winnipeg, for valued help and esteemed courtesies; and to Dr. T. S. Palmer, of the United States Bureau of Biological Survey; Governor Simeon E. Baldwin of Connecticut, and Dr. L. A. Clinton, then of The Storrs Agricultural Experiment Station of Connecticut, for further important assistance.

There is a further debt of gratitude to record. Much of the material of this Manual is in a sense pioneer work. Lest it should be said by some, with any show of reason, that it represented simply the ideas or theories of one man, I have submitted the material to several experts, all of whom have approved the book, as far as they have read the manuscript. What few changes or additions they have suggested, all in minor details, have been incorporated in every case. Fredcric C. Walcott, a Director of the American Game Protective and Propagation Association, and one of the foremost experts in America in practical propagation of waterfowl and game-birds, has carefully read the whole book, and has gone over most of it with me in person, at the sacrifice of valuable time. He cordially endorses this material, as well as my work in general, and has sent such endorsement in writing to T. Gilbert Pearson. U. S. Senator George P. McLean has also written endorsement and congratulation on the success and value of the work and investigations. The material of Part I has also been read and approved 
by Wallace Evans, owner of the most successful game farm in America; by George W. Field, chairman of the Massachusetts Commission of Fisheries and Game; and by Dwight W. Huntington, editor of The Game Brecder. Part III I have gone over in person with Edward $H$. Forbush, State Ornithologist of Massachusetts, author of "Useful Birds and Their Protection." T. Gilbert Pearson has also read and approved the book. The technical sections in Parts I and II I have read with Alexander G. MacVicar, one of the most expert game-keepers to be found in America. Dr. L. F. Rettger has approved the sections relating to diseases. I am deeply grateful to these gentlemen for setting the seal of their reputation upon the accuracy and value of this work. 

PART I

METHODS WITH GALLINACEOUS

BIRDS 



\section{CHAPTER I}

\section{GENERAL METHODS}

Experimental work has shown that all our wild gallinaceous species have very much in common, and that much the same general methods, varied more or less in minor details, are adapted to them all. Hence it will be well to consider at the outset methods which apply to all species.

Natural and Artificial. First, then, we come to the broad distinction between natural and artificial methods. The latter signifies the propagation and rearing of birds in confinement or under restraint; the former that they are free and propagate in the state of nature, though protected and assisted as much as possible. Both systems have advantages and special uses. In some cases one or the other is impracticable. In some wild, wooded districts only natural methods may apply. On the other hand, near populous centres, where birds in the wild state would inevitably succumb or be driven off, it may be possible to rear them in large enclosures. Again, circumstances may favour a combination of the two methods, and the birds, artificially started, may be liberated, and furnish breeding-stock for natural increase, while some may be retained for artificial breeding.

Artificial Method Important. There is a way in which methods of artificial propagation may prove of great importance in naturalizing in a locality gallinaceous birds, even of new species, which otherwise could not be induced 
to remain. It is notorious that various kinds of such birds, liberated by proper methods in a locality, raise broods, but in the autumn leave with their young for parts unknown. This has repeatedly occurred in America with the Messina quail of Europe, the gray or "Hungarian" partridge, and with bob-whites from the South. These southern quails, for instance, have been shipped North and liberated in great numbers. They breed, and then usually disappear. As I have often seen them winter safely in the Northern States in open enclosures, I do not think that those liberated die off, but that they migrate. But if we take the eggs and rear the young artificially, they know no other home and remain in the locality of their birth. In my experiment on the William Rockefeller estate, described farther on, we reared bob-whites from Mexican stock, and these and their offspring are believed to have established themselves in permanent residence. Had Mr. Rockefeller liberated the original shipment instead of breeding them artificially, there would doubtless have been no result. Likewise there would be far more probability of establishing the gray partridge in America by this method than by liberating adult birds.

Natural Method. The natural method applies equally to all species which are found upon the land. Protection from enemies and food supply are the chief factors involved. If the tract of land is not of considerable size, the birds will not stay on it all the time, and will be subject to outside dangers.

Protection from Shooting. Perhaps the first need will be to secure protection from shooting. The first step generally is to post the land. Unfortunately this is not always effective. It sometimes comes to an issue of respect or contempt for law, and whether or not a man has property rights in his land as well as in his house. I knew personally of a 
case where signs proved ineffective, and the owner published a request or warning in the local papers. Next night all his wire fencing around a large farm was cut and ruined, and his whole season's work handicapped. People who resort to such vandalism are in the class with the wild vermin and should be treated accordingly.

In another recent case, a country town in Connecticut, Morris, was overrun by "sports" who came up in autos from neighbouring cities, slaughtered the game and fish, and defied every law. The local game-warden did nothing. At last the farmers organized a Protective Association, posted nearly the whole town, hired their own attorney, and rigorously prosecuted every trespasser. After several invaders had been heavily mulcted, the rest of them gave that town a wide berth. Hunters deplore the closing of private land, but it is often their own fault, and the innocent, unfortunately, have to suffer with the guilty.

Protection from Vermin. A second line of protective effort lies in the extermination of vermin. A separate chapter will be devoted to this subject, but some things may here be said about the problem. It is astonishing how many noxious creatures there are upon the average innocentlooking tract of land. Following is a list of vermin killed on the Childs-Walcott estate in Norfolk, Connecticut, from February, I9I I, to September, I9I3:

Nine foxes, 24 raccoons, 159 weasels, 7 muskrats, 6 skunks, 8I domestic cats, 39 rats, 5 wildcats, 20 I red squirrels, 9 large owls, 4 hawks, 8I crows. In this list the number of hawks is unusually small, and I know a case where the number of domestic cats taken was considerably larger. On the average wild tract, unless extermination of vermin is resorted to, birds can barely hold their own. One of the most necessary qualities of a keeper is that he be a good trapper 
and well versed in the signs and ways of these destroyers of bird life.

Food Supply. The maintenance of a supply of food is an important factor in holding birds upon the land. Under diverse conditions there will be a variety of berries and foodplants growing naturally. The ruffed grouse is fond of the fruit of the sumac, partridge-berry, wild grape, hawthorn, and in fact of almost every wild berry that grows in the woods. I have even seen their crops stuffed with whole acorns. The quail likewise feasts upon fruit and berries, and is fond of the huckleberry pasture and the blackberry field during the late summer.

Planting Grain. Of course winter feeding is most important. The planting of patches of buckwheat, or other grains such as wheat or millet, and letting it stand is an excellent practice. The birds frequent such fields in the fall, and are likely to be held there for the winter.

Feeding Stations. There should also be shelters under which grain is placed. Whatever form is used, care should be taken not to have them so enclosed that a fox or other animal could surprise and catch the birds when feeding. So there should at least be openings on opposite sides. One good way is to make a frame of saplings upon low posts, quite close to the ground, and cover with a thick thatch or pile of evergreen boughs. Build these in the haunts of the birds, and do it before the severe weather sets in, so they will get accustomed to being fed, and will surely go there when in need. Wheat, corn, buckwheat, barley, or other small grains, preferably in the shock or on the straw, are good. Hang up such grain, heads down, so that birds can reach it, but not the rodents. People often ask whether the ruffed grouse or partridge will eat grain thus placed, and I would say that it certainly does so. 
Restocking. If the natural stock is entirely depleted, either birds can be bought and liberated, or else the stock secured can be made to breed in confinement and the young allowed to go free where they were raised. This latter is the surest way of making birds stay. There is a natural homing instinct in birds, as probably in most creatures, which inclines them to remain on or return to the land of their nativity. They are far more likely to stay than are strange birds.

Liberating Stock. When birds are to be liberated in a strange locality, the coops should be taken to some attractive natural cover at dusk, food placed where they will see it when they come out, and water if there is none handy. Open the doors quietly and withdraw, letting them come out of their own accord. The probability is that they will stay for the night close by, feed, and perhaps locate there; especially if food is further provided. If it is feasible to keep them a few days in a naturally attractive location in a temporary pen with plenty of cover, and then liberate them in this manner, there is even more chance that they will stay. Such method I have found very successful. About the worst way to manage is to rip off the covers and send the birds whirring off in great fright. It is probable that they will not find each other again, and never get back to the spot, but keep going. Another bad practice is to libers te them in winter, when they are likely to weaken from cold and hunger, and to get caught by vermin. If received in winter, they should be kept in a suitable enclosure, as described later, and released when spring opens up. Ofttimes, especially with stock imported or shipped from a distance, the birds are weakened by the journey and are in no condition to combat the dangers of the wilds. It is usually a good plan to hold birds a while in comfortable 
quarters and feed them up, to make sure that they are thoroughly fit.

Fundamentals of Artificial Method. Extensive experiment has shown conclusively that all kinds of wild gallinaceous birds can be kept in health in confinement. Most kinds, however, cannot, with safety, be closely confined in small quarters, like domestic fowl. Under such conditions they are very susceptible to various diseases, especially of the digestive tract, which are likely to become epidemic. To these the domesticated species have become considerably immune. Some species require more room and range than others and cannot stand any crowding. Another matter of importance is that the same ground surface must not be used for too long a period continuously.

Hatching and Brooding. For incubation under artificial conditions there are three possible methods: One, which is the most artificial, is to hatch the eggs in incubators. This necessitates raising the young in brooders, with artificial heat. The other two, which are more natural, are either to let the birds hatch and raise their own young, which in many cases they refuse to do, or to set the eggs under hens or bantams and have these brood the young. This last is altogether the best as the general system in the great majority of cases, though there are possible exceptions. It is, in fact, the system almost universal among professional gamekeepers.

Incubator vs. Hens. In incubator work, with quail eggs, I usually had hatches from 50 to 60 per cent. This is about a fair average, I think, for most workers. With hens, an average hatch is 75 to 80 per cent., and quite frequently all the eggs of a litter hatch. C. H. Shaw, of Eccles, California, reports incubator hatches of 75 per cent. with eggs of California quail, but this is exceptionally good. More- 
over, the young hatched by natural incubation are likely to be stronger. Besides, it is easier and safer to raise young with hens than with brooders. Brooders are a perpetual care and anxiety. Without incessant care the variations of temperature are liable to enfeeble and kill the young. One little mistake or lapse of care will often destroy a whole batch. The steady heat and close air does not tend to vigour as does the open-air life with occasional brooding by the hen. Later the hen can range with the young and care for them, enabling them also to pick up much insect and other natural food. In short, though the eggs of gallinaceous birds can be hatched in incubators, and the young have been reared in brooders, on a small scale, with great care, the method with hens is by far the better, and the other should not be attempted.

Failure to Incubate. Many of these birds in confinement do not, as a rule, care to incubate their own eggs. This may be in part because they are more or less disturbed and nervous. So while mating and egg-production are wellnigh obligatory in nature, the actual care of the family is less so. There is this advantage, that the birds produce more eggs than they would if they brooded, and consequent increase is more rapid.

Quails, I have noticed, are more likely to incubate their last eggs of the season than those of an earlier period, and this may be true of other species. In case that a bird attempts to incubate a late clutch, it is best to allow her to do so. Late broods are always hard to raise, and the natural mother is likely to succeed where even hens would fail. Young thus raised are very much shyer than those produced by the other methods, and are wild, wary skulkers, just as in nature. It is often hard even to catch a glimpse of them.

Securing Stock. When one has decided to raise birds, 
the question is how to secure breeding-stock. In the case of various foreign species, notably pheasants and the gray or Hungarian partridge, these are readily purchased. With native species, however, the case is different. Most States have forbidden the shipment and sale of native game. There is an occasional game commissioner or chief warden who grants special permission to secure a few birds for propagation only.

Though there is a real difficulty at present, the problem will undoubtedly soon be solved. Laws are being passed in various states to encourage, under proper supervision and regulation, the propagation of game as an industry. Many people are now making small beginnings, and before long will have breeding-stock for sale. The high prices for live birds will for some time to come make it more profitable to sell them for breeding than for food purposes, except with such common species as the ring-necked pheasant and the mallard.

Respect Law. It is from every standpoint undesirable to take eggs or catch birds contrary to law. If every one should begin doing this it would result in a great decrease of species already too scarce.

Starting. A start could often be made with birds taken in the hunting season slightly wounded in the wing. Breeding of the ruffed grouse was begun in this way by F. N. Manross, of Forestville, Connecticut, who was the first actually to raise the species artificially in the State. If not thus used, the birds would have been killed and eaten, and surely they served a much more useful purpose for propagation and public education than for the pot. The authorities granted permission to hold these birds in possession. Dr. C. F. Hodge secured special permission to take a few eggs with which to begin his epoch-making experiments. 
Southern Stock. The traffic in live game-birds from Mexico has served to furnish material for valuable experimental work. Many of the live quails sold to-day are from Mexico. I confess that I had supposed that these birds could not stand a northern winter. They can, nevertheless. In a most successful quail-breeding experiment which I conducted on the estate of William Rockefeller, Tarrytown, New York, the stock, of several dozen birds, came from Mexico, and was received late in the fall of $\mathrm{IgI} 2$. They were kept in a large fenced enclosure, open above, with no buildings, and only small brush shelters or open frames with roofing-paper. They survived the winter in splendid shape, the only casualties being one or two that were killed by hawks. The breeding was most successful, nearly two hundred young being matured without any sign of disease. These, in turn, were liberated on the estate, and, being fed, survived the severe winter of I9I3-I4, and now, apparently, are breeding all over the estate and vicinity. While naturally we should prefer indigenous races, it is encouraging that there seems to be some latitude in the processes of nature.

Sources of Supply. The following dealers in gamebirds, waterfowl, or other wild live-stock are well known, and have good facilities for supplying whatever breedingstock may be available:

Wallace Evans, Oak Park, Illinois. Mr. Evans raises much of his stock, as well as buying stock for sale. He has the largest propagating farm in America, and has made a great success. He sells his own prepared foods.

I. S. Horne, Horne's Zoölogical Arena, Kansas City, Missouri. Mr. Horne does not propagate, but buys and handles wild game-birds and waterfowl. I have dealt with him considerably and found him reliable.

Wur. J. Mackensen, Yardley, Pennsylvania. Mr. Mackensen is another large dealer and importer well known. His 
place is accessible from Trenton, New Jersey, a half hour's ride by trolley, across the river.

George D. Tilley, Darien, Connecticut, general dealer and importer. He is a well-informed naturalist, a good man to look up specialties.

Whealton Wild Waterfowl Farms, Chincoteague Island, Virginia. Raises and sells wild geese, ducks, and swans.

George J. KleiN, Ellinwood, Kansas. Wild ducks and geese.

H. P. Bridges, I Iog Calvert Building, Baltimore, Maryland. Genuine eastern wild turkeys, pheasants, etc.

Buckwood Pheasantries, Dunfield, Warren Co., New Jersey. Pheasants and their eggs.

JoHn HEywood, Gardner, Massachusetts. Eggs of waterfowl and of pheasants.

John W. TAlbot, South Bend, Indiana. Pheasants. Helen Bartletr, Cassapolis, Michigan. Pheasants.

O. R. Austin, Foster Center, Rhode Island. Gamebirds and waterfowl.

There are many other reliable persons also who are breeding and selling stock on a smaller scale. 


\section{CHAPTER II}

\section{QUAIL PROPAGATION METHODS}

\section{(Considered as a basis for the breeding and rearing of}

gallinaceous species generally)

Bob-white as a Model. Since the methods used for the propagation of all groups of gallinaceous species are similar, I shall describe minutely approved methods now in use for the propagation of one species. This will serve as a model for all, minor differences being specified in the chapters dealing with the others. The species selected for this special treatment is the bob-white or common quail, well known over a large part of the United States, considered by sportsmen as one of the choicest game-birds, a species valuable and important to agriculture, and universally beloved.

Further Reasons. Further reasons for making methods with quails the standard, rather than those for pheasants, are as follows: The main purpose of this Manual is to promote the increase of native birds. Foreign species, however interesting and valuable, are secondary. Pheasant-rearing, moreover, has been practised for centuries, and is well known, though I trust that the account farther on of methods by American experts will be of practical value. Particular interest has arisen all over this country in the problems of propagating and increasing native "upland game-birds," notably the bob-white. Very many persons are either working at it or inquiring about it. Realizing this, I have 
devoted much study to the problem, and now for two years have been able to raise quails in numbers up to a couple of hundred without disease or more than incidental loss. As I am personally familiar with every detail of the process, I felt and have been assured that a detailed monograph on the subject would be of especial timeliness and value.

Recent Success. The bob-white is without question the native gallinaceous species to emphasize for further experiments in propagation, especially on a larger scale, as success has now been secured in a number of cases, and the movement to propagate it is well under way. Among recent instances of reasonable success I would name the following: Harry T. Rogers, Sherburne, New York, has raised four or five hundred or more in a season. B. H. Selden, of Richmond, Virginia, is reported to have raised quails in considerable numbers. The Massachusetts Game Commission raised several hundred of them in I 9 I 4 , the Connecticut State Game Farm at Madison about two hundred, and the New Jersey Commission are reported to have reared about five hundred. A. G. MacVicar has raised as many as one hundred and fifty in a season in New Jersey. Wallace Evans has for several years raised them in moderate numbers, not going into it extensively because it has not been commercially profitable on account of the cost of the necessary $\frac{1}{2}$-inch mesh wire. Prices for quail stock have now soared so high that he has stated to me in person that he would henceforth undertake it on a larger scale, considering it thoroughly practicable. Results of experiments under my own supervision on the estates of United States Senator George P. McLean and of William Rockefeller are described elsewhere.

Pioneer Work. It was Dr. C. F. Hodge, then of Clark University, Worcester, Massachusetts, who first interested 
the public in the possibilities of quail and grouse propagation by his fascinating experiments, successful on a small scale His work was continued by the State of Massachusetts. F. N. Manross first did it in Connecticut. Later the writer and others took up the work along somewhat different lines. The early method of confining young birds in small coops was abandoned, and a new method which has been worked out is proving successful on a considerable scale. The main thing has been to learn what precautions are necessary to avoid the outbreak of epidemic diseases.

Quail Disease. Were it not for the epidemics to which quails are subject, they could be bred and reared quite easily, now that we know the methods which coincide with their habits. The typical quail disease is characterized by a disarrangement of the digestive tract, in which the intestines and the coeca are ulcerated and bloodshot, with ulcers sometimes on the liver. This disease becomes very infectious, and usually kills all the birds in a pen where it breaks out. Dr. L. F. Rettger, bacteriologist of Yale University, worked with me on this problem in connection with experimental work at the Storrs Agricultural Experiment Station of Connecticut. First and last he examined a large number of quails which had died of this complaint. In cases of a few adult birds he isolated a virulent bacterial organism, injection of which into healthy birds proved fatal in about two days. In many other cases of adult birds, however, no causative organism was found. He also examined and made cultures from a large series of young quails which had died of the disease, but not in a single case did he discover any causative organism. Careful search was also made for coccidia, both with adults and young, and in no case did he find enough of these to have caused trouble. A great deal of time was devoted to this investigation. Although the 
above results are partly negative, in conjunction with other general observations of the disease, considerable light has been thrown upon the problem, particularly from the practical standpoint, and some important negative deductions at least are possible.

Disease Not Local. The first is that the original theory of the disease, that it spread from an organism of purely local origin, is not tenable. Upon this theory was based the former use of the term "Alabama quail disease," which originated from the fact that the disease was first noticed in a consignment of live quails shipped from Alabama. The "infection" was subsequently detected in shipments of quails from Oklahoma, whither it was supposed to have spread. But when it was found to exist in bob-whites imported from Mexico, or from various other points, and, furthermore, in several other species of quails, and also that other gallinaceous species, such as the ruffed grouse and prairie chicken, were subject to a trouble similar and perhaps identical, it was clear that the theory was disproved. The fact, however, that the disease is communicable indicates, according to modern scientific conclusions, that there must be some sort of organism as the first cause, which seems to be found everywhere. As far as is known at present, it is a disease of captivity, under artificial conditions and feeding.

Second Causes. Extended observation convinces me-and this opinion is endorsed by such practical men as Evans, Rogers, and Horne - that the disease is liable to break out anywhere under wrong handling or feeding of wild gallinaceous birds in confinement. The practical problem, then, is one of prevention, of so handling and feeding these species under artificial conditions that the system remains in a condition of vigour to resist invasion. We ourselves are said 


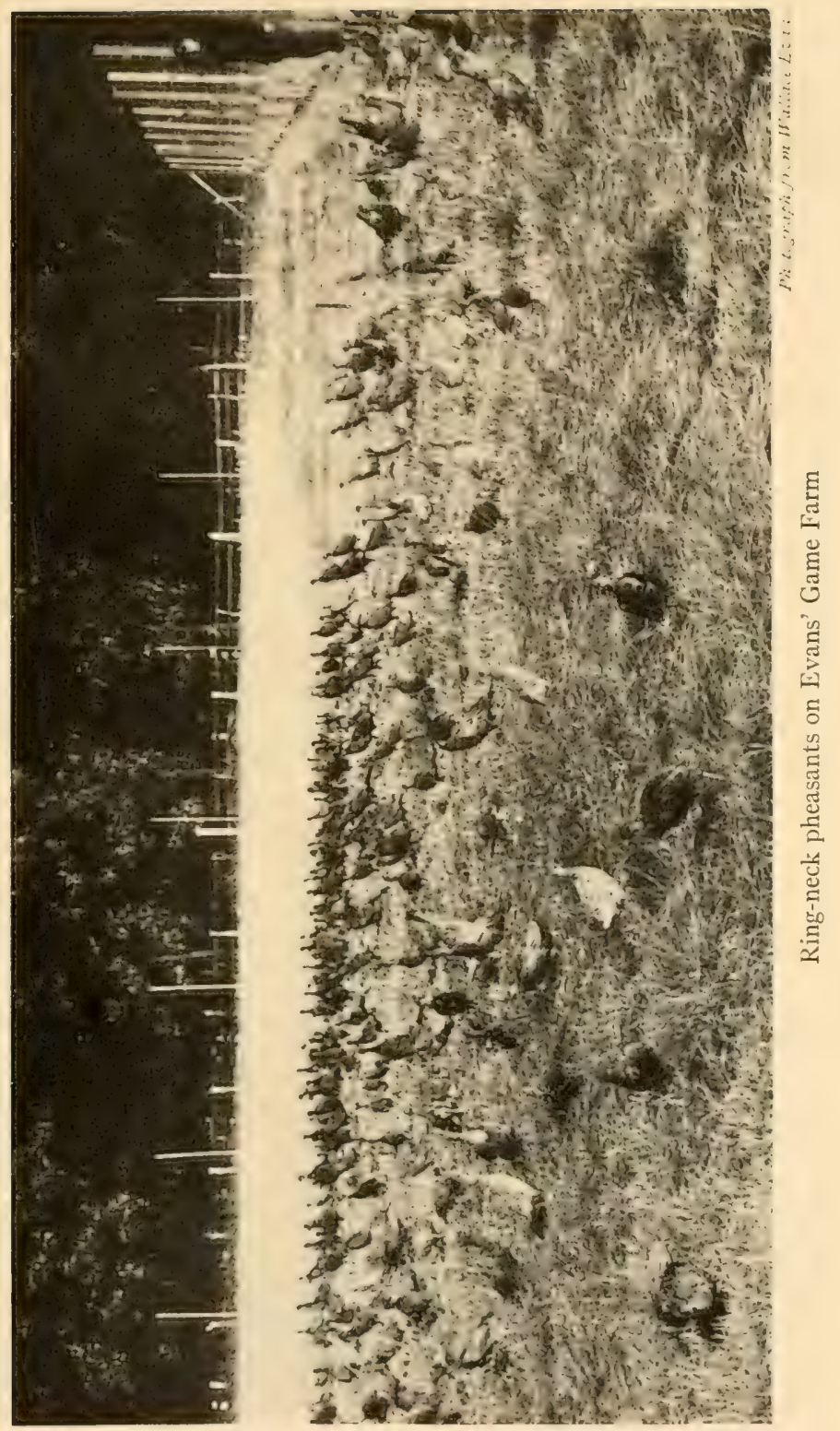




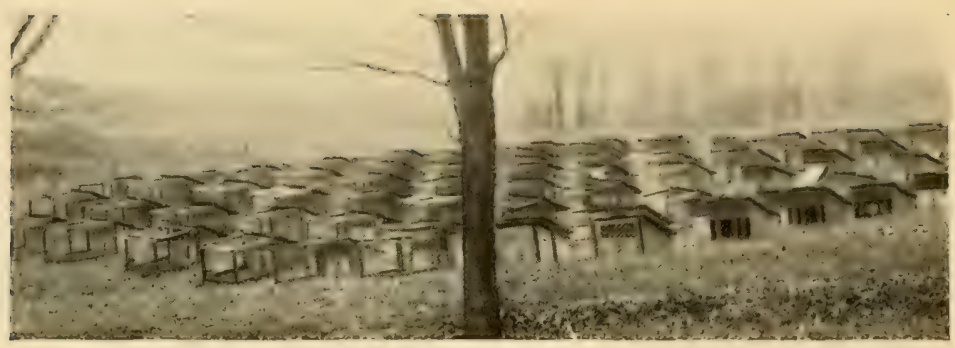

Hatching-coops, State Game Iarm, Sherburne, New Jork

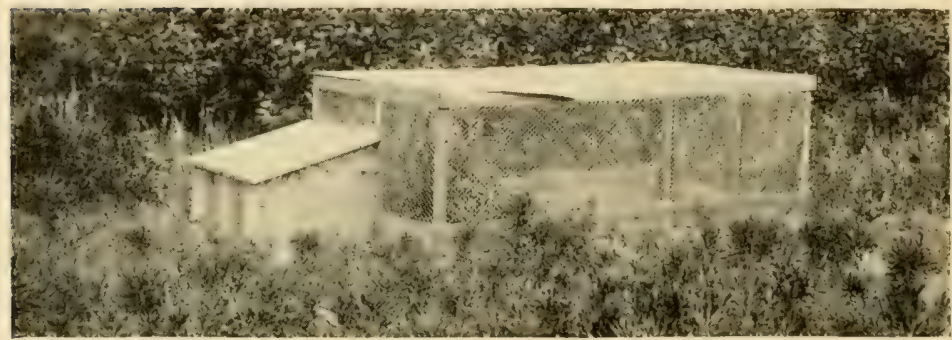

Breeding-pen for pair of quails, Storrs, Connecticut

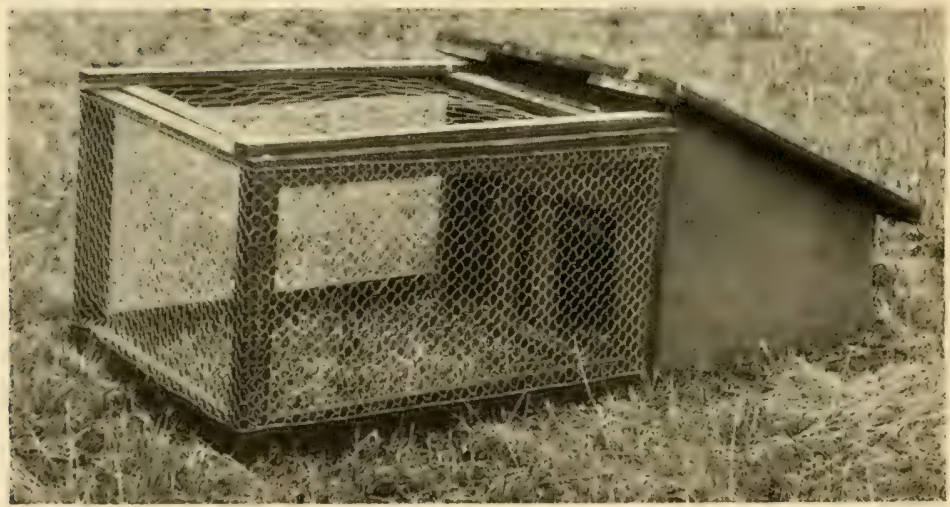

Typical hatching and rearing coop, Sherburne, New York 
commonly to carry germs of pneumonia, tuberculosis, and the like, which are unable to overwhelm the system so long as it remains normally resistant.

Are Wild Quails Ever Infected. The fear is often expressed that the quail disease, started from imported birds or from those having the disease on game-preserves, might spread among the wild native quails. Of this I do not believe there is any likelihood. That the disease spreads among birds in captivity is amply proven by the Massachusetts experiments. I had a case at Storrs, Connecticut, where it invaded from one pen to another and swept off every mem. ber of a brood, parents as well as young, of what appeared to be absolutely healthy and vigorous birds. In another case, on a private preserve, it seemed that the ground where there had been disease for several seasons had become so thoroughly infected as to communicate the disease to birds confined upon it even after a lapse of a year or two. I am aware, however, of no evidence to indicate that wild birds ranging over even such ground are in any danger. At Storrs, Connecticut, where there was a bad epidemic among the propagated young quails kept on a certain tract of pasture, the wild quails have continued abundant upon that ground and in the vicinity year after year.

Sometimes Recover in Freedom. Furthermore, infected birds, when the disease has not progressed too far, sometimes recover when liberated. A shipment of quails was received by the Game Breeders' Association, on Long Island, New York, and put by the keeper in an old hen-house, which happens to be one of the surest ways of starting the disease. As a matter of course the epidemic broke out. After about half the birds had died the rest were liberated. Most of them seemed to recover, for the species suddenly became abundant in the vicinity and raised broods, and the next 
autumn there were more quails on the premises than there had been for many a year.

Poultry Dangerous. As is true in the case of the domestic turkey, ground fouled by poultry is likely to introduce the characteristic diseases among quails or other wild gallinaceous birds confined upon it. Hence, care should be taken to keep the birds away from ground where poultry has been kept. On the other hand, young quails or grouse do not seem to contract disease from the foster-mother bantam when they have proper range. Moreover, quails in the wild state frequently feed on ground overrun with poultry, and sometimes feed with poultry, or in barnyards, particularly in winter, and no evidence has come to light of harm from this cause.

Analogy of Grouse Disease. In the British Isles a disease is known to break out occasionally among the wild grouse, occurring especially after long-continued spells of cold or wet weather, when the birds had been weakened by privation or exposure. Examination of many specimens showed that the intestinal tract was overrun with small, slender worms, very similar to the hookworms which cause the well-known hookworm disease in man. These were found in large numbers in the grouse, attached to the walls of the intestine or the cœcum, often piercing it and causing sceptic poisoning. In examining some diseased quails at one time, Dr. Rettger was astonished to find a considerable number of tiny, wirelike worms, of the genus Strongylus, closely resembling the hookworm in man, and answering to the descriptions of those found in the grouse abroad. For a time it looked as though a new cause of quail disease had been discovered. Further investigations, however, showed that other specimens of diseased quails had few or none of these worms. It has been believed that there have been 
outbreaks of a disease among the ruffed grouse in this country, at long intervals, but nothing seems to be definitely known of its nature or cause. By analogy it is supposable that quails undergoing privation in severe winters might have a spontaneous outbreak of the quail disease when resistance of the system is weakened. As yet, however, I have learned of no evidence of any outbreak of the epidemic of the quail disease of captivity in the wild state. If, perchance, it does ever occur, it is evidently rare and not especially to be feared.

Inviting Disease. It is easy to understand why, in the past, shipments of quails from dealers have arrived dead and dying from this infection. Trappers caught them, a few at a time, and put them in small coops, in poultry yards, or in pens repeatedly used and fouled. There they were kept until a sufficient number for shipment were secured. Like as not they were fed on coarse grain without grit, which they could not properly digest. Then the fright and close confinement in shipment, sometimes in fouled or infected crates, did the rest. Quarantine has been proposed, to make sure that the stock is not infected. But the longer the delay in close confinement, the more likely they are to become sick. Such a practice would hark back to the discarded theory of a local disease organism.

Practical Precautions. Since it is important that the public should be able to purchase healthy breeding-stock from dealers, with the minimum danger of disease and loss, I will suggest some practical measures for safety. The Government, in regulating this traffic, might issue a bulletin of instruction as to the care, feeding, and handling of birds, place this in the hands of the dealers, and make them responsible for the carrying out of the instructions by their agents who capture or buy up the birds. It is for the 
interest of all concerned not to lose valuable property, especially as much of the loss could be prevented by reasonable precautions. One firm of game dealers have written me that they have recently prepared published instructions for their agents. In brief, the instructions should require that captured birds should be kept on fresh ground, in enclosures of fair size, with alternation of pens or change of the location of these; that the method of feeding prescribed should be followed; the proper area needed for a certain number of birds should be defined; and that crates not new should be cleaned and disinfected before birds are shipped in them. The observance of such regulations would do much to prevent disease in shipments of quails.

Securing Stock. The present demand for quails for breeding is so great that prices are very high, ruling at two to three dollars per bird. These rates may lessen when quail breeding becomes more general and people sell stock that they raise. Quails are largely monogamous, and should be bought with sexes in equal numbers. Naturally it is best to secure stock from as near home as possible, though in view of some successful ventures with southern birds in the North, one need not hesitate to buy southern, or even Mexican, stock, if no other can be secured.

Coöperation from Authorities. Inasmuch as the public are bound to breed quails, it would be well for such states as have game farms, in regions where quails are found naturally, to secure native acclimated stock in their own locality, breed and rear quails as will be described, and distribute the stock to persons interested and responsible who will undertake breeding operations. Proper persons should be licensed to capture and keep a specified number of quails under official supervision. Birds are for the benefit of mankind, and surely it is, to say the least, as beneficial to allow 
a person of proper character and knowledge to catch and breed a few quails, as to allow irresponsible persons to shoot a much larger number. Supervision of breeders by the State is far more practicable than the enforcement of a bag limit.

Time to Acquire. The best time to acquire stock is in autumn or early winter-when the young birds are sufficiently matured, not too near spring when breeding might be interfered with. Moreover, those who order early from dealers are much more likely to get stock, for at present far more birds are being ordered than can possibly be supplied. Orders should be placed in spring or summer for delivery in November or as soon thereafter as possible.

Winter Quarters. In anticipation of the arrival of stock, winter quarters should be prepared. No expensive or elaborate outfit is necessary. Quails are hardy, like poultry, and can easily endure the winter temperatures in their natural range. The most mistaken kindness is to shut them in a building and give them artificial heat. The most elaborate shelter they can possibly need is a shed open to the south. They will do just as well in a yard with generous piles of evergreen boughs, or frames covered on top with roofing-paper, with brush or straw under them. Another good device is to have the north and west sides of the yard boarded up a little to break the cold wind, and a long wide board cover, slightly sloping, nailed along the windbreak, to make a simple shelter. There should be brush or straw under this, and piles of brush about the yard, as quails are great skulkers. They are contented when they can hide, but are always in a state of alarm in an open place.

Holding-pen. Before the ground freezes, select a piece of fairly level ground, preferably with turf and sheltered somewhat from the north and west, free from defilement by poul- 
try, accessible to the house, yet not too public, and build a wire enclosure. One of about 30 feet each way will be large enough for about a dozen pairs of birds. If there are to be many more birds than this, or other kinds, it is better to build larger and divide it into the desired number of sections of about the above size. Posts from small trees cut in the woods, sharpened at one end and driven with a mallet, will suffice. For keeping a few birds, it is safest to have the pen wired on top, as then the few birds will be quite secure. On large game farms they use larger open fields, with fence at least 8 feet high. For a small covered pen 6 feet will do, high enough so a man can spade over the ground if the pen is not moved.

For small pens use $\frac{3}{4}$-inch mesh wire next to the ground, for special precaution, and I-inch size above this, with $\mathrm{I} \frac{1}{2}$ inch overhead. The $\frac{3}{4}$-inch wire need extend only $2 \frac{1}{2}$ feet from the ground, and the I-inch size above that. The wire should be sunk into the ground not less than 6 inches, to keep vermin from digging under. Some advise having it also extend horizontally outward underground from 4 to 6 inches, as an additional precaution. This will depend upon whether rats are abundant or not. Ordinarily trapping should keep vermin down. Posts should be set about ro feet apart. Instead of sinking wire under the ground, board or slabs can be used for the lower part, buried the same as the wire, having the wire stapled to the top of the board.

Open Yards. If desired, and the stock of birds is large enough to risk losing a few, a larger enclosure open above can be used. In this case the fence should be 8 feet high, the wire of $\frac{3}{4}$ - or I- inch mesh $2 \frac{1}{2}$ feet up, the rest $I \frac{1}{2}$-inch mesh.

Birds when pursued will sometimes scramble up 4 or 5 feet, but seldom as high as 8 feet. Plenty of evergreen boughs, brush, or planted evergreens, and weed clumps are 


\section{QUAIL PROPAGATION METHODS}

good protection against birds of prey, enabling the stock to hide. An open enclosure had better be at least, say, 60 by 40 feet, as birds are less likely to try to escape from a roomy place.

Making Fence Vermin Proof. Weasels and rats are terribly destructive, and are so small that some are said to get through I-inch mesh, or even the $\frac{3}{4}$-inch size. Moreover, they can climb wire. To make a fence absolutely impervious to them would require great expense, as follows: A fence 8 feet high, with $\frac{1}{2}$-inch mesh $2 \frac{1}{2}$-feet up, then a strip of tin about one foot high, and above this $1 \frac{1}{2}$-inch mesh. Without the tin there would have to be fine wire all the way up, and an overhang on top, made by nailing an arm of $2 \times 4$ to the top of each post, and on it a strip of $\frac{1}{2}$-inch mesh a foot out and hanging down 6 inches. To prevent digging under, $\frac{1}{2}$-inch wire would have to be buried, running down, say, 9 inches, and out horizontally 9 inches more. This all costs so much that few would go to such extreme.

Practical Fence. For ordinary practical purposes most people will prefer to depend partly upon trapping, and build a fence that will keep out most vermin, taking some slight chances. For such a fence to an enclosure open above, I would suggest $\frac{3}{4}$ - or $I$ - inch wire $2 \frac{1}{2}$ to 3 feet up, and then 5 or 6 feet of $\mathbf{1} \frac{1}{2}$-inch mesh, without any overhang. It would be well to buy the rolls of the finer wire not less than 3 feet wide, and run about 6 inches underground. With traps set along the wire, and with watchfulness, there will seldom be anything that will dig under. In many cases no burrowing is ever attempted. It is well to watch for the beginnings of vermin digging, and set traps. Some persons only run the wire down perhaps 4 inches, or even not at all, and take chances.

Change of Pen. The axiom or pivotal proposition 
about raising quails and related species is that the same ground surface must not be used continuously. Neglect of this has wrecked many an undertaking. We have not yet discovered the direct chemical or bacteriological cause, but the fact is proved without question. Domestic poultry have become largely immune to the diseases caused by "fouled" ground, but their wild relatives have not. If the pen is to be used for successive seasons, the ground must be limed, turned under, and freshly seeded. Otherwise one should either move the posts and wire to another spot, or else provide another pen for alternation. Some careful workers who have plenty of room raise crops for two years on all land before they use it again for birds. When the ground is fresh at the start, and is not crowded, and has good turf, it might be used another season with impunity.

Light Construction. It is best to build lightly and cheaply. Do not drive the posts deeper than is necessary for firmness. Drive lightly the staples holding the wire, so that they may easily be withdrawn. This is so the pen could be moved, if desired. Permanent buildings or fixtures are dangerous; the more elaborate, the worse they are. I have seen a quail house and pen which cost more than $\$ 2, \infty 00$ become a veritable pesthouse.

When Received. When the stock is received, as the birds are removed from the crate, before being released in the pen, clip closely the primary quills of one wing, even when the pen is covered. Do not clip both wings, as the birds will fly more thus than with the balance uneven. I knew a case where quails which had both wings trimmed and were placed in an enclosure open above soon soared over the fence. There should be plenty of brush to hide under, else they will dash into the wire and hurt themselves.

Food for Adults. In feeding quails or other species, 
ileanliness and moderation are the keynotes of success. It is fatal in the end to these wild birds to stuff them with food when they can get little exercise, or to allow some food to remain and poison the ground for them.

For a beginner with a few birds to learn how much they will eat at a feeding, it is a good plan to feed at first in a dish and note the quantity they consume. The ideal is to give them only what they will eat up clean at one time, with a relish, rather than to keep them perpetually "lunching." They should have sufficient for full nourishment, yet not enough to gorge themselves.

Exercise. It is also important, particularly in winter, that they should be made to exercise by hunting for their food. Hence it should be thrown into the pen among grass, leaves, or litter, to make them scratch for it. They will find all of it they want, never fear. But avoid throwing in more than they can eat up. In winter have straw or litter under a shelter and feed in that, and renew it from time to time. If food is found remaining under it, scrape it up, and feed less in future.

Food Simple. The food for adults is simple, the chief staple being a mixture of small or ground grains and seeds. Nearly any sorts of these are good, including wheat, buckwheat, millet, rye, barley, ground oats, cracked corn, hemp. rape, canary and sunflower seed, and others. The corn element should be given sparingly, but more may be given in winter.

Prepared Grains. For a small number of birds, it is easier to buy grain and seed mixtures which are sold ready prepared. While ordinary "chick grain" mixtures will do, in conjunction with the other foods mentioned below, it is well to get the preparations made especially for game-birds, which, in addition to a liberal variety of seeds, have a little 
meat and spice added. Both Spratt's chick-grain and Evans's No. 5 pheasant food are good. These are fed dry.

Animal Food. Some animal food is essential to these wild birds as a substitute for their natural insect food. It is not necessary to provide insects for adults, but meat-scrap preparations can be substituted. These must be of a highgrade quality, and must be sparingly fed. One can easily kill the birds by giving cheap preparations made from decaying meat, or by giving too much, even of the best. Spratt's crissel is a standard preparation widely used, said to be from clean lean meat. If mixed with the grain it should be used very sparingly, probably not over about 5 per cent. The safest plan is to feed it separately. Some scald it and give a meal of it, as much as the birds will eat, twice a week. Others feed it dry twice a week, or keep a dish of it under shelter before the birds all the time. They seem to take only what the system craves, and do not overload with it. It is dangerous to mix a lot of it in the feed and force the birds to eat it. Instead of this, a feed of chopped raw meat or of mealworms twice a week is excellent.

Green Food. Green food is also essential. In summer the grass and weeds in a proper pen will pretty well supply this. Clover sown in the pens is a splendid food. In the fall give them green corn on the cob, elderberries or other fruit, split apples, chickweed, and the like. For winter vegetation anything available will answer, such as apple, ground beet, carrot, turnip, etc., green sprouts or tops, cabbage in moderation. Some think that cabbage causes indigestion, and it is well to vary or alternate. In the spring fresh lettuce, cowslips, or watercress will help to stimulate laying.

Forcing-food. For this latter purpose most skilled breeders use for pheasants some sort of forcing-food, to aid 
fertility and early egg-production. Here is the receipt used by Harry T. Rogers: One third of the whole is shredded (not mealed) alfalfa; scald this separately, about half an hour. For the remaining two thirds mix equal parts of ground corn, ground oats, middlings, and bran, scalding this also separately from the alfalfa. Wet only crumbly moist, never sloppy. Then mix the two, and to each pailful, or twelve quarts, of the mash, mix one quart of dry bone meal. Rogers begins this from March 15 to April I, and continues it through the laying and moulting seasons, to September I, substituting it for one of the two daily feeds, preferably in the morning, as the dry grain feed stays in the crop longer. This might serve to start quails to breed earlier, but otherwise they lay well without it.

The game-food dealers also make forcing-foods. Evans's is his No. 6 pheasant food, and Spratt's is called egg manna. Both of these are to be slightly moistened. Spratt's cordiac, which is a peppery stimulant, can be added to any of these mixtures now and then. These various special foods need only be used with quails during laying time.

Other Needs. In addition to the above, it is very important to have fine grit or gravel always before the birds, otherwise they cannot properly digest their grain food. With this mix in some ground charcoal and oyster shells. Rogers also now and then mixes a handful of sulphur with the food. He also keeps a stick of sulphur in the water, which preserves its purity and is good for the birds. It does not dissolve. Clean water, of course, should be accessible, and be kept in the shade. In severe winter weather, when water freezes, they can get along for a while with eating snow.

Mating Monogamous. The bob-white is probably normally monogamous, though possibly it may become polygamous in captivity to a limited degree. Some workers 
have thought that cocks occasionally mate with two hens. The few times when I confined a cock and two hens together in a small pen, no more eggs were obtained than the normal number laid by one bird. Further experiments should be tried, or the results published of past experiments not yet made public.

Privacy Essential. Privacy is of primary importance for the successful breeding of bob-whites. They are exceedingly secretive in habits, particularly in mating and breeding, and skulk nearly all the time under cover, unless convinced that no observer is near. It is essential that they should always have abundance of brush or other thick cover, else they will breed very little. Strangers should be kept away from the breeding-pens, and even the keeper should approach with caution and no oftener than necessary.

Breeding in Covies. Though pheasants breed readily when there are a number together in a field, it is quite different with the bob-white. In an experiment which I tried, I kept six pairs a whole season in a pen 30 feet square, with half a dozen brush-piles. They produced only two or three clutches of eggs, and that not until July and August, too late to be of value. I had other bob-whites also, which delayed breeding in the same way till I caught them up and put a male and female, selected at random, together in a small pen or coop, as described below. Only two out of eighteen hens failed to produce any eggs, and the rest each laid from one to three clutches.

A. G. MacVicar, however, has secured a good number of eggs from bob-whites by both methods. For single pairs he had pens Io by 12 feet. For collective breeding he used enclosures about 35 by 50 feet, about a dozen pairs in each. One third of the ground space was covered with cedar brush, and the rest grew to a tangle of orchard grass. It was rarely 
that a bird could be seen, which is exactly what they prefer. Strangers were kept away, and as little disturbance was made as possible. At intervals the eggs must be hunted out, but they are so skilfully concealed that it is hard to find them all when cover is really thick. In many cases the birds, as elsewhere stated, fail to incubate their own eggs, and such eggs, overlooked, will spoil. It complicates matters also to have the young hatch in the enclosure.

Single Pairs. The way which has thus far proved most successful is to separate the bob-whites into pairs, and put each pair by itself in a small pen during the laying season. With few exceptions any male and female will mate, and nearly always they produce fertile eggs in abundance if properly fed and handled.

Breeding-pens. Experience shows that a little movable pen 4 by 8 feet is of sufficient size for one pair of quails for the breeding season. This consists of a simple, rectangular frame covered with wire above and on the sides. The wire for the sides should be $\frac{3}{4}$-inch mesh. Around the bottom of the frame should be a baseboard a foot high, to the inner edge of which the wire of the sides and ends should be tacked. This is in case the quails should hatch a brood themselves or if it should be used for a brood of small young with the bantam. At first the young can get through $\frac{3}{4}$-inch mesh. The baseboard keeps them in till they have grown too large to get through the wire. Tacking the wire, however, to the outer edge of the board leaves a ledge upon which even small chicks can scramble and secure leverage to squeeze through. The board, moreover, shuts off the view from the outside and makes the adults more contented with the small quarters. For the top of the frame r-inch mesh will do, which is just small enough to keep out English sparrows. At each end there should be a door, one large enough for a man to 
enter, if necessary, the other merely for reaching in to get the eggs under the brush at that end, as it would be a detriment to breeding to frighten the birds by crawling clear through.

At each end there should be a thick pile of evergreen boughs, brush, or straw in which the birds can skulk and build nests, and it is well if there is some natural long grass and weeds. At any rate, the pen should be over green turf. In this case the grass will grow faster than two birds can reduce it, and the pen need not be moved during the breeding season. Sod or earth should be banked around it. If rats or vermin are troublesome, it may be necessary to dig a slight trench and bury $\frac{3}{4}$ - or $\mathrm{I}$-inch mesh wire about 6 inches in the ground, tacking it to the bottom of the pen.

Over one end of the frame may be tacked a strip of roofingpaper, which will give the birds a chance to keep dry during severe rains. Formerly I placed a small coop, with bottom, against the smaller door, with sand on the bottom and brush for hiding. This is not necessary, but is very convenient for moving the birds without handling them. They are easily driven in, and one can shut the slide and move the coop. This would be well enough with a few pairs, but on a larger scale it is well to practise reasonable economy.

Arbitrary Pairing. The latter part of April is the proper time to separate the birds arbitrarily into pairs for breeding. Any male and female will mate. Catching them in the winter pen is a simple matter. Make a small, compact pile of evergreen boughs in a corner of the pen, so thick the birds cannot fly out from the top, with a small opening for entrance on either side. The quails will hide in this corner. Either they can be chased out into a scoop-net or sack, or they can be taken out by hand. Handle them carefully to avoid loss of feathers, as this seems to put them back in laying. 
Hatching and Rearing Coops. Aside from wire enclosures with their simple shelters, and the small breeding-pens for single pairs, the only other equipments necessary to build are hatching-coops and rearing-coops. These may as well be exactly the same and be used interchangeably. In any case there should be no board bottom, and nests or birds should be directly on the ground, for moisture, in the first case, and cleanliness in the second.

Another Device. Some build, as for poultry work, a simple board affair for hatching purposes. There is a square of boards nailed together, about 5 feet long and 2 feet high. Boards inside this divide it into three or four long compartments. One end of each of these, a small square of about a foot and a half, is partitioned off for a nest-place, the rest being a run for the hen to feed and exercise. A long hinged cover, sloping down to the rear, protects the nests. A slide door shuts in hen or chicks. The yard part is covered with slats. This makes a handy tier of nests and runs.

Construction of Coop. The separate coops should be about 2 feet square, with the roof sloping to the rear. There should be a solid door in front to shut the chicks in at night, and another one with bars or slats to keep the hen in and let the young run out into the yard. On one side there had better be another door, hinged, to let the hen and chicks out to range when desired.

Wire Run. Each coop should have also a small frame for a yard, just high enough for the hen to stand up in, boards along the base, $\frac{3}{4}$-inch wire above this on the sides, and the same or I-inch size, as convenient, for the top; four feet by two will answer for this. It will serve for the setting hen to feed and exercise in, and later for her and the chicks for the first few days, before they are liberated. For the latter purpose either there must be a baseboard a foot high, or else 
the wire must be as fine as $\frac{1}{2}$-inch mesh. There should be a door on top by which to reach in easily. There need be no other door, as the run can be removed when hen and chicks are let out.

Egg-production. Quails are naturally late breeders. They seldom begin laying before the middle of May, and often not till the first or second week of June. Sometimes it drags along till even July. This extreme delay is probably due to artificial conditions, and is unfortunate, because it brings the young along so late that they are likely to succumb to autumn storms and frosts. Stimulating food is one factor to hasten matters. Another is quiet and absence of excitement. The birds when caught and distributed among the breeding-pens should be handled carefully. They should have abundance of cover in the pens, and should not be molested or frightened. All approach should be quietly and with caution, and strangers should be kept away.

Nesting and Laying. A few days before any eggs are laid a simple nest is formed, a mere hollow lined with grass or leaves, beneath the brush-pile or tunnelled in under thick grass. The eggs are white and pointed. They are laid on successive or alternate days, averaging about five a week. Quails should average from thirty-five to fifty eggs in a season, if allowed to lay as late as they will. Ordinarily a hen will lay her normal complement continuously, stop for a week or two, and start in again, producing perhaps three litters. These are so irregular in number that it is often hard to tell what a litter really is. One quail that I had laid thirty-five eggs in forty days in one nest, which laying may have been stimulated by my removing the eggs. Most clutches are from nine to fifteen or eighteen eggs. If the eggs are not taken, the bird ordinarily finishes her clutch, deserts it, builds another nest, and presently begins to lay 


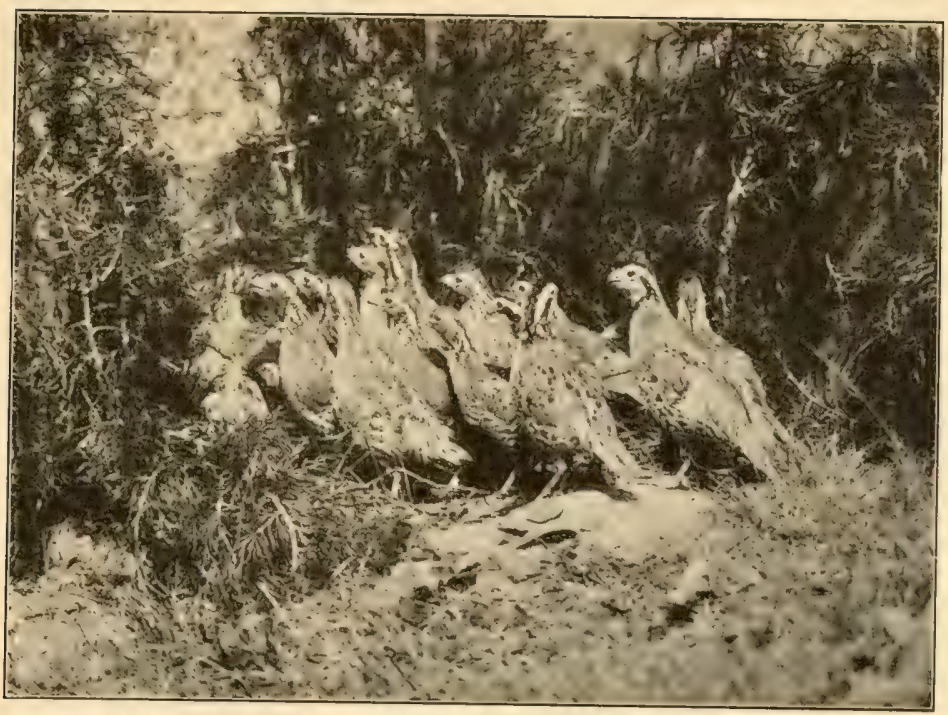

Bob-white breeding-stock before being paired off

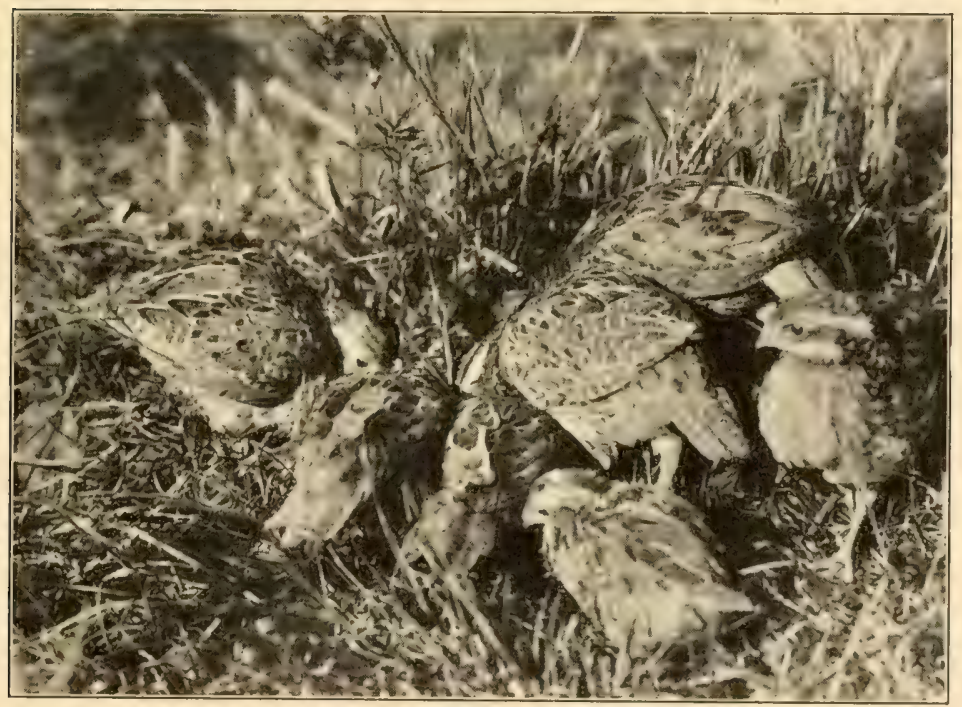

Group of young bob-whites feeding , 


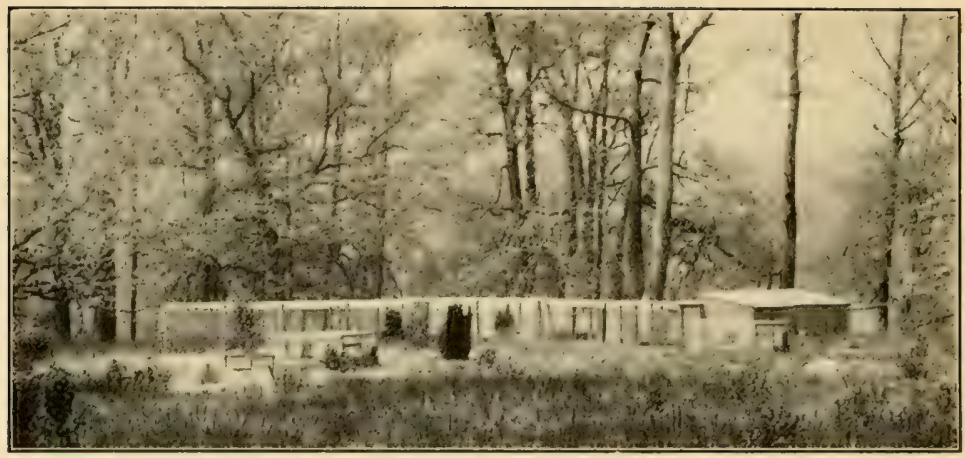

Main holding-pen for quails, and a few single breeding-pens, Storrs, Connecticut

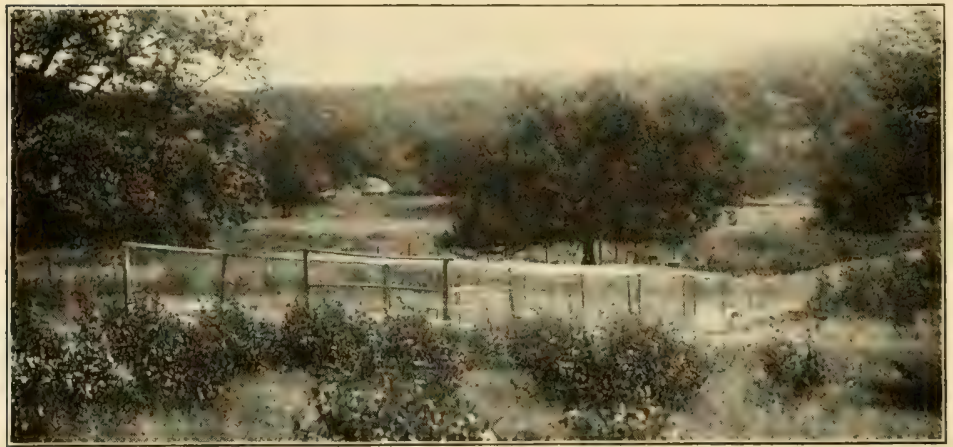

() uail rearing-field, Storrs, Connecticut, with covered corral in near corner

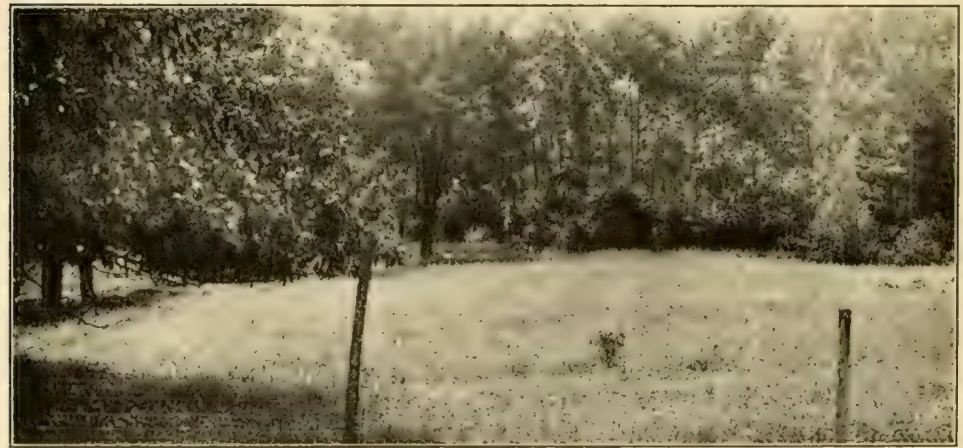

Buckwheat left standing for birds 
her second set. Something about the artificial conditions weakens the maternal instinct, the mere production of eggs being more nearly automatic. Probably in a good large enclosure the quail would generally incubate her own eggs. In my experiments the maximum number of eggs laid by one quail in a season was seventy-three. This was surpassed in the Massachusetts experiments, where one hundred and one hundred and two were secured from one bird.

Taking Eggs. It is well not to disturb the birds by frequent search for eggs. About once a week will answer. Avoid entering the small pen, but search each brush-pile from the door near it, and leave a couple of the freshestlooking eggs in the nest to encourage further laying. Some eggs, especially at first, may be dropped at random on the ground. Mark the eggs as taken with number of pen and the date, and keep careful record of all details, which will prove interesting and valuable. Keep the eggs in bran or sawdust, not on the side, but on end, in a fairly cool place, and turn them each day, the other end up.

Setting Eggs. By all means use hens, and not incubators. For quails it is necessary to have bantams, as ordinary hens crush the fragile eggs. Buff cochins are in most general uses but silkies and white cochins are just as good. Some keepers recommend Seabrights, which are very light, without the clumsy feathering on the legs, and later range farther with the young, getting them more food. Some of them, though, are rather wild and make the young so. Cochins and silkies are sluggish, and the young are more likely to outstrip them. However, where there are a number of broods, it is often best to keep the hens shut up much of the time, and these are better content and quiet. Besides, the cochins and silkies cover more eggs.

Set on Ground. In setting quail eggs, it is much better 
to have the nests on the ground than on dry boards in hatching-houses. These eggs are so small and the shells so thin that evaporation is rapid, and they require much moisture. The nest can be directly on the ground, or made from a square of sod, set grass side down, hollowed out, and well lined with soft hay. This slight elevation will keep rain from flooding the nest. The moisture from the ground is probably sufficient. If the nest is indoors, the eggs should be sprinkled daily. Both Evans and Rogers are against hatching-houses, finding that with wild species results are better by setting the eggs on the ground in small coops. The latter, moreover, are easier to keep clean and free from vermin. Cochins and silkies can cover about twenty quail eggs, but give the hen only what she can readily cover.

Setting Hens. Before setting the hens, make sure that they are fully ready to sit, and dust thoroughly with insect powder. Do this again at the end of the first and second weeks. Neglect of this is a very serious matter, and is likely to make the hen desert or die, and cause the destruction of the brood. Take the hens off each morning to feed, and clean the nest and eggs, washing the latter as little as possible. Have the hen go back to the eggs when these begin to feel cool held against the eye.

Hatching. The period of incubation is normally twentythree days, sometimes twenty-four if the weather is cool or wet. The eggs pip a day or two before hatching. The hen should then remain off but a short time. When hatching begins she should not be disturbed. Young quails are exceedingly small, about the size of the last joint of the thumb, and are easily crushed.

Finishing with Incubator. Some workers adopt the plan of removing the eggs when pipped to an incubator running at ro4 degrees, giving the hen a few poultry eggs to hold her. 
After hatching the temperature may be from 100 to 103 degrees. The young are kept in the machine till they are dried off and lively, and then are replaced under the hen at night. This doubtless saves some from being crushed and is all right if one wishes to take the trouble and will keep the temperature right in the incubator. It is not necessarv, though, if the hen is kept quiet and in the dark. The eggshells should be removed without lifting the hen.

Removal to Rearing-field. Let the hen brood the little quails until they are a day old or a little more. There should be no hole or crevice through which the young could possibly escape. Then remove her to a fresh coop and run, out on fresh turf, and give her the chicks. She should have whole corn or coarse grain accessible, which will keep her quiet during this critical period, nor will she be so likely, in eagerness for food, to trample the chicks when they are first fed. Here, again, make sure that the little fellows cannot escape. They do not yet know the hen's call and would certainly get lost. It is well to watch them awhile to make sure that they know enough to brood when chilly. If the weather is cold or wet, they should be kept at first shut in the coop; otherwise they can run out in the little yard.

Food for Young. Young quails and other gallinaceous species in the wild state are mainly insectivorous, and require animal food. So it has been a matter of experimentation to ascertain to what extent artificial feeding could be modified and yet hold the young birds in health. It has been found, in short, that they will thrive on various artificial foods, provided that during the period of growth they are allowed to range in the open and supplement the artificial diet by the insects which they catch.

Feed Lightly. Another axiom of successful propagation of wild birds is to feed lightly. This is especially true of the 
young. The poorest kindness and the surest way to kill them is to deluge them with food and let it stand around sour or accumulate on the ground. Watch an experienced gamekeeper feed young broods on a pheasant farm. Going from coop to coop, where usually the hen is shut in and about a dozen to fifteen young are ranging in the grass nearby, he throws about three times what he can take up with thumb and fingers, one throw by the slats where the hen can reach it, the rest in the grass just beyond. It is just the same for quails, only they eat less. They find it all, never fear, eating it up quickly. If some birds are not on hand, hunger will make them ready next time. Each bird gets just a few mouthfuls, but it is enough.

How Often to Feed. Feed little and often is the rule at first. Begin after the chicks are a day old and feed four or five times a day the first week, and four times the second week. Then, since they have learned to range actively, three times a day is enough, and twice a day after they are two months old. Rogers drops to two feeds a day after six weeks. This should depend upon the amount of food the birds pick up. Some feed five times the first few days, while the chicks are learning to eat, which is all right, as they will eat very little at a time. I think the chicks get a better start to eat a little food quite often. They are then less apt to overeat and start trouble.

Boiled Egg. It is now generally believed that cooked egg is the most practical first food. Two methods are used successfully: One is to boil eggs fairly hard, preferably about five minutes, remove the shell, grate through a sieve, and mix with fine cracker crumbs, or parched bread crumbs, just crumbly moist, not wet or sticky, which latter is also the rule for all mixtures.

Custard. The second method is to make egg-and-milk 


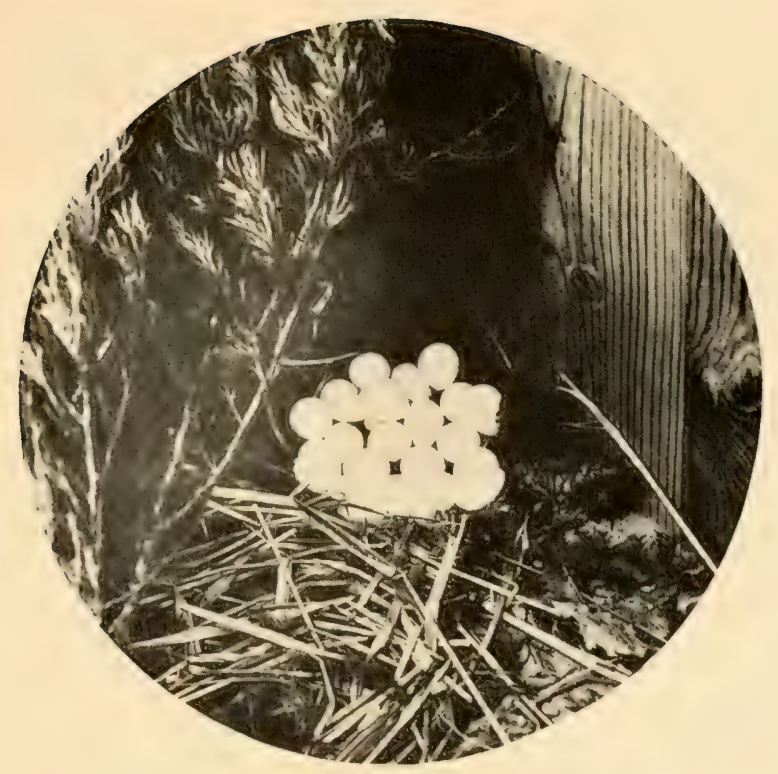

Nest with twenty-four eggs of bob-white in a coop

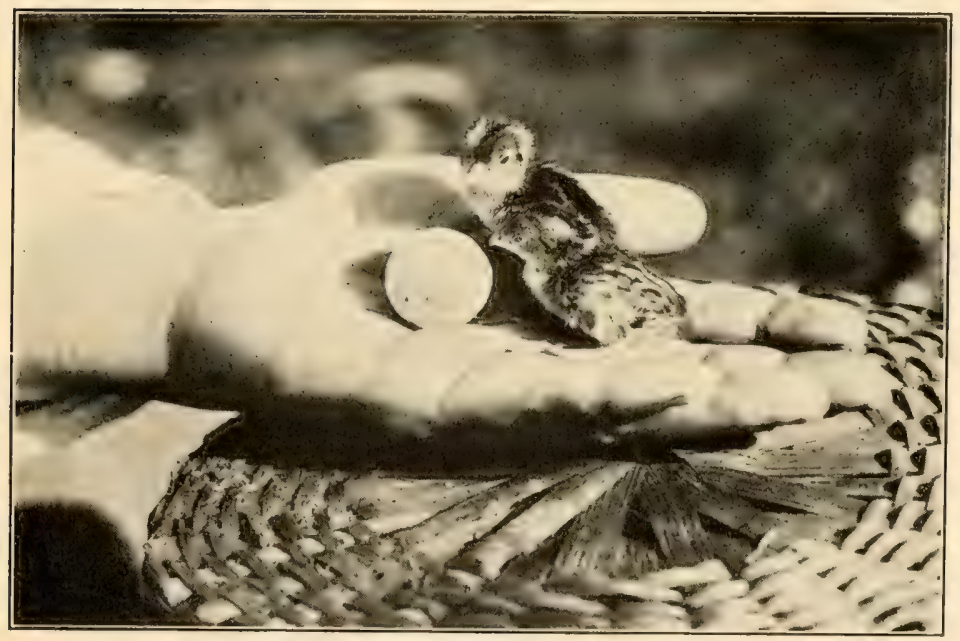

Day-old quails and empty egg-shell 

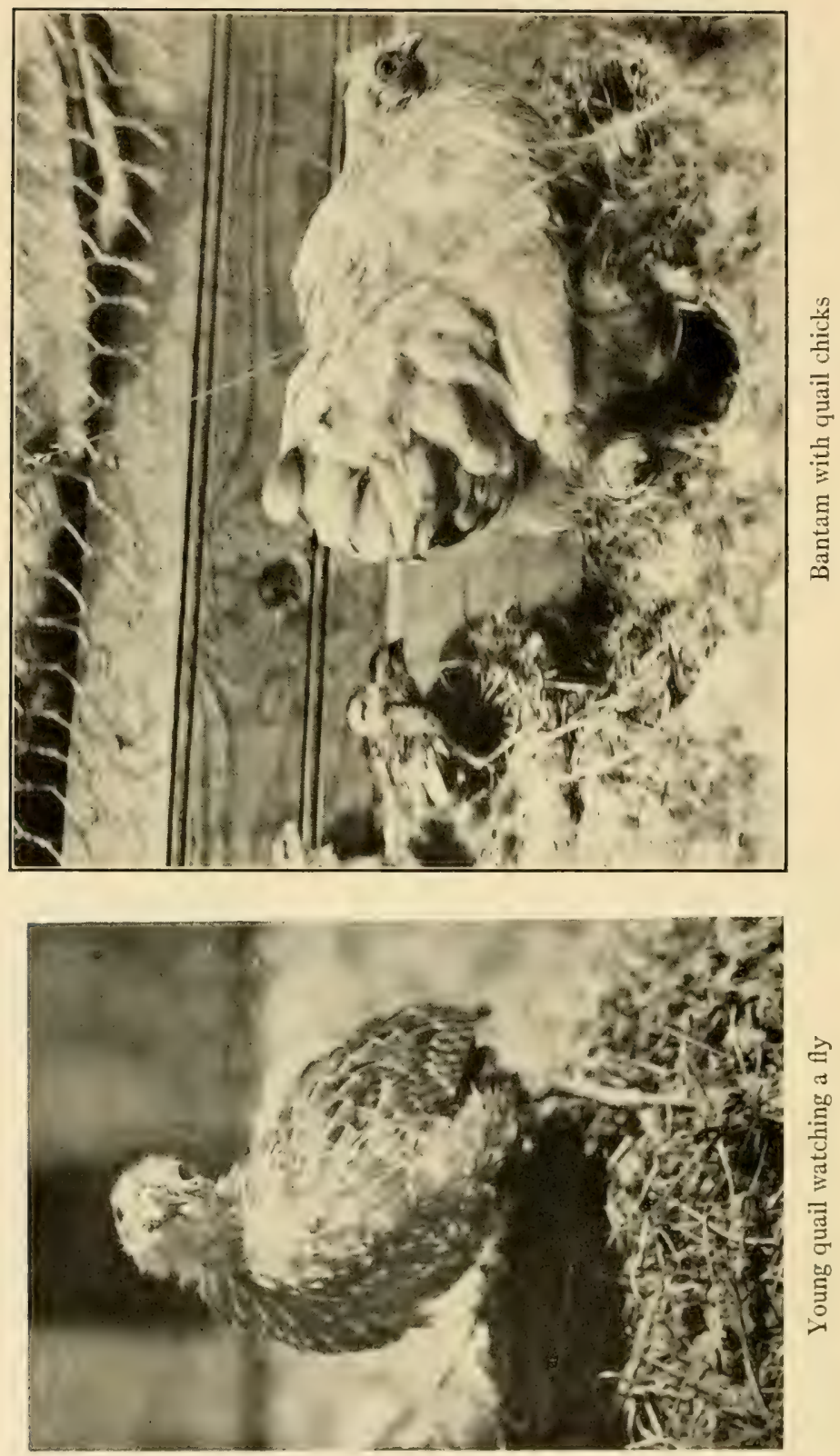
custard. Use three eggs to a good cup or half pint of milk, or ten to twelve to the quart. Beat well together, and cook slowly till the custard is $d r y$ and hard, firm enough to be held like a cake in the hands. The custard that people find bad for young birds is that which is soft and wet, such as we would prefer for ourselves. Rub this hard custard through the sieve, mix some crumbs with it as above, and it makes a good feed.

Grit and Water. Along with this, from the very first, there should always be before the chicks a mixture of finely ground grit and charcoal and clean water in a small drinking font.

Milk Curd. A supplementary food for very young birds which is coming into general favour is sour-milk curd or "cottage cheese." The experiments of Dr. L. F. Rettger, with milk, either fresh or sour, as a preventive and cure for white diarrhœa in chicks are very convincing. Some breeders mix an occasional mash with milk, fresh or sour, thus using the whey as well as the curd. On the principle of using dry-moist food, the dry crumbly curd answers well, and a little can be fed once each day, say one of the meals during the four-meal period, or every other day for a couple of weeks. It is the milk food that is effective, not the acidity, according to Doctor Rettger.

Ants' Eggs. Another useful early food is the commercial dried ants' eggs. There may be some question as to just how much nourishment these really contain. At any rate, the young birds are fond of them, and they are supposed to supply an element of insect food. Being rather expensive, they would not be practicable for large flocks of young pheasants, but for a moderate number of little quails or grouse they are very useful. They are purchased from dealers, and should be scalded and fed moist, once a day. 
Early Regimen. A good regimen, then, after the first few days, would be four meals, say at six, ten, two, and six o'clock, mostly egg or custard, perhaps varied with a little dry curd and ants' eggs. More food should be given morning and night, less during the day. For the first few days give a very little food every two to three hours.

Transition. After a few days' feeding, the use of prepared "pheasant meals" and seed mixtures may be begun. The idea is to begin gradually to mix in these other foods, and slowly reduce the quantity of egg, giving very little egg toward the last, and stopping it when the young are six weeks old, or even before, as some do. The practice is, in general, to begin to use the pheasant meal in small proportion with the egg, and eventually to substitute it for the latter. This article is a balanced ration of cereal, meat, spice, etc., similar to dog biscuit finely ground. Both Spratt and Evans supply a good article. Especially for very young birds it is well to scald the meal separately, and let it stand for an hour or so to swell. It may be mixed overnight, if kept cool, but no longer. Beware of food even slightly soured.

Begin Grain. Since gallinaceous birds feed considerably on seeds and grain, the chicks should learn to eat such food, beginning when about a week old. Spratt's chick-grain and Evans' pheasant feed, fine, No. 3, are both excellent mixtures of various nutritious seeds, ground grain, and peas, meat, grit, and the like. Some mix a little with the mash at first, to get the birds accustomed to it; others give one meal a day of it clear, usually the midday feed. Rogers finds that some seeds and grains ferment rather soon when wet, but that canary seed does not. So he begins by mixing canary seed in the mash, and soon the chicks, getting used to hard seeds, will eat the chick-grain dry. After they are two months old 
the mash can be discontinued, and the chick-grain mixture made the principal food. A. G. MacVicar soaks the chickgrain while the chicks are small.

Insects. The birds, being reared on the free range plan, are supposed to secure considerable insect food. It is well to supplement this by catching insects for the young birds. They are eager for grasshoppers, and any such food is sure to do them good. One way to secure insects is to sweep the grass with a butterfly net. Some striped beetles, however, Doctor Hodge found to be injurious in any quantity. Another plan is to set fly-traps, kill the flies by heat, moisten, and feed with the egg as mash. This is merely a makeshift. Moreover, large quantities of flies sometimes kill young birds.

Maggots. Formerly it was believed that birds of this class could not be reared without maggots. The breeding of these is disgusting work, and it is fortunate that they are now found unnecessary. The most successful breeders now never use them. Evans considers them rank poison when raised in rotten meat. Inasmuch as he and Rogers and others raise thousands of birds of various sorts without them, it hardly seems desirable to incur the annoyance of producing them.

Green Food. Another important food element is green vegetation. On range the birds, under favourable conditions, secure this for themselves, browsing on clover and all sorts of tender growths. In case this is lacking, as in very dry weather, it is well to throw them a little lettuce, chickweed, or other succulent growth.

Dried Meats. For an additional meat element many use and recommend Spratt's crissel. Ordinary beef-scrap, unless known to be made from fresh meat, is dangerous. Even crissel is dangerous if fed too freely. It is safe not to begin it till about the time the egg is left off. Then use it in the 
mash, not over about 5 to 8 per cent. of the bulk, and using it not oftener than once a day. Some scald it separately.

Later Regimen. When the young are reduced to two feeds a day, after about eight weeks, the morning food should be the mash and the evening meal chick-grain.

Other Ingredients. Another article often used with the mash is boiled rice, in moderate quantity, and not too often, say every two or three days, when the birds are one to two weeks old. This is valuable to check or prevent diarrhœa. Neil Clark at the Clove Valley Club mixes oatmeal with the egg instead of cracker crumbs. Frank Hopkins, of the Connecticut State Game Farm, mixes fine grit and charcoal in small quantity with the mash.

Evans's Method. Wallace Evans's great success certainly justifies his method. In feeding young pheasants or other species he begins with dry grated custard, as above. At the age of three to four days he begins to mix in with the custard his own preparation, called pheasant meal No. I, a little at first, and at three weeks he discontinues the custard. When the birds are about ten days old he begins his seed and grain mixture, pheasant feed, fine, No. 3, giving it dry, once a day, at noon, and the custard and mash morning and night. At three weeks he substitutes coarser grades of the same for pheasants, Nos. 2 and 4 , but for quails the finer grades are probably coarse enough. After eight weeks, when practically mature, they have no more mash, only grain mixture, probably the medium, No. 4.

MacVicar Methods. A. G. MacVicar, who has raised quails as a side issue with waterfowl and pheasants, gives the chicks egg-and-milk custard at first, or grated hard-boiled egg. About the fourth day he begins mixing in Spratt's chick-grain, scalded. He scalds it to make it swell before being eaten, rather than in the tender stomachs, which last 
he considers a cause of indigestion. Only enough for one feed should be scalded at a time, as it sours very quickly. Sometimes he uses instead Spratt's pheasant meal No. I2, fine, but prefers the chick-grain for this purpose, and thinks that breeders are doing this more. He does not use flies or maggots, believing that they spread diseases; both, he finds, are going out of fashion. In England they use boiled rabbit, chopped up, for animal food, mixing it with boiled broken rice just cooked through, not mushy. Rice has a constipating effect, and rice-water is also used to secure this. Chopped suet he finds good to bring birds to proper condition. $\mathrm{He}$ advises against sudden changes from one food to another.

$\mathrm{He}$ is one of the school which does not believe in having water left standing before young pheasants or quails. He says he has seen young pheasants drink from a dish of sunheated water and fall dead. Until his birds are ten days old they are given no water except what is in their food. After that he fills their water dishes twice a day, and empties them again in a short time. Ludwig Seidler also follows this plan, and there are others not a few. On the other hand, Wallace Evans always keeps water before his young gallinaceous stock, and raises them by thousands, without any such trouble.

Table of Feeding. For convenience I give a table for the feeding of young quails, or other species, rather as a line of suggestion than to be slavishly followed:

\section{FOOD TABLE FOR YOUNG QUAILS OR OTHER GALLINACEOUS SPECIES}

First Week. Four or five meals a day, or every two hours in minute quantities:

I. Egg or custard.

2. Same, or curd. 
3. Same or ants' eggs.

4. Egg or custard, etc.

Always keep before them fine grit and charcoal mixed. Water should be in fonts which cannot be fouled, and kept in the shade. Otherwise give it only at meal times.

Second Week. Four meals a day:

I. Egg or custard, pheasant meal or canary seed or chickgrain added.

2. Same, or ants' eggs or insects, or these added to mash if not enough. Occasionally curd, in which case give the insects after it, or at another meal.

3. Same as first meal.

4. Same as first meal, a little boiled rice added every day or second day.

Third to Sixth Week, inclusive. Three meals:

I. Mash as above, reducing egg, increasing pheasant meal, adding ants' eggs or insects as convenient.

2. Chick-grain or grain and seed mixtures.

3. Same as first meal, rice every two days.

Seventh Week to Two Months. Three meals, or two if insects are plenty and birds do not act as if hungry:

I. Chick-grain or small grain and seeds.

2. Same, light feed.

3. Pheasant-meal mash, with crissel.

After Two Months. Same as adults.

Handling of Young. The discussion of feeding has taken us in advance of the order of our subject, to which let us return.

Move Coop. Each day, or certainly every other day, the coop and run should be moved to a fresh spot of turf adjoining, to avoid fouling of the ground. Move either coop or run while the hen and young are in the other part. Transfer the hen first, and then the chicks. Make sure that there is no hole through which the tiny things can escape. 
Free Range. After the fourth or fifth day the young have learned to obey the call of the hen, and they can be allowed to run out at large, provided that the weather is good. They are so small, however, that it is just as well to keep them shut up the first week. Then they can be let out with safety, for they will not desert the hen.

The Hen. It is optional whether the hen shall be allowed to wander with them, or remain shut up and the young run back and forth through the slats. This is according to circumstances. If there are a number of broods in adjoining coops, it is rather necessary to keep the hens shut up, as they are liable either to fight or to flock together, and mix the broods or foul the ground. Where feasible, I should let the brood out with the hen, as they will then range farther and catch more insects. In large pheasantries it is customary to let late broods roam with the hen in order to give them the best chance to get strong and survive.

Other Details. Fencing is unnecessary, provided that there are no cats and dogs about, and that rats and other vermin have been kept down. The coops can be scattered about as convenient, in fields, on lawns, in openings at the edge of shrubbery or groves, wherever it is fairly level and grassy, and should be moved every other day. The hen will not go very far, and will lead the young into the coop at night or in case of hard showers.

Whether the hen is at liberty or not, there should always be some pile of brush, evergreen preferred, or clump of weeds near the coop. The young love to hide, especially if alarmed, and they must have shade on hot days. Moreover, a hidingplace is a refuge from hawks or other dangers. If this is provided they will stay better near the coop.

Fenced Fields. If breeding operations are to be on any considerable scale, it is best to have at least a couple of 
fenced rearing-fields, which can be used alternate years, and will prove a great convenience. Each should contain at least half an acre. For work on a large scale with pheasants, such rearing-fields are often five or six acres, or more. The best land for these purposes is not wild, but arable land, such as can be ploughed and seeded. The soil should be light and porous, well drained. For a very few birds smaller enclosures will do. Yet even for a brood or two an enclosure should hardly be less than about roo feet square. The fence should be 6 to 8 feet high. For quails there must be a strip of $\frac{1}{2}$-inch mesh wire at the bottom, and it should be buried from 4 to 6 inches. This $\frac{1}{2}$-inch wire should be bought in rolls 18 inches high. Above this should be a roll of I-inch mesh, say 3 feet high, and above this, for an 8-foot fence, a 4 -foot width of $1 \frac{1}{2}$-inch mesh. Quails when a month old will begin to make low, short flights. The inch mesh will then stop them, but they would fly through the I $\frac{1}{2}$-inch mesh, which will check them later. A fence 4 to 5 feet high would be of some assistance, but foxes can leap over it, and cats easily scramble up. It is seldom that a fourfooted enemy gets over an 8-foot fence, and this keeps the birds in longer and better. Fledglings easily fly over a low fence, but not readily over the 8-foot, which gives a longer period of protection. With pheasants, the majority remain inside, and the few that fly over try to run back, and can be let in or caught. Quails are bound to fly out in time, but after being let back a few times, they learn to go back and forth at will, and they return for the night.

Field System. The coops in a rearing-field should be at least 40 feet from each other, the farther the better. Wallace Evans has his 80 feet apart in the rows, and the rows roo feet apart. When the grass grows up, a good wide swath should be cut for each line of coops, or spots mowed 


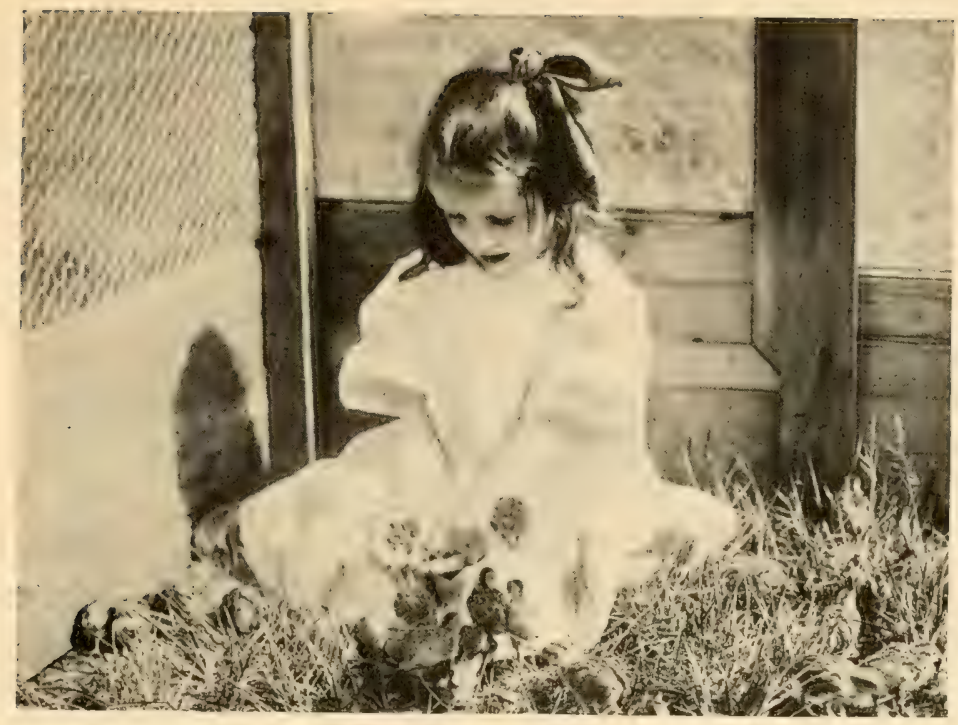

Muriel, daughter of author, feeding little bob-whites

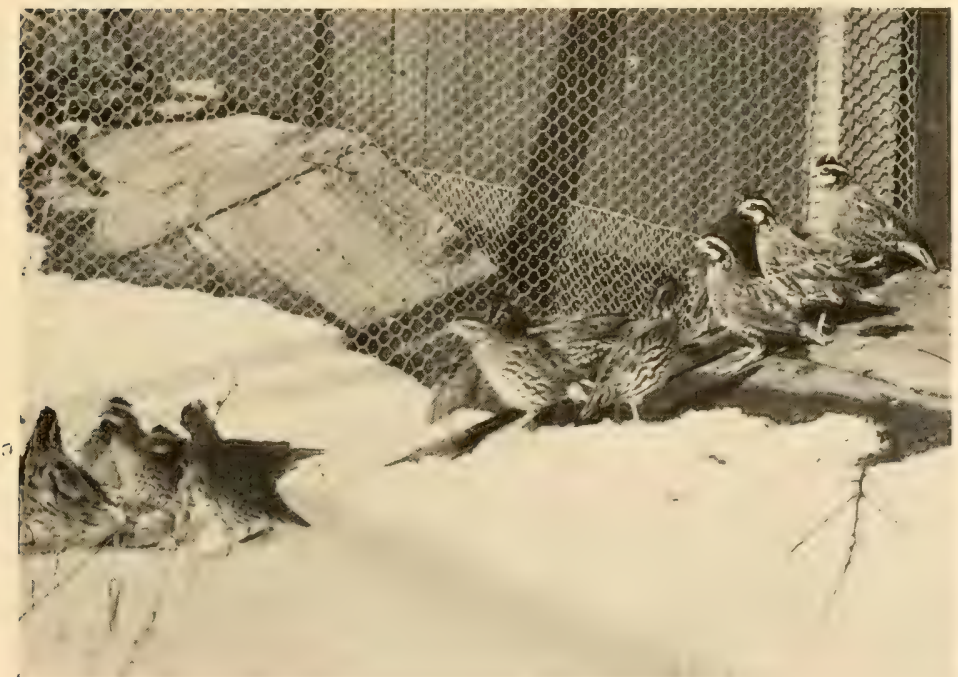

Bob-white stock of T. A. Howell in winter quarters 


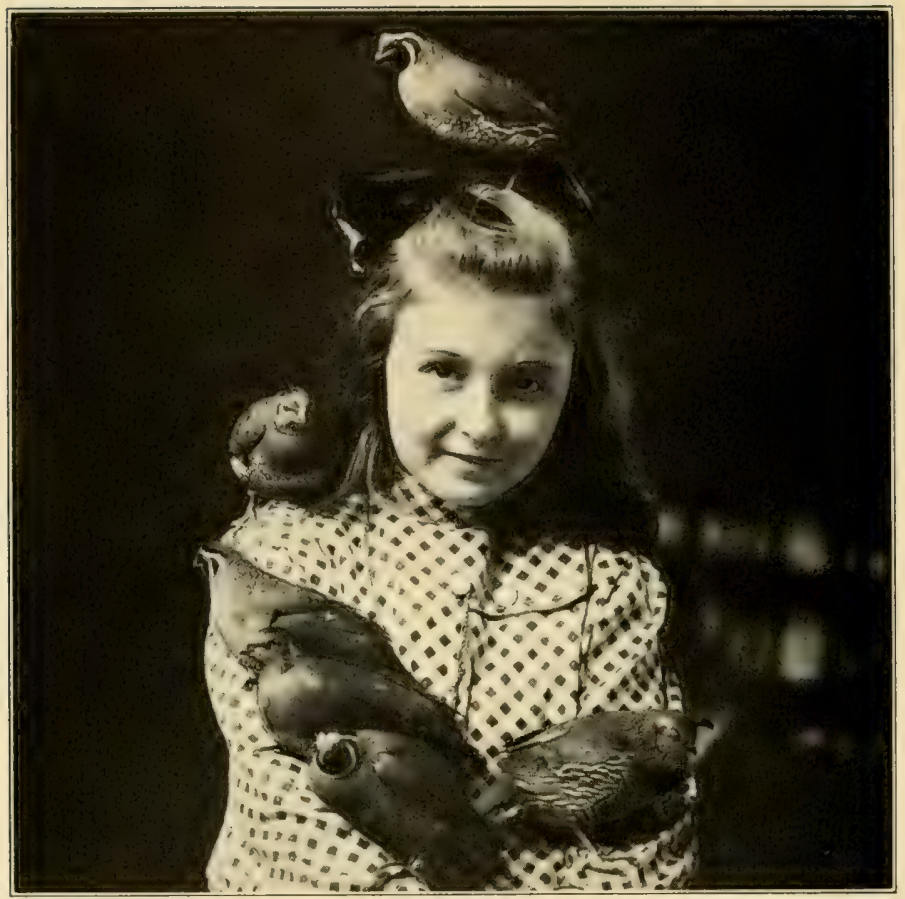

Ruth, daughter of Superintendent Dirks, with California or valley quails, State Game Farm of California

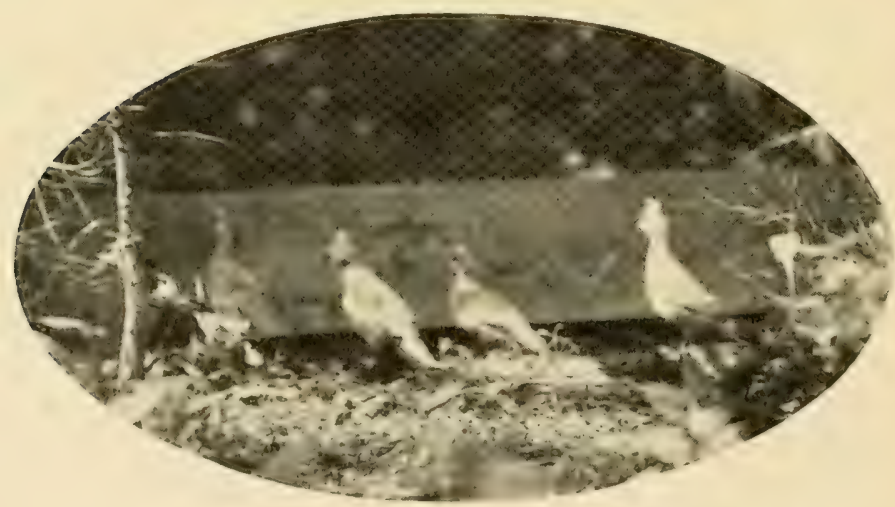

Scaled or "blue" quails on estate of U. S. Senator George P. McLean 


\section{QUAIL PROPAGATION METHODS}

for single ones. A heap of brush should stand near each coop. In the areas between lines of coops some shade crop can be planted, such as corn or sunflowers, or else oats, buckwheat, or vetch, or a mixture of these. The latter makes fine shade in late summer, and the birds are very fond of the seeds when matured in the fall.

Avoid Crowding. At the present stage of the experimental work with quails we are not yet sure how large a number can safely be reared in one field. Myself and others have demonstrated that a few hundred can be raised successfully on the free-range plan, and where we err on the side of abundance of room. In a five or six acre enclosure at the Clove Valley Club I saw two thousand young pheasants raised without danger. But quails would certainly not stand anything like that amount of herding. We do not yet know how far we can go with numbers and crowding, and this is to be worked out. Till this is done, it is well to be cautious with the rearing-field system, using, preferably, fields of moderate size and more of them. For the present, I should not try to keep more than half a dozen broods in a field of half an acre. For other broods it will be safer to scatter the coops in the open about the estate, preserve, or farm, as above.

Quail Social. Fortunately the quail is a very social bird and the young are quite easily managed, owing to their attachment to each other and to their foster-mother. Sometimes, if the hen is not taken away, they will run with her till late fall or even through the winter. I have laughed to see a bevy of fully matured quails in winter obediently following a little yellow bantam. Mr. Rogers considers that the last crisis is past with quails when the neck feathers, which are the last to mature, are fully grown out. This is when they are from eight to ten weeks of age. Beyond this period, 
as with the adults, it is possible to confine them under proper conditions. Hence the safest way is to give the young ones liberty till they are fully grown.

Critical Period. The time when young quails are most liable to epidemics of the dreaded enteritis is from late August for about a month, when the first fall rains and cool nights test their vitality. Disease starts with weaklings, but becomes epidemic, like cholera. If a number were penned together at the time of such an outbreak, the pestilence would probably sweep the whole flock. Hence it is safer to wait till they show signs of wandering off before enclosing them. Also safety suggests putting no partly grown young with the adult stock or with mature young, lest they sicken and contaminate those safely raised. Let the late broods run free with the hens till cold weather, or else give them separate enclosures, with wings trimmed if the pen is not covered.

Clipping Wings. Another point which needs to be further worked out is to what extent it is advisable to clip the wings of young birds like quails which are susceptible to the intestinal trouble. Flight is very active exercise and tends to keep a bird in health and vigour. Depriving it of power to fly during the growing period might make it less able to combat contagion when a considerable number are together. To trim a wing does not harm them when they have range, but it renders them unable to escape from enemies.

In the case of pheasants in a rearing-field, Evans is able to control them through only a slight temporary impeding of their power of flight by clipping only the first three or four primaries, as will be explained later. Quails can be controlled in the same way, but the temptation must be carefully guarded against keeping too many in the same 
field. Clipping, of course, should not be practised on birds intended for liberation that fall, but for only those to be kept or sold for breeding-stock.

Habits of Young. The young quails, whether at large or in a rearing-field, grow up in a sort of wild state, shyer than pheasants, more liable to hide and lie close in the grass and flush wildly. It is well to keep strangers out of the rearingfields, or have them closely follow the keeper if the young are in shape to fly strongly, as fright makes them flush like wild birds, and they are likely to bring up hard against the wire and injure themselves. By themselves, they learn to avoid the wire, and fly out to feed in adjoining pastures, returning in the same way to stay with the hen at night. Usually they follow her into the coop, even when quite large, but some broods get to roosting outside, especially in good weather, sleeping on the ground in a ring, tails together and heads out, after the orthodox quail fashion.

Escaped Young. When the young are with bantams in a fenced rearing-field and first fly out over the wire they are soon anxious to return. They do not know enough to fly back, but run along the wire, peeping plaintively, like lost chickens. One way to recover them is to open a gate or slide and drive them in. Another good device, shown me by Neil Clark, is to have, on each side of the field, a strip of wire two feet high, and only a few feet long, erected and meeting the fence at an acute angle. The part nearest the fence should be bent over to make an arched passage, ending in a small pocket. The bird or birds, following the fence, will be guided into this, and can easily be caught and put back. This gives a good chance to clip slightly the wing of these more adventurous ones of the flock.

Staying with Hens. When the young are from eight to ten weeks old they no longer need the hen, as far as brooding 
or mothering is concerned. The hen, however, still has a useful function, to keep the young from wandering off. In pheasant rearing it is customary to remove the hens when the young are about eight weeks, and are old enough to be confined. Young quails do not stand captivity well till they are fully matured. Hence it is better to let the hens stay with them, to hold them out in the open as long as possible before any are to be caught up. It is an interesting and an arnusing sight to watch a covey of full-grown quails trooping obediently after a little yellow hen. Young quails are especially prone to stay with the hen foster-mother. For example, on the estate of United States Senator George P. McLean, at Simsbury, Connecticut, at the time of this writing, in December, the coveys of hand-reared young quails, fully matured, are still running with the hens closely about the house. The attempt will be made to hold them thus through the winter, on free range.

Holding in Vicinity. Everything possible should be done to induce the young stock reared to remain free in the vicinity under partial supervision and care. Feeding should be continued as long as possible at the accustomed places. If it is desired to allow some of the stock to remain free, their feeding-place should gradually be shifted to a spot suitable to attract wild birds as well, and grain should be kept there under covers or shelters, as already described for winter feeding, using ordinary mixed grain or scratch-feed. Especial care should be exercised when there is severe cold and heavy snow. Leaving patches of standing grain is an excellent practice, as noted above.

Catching up Stock. If it is desired to catch up some or all of the young stock, this may be attempted when they are fully matured, which is after the feathers of the neck are fully grown out. Following are some of the methods which 


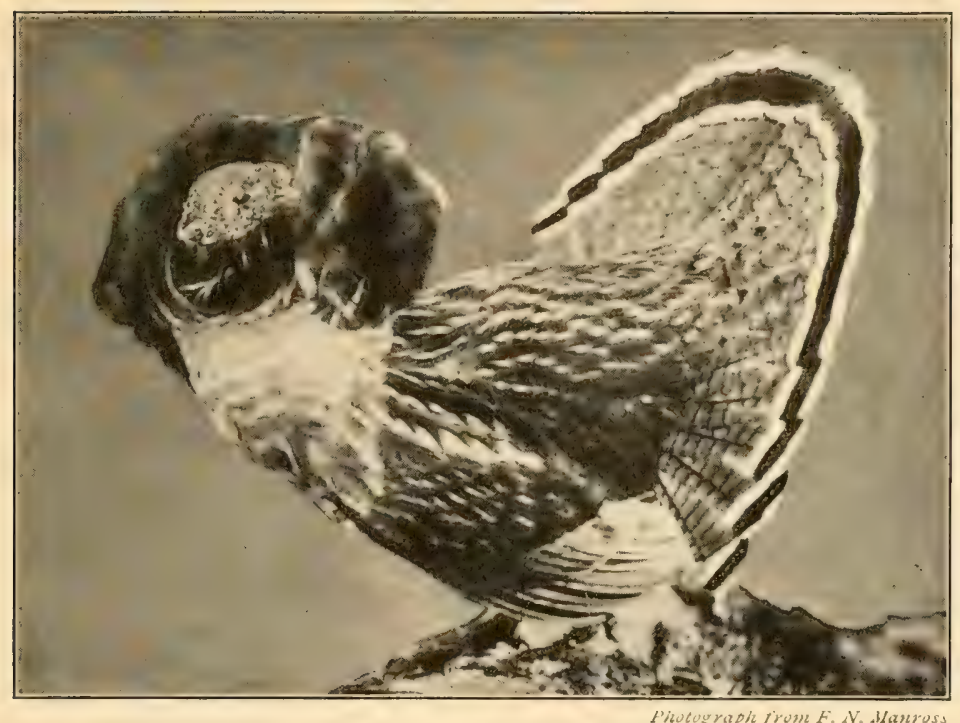

Young ruffed grouse strutting

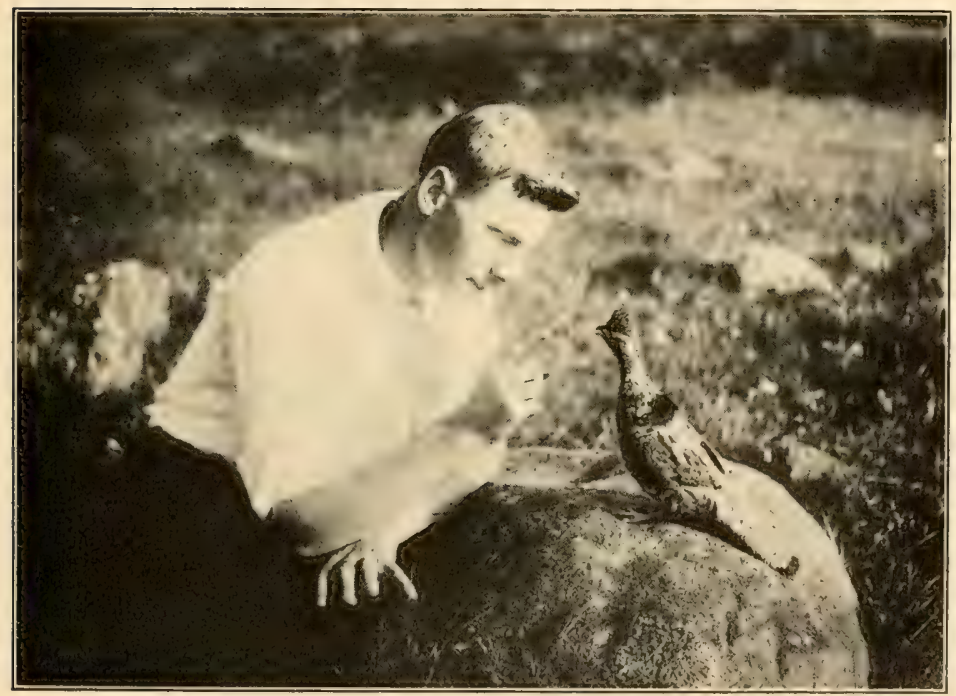

Tame ruffed grouse, captured wild 

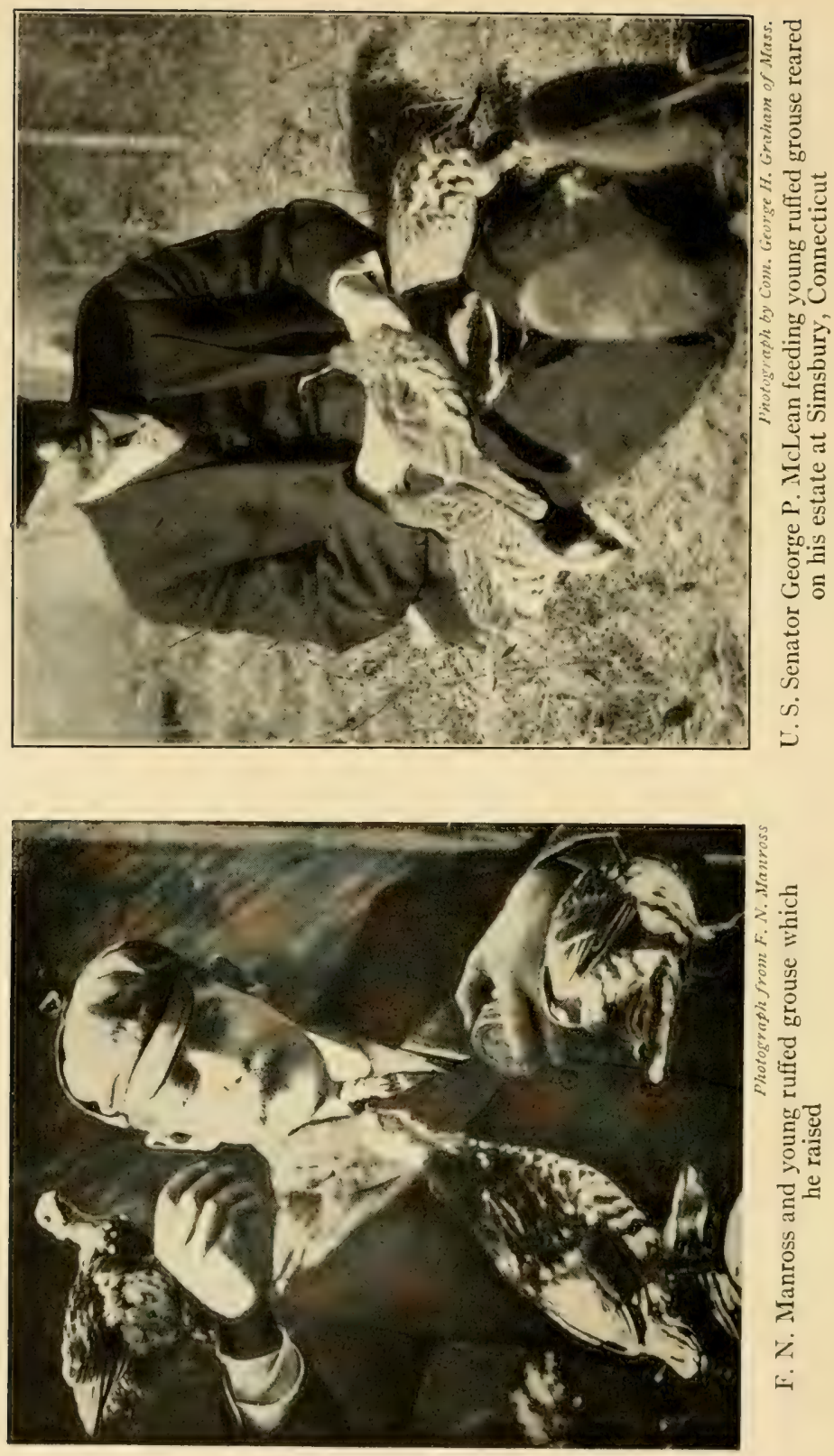
can be employed: The usual and most obvious way, in case the young still sleep in a coop or yard with the hen, is to shut the door on them at night. Another way, whether they are with or without the hen, is to get them accustomed to feeding inside a wire frame, and close the door when they have gone in. Grain sprinkled in a line leading up to the place will help attract them. I have seen Rogers use a frame entirely open at one end in catching pheasants. When the birds were feeding inside he walked up openly, blocked the entrance with his body, and caught them by hand. They did not try to run toward him, but retreated to the farther end. With quails it would be well to have some brush there for them to hide under.

In cases where a remnant is made shy by previous trapping it would be well to attach a cord to the door and pull it shut from a distance. Another way is to use traps. One type is like a lobster-trap in principal. The birds follow a line of grain into a funnel which projects back into the centre of the trap. The birds, once in, run around the sides, and do not notice the opening in this projection. Still another method is by automatic traps of various sorts, such as the figure-of-four trap, the "clover-leaf trap," mentioned later, and others.

Résumé of Plan. Following is a résumé of the general plan, based upon my own experience and observation, which I suggest for the handling of quails on an estate, farm, or preserve:

I. Secure breeding-stock in late fall or early winter either by purchase or by capture of a small stock by permission of the authorities.

2. Keep these through the winter in a wire enclosure with simple shelter from storms and cold winds.

3. In April separate the pairs, having each pair in a small 
pen by itself. Some can remain in the larger pen together, if there are not enough small pens.

4. Hatch out the eggs and raise the young with bantams. Do not attempt incubators and brooders.

5. Put the breeders back into the large pen together by the latter part of July, unless they wish to incubate.

6. In late fall or early winter catch up what young are desired. The rest can be left wild to breed naturally next summer. Feed regularly under shelters throughout the winter, to hold them on the land, as also by planted areas of grain left standing for them. In severe winter weather coveys might be shut up and cared for, and let go again.

Such plans, carefully followed, should prove practicable, and should become an important factor in restoring quails and other birds of this class.

Quails of Other Species. Several other Western and Southwestern species of quails are fully as easy to breed and raise as the bob-white, and in some respects even easier. Three kinds are of especial interest: The California or valley quail is a very beautiful species with plumed head, abundant in California and neighbouring states. It gathers in large flocks, and is quite gentle and confiding. Gambel's quail is similar, and abounds in New Mexico, Arizona, and vicinity. The scaled or "blue quail" is a beautiful, docile bird, of a pearly gray colour, with a tuft on the head, and is found from the tablelands of Mexico north to western Texas, New Mexico, and southern Arizona. Still another kind is the mountain quail, of the Pacific Coast region north of San Francisco, a larger bird than the others, hardier, but wilder.

Though the scaled, valley, and Gambel's quails come from mild and even warm climates, they are remarkably hardy, 
and in open pens with a little shelter survive the temperatures met in southern New England and Long Island. It will take years of experiment to ascertain whether they can maintain themselves in the wild state. I was told, however, by Harry T. Rogers that the scaled quail was propagated on his father's place on Long Island, New York, and, in spite of shooting in the fall, did not disappear for several seasons. At any rate, it is proved that they breed abundantly and successfully in captivity.

McLean Experiment. During the season of I9I4, on the estate of United States Senator George P. McLean, at Simsbury, Connecticut, I directed experiments with a small stock of scaled quails and bob-whites. The first thing noticeable is that the former are tamer than the bob-whites, showing themselves more so, and not skulking so much under the brush-piles. They laid equally well separated into pairs in small coops or together in a larger pen, in this respect also surpassing the bob-white. We raised the young of both kinds with bantams, on the free-range plan, without disease or loss. They flew off into the woods and alighted in the trees, but at night went into the coops with the bantams. By early September the older scaled quails were fully grown, and some of them began to stay out nights away from the hen, though they ran with her by day. Where broods were of the same age, both kinds associated, and were fond of frequenting an ash-heap and the tracts of weed around it close to the gamekeeper's house. They would all run into the weeds when closely approached. If further pressed, they whirred off to the wooded side-hill nearby. The bantams would chase after them, call, gather the broods, and lead them back to the dump. At night they would go with the hens into the coops nearby, the broods considerably mixed. At present writing, in December, they are perfectly 
well and hardy, and not a bird has died of any disease from the start. They remain with the hens, and stay close about the keeper's house. The scaled quails are especially tame, and persist in following the bantams into the hen-house, or going in on their own account to forage. The keeper drives them out, but often in a few minutes they are back again. The temperature has already been down to 22 below zero, without harm to them. The Senator has royal good times with his birds, and is a firm believer in the practicability of propagating native game-birds. If any one is skeptical on the subject, I advise them to talk with Senator McLean.

Later Developments. While reading proof of the above, March 3I, I9I5, I would add that the bob-whites, though of southerly stock, have wintered with inconsiderable loss. They range freely, but return every day for feeding. The scaled quails did well into January. Then a spell of alternate heavy rains and sudden bitter cold killed about two thirds of them. They refuse to sleep, like the bobwhites, under shelters, but persist in roosting in cedars near the lodge. During the above rains they became soaked and chilled. After this spell no more died, and a nice covey of them are now in fine condition. Yesterday I flushed them at the edge of the woods close to the house; they alighted nearby, and stood and watched me. They stay persistently, refusing to be driven off. If pursued, they run with great speed. Senator McLean is very fond of them because they are so docile about the house, and considers them remarkably well able to care for themselves. The main problem is whether they can normally winter in the Northern States. Apropos of this, A. G. MacVicar raised them in New Jersey for three years without set-back, and wintered them successfully each year. Moreover, it is believed that there is a tendency with birds 
introduced into a colder climate that each new generation which survives becomes hardier and better acclimated. Senator McLean's birds readily enter buildings, and they could easily have been shut up during the winter. He will let them breed this summer unconfined, and try to work out a practical plan. It looks as though coveys of these birds, started artificially, could be maintained in freedom with reasonable care and feeding. I have no question but that the California and Gambel's quails, which are likewise docile, could be managed in the same way.

Gambel's Quail. I have watched some small experiments also with the valley and Gambel's quails, and judge that they are no harder to breed and raise than the above. The methods to be employed with each are the same as with the bob-white, except that the scaled and valley quails seem to breed well in groups, pairing off naturally. Probably it is the same with the Gambel's.

Valley Quail. A very interesting and important propagation experiment with the valley quail is being conducted by C. H. Shaw, of Eccles, California. He began in I912, and raised a few broods successfully. In I9I3, using both bantams and incubators, he raised about I50. Owing to lack of bantams, he had to resort to artificial incubation. In I9I4, from a breeding-stock of forty pairs of tame, handreared birds, he secured I,350 eggs. Those which were hatched under what hens he could muster he reared successfully with little loss and without disease. He had remarkable hatches with incubators, from 220 eggs hatching I 84 , and from another of 208 getting 160 chicks, an average of over 80 per cent. Other hatches averaged about the same. But the brooder record was tragic, for he raised but very few by that method. He writes that the problem of propagating the California or valley quail, at least in its natural habitat, 
is largely one of providing enough broody bantams at the right time.

Mr. Shaw kept his breeding-stock of forty pairs in an enclosure, wired overhead, which contained, he writes, only about I,O00 square feet, having two stunted trees for roosting. The hens laid mostly in nests, but dropped some eggs around the pen. Several pairs, at last writing, were incubating their eggs in the pen, but these are liable, he says, to get broken up before hatching, owing to fighting. He keeps each brood with the bantam in a small coop or run till three or four weeks old. The ground is sandy and bare, and he moves them occasionally. Then he releases hen and brood in a large enclosure. These birds get very tame, almost domesticated. Some hand-reared birds, which he released this spring, stay about the dooryard. On twenty acres of land he estimates that there are about 400 of these quails, and they are rearing a swarm of young.

The feeding system used by Mr. Shaw has been one feed of ants' eggs each day, chick-grain twice or three times, and clover clippings in the middle of the day. The old birds are fed entirely on chick-grain, with one feed of clover daily. They winter in the open, with merely a roof over the roostingplace to break the heavy rains. Temperature in winter is never below 20 degrees above zero. The normal egg-laying season of wild birds is from about May I to June ${ }_{5}$.

Comparison. From what I have seen of the birds in captivity on the preserve of T. A. Howell, the habits of the Gambel's quail are similar to those of the valley quail. Mountain quails kept and bred on the same estate, in similar enclosures, seemed wilder and did not lay so well. One inconvenience about the species for artificial handling is that the sexes are almost identical in appearance, though the male is apt to have slightly longer plumes on the head. 


\section{CHAPTER III}

\section{THE GROUSE FAMILY}

No Inherent Wildness. It is interesting to note how one's conceptions about this noble tribe differ when viewed from different standpoints. The wild, whirring creature of the forest, self-reliant through its constant battle with innumerable dangers, is hardly recognizable as the same when it learns to know man as a friend. It seems characteristic of birds of this family to be capable of most remarkable tameness, in contrast to the supposedly incurable wildness of their nature. From the standpoint of Applied Ornithology they form a unique and peculiarly interesting group.

Grouse Species. The ruffed grouse, commonly called "partridge" in the North, is the best known and most widely distributed of the group. Next, probably, come the "prairie chickens" - the pinnated grouse of the Middle West, its nearly extinct relative, the heath-hen, formerly abundant in the East, and the sharp-tailed grouse of the plains. The Northern woods furnish the spruce partridge, while the mossy and rocky barrens still farther on toward the cold supply several varieties of ptarmigan which change their mottled garb of summer to blend with the snow, which has no terror for them. In the far West are the sage grouse and the dusky or "blue grouse."

Peculiar Birds. The general impression of the whole tribe, from the standpoint of artificial propagation, is that grouse are peculiar birds, rather difficult to keep protractedly 
in confinement owing to peculiar habits, and particularly their decided liability to epidemic diseases.

Ruffed Grouse. Considerable progress has been made with rearing the ruffed grouse, and it is probable that experiments with the other species will develop interesting possibilities. Having experimented with the ruffed grouse myself, with some success, and carefully studied its habits and peculiarities under artificial conditions, I shall treat of this species in detail. Dr. C. F. Hodge of Worcester, Massachusetts, was the first to breed ruffed grouse in captivity, followed by F. N. Manross in Connecticut, who likewise bred them and reared young to maturity.

Preliminary Notes. Full-grown birds, captured wild, are at first very shy. Personal care, however, can make them in a short time so tame that they will eat out of one's hand. If they are put in a large pen at first, they remain rather timid, though not long desperately wild. Sometimes it happens that hunters capture specimens alive which are only slightly wounded, and make good breeding-stock. Owing to the laws, dealers are seldom able to supply them. State authorities should permit the capture of limited numbers of birds by responsible persons who have been successful with pheasants, or the taking of a set of eggs to start a stock. When eggs are taken in the early stages of incubation, the birds will probably produce another litter of eggs, and thus the wild stock will not be diminished.

A Difficulty. Varied experience has shown that grouse cannot be kept in health protractedly in a small coop or enclosure. The quarters provided must be of considerable size. Even then, unless these are quite large, the birds are likely not to live out their natural term. Lack of exercise makes them unduly fat and brings on troubles which have 
the symptoms of gout or apoplexy. Mr. Manross has had birds, after being kept two or three years, plump and apparently healthy, which would go to roost and suddenly fall off dead.

Pugnacity. Another difficulty is that the males are excessively pugnacious. Toward spring they begin to fight terribly, when they are with hens, killing one another, until only the strongest cock survives, and he may be so crippled that he is useless. So the only way is to build at least a fair-sized separate enclosure for each pair. To some extent, at any rate, the ruffed grouse seems to be polygamous, so the cock can be put with more than one hen. If there are males enough, however, it is safer to pair them.

Attacks the Hen. Another of the numerous obstacles to the propagation of the ruffed grouse in confinement is that the cock is often brutally severe with the hen in mating; sometimes she gets scalped or maimed, and even killed. At times the hen is saved only by removing the cock. Doctor Hodge believes that the cock should always be removed immediately after mating.

I once witnessed an accident which is very instructive in this connection. Having found the nest of a grouse in the woods, I had set a camera for a photograph. The hen returned to the nest and from behind a tree I was about to pull the thread to release the shutter when suddenly the male appeared, behind the nest, every feather bristled out like a turkey gobbler. Stealing around in front, he made a sudden violent rush at the hen. She flew off the nest like a shot, and was gone about half an hour. The old rascal withdrew, waited for her, and tried, with the same result, to rush her when she returned. Had she been in a pen she would have been at his mercy. Doctor Hodge believes that one mating suffices for a set of eggs. He also found that if the 
male in the spring were separated from the female, he would at once begin "drumming," even when he had not done it before.

Probable Polygamy. The above would suggest that the grouse may be naturally polygamous, and that several hens might be kept together separate from the male, putting him with them only for a short time, or a succession of cocks, one at a time, if there were a number of hens in the pen, then giving them a chance to lay their eggs in peace. The eggs could be removed to be set under bantams, and it might be that the birds, after mutual abstinence, would be more liable to mate again and produce second layings. I have not had opportunity as yet to try out these details, but give them as suggestions for future experiments.

The Pen. I should say that for each breeding pair the enclosure should be at least 30 feet square. Open ground is not favourable for grouse, as it is for quail and pheasants. They are fond of browsing on leaves, shoots, and buds. Recently I watched one of the young we had raised in captivity tearing and devouring an oak leaf. The pens should therefore be built at the edge of the woods, enclosing small trees and bushes, partly in the shade, but with some grass and sunlight. The birds should have a wing clipped, so that they cannot hurt themselves. The pen if open above should have the fence 8 feet high. Stock is so scarce and valuable that it is hardly safe, with only a pair or two at first, to risk hawks and owls, so the top had better be covered, in which case 6 feet high will suffice. Build as described for quails. In case the birds are allowed to rear their own young in the pen, a strip 2 feet high of $\frac{1}{2}$-inch mesh must be at the bottom. It could be attached outside the other after the birds had laid. It is better, in pens of any size, to have wire at the bottom rather than boards, as the 
latter impede the spread into the pen of insect life, which is very important for the young.

Second Laying. Usually the ruffed grouse in confinement lays but one clutch of eggs in a season. From nine to thirteen eggs may be expected, though in the wild state $I$ have known them to lay sixteen. If the clutch is taken soon after being laid, it is possible that a second may be produced if the pen is large. Most wild birds which raise but one brood will lay again if the first eggs are taken while fresh or nearly so. Such accidents may account for late broods sometimes found. A plan suggested to me by H. B. Bridges is that the pens of moderate size be connected with a large enclosure, open above, and that wing-clipped stock, after having their first set taken, be turned into the larger area, in which case they would probably lay again. In a large enclosure the males would not be so likely to hurt each other.

Privacy. Grouse seem more sensitive to disturbance in laying time than the quail, and they should be given the utmost possible privacy. The nest should not be closely approached nor the eggs touched or removed before the laying is complete, and not at all if the grouse is to incubate. Do not allow any stranger to approach. Only the same attendant should have access to them in nesting time.

Chicks Tame. Where the grouse is allowed to rear her own young they grow up rather shy. The opposite is the case when they are raised by a hen. In that case, they are exceedingly tame. They pay no attention even to a stranger, and, in their absorbed search for insects, even allow themselves to be stepped on. When the chicks are small I have to watch every step while in the pen. On the whole, the grouse is rather more likely to raise her brood than the hen would be, yet even she frequently fails, particularly if the pen is not large. 
Handling Chicks. It is useless to attempt incubators and brooders. The bantam mother is the best artificial medium. Twenty-four days is the period of incubation. Then the chicks should be handled about as young quails. They are most sensitive to direct sunshine, and must always have plenty of shade on hot days, else they will die of sunstroke. A gamekeeper once, despite my warning, gave a brood a bare yard, without shade. In the middle of the day the little fellows suddenly began to stretch up their necks, stagger, and fall dead. He saved only one, by giving it shade, and reared it to maturity.

Raising a Brood. An experience that I had in successfully raising a brood of ruffed grouse under my supervision is instructive enough to be worth describing in detail. This was for Senator George P. McLean. Thirteen eggs were placed under a buff cochin bantam, and all hatched on June

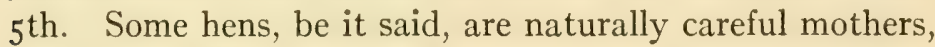
and never hurt their chicks; others are utter blockheads, and trample their young or rake them in scratching with utter indifference. A gentleman who had a nice young brood of sixteen with a hen suddenly saw the hen begin to scratch vigorously and throw the chicks by handfuls against the wire, killing a number of them. She finally exterminated the whole brood. This hen of ours was likewise stupid and clumsy. In the first four days she crushed five chicks. I am inclined to think that, in view of the tameness of young grouse, a light Seabright or part game bantam, with small, unfeathered feet, would be better.

Grouse Ways. Hen and chicks slept in a small, bottomless coop, and ranged about during the day in an open pen, with a fence 5 feet high. The area was about 60 feet square, and had in it a small clump of trees, also bushes and grass. Less than half of it was shaded, but the grass gave consider- 
able cover. Now and then the chicks went to the hen to brood, but a good deal of the time they were scattered all over the place hunting for bugs. It was not safe to step anywhere without caution. The grass would move by one's foot, and there would be a little yellow and brown striped fellow, very intent on entomological researches, away in underneath. They are very deliberate in their movements, and steal along with slow, measured gait, like some old man. The sight of a luscious bug, however, puts ginger into them, and induces a sudden dash, which is usually brief. Old and young act in about the same way.

Their Food. The keeper fed them on grated hard-boiled egg and cracker crumbs, presently a little chick-grain, wild strawberries, and especially insects, which he and his boy caught with a net. In the pen they also got a good deal of insect food, and plenty of "browse" of leaves and shoots. I had sent the keeper commercial ants' eggs, which he did not use for the grouse, as he had plenty of insects. The feeding was intended to be about the same as for quails or pheasants.

A Crisis Passed. All went well until they were twelve days old, when one day the whole eight became sick and drooped their wings. The weather was good and we could not ascertain what the trouble was. Possibly they got chilled during the night. The keeper, Amos E. George, is a resourceful man. He put the chicks in a basket of cotton on the shelf over the kitchen stove. For over a day he kept them warm there, taking them out at frequent intervals, and feeding them by hand. Two of them died, but the other six pulled through, though one had become so weak it could not stand up. That the six grew to maturity is due to his resourceful meeting of this crisis. Another time, I should see that they also had an occasional feed of sour milk 
curd, which Mr. Rogers considers almost indispensable in raising delicate stock of this type.

Growing Up. When about four weeks old, the young grouse began to fly over the fence. Not wishing to take any chances, the keeper clipped their wings slightly, and a covered enclosure, about roo feet square, was constructed for them. They slept apart from the hen when about five weeks old, and had no further brooding from her. In the new pen was a shelter of boards under which they generally spent the night. They seemed to have sense enough to go under it when it rained. Their wings soon grew out again, and at times they flew rather hard against the wire, so the keeper hung strips of cheesecloth in the pen, just back from the wire, to keep them from striking. Probably this was not necessary, as they seemed to learn in time. They have grown up normally, and are absolutely tame and gentle, fearless even of strangers. Their time is spent hunting for bugs, browsing, dusting, and wandering around in their leisurely way. Wild grapevines have been transplanted into the pen, and the birds are fond of flying up and feasting on the grapes. In the autumn, when fully fledged, they went through the peculiar strutting performance. The Senator sits on the ground with them, and they are all over him, begging for food. The ruffed grouse is his favourite species, and he takes the keenest enjoyment with the birds, as well as with his hand-raised quail coveys.

Rearing in Open. Young grouse possibly might be raised in the open, by the same plan as quails. Mr. Rogers had a brood of five or six one fall, which had grown up on free range with a hen, and lived in a piece of swamp adjoining a pheasant rearing-field. A few years before this he had raised about seventy-five with hens in a large fenced enclosure. It is doubtful if they can be controlled in numbers on 
free range as well as quail. Quails are gregarious and social, keeping together, whereas the young grouse is more independent and solitary in temperament. Even when the grouse hatches her own young, they are pretty independent of her and soon begin to sneak off alone. When reared with the hen, I find it characteristic of them to wander on their own hook, and especially when small they are likely to get lost. This has been tried out by Donald MacVicar, as reported to me by his son, A. G. MacVicar. He tried rearing them on the plan used with pheasants, but they wandered off and got lost. In this case the hens were probably shut in the coops. It would be better to have the hen roam with them, but even then, from my observation of their ways, I am convinced that the hen would lose a good many of them, especially if they were let out thus at an early age. It is likely that Mr. Rogers kept the brood above mentioned in an enclosure for the first few weeks. As they get older they seem to show attachment to locality and a sense of direction, and might be able to find their way back. Further experimentation is needed, and meanwhile the safest plan is to keep the hen and brood inside a fenced area.

Other Experiments. Doubtless various people are experimenting with the ruffed grouse. I was told of a man in the Middle West who had raised seventy-five the previous season, but I could not secure his name or address. The American Game Protective and Propagation Association has raised a number of them for three successive generations on their game farm at South Carver, Massachusetts.

Tameness a Problem. The tameness of the young when raised artificially is more of a problem than any supposed "unconquerable wild nature." Such docile birds would naturally fall an easy prey to vermin. They quickly, however, learn wild ways when free, as Rogers has ascertained. 
On the Howell preserve, where a young grouse grew up in a large pen with a flock of pheasants, as it reached maturity it began to combine stealth with its tameness. Only when hungry would it come to the keeper, flying up on his arm or shoulder to feed. As soon as satisfied, it would sneak off in to the bushes, to be seen no more till the next feeding-time. If liberated in a place where vermin are kept down they soon learn to take care of themselves.

Value of Propagation. Even if it should not prove possible, owing to the expense of pens and difficulties above mentioned, to raise grouse on a large scale, their successful culture in a limited way would be of value. It is axiomatic that all young birds raised in a certain locality tend to remain there or to return thither, provided that the proper conditions are found, whereas adult birds released, being strange to the land, are much less likely to stay in the vicinity. Hence a good way to stock a locality with the ruffed grouse is to raise the young, give them free range when partly grown, and let them gradually take to the woods, to breed there in the wild state.

Food for Adults. The adult birds, as well as the young, may be fed much the same as quails and pheasants, with the addition of certain "browse" staples. So long as they are given a fair amount each of animal cereal and green food, they do well in confinement, and seem to get along with less variety than they glean in the wild state. Bulletin No. 24. page 29, of the Biological Survey, on the Grouse and Wild Turkeys of the United States, shows that their food consists of about ro per cent. insects and 90 per cent. vegetable matter. Of the latter about Io per cent. is seed, nearly 30 per cent. fruit, and almost 50 per cent. leaves and buds. About half the seed component is acorns and some beechnuts, swallowed whole. They eat grain readily when they 


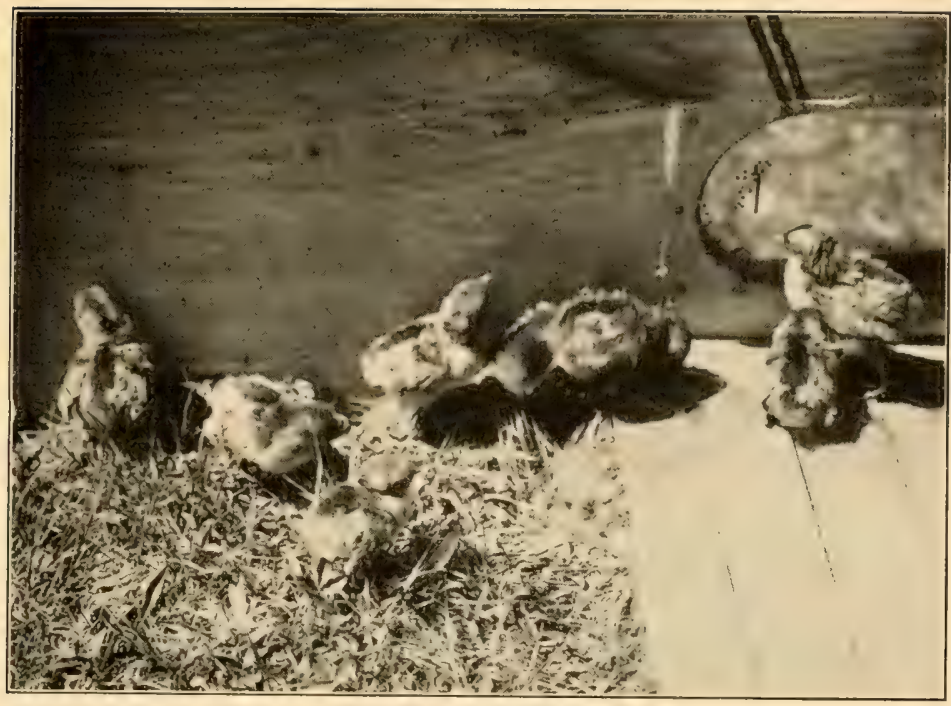

Ruffed grouse chicks

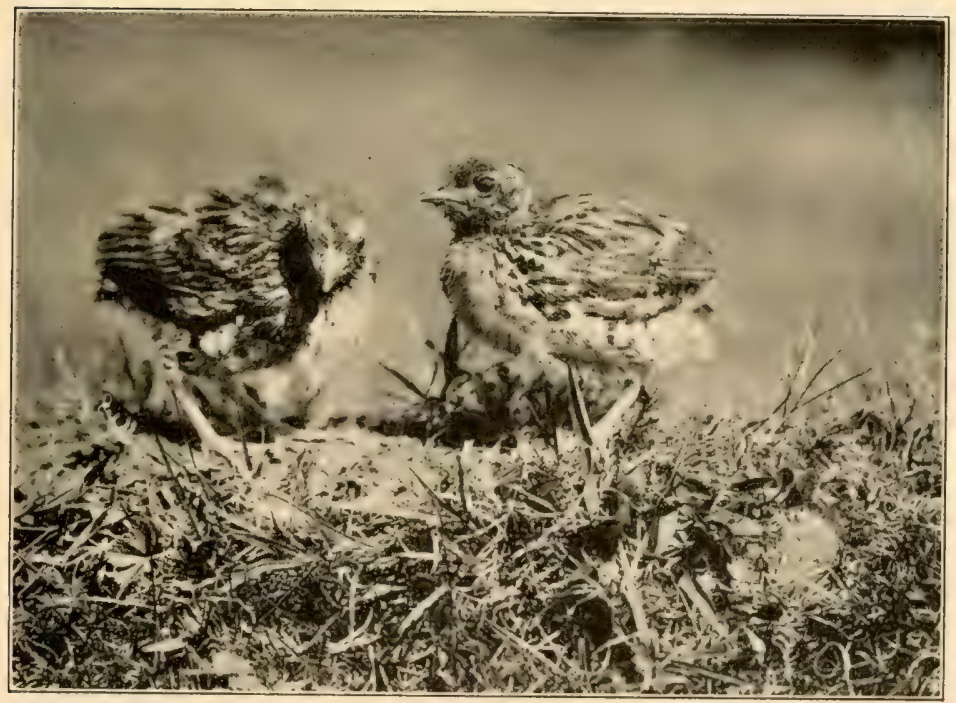

Young ruffed grouse three weeks old 


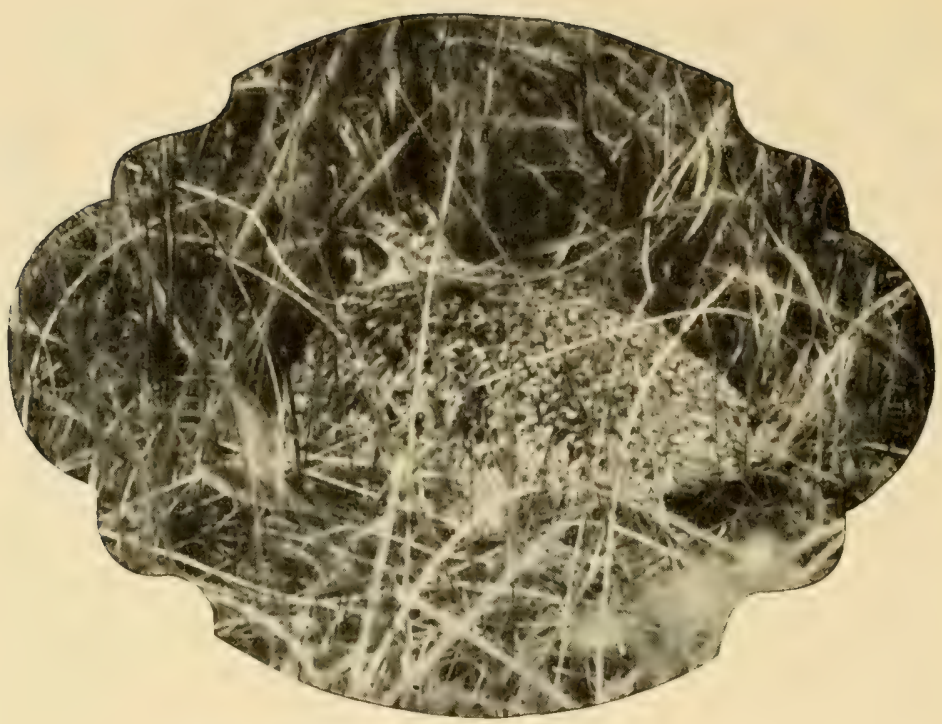

Sharp-tailed grouse or "prairie-chicken" on nest

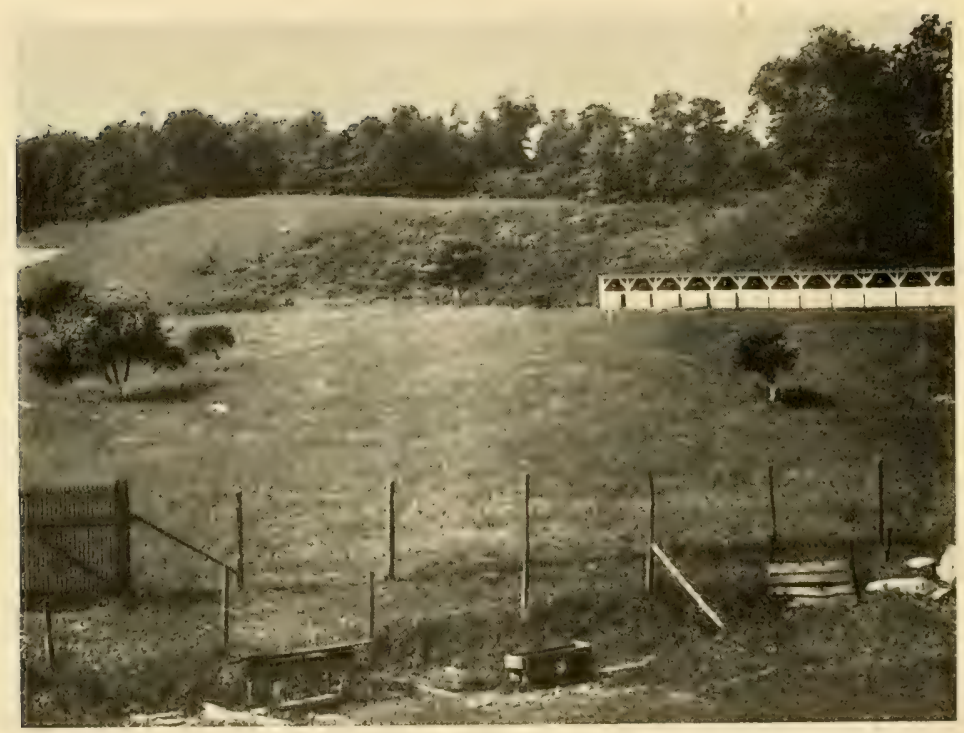

Rearing-field and shelter-house for wild turkeys of H. P. Bridges 
can get it. Almost all wild berries are acceptable. Elderberries are easily gathered in quantity, and could be hung up and dried, and fed to them in winter. They are fond also of various buds, such as maple, birch, and willow. Branches could be trimmed off and given them. In a proper pen they will find a good deal of this "browse." As they are so largely vegetarian, the food problem is not the main difficulty.

Reaching Maturity. During the latter part of August the young birds begin to moult into the adult plumage. When this is complete, from the middle to the last of September, they begin their interesting strutting performance, both males and females. The ruff or black collar is spread about the neck, the elegant black-bordered tail is extended like a fan, and every feather stands out. This "show" lasts till settled cold weather in November, and begins again, Doctor Hodge says, with the first springlike days in February, and during mild snow-flurries, continuing until the middle of June. The cock begins his remarkable drumming in April, and continues it about as long as the strutting stunt.

Prairie Chickens. The few small experiments which have been tried with the prairie hen, and perhaps with the sharp-tailed grouse, both commonly known as prairie chickens, indicate that the problem with them is similar to that of the ruffed grouse. These birds, being largely eaters of grain and seeds, are easily kept, as far as food is concerned, and they become sufficiently tame. They are, however, fully as sensitive to disease in confinement as the ruffed grouse. In spring they go through their peculiar tooting and strutting performances and lay one set of eggs in the enclosure. Mr. Rogers says they are polygamous. He has raised them in the Middle West from wild eggs, with hens, 
as has Mr. Evans. He also says that he found sour milk curd almost essential in raising them. The young are tame, like the young ruffed grouse, and act much like them.

Stock Scarce. Hitherto it has been practically impossible to secure any stock whatever for proper experiments, but now, owing to the great popular interest in the subject, State authorities will probably allow this important matter to be thoroughly studied by competent investigators.

Other Grouse. The same things are probably true of our other native grouse, about which I am at present unable to offer definite information. Experiments with the ptarmigans would be of especial interest. It is probable that the experiments with the ruffed grouse will furnish the clue to successful measures with the other grouse species. 


\section{CHAPTER IV}

\section{THE WILD TURKEY}

Still Found. The idea seems widely prevalent that the genuine wild turkey is nearly extinct, and, furthermore, even if it were not, that it is by nature so hopelessly wild that nothing could be done with it under the control of man. Both these notions are mistaken. The noble great birds are still quite plentiful in various forested parts of the Middle and Southern States, both in mountainous and in swampy regions.

Races of Turkey. There is also widespread uncertainty as to what constitutes a "wild turkey," so explanation may be desirable. Our Eastern wild turkey (Meleagris gallopavo sylvestris) is a subspecies of the Mexican turkey, which was the form originally described, and from which the domesticated race, introduced over Europe and America, was derived. There are also other subspecific forms now recognized. The Florida turkey is a somewhat smaller race, similar to the Eastern form, found in southern Florida. The Merriam's and Rio Grande turkeys grade toward the Mexican form, and are more like it.

True Type Described. The essential and easily recognizable characters of the wild turkey are found in the feathers of the tail and rump. In the genuine native Eastern wild turkey the tail is of a dark reddish cast and ends in a tip of dark brown, never of white or whitish. Also the rump feathers of the back, above the tail, are dark reddish at their 
extremities, and have no whitish or light buffy emargination. White margins on tail or rump are characteristic of the Mexican race and the domestic turkey. Buffy shades in these parts indicate more or less mongrel origin.

Mixture of Stock. This is not saying that such mongrels are not found in the wild state. F. H. Kennard showed me a series of skins recently collected in Florida, near the Everglades, about half of which were clearly mongrels. The designation "wild" is more or less ambiguous, as turkeys easily revert to the wild state, and "wild" turkeys can be made as tame as any. All turkeys are great travellers afoot, and undoubtedly domestic birds often take to the woods and wander indefinitely, probably breeding with the native stock.

Tameness No Criterion. Speaking of the possible tameness of the real wild turkey, I recall a recent experience in South Carolina, on the preserve of the Okeetee Club. Seeing a flock of domestic turkeys feeding near a house, I walked up close to examine them. One, a gobbler, was in full typical plumage of the Eastern wild turkey. Upon inquiry, I found that some one had found some wild turkey eggs and had taken them and raised the young. This "wild" turkey was fully as docile as the "tame" ones.

Mongrels Common. I regret to have to say that most of the supposed "wild turkeys" which I have seen upon preserves and estates are mongrels, and it seems to be very difficult to actually secure the pure Eastern form. Lest this form should ever disappear in the wild state, it would be well to make sure that breeding-stock is the real thing. The above may serve to put people on their guard against mistake or deception.

Turkey Disease. The problem of the propagation of the wild turkey is largely the familiar one of the turkey disease, 


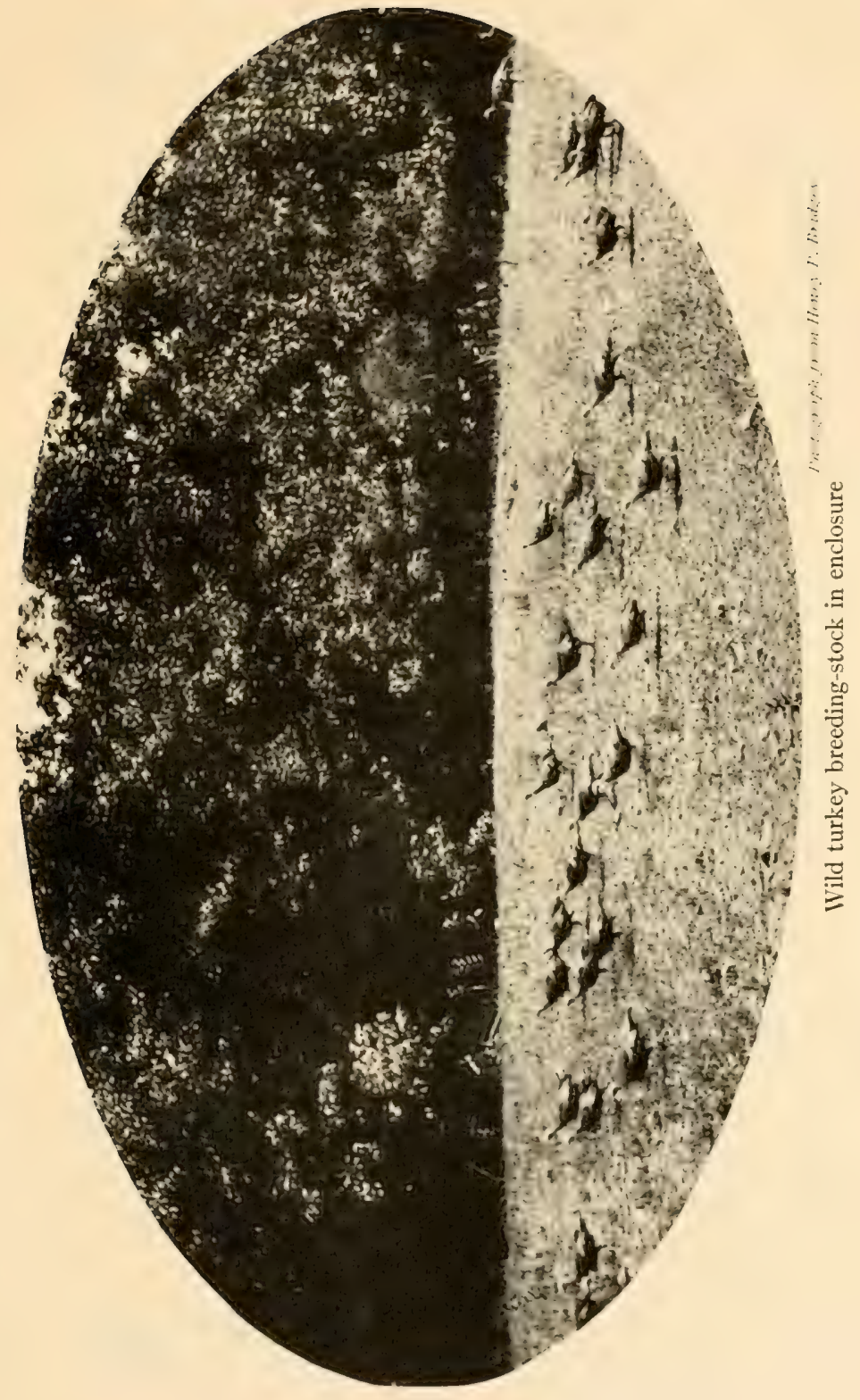




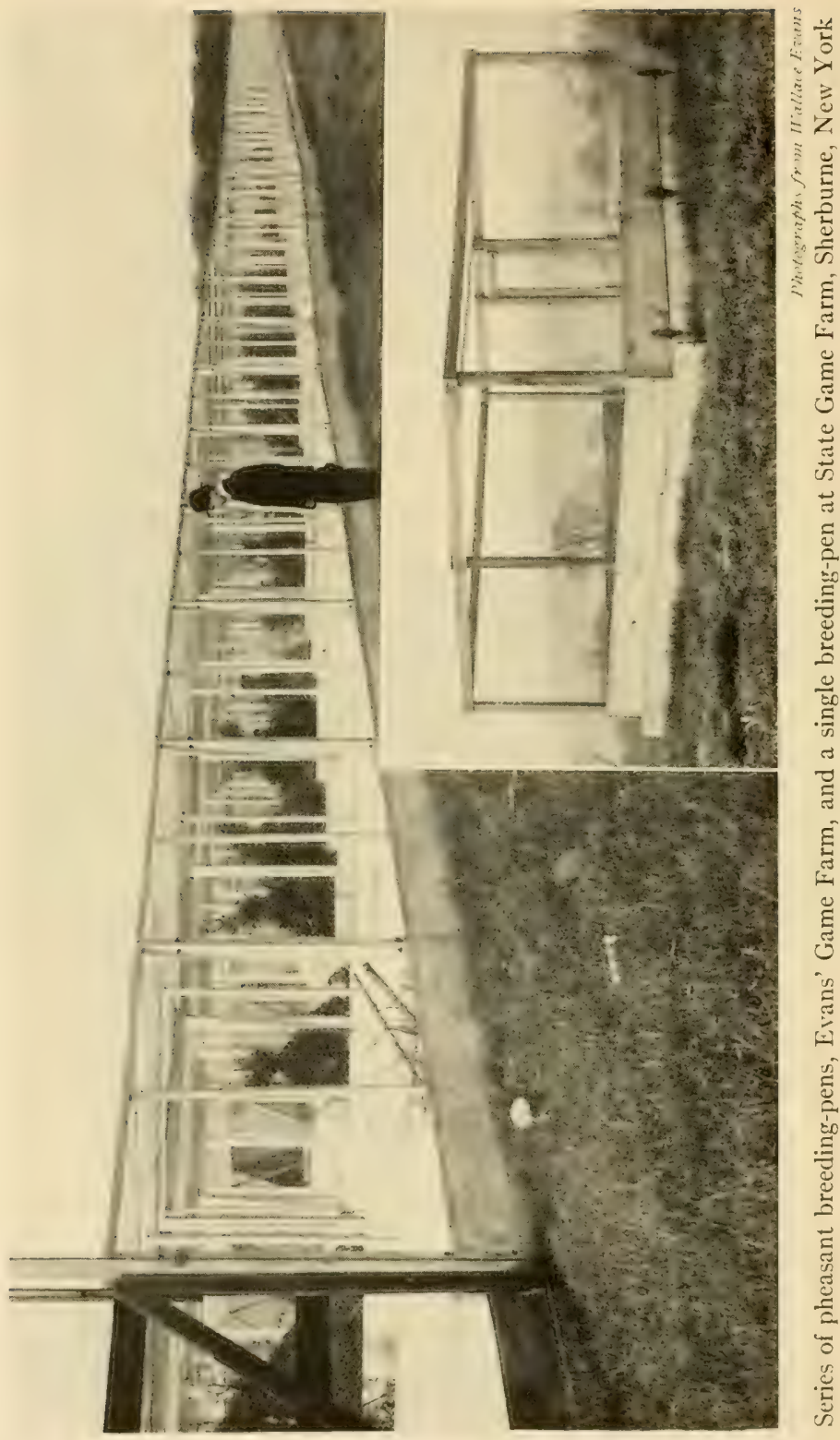


usually known as "blackhead." I have seen it stated that the wild turkey is not subject to this like the domestic bird, which, unhappily, is not true. A distemper, which has the same symptoms as the well-known trouble, attacks the young wild turkey under artificial conditions.

This disease is supposed to be caused by an organism about which specialists differ. It is evidently widespread, as young turkeys die from it practically everywhere. Adult birds are better able to resist it. The main hope, as in the case of the quail disease, seems to be to learn to feed and handle the stock so that it will keep in healthy condition and resist infection. Wild gallinaceous birds may habitually carry various organisms in their systems, as the diseases seem to break out when they are improperly fed or handled. In the case of the turkey, the chief danger seems to lie in close confinement and fouling of the ground through overcrowding, especially in conjunction with cold, wet weather. Harry T. Rogers found that sour milk curd as an article of diet was very important for keeping young turkeys in health.

Woodmont System. To describe adequately the best methods for the propagation of the wild turkey, the best thing I can do will be to give in detail the methods used by Henry P. Bridges, secretary of the Woodmont Rod and Gun Club, on the preserve of the club and his private farm, both in Washington County, Maryland, a most picturesque mountainous region along the Potomac River. He breeds the genuine wild turkey in captivity quite successfully, and also has a splendid system for attracting and holding large numbers in the wild state.

Holding Wild Coveys. The latter undertaking is based upon planting foods, destroying vermin, and regulating shooting. The club owns or controls a large tract of land, principally forest, among the mountains. Bridle-paths run 
through the forest. Here and there, off from these paths, are cleared open fields, from about five to ten acres each in area. There are thirty of these in all, and each is sown to grain, which is left standing for the turkeys and other game. Wheat is the principal grain sowed, but there are also corn, buckwheat, and millet. Flocks of wild turkeys frequent these fields regularly. They feed there in the morning and in the middle or latter part of the afternoon. They are very shy, but are surprised in these fields through careful approach. If they are out in the middle when intruders are detected, they fly out, making an imposing sight. If near the edge they run off into the forest.

An Experience. This last I saw a fine flock of at least fifteen do one September afternoon. Though we crept up carefully and stood back in the dark woods, the turkeys detected our presence. In single file, a couple of gunshots or more away, they ran along the edge of the field, up a high slope, and disappeared into the forest-noble, great birds they were. At this season they were not yet resorting much to the grain, and would not till the frost killed off the insect life.

Shooting Restricted. Only on certain days, in accordance with a careful schedule, can shots be fired in a given field. Each member or guest is allowed to shoot but two turkeys in a season. About one hundred are said to be taken each year. Four Presidents of the United States have been entertained at this club: Cleveland, Harrison, Garfield, and Arthur.

Cleaning Out Vermin. Periodically there is a killing off of vermin by a system of poisoning. This is done every year during January and February. The method used is by distributing poisoned dead birds along the trails over the preserve, from 500 to 1,000 at a time. Pigeons are bought 
from dealers for this purpose, or trapped English sparrows are employed at times. Eight to ten bottles of one eighth ounce of powdered strychnine are used to each one hundred birds. As much as is held on the end of the blade of a penknife is placed in the mouth. The flesh of the breast on one side of the bone is slit and the same dose is inserted. These pigeons are dropped on the paths, about a quarter of a mile apart. When English sparrows are used, they are more readily seen if impaled on a cut-off sprout 8 to to inches from the ground. They are put out at the beginning of the coldest weather and will keep. Foxes and other animals will eat them even if not fresh. Minks and weasels eat only the head, so it is important to put poison in the mouth. The fox usually gulps the sparrow down whole. The victims seem to have no suspicion, and are frequently found dead nearby. A good way is to put out the bait in two plantings, half in January, the rest in February. Mr. Bridges declares that no deer or useful birds are affected by the practice, and it is very effective, making the game uncommonly abundant. In so wild a region there are no dogs roaming about to be poisoned. On the other hand, C. C. Worthington is quoted by F. C. Walcott as having had thirty-four deer on his preserve killed by eating poisoned sparrows, the latter being found in their stomachs.

Artificial Breeding. The artificial breeding is mostly conducted on Mr. Bridges's farm. Dissatisfied with the socalled "wild" turkey stock usually offered for sale, at large expense and trouble he finally secured a stock of the genuine wild turkeys for breeding-forty-six hens and six gobblers. For that number of hens he now prefers as many as ten males, or one to four or five, believing that the young have thus more stamina.

To keep them he has a four-acre fenced field, mostly open 
ground, but with bordering woods, with which is connected by gates a larger fenced tract of sixty or seventy acres, mostly woodland. Fences are 9 feet high, made of ordinary sheep-fencing, the wires being close together at bottom and farther and farther apart above. There is a 5 -foot strip of this and a 4-foot strip of coarser mesh above. Owing to the poisoning of vermin, he does not have to sink the wire in the ground.

In the smaller field, on a southerly slope, is a modern poultry-house building, I 50 x I 5 feet, divided into ten sections, with connecting doors and open-front arrangement with coarse wire before the upper half. There are roosts and a single tier of nests directly on the ground in each one. This is to shelter the stock in winter. During that season he gives the turkeys the range of the entire tract. Toward evening they are driven into the smaller field, and thence into the shed. At times they are reluctant to enter, and a strip of wire is run out to guide them. All breeders and young not intended for liberation are pinioned. They are shut in at night and on stormy days.

Food for Adults. The food is any grain mixture or scratch feed, and whole corn. Wheat is sowed in the pen for winter use, and corn and millet are planted in the spring. The large enclosure is divided in halves by another fence, which makes it possible to alternate the birds on the land during growing and planting times. Thus in spring and early summer they are kept out of the growing crops till these are matured.

Laying and Hatching. Plenty of brush-heaps are scattered about the four-acre tract, under which the hens lay their eggs. Eggs are collected every day, leaving one in the nest, or a china egg. The eggs are removed with a longhandled spoon, which mode is thought to be less likely to 
stop the bird from laying there. This is unnecessary with reasonable precautions. Sometimes, toward the end of the laying season, the wild turkey is allowed to hatch her own eggs. Those taken are set either under tame turkeys or under ordinary hens. At first Mr. Bridges was inclined to favour the former, as taking the young over more ground to feed, but now he thinks that a quiet hen is about as good, and brings up the young tamer. They stay very well with the hens, even till they are grown up. The eggs are hatched in ground nests in the shed, where they get sufficient moisture and yet are protected from the rain.

Local Plans. Eventually it is intended to liberate the young on the preserve. They are fairly shy naturally when they grow up in so large a tract. Those that escape quickly become wild. Owing to the poisoning of vermin, they have a good chance of survival. At present, however, they are being held to increase the breeding-stock and to supply other preserves.

Handling and Feeding Young. After hatching they are put out in the four-acre field with a fair-sized coop and small run, and the ordinary pheasant plan is followed, letting them range in the field, but with the hen or turkey foster-mother. They are shut in at night and kept in till the dew is off the grass, as well as in wet weather. When about a month old they are allowed to roam in the big lot. At first they are fed on hard-boiled egg, which, after a week or so, is mixed with pheasant-meal and the chick-grain, following the method of feeding of young quails and pheasants. Sufficient green and insect food is secured in the enclosure.

Success and Failure. The keeper at this farm said he had in the enclosure at the time of my visit at least two hundred young wild turkeys. On the club's preserve they have another keeper and another enclosure of sixty acres. They 
brought from the farm to this latter place wild turkey eggs, and had six hundred young in this tract. Disease broke out and swept them all off in the absence of Mr. Bridges. This disaster was doubtless due to overcrowding. The sagacious keeper did not inform the owner, saying he was "afraid it would worry him." Had he known it at the outset, the young would have been liberated, and most of them probably would have survived. This is on the principle coming to be accepted that these troubles are diseases of captivity, and that the release of "infected" birds does not seriously endanger the wild stock.

Restocking Projects. Twenty-five young wild turkeys raised on the above preserve have now been sent to Jekyl Island, Georgia, for a breeding experiment. This island may serve as a typical case of southern islands considerably overrun with snakes, raccoons, hogs, and other vermin. Mr. Bridges advised in this case to hold such a breedingstock in an enclosure of not less than ten acres, to hatch the eggs under hens, and to let the broods range, on the clear and protected grounds near the houses, if there were no cats and rats to attack them. As they grew up they would roam off and scatter over the island.

On islands and in really wild sections of country it is probably feasible to propagate the species and stock the vicinity by the Woodmont plan, especially if vermin are kept down. In populated regions, however, the wild turkey is too large and valuable a bird to stand any chance, save in fenced enclosures. Undertakings of these sorts described above are interesting and well worth while. 


\section{CHAPTER V}

\section{PHEASANT REARING}

Best for Beginning. The family of the Phasianida, or pheasants, presents a new realm of opportunity and interest to those who love to propagate and cultivate wild birds. One species, the ring-necked pheasant, has become widely naturalized in many states of the Union, and is as much an American bird as the English sparrow, withal a much more useful one. This is preëminently the species for would-be propagators to begin with. It is easily raised by the methods described in this book, presenting less difficulties than any other species of the group. Being wonderfully hardy, it thrives in spite of severe cold and deep snow, especially if food is provided. Its flesh is excellent, and it brings good prices, either dead or alive. At present indications it seems likely to become one of the principal game-birds of America.

Definition. To avoid confusion of terms, it may be well to state that another species known as the English pheasant was imported from western Asia into Europe about the time of Alexander the Great. It is quite similar to the ring-neck, the most notable difference being the lack of the white neckring or collar. About a century ago the ring-neck was introduced into England and crossed freely with the other species, until now there are very few of pure blood, and both names are applied rather indiscriminately to the same bird. The pure ring-neck, direct from its native haunts in China, was introduced into Oregon, beginning in 1880 . The 
species is now naturalized and abundant there, and is often called the Oregon pheasant. It is the true ring-neck, a trifle smaller than the other, perhaps through inbreeding, but is a splendid, active game-bird. Harry $\mathrm{T}$. Rogers has used this strain to breed for stocking New York State.

Other Pheasants. Various other species of pheasants also are bred in this country. The Mongolian is fairly popular, a larger bird, and also very hardy. Golden and silver pheasants, gorgeous in plumage, are also in vogue, but rather as aviary birds, being less able to withstand cold, requiring at least slight shelter in winter. The Lady Amherst and Reeve's pheasants are also well-known aviary species, and there are various others, likewise brilliant of hue, which can be cultivated. These fancy kinds are often kept for ornamental purposes. A lady of my acquaintance raises them, because of her love of colour, to beautify her lawns. Some of these species are very easily kept, and stand confinement better than the wild, hardy ring-neck. The young, moreover, can be raised in confinement, whereas those of the ring-neck must have open range.

The Manchurian eared pheasant, a large species, is notable for its tameness under artificial conditions. It loses all fear of man and will eat out of one's hand. Such a bird is not adapted to game purposes, but is easy to keep on an estate wandering around like guinea-fowl.

Methods Similar. The methods described are those used for the ring-neck, and are similar to those for raising quails, with modifications. Descriptions in this chapter will be only of traits and methods which differ from those treated in the chapter on quail propagation.

Diseases. Though pheasants are subject to diseases and epidemics similar to those of the quail, they are more resistant to them, as they have been bred in captivity longer and 


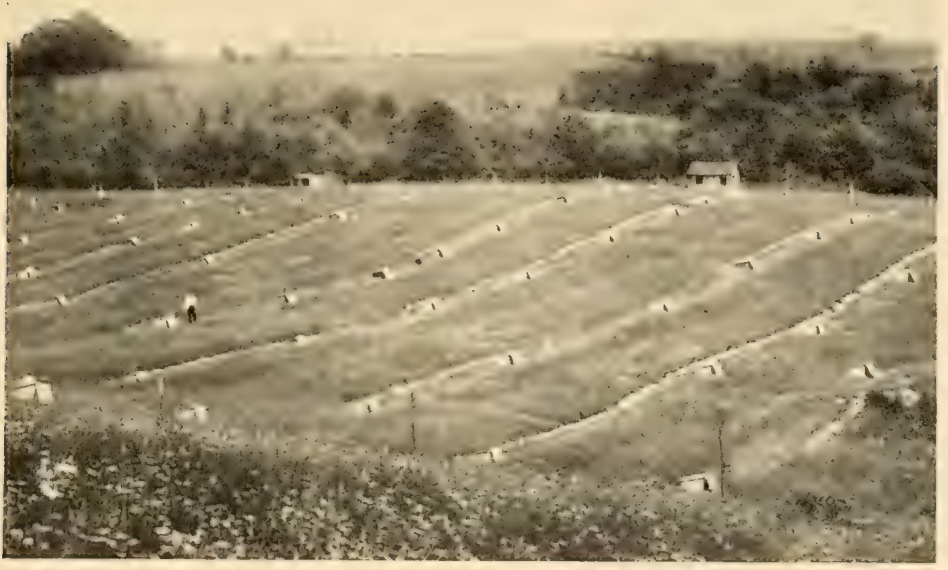

Pheasant rearing-field, showing arrangement of coops and mowed runways

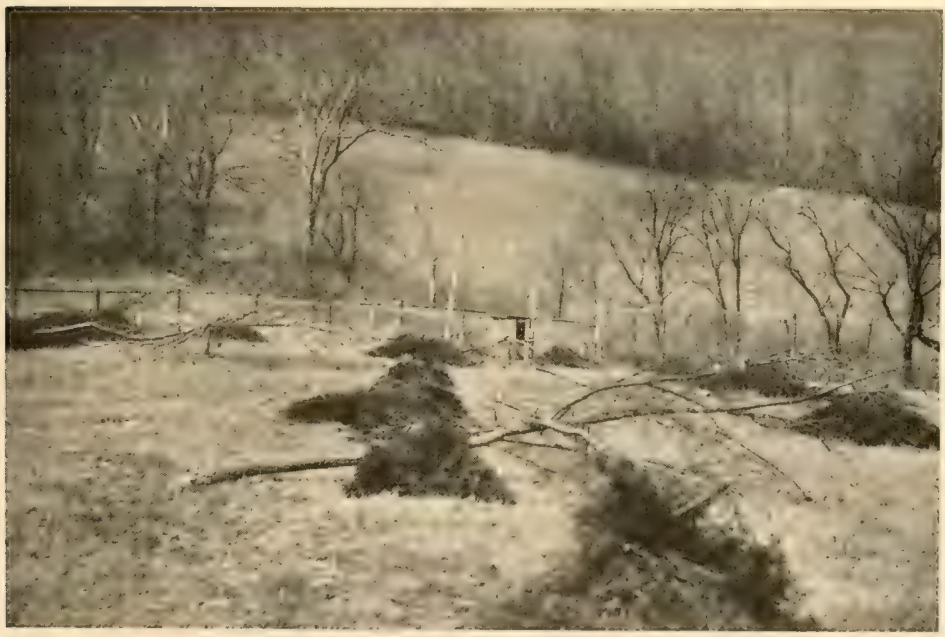

Wholograth by Thorn L. Germun

Breeding-field for pheasants, Clove Valley Club, New York 


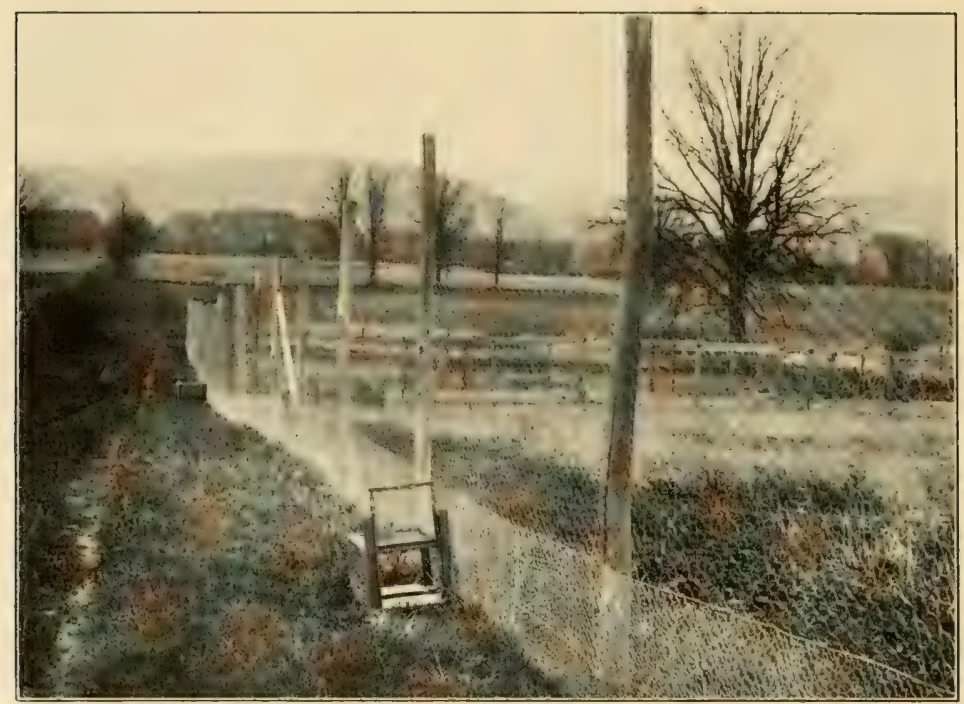

Fence of pheasant rearing-field and traps set for vermin

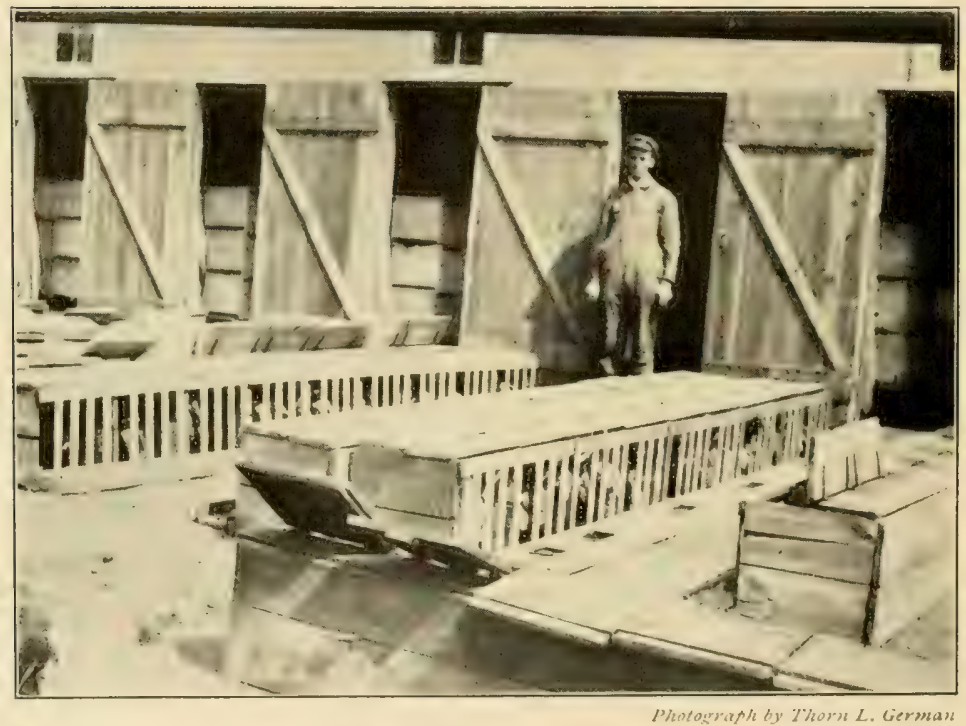

Hatching-house. Putting out hens to feed 
are further along the road to that immunity which domesticated poultry have largely acquired. For this reason it is much better for beginners first to learn to raise a few ringnecked pheasants, after which they will be much more likely to succeed with quails or grouse.

Stand More Crowding. One main difference is that more pheasants than quails can be kept in an enclosure. True, they must have more room than poultry, and the ground must regularly be ploughed or alternated. Yet, rightly handled, they can be managed in large numbers. Rogers winters a thousand or so of young birds in a fenced field of five or six acres. But there is a limit, beyond which is danger.

Starting. Start can be made either by buying eggs from the increasing number of pheasant breeders or by securing birds to produce the eggs. The latter method is preferable. Purchased eggs may come from poor scrub stock. If the eggs vary in size, shape, and colour, it is a bad sign. In buying birds, one should insist on having only good stock, and no lean, ragged runts. Starting with good birds, and giving them proper care, the eggs should produce strong chicks. Young from weakly stock lack vitality and are liable to die off, in spite of all care, thus giving unnecessary discouragement to the beginner. Moreover, eggs raised on the premises are more likely to hatch than those shipped by express.

Wintering Stock. Secure stock in fall or early winter if possible, and provide winter quarters much as for quails, though more birds can be kept together with safety. The aviary or fancy kinds must have sheds or coops for shelter, whereas the hardy ring-necks can stand almost anything. Mr. Rogers says that his ring-necks in large fenced fields seldom use the coops he has provided, but prefer to roost out on the most exposed ridge of the fields. They have withstood safely a temperature of 45 degrees below zero. 
Sometimes they are buried several feet under the snow for days at a time. They dig burrows and eat grass and clover. When they wish, they can get to the surface. A normal, full-winged pheasant can fly from soft deep snow like a ruffed grouse, which it is said that quails cannot do. After snowstorms, at the New York State Game Farm, they plough out strips in the pheasant enclosures, and the birds emerge from the snow and come to feed. Notwithstanding their hardiness, however, reasonable shelter should be provided, as all birds are not always in such prime condition.

Prices. As to comparative expense, one can figure it out. Eggs cost about 25 cents each, or $\$ 3$ a dozen. Breedingstock would be about $\$ 2.75$ to $\$ 3.5 \circ$ per bird, prices being less in fall and early winter. Another thing to consider is that early eggs and chicks are by far the best. Late eggs are cheaper, but fewer of them may hatch, and the young are likely to die. Early eggs may cost more, but they are worth it.

Polygamy. Unlike quails, most pheasants are polygamous. The ring-neck is notably so. One cock to five hens seems to be the prevailing practice, though some use one to three or four. The silver pheasant, and a few rarer kinds, breed in pairs.

Fighting. As spring approaches there is liable to be some fighting and chasing on the part of the cocks, which may do damage unless proper care is taken. Too large a proportion of cocks in a pen is one cause. Superfluous males should be shut up by themselves. Another preventive is to have the yard large enough, and plenty of brush-heaps for hiding. Rogers's theory is that pheasants are cowardly, skulking birds and that more often birds get hurt by dashing into the wire when chased than by actual combat.

Effect on Native Species. This matter of pugnacity raises 
the question so often asked as to whether pheasants drive away quails and grouse from their haunts or destroy them by attack or breaking up nests. I believe there is no cause for apprehension. Pheasants are natural cowards, and Rogers says he has often seen a quail or a sparrow in a pen drive a pheasant. As to the ruffed grouse, these frequent the woods, while the pheasant shuns the forest and selects scrub pastures, swamps, and agricultural land. That pheasants do not destroy quails is indicated by the case of Gardiner's Island, New York, where pheasants and quails both abound, neither being able to fly to the mainland.

Vices. Feather-plucking and egg-eating are other bad habits in confinement which sometimes break out. It is recognized that these come from lack of needed animal food. Increasing this will generally stop the former. In case an individual persists, it should be removed. Egg-eating is harder to stop. Devices which sometimes work, in conjunction with giving more animal food, are as follows: Eggs should be collected often, and emptied eggs filled with kerosene and red pepper can be left out for them to try. Sometimes artificial eggs are placed around the pen. Another plan used is to clip off the point of the bill, just to the quick, to make it a trifle sore, so they will not peck. Birds that have the habit badly should be removed, especially at the beginning, for one such bird seems to teach the others.

Preparation for Breeding. Pheasants are early breeders, beginning to lay usually about the middle of April, or earlier in mild weather. Mating begins by March, or even February, and lasts till July. Stock should be put in breedingquarters about a month before the laying period, soon after the snow melts off.

Large Pen Breeding Method. For breeding, two plans are employed: The first is to keep a considerable number of 
breeding birds in one large enclosure. This may be open on top, in which case the birds, if not already pinioned, should have one wing closely clipped. Fences for such breedingyards should have at the bottom a strip of $\mathrm{I}$-inch mesh wire about $2 \frac{1}{2}$ feet high to keep out vermin. Above this ordinary chicken wire, 2-inch mesh, may be used. For large rearingfields the same is used, or the chicks do not try to get out. In case one has only a few pheasants, it is well to cover the pen above, as one occasionally might scramble out when frightened, and then there will be no fear from hawks and owls. Scrambling in or out by birds or larger animals can be prevented by nailing on top of each post a stout slat projecting in and out a foot each way, and tacking to these a 2-foot strip of 2-inch mesh wire, making an overhang. With this device the fence could be made only 6 or 7 feet high. It should, at any rate, be high enough to prevent a fox from leaping over. A plain 8-foot fence, however, usually answers every purpose. There should be plenty of brush in the pen.

Number in Pens. There is no exact rule as to the number of breeders that can be kept in one enclosure. In general it is well not to have a very large number running together, not over 100 in a good large pen, say 200 by roo feet. If the birds appear to be crowded and to interfere, and the average of egg-laying is not good, some should be removed. Change of ground stimulates laying. Sometimes, when a pen of birds stops laying, change to fresh ground and good grass will start them up again.

Harem Method. The other method is to keep each breeding unit of a cock and three to five hens in a separate pen by themselves. This method seems to produce more eggs, though it involves more initial expense for apparatus. Rogers, at the New York State Game Farm, prefers this 


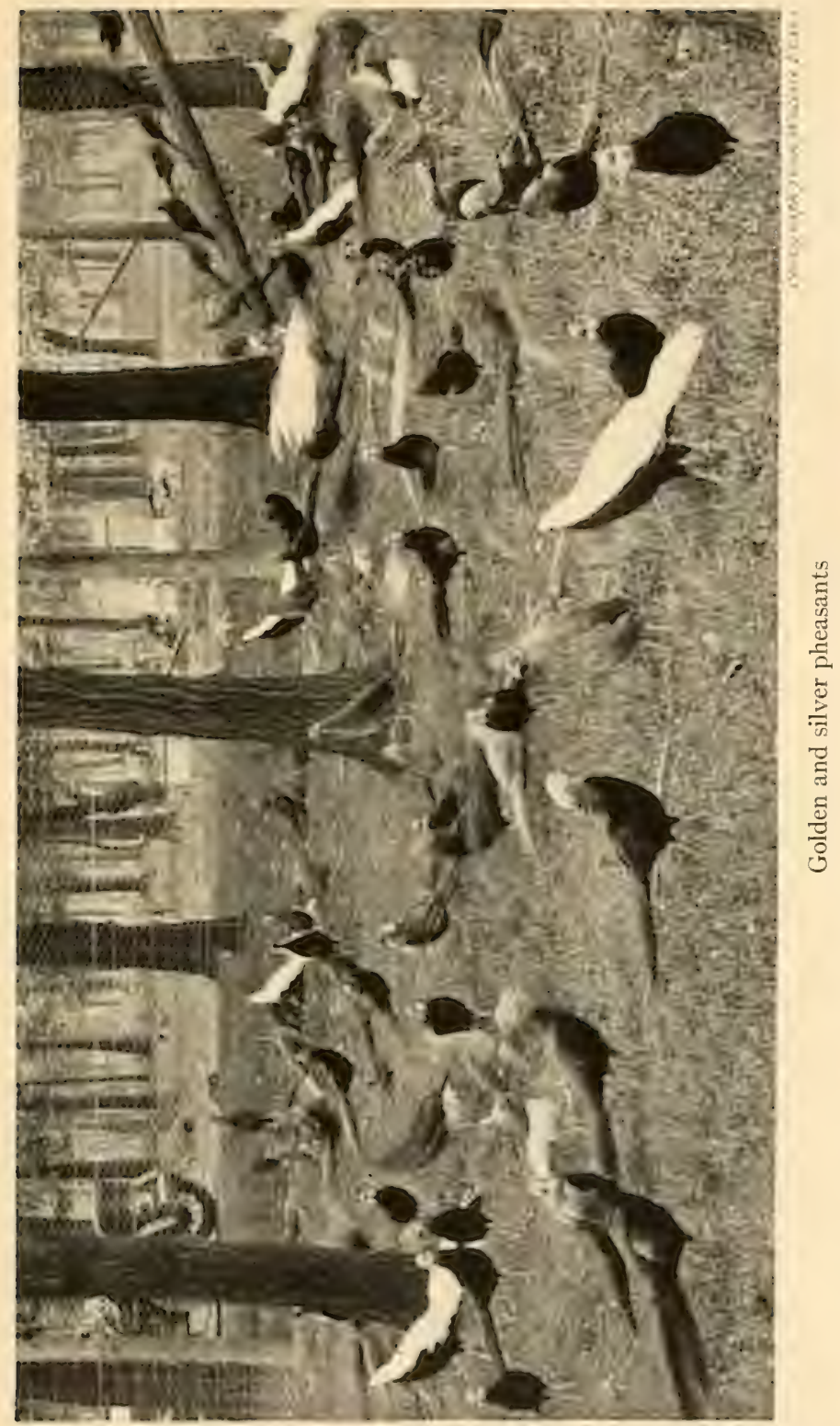




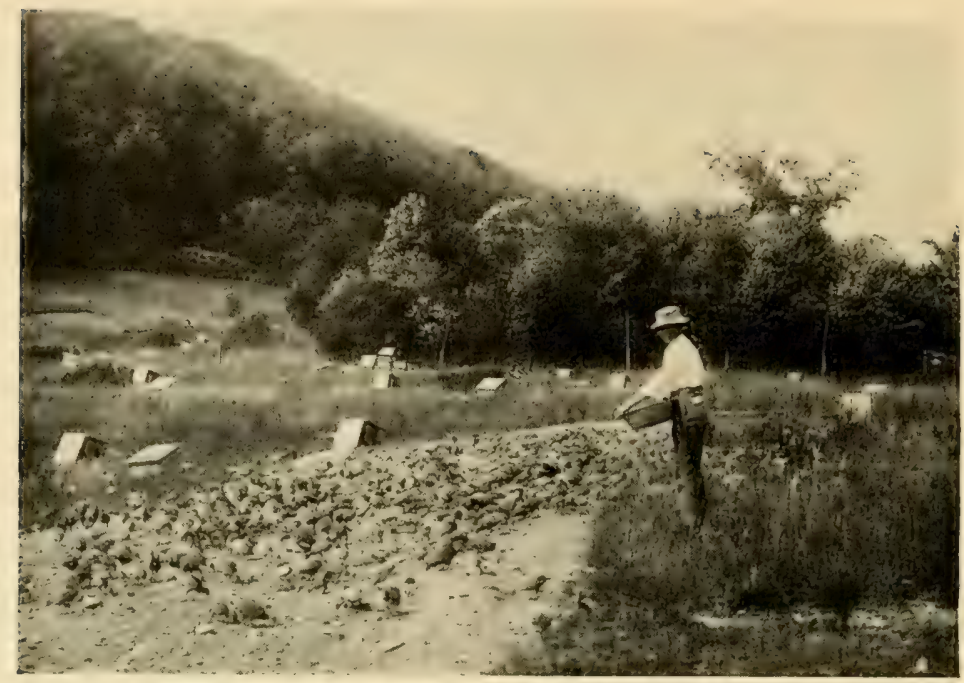

Feeding young pheasants, Clove Valley Club, New York

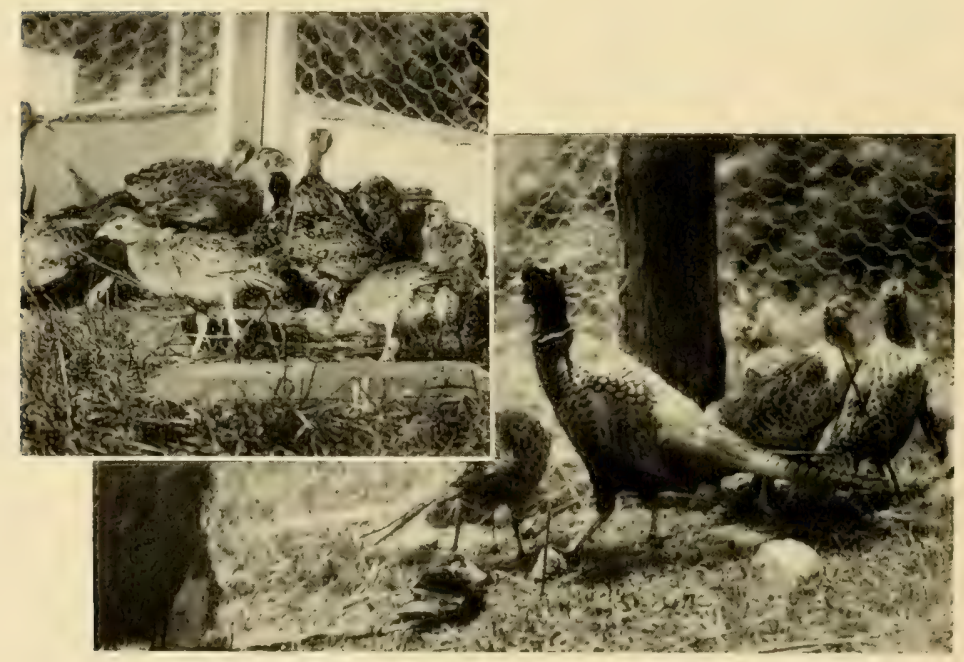

Breeding harem of pheasants of T. A. Howell

Young pheasants caught for shipment, Massachusetts State Game Farm, Sutton 
method, and generally emiloys it unless short of small pens.

Unit Pens. In working out this method he builds a considerable number of portable pens, without bottoms, and about I 2 x i 6 feet, covered on top, and boarded up from the ground about 3 feet. The ends of the bottom boards of the two longer sides are sharpened up, like sleigh runners, so that a horse can drag the structure to fresh ground. Along one end inside there is a shelter of boards, some 3 feet wide, sloping down toward the centre of the pen, for protection from storm and sun. These pens should be placed on turf, with a brush-pile in each, and be banked up outside a little. This will prevent the birds from digging their way out, while traps and watchfulness must take care of vermin. The pens need be moved only at considerable intervals, when the grass is getting used up and the ground shows signs of becoming fouled. On level ground they can be dragged slowly, with the birds in them. In these arrangements Rogers gets from five hens sometimes twenty-three to twentyfive eggs per pen a week at the height of the breeding season.

The number of eggs produced by each hen pheasant varies with the vigour of the stock, the feeding, and the surroundings. From thirty to fifty per season is a frequent average, and some birds lay seventy or even over one hundred. Many of the late eggs, however, are useless, as it does not pay to set eggs after about the first of July. One large breeder who had quite a number of small chicks the first week in August told me that he could not raise over one third of them. Another expert remarked that he would not dare to have such birds on the place, as it is very likely to start epidemics.

Avoid Close Confinement. It is not good for wild birds to keep them shut up in a small yard indefinitely, as they 
deteriorate from want of exercise. Though pheasants can exist thus for some time, they will lay less eggs, low in fertility, and producing weaker offspring. At the close of the feeding season they should have more room for exercise. Oneway is to catch them and put them in a largefenced field, if pinioned, or, if not, in a larger covered pen. The flight feathers are growing during late summer and fall, up to November. Another method employed by Mr. Rogers is as follows: His portable pens are made with the bottom board at the front and rear ends on hinges, so that these can be raised and hooked up. The pens are dragged together and set end to end, with these boards raised, making a continuous run as long as is desired. The hinged boards when raised just meet, forming a roof, and all that is then needed is to nail a bit of board to the junctures on the sides. By this means the pheasants can range together through quite a long enclosure, and can be kept thus through the winter.

Hatching Pheasants. In the matter of hatching, the only difference from the quail methods is that the eggs are stout enough to allow the use of ordinary hens instead of bantams. Pheasant chicks, however, are considerably smaller than those of poultry, and the smaller the hen the better. Bantams are all right for this work, if one has them, only they are not, as with quail, absolutely necessary. Fifteen to eighteen eggs should be set under an ordinary hen, and a less number under bantams, using no more than can be properly covered.

Rearing Systems. Where there are only one or a few broods, the easiest way is, as with the quail, to give each brood a coop and let them roam with the hen during the day. If safe ground is scant, the hen can be shut up in the coop, and the young kept near by providing shade, food, and water, and skulking places. In New York State, where settings of eggs are sent out with printed instructions, farmers 
and other landowners are instructed to let the brood range with the hen, like turkeys, and it is claimed that 50 per cent. from the number of eggs on the average are reared to maturity.

For rearing pheasants on a larger scale almost every breeder has a method or system which is more or less individual in some details. It will suffice to describe a few representative methods which have come under my personal observation. Feeding and other details not mentioned are the same as described for quails.

The Rogers System. First I will outline the free-range rearing, a leading exponent of which is Harry T. Rogers, superintendent of the New York State Game Farms. Sometimes Mr. Rogers has used large fenced rearing-fields, in which cases he made no attempt to prevent the birds from flying out, letting them range as far as they wished. Latterly he has found unnecessary all fences or rearing-fields, and he now rears about $5, \infty 00$ young pheasants each year on open farm land.

Prefers Good Soil. Many people have the idea that any wild, rough land will do for a game farm. From Rogers's standpoint, the best arable land is none too good. Aside from patches of swamp or outlying woodland, he would have the whole farm tillable, of light soil to allow of good drainage, which is a great preventive of disease, and fertile, so as to raise good crops of grass, clover, and grain. $\mathrm{He}$ plans to raise no birds on the same ground two years in succession, and to plough and seed down each fall the land used for rearing during the past season. Or it may be sown to a grain crop in fall or spring, with grass and clover as an undercrop. In late summer, when the grain is harvested, there will be a fine stand of clover, which is splendid for the pheasants. In fall such renovated land is ready for caught- 
up young or adult stock, or for rearing operations again the following spring.

Rotation. In this way, every two years, Rogers has the whole farm turned over, and he has no epidemics. A man and team with plough can turn over about two acres a day, and there is the harrowing and seeding besides. It pays, however, if it makes safe the raising of thousands of birds worth from $\$ 5$ to $\$ 7$ a pair.

Control Methods. Though the birds wander off during the day, they return at night to feed, particularly in response to some recognized whistle or call, even when they are quite large and have left the hens. Rogers begins to catch them for distribution when they are about two months old, mostly by enticing them into enclosures to feed. The last ones become quite shy, and it takes considerable ingenuity to catch or trap them. Out of some 5,000 he estimates that about 300 get away and remain in the wild state. These, however, are by no means wasted, as they breed wild and help to stock the State, which already, after but a few years of breeding, has an open season for pheasant shooting in a number of counties.

Good Method for States. This method is particularly adapted to the purpose of liberating, by the State, for hunting, birds that are full-winged, and through freedom are vigorous and somewhat accustomed to finding their own living and escaping enemies.

The Evans System. The rearing system employed on the Wallace Evans Game Farm is likewise successful, and is ideal from the commercial standpoint, as the birds, while having considerable and sufficient range, are under full control, and very few get away. Everything here is raised and kept inside wire fencing 8 feet high. The fields are large, averaging, I should say, five to ten acres each. Evans has a num- 
ber of these, and does not plough to any considerable extent, but alternates, letting them lie idle for a year to recover. For three or four years, however, at first, when the land is new, he finds he can use fields continuously if only a moderate number of birds are kept on the land. He says that after a time not so many birds can be kept upon the land as when it was virgin soil. Insect life, moreover, becomes exterminated, and it is important to give this time to recover.

Control. To control the birds and keep them in pens he trims slightly a wing of each, cutting back only three or four primary quills. This is not enough to prevent flight, but just enough to impede high flying, so that they do not get over the fences. It has to be repeated every three weeks, or up to about the first of November. The birds become accustomed to catching, and are reasonably tame. By erecting strips of wire mesh it is easy to steer them into pens to catch them up.

At Five Weeks. When they are about five weeks old he combines two batches of about the same size and puts them in a fresh field where there is good grass and insect life has caught up. He uses only half the number of hens, about one hen to thirty young. These do not then need brooding, but the hens keep them more contented and lead them into coops at night. Later he removes the hens.

Other Details. In case a batch in some particular field do not grow well or some die, he transfers them to fresh ground, which gives them a new start. It is noteworthy that certain ground, even though it may produce luxuriant clover or other crops, is not so good for the birds as some other land, apparently similar, nearby. Mr. Rogers showed me some apparently fine plots, with splendid clover, on which he said the birds, though they did not die, never grew so fast or did so well. The cause may be the composition 
of the soil, and a scientific analysis would be of interest. Mr. Evans is fortunate in having a considerable number of fenced fields for these changes or for alternation. Having the flight impeded, it is easy to catch the birds when desired by getting them into covered pens, either by feeding them there or by driving. Strips of wire netting, temporarily placed, help to steer them into the enclosure.

Pinioning. In the case of the ornamental or aviary species, which are not intended to keep in the wild state, he pinions all his stock when two or three weeks old. This he does by snipping off with scissors the last joint of one wing. A thread for ligature is tied just above the cut, to be removed a few days later. At this early stage there is almost no loss of blood. Pinioning adult birds is a more serious matter, and one had better see it done by a more experienced person before attempting it. The main artery, which is protected between the bones, should be tightly bound.

Fancy Kinds. The aviary species are kept in fenced tracts which contain groves of trees. This Mr. Evans finds is sufficient shelter for them in winter. Ordinarily, it is desirable to have open-front sheds or coops.

Laying Out Coops. In laying out coops in a rearing-field, he has them 80 feet apart in the rows, and each row Ioo feet apart, the coops being set in a mowed swathe. Some others set them nearer, about half the distance, but some hens kill chicks that come to them from other coops.

The Clark System. At the Clove Valley Club, near Poughkeepsie, New York, Neil Clark, in charge of game breeding, raises large numbers of ring-necked pheasants.

Breeding. The breeding-stock he keeps in good-sized yards, with plenty of shrubbery and brush-heaps. The hens average about thirty-five eggs each season, He admits 
they would lay more by the Rogers plan, but the ground is irregular, so the large enclosure method is easier.

Hatching. For incubation he employs ordinary hens, in a hatching-house, which is quite a model establishment in its line. The tiers of nests are not along the wall, but across the house, which is in the shape of a long shed. Opposite each aisle, with its tiers of nests on both sides, is a door. Outside the door is a double row of small compartments, or feeding-coops, as many as there are nests on one side of an aisle of the hatching-house, numbered to correspond, so that the same hen will always be put back on the same nest. They feed the hens on one side of the aisle, then put them back and use the same feeding-coops for the hens on the other side.

Cleaning Nests. The nests are constructed in movable tiers or sections, like sectional bookcases. Back of the shed is a large tank or cauldron, in which, before each new hatch, the whole set of three nests is immersed to destroy all insect life. This radical treatment seemed thoroughly effective. The eggs, under this system, are sprinkled, which is ordinarily unnecessary when the nest is directly on the ground, except perhaps in very hot, dry spells. The nests built in the boxes are of turf, with a little hay.

Alternation. Rearing-fields are used but one year in three or four, being employed for farm crops when not for birds. On my visit three rearing-fields were in use. One was a large open tract of ten or twelve acres, and had 2,000 young, mostly well grown. Another was also open land, about half the area, with birds medium size; while for the third an orchard was used for the smaller broods. In all there were about 4,000 young birds.

Control. The fences are ro feet high, and the birds mostly remain inside the wire. They seemed to me re- 
markably tame, and did not try to fly out. Especially in the large field they were very little afraid of a stranger, and came readily to feed while I photographed them. People are kept away and no one is allowed to frighten them. As the fields are large, even if the birds fly they are apt not to go to the wire. Some fly out, but there is so little company outside that they want to get back, and are caught by means of the V-shaped spurs of wire netting previously described.

Catching. To catch them in the pen, Mr. Clark builds a temporary wire enclosure 50 feet long and about half as wide. He gets them accustomed to feeding inside this, and shuts up large numbers at a time. This is in early fall, when they are pretty well grown. The last ones, even in the enclosure, are rather hard to catch.

For Hunting. They are then confined in pens wired over the top. A few days before shooting, numbers are taken out and released in certain areas of swampy woods and meadow which are naturally attractive to pheasants, where they are hunted before they scatter very far. A good many at various times get away, and they are found for ten miles up and down the valley, as well as occasionally across the ranges of hills.

A Pastime. The raising of pheasants may be made a most fascinating pastime. It is charming to have these large and brilliant birds roaming upon one's own land and to be able to breed and control them. True, they cannot be depended upon to stay permanently upon the immediate premises, yet they will to some extent, if the surroundings are to their liking. But by catching and penning a moderate number of young each year, when they are well grown, one can always have enough stock to obtain plenty of eggs and maintain the output. Much can be learned from them of the ways of wild gallinaceous birds. New species can be 
acquired from time to time. From the standpoint of pleasure and recreation it is less arduous to have a rather small stock, and, after learning methods from ring-necks, to try different varieties.

An Industry. Pheasant raising can also be made a source of profit. It is a pleasant way for young people to make a little money on the side by raising a few game-birds or waterfowl. With hardly any expense, on the average farm, a boy could have a few broods of pheasants roaming around and growing up. What little work there is will seem more like sport, and the watchfulness required is good training. After buying the original breeding-stock, the expense is very light. Little apparatus is required, and the birds are small eaters. Ring-neck stock will probably cost \$5 to \$6 per pair in the late fall. A cock and four hens, say, might cost from \$10 to \$15. These should lay at the very least I 20 eggs, which are worth usually 25 cents each, or more than double the cost of the original stock. If even a moderate number of young are reared and sold, the undertaking would considerably more than pay. Wallace Evans began pheasant raising as a boy, and was so successful that it grew into a large industry.

The demand for live pheasants from the many that are beginning to breed them is so great that there is an almost unlimited market at present for them alive. When this demand is finally met, there is still an enormous field for sale for food purposes as wild game. It should be carefully considered that it is just as proper to sell or eat wild species as domesticated ones when this product is the result of one's own industry, and also that such work is directly an aid to the increase and protection of wild life. Propagators of wild game are not only liberating more or less of it to increase the natural supply, but personal interest impels them 
to realize more fully the value and importance of wild life in general, and to demand its adequate protection and conservation. This new movement, with an emphasis on the practical side, will come as a mighty aid in the battle against waste of wild life and the thoughtless cruelty which goes with this. 


\section{CHAPTER VI}

\section{OTHER FOREIGN GALLINACEOUS SPECIES}

Need Careful Study. Besides pheasants there are other foreign species which have been experimented with in America, and many more which might be. While the major emphasis should be placed upon the native birds, there is no reason why interest should not be directed, in proper ways, to any other attractive and valuable species of this class. It should be remembered, however, that of numerous attempts tointroduce foreign species in the wild state by merely shipping them in and liberating them, with only one species, the ring-necked pheasant, have the attempts as yet been successful. Large sums of money, both public and private, have been wasted in such attempts. Before embarking upon such schemes on a large scale, careful experiments should first be made, to ascertain whether the bird in question can be successfully bred and whether it can maintain itself under the new conditions.

Unsuccessful Attempts. Clearly unsuccessful attempts at introduction have been made with the following species: the migratory or Messina quail, red-legged or French partridge, black grouse, and capercailzie, all of Europe, the sand grouse and chukar partridge of India, and numerous fancy pheasants and tragopans.

Breeding Tinamou. Probably it would be possible to breed any of these and maintain them under artificial conditions. This is being done on the estate of William Rocke- 
feller with a South American tinamou. This is a peculiar, long-legged gallinaceous species of medium size, mottled brown in colour, which utters loud, prolonged wailing cries. Tinamous are tame, docile birds, and they do very well in grassy pens, being entirely maintained upon small grain and seeds. They breed quite readily, laying good numbers of very peculiar-looking eggs, of a uniform deep, rich brown colour, with a gloss as if varnished. The young are easily raised with bantams, by the same food as pheasants. They do not appear sensitive to epidemics, and grow up in an enclosure without complications. They are at least fairly hardy, and stand winter weather without artificial heat, with only shelter from storms. Further experimentation might show that they could be trusted to wander like guineafowl and come home to roost. They are so singular and quaint that it is decidedly amusing to breed them.

Dangers of Wild State. It is a very different problem, however, when it comes to introducing these strange species into this country in the wild state. All sorts of factors arise to complicate the problem. It is not enough that a species should be hardy. For example, I was interested once to watch a little European quail that George D. Tilley had on his place. It remained all winter in a small yard, entirely in the open, in deep snow, exposed to cold and storms, living mostly under a little cedar bush, the only shelter it had. When attempts were made to introduce the species through liberation, the birds nested in the vicinity and raised their broods, but migrated in the autumn, after their habit, and were never seen again. In this case, the obstacle was the migratory instinct; in others it seems to be in securing food, resisting vermin, and the like.

The Gray Partridge. The only other foreign species which may be discussed at length is the gray partridge of 
Europe, usually known in this country as the Hungarian partridge, because most of the stock imported came to us from the region of Hungary. A great many thousands have been liberated in various states, from Atlantic to Pacific, at a cost of hundreds of thousands of dollars, with very little thus far to show for it. The species is a valuable one, and it may yet take hold, as some encouraging reports have come in.

Experience of Rogers. The case was put to me as follows by Harry 'T. Rogers, who, for the States of New York and Illinois, has liberated thousands of them. In his experience, though they frequently bred for a couple of seasons, he says that about half of them disappeared after the first breeding season, half of the remainder the second year, and the third year they were all gone.

Unfavourable Habits. This is not altogether due to foolish modes of liberating, but evidently to the habits of the bird. Here is a typical case: C. H. Savage, of Storrs, Connecticut, in I9I I had one pair on his farm with a brood of young. These were seen frequently feeding in open fields on a hilltop, where they were quite conspicuous. Their first mishap was when three or four of them flew into a wire fence, were more or less hurt, and one was so crippled that it had to be killed. The others remained about, and disappeared one by one, till in October there were said to be only three left. Apparently they were an easy mark for hawks and vermin. Comparing them with the bob-white, in confinement, the quail hides upon the approach of danger, while the partridge runs off squawking, thus exposing itself. - Lack of Natural Food. The food supply may be another important factor. Our Eastern farmers now plant very little small grain, and the average farm in winter affords scant food supply. The lands from which these partridges 
come to us are said to be notable for their grain crops. They are largely eaters of seed and grain, and there live amid the grainfields.

Conditions in Eastern Europe. An article descriptive of this region, written by Mr. Larsen, of the game-exporting firm of Loewith and Larsen, in The Game Breeder is very instructive. In parts of eastern Europe where many thousands of thesepartridges are netted for shipment to America, the following are the conditions: The peasants live in compact villages, not on their farm land, and go back and forth to work. For miles there are uninterrupted stretches of grain and crops, no houses to harbour rats or cats, no woods to shelter foxes. The fields provide abundant food and shelter. Young broods, undisturbed, grow up in thousands. Here, on the other hand, they encounter winter starvation and enemies on every hand combined with indiscriminate gunning which is there prohibited.

Since the species has been brought here, it will be worth while to use all possible measures to protect and establish it, so following are some suggestions for management and propagation:

Method of Liberating. When stock of this or other species is to be liberated for natural breeding, there are certain cautions which should be observed.

I. Birds should not be released in winter, in strange and rigorous surroundings, when there is every prospect that they will perish from hunger and cold.

2. They should not be released immediately upon being received, especially if imported from abroad, or after any long journey. Keep them and feed them a while, in sufficiently large and comfortable quarters, till they are in good physical condition.

3. Do not release them suddenly, or in alarm. The poor- 
est method is to take them afield, pull off the cover of the crate, and see them whir off, like a shot from a cannon. The chances are that they will never find one another and never return to the desired location.

An Instance. Here is a method I once tried with a consignment of gray partridges: For about ten days they were kept in a covered wire enclosure, in a retired place at the edge of a suitable huckleberry pasture, bordering the woods. They had plenty of grass and bushes, and of food and water. One night, after feeding, I left the gate open, having scattered grain outside. Next morning only a few had gone out, and these were in the bushes close by. The others had not cared to leave. They would walk to the gate, look out, and go back. Finally I had to urge them gently from a distance, till they stepped out and trotted to the bushes to join their friends. They remained nearby and came back to the pen regularly to feed. A field of buckwheat was planted near, and the grain left to stand for their use in winter. Most of them remained in the vicinity, and three nests, with from fifteen to twenty eggs in each, were found in that same pasture the next summer.

Difficult to Breed. Though easy to keep in confinement, the gray partridge is a difficult species to breed under restraint. They are wild and restless by nature, and usually do not tame at all. Even if kept for years in an enclosure, they often remain as wild as ever. Whenever any one approaches, instead of hiding like the quail, they race about or flutter, uttering their raucous cackle. "Fool birds" is a term I have heard applied by many an observer. They have, however, the virtue of not being very susceptible to the enteric epidemics.

Hard to Mate. It is almost hopeless to expect them to breed in a small yard or enclosure. They are very finicky 
about mating, and must select their own partners. Arbitrary mating cannot be arranged, as with quails.

Nesting in Large Pen. One way to manage is to put out a number in a good large enclosure, preferably of an acre or more, and hardly less than half an acre, and let them mate and nest there. One trouble, however, is that the males are terrible fighters, and another is that the sexes are hard to tell apart. Generally the males are the more reddish brown in their markings, but I have found that this does not always hold, for some males, perhaps younger ones, lacked the reddish markings. Another sign, only discernible by catching the birds, is that the males generally have the under side of the wing nearly white and only faintly barred with gray, while with the female it is more heavily barred. Some cases, though, are indecisive. The size of the brown patch on the abdomen is not a distinguishing character. So one is apt to get in more males than females, and then there is no peace.

French System. The approved way of dodging the difficulties is the French system. In this there is a central field as above. Around it are built smaller pens, each of moderate size, say i 5 feet square, having a door or slide connected with the field. In this field place a number of birds, at least enough for a pair for each side pen, or more. Amid great fighting the matings are made, and the mated pairs withdraw into the smaller pens. There they can be shut in to breed, or be caught and removed to other quarters, to make room for others. The young can be hatched and reared with bantams. They are fully as easy as pheasants to raise, and are quite docile, unlike the parents. The latter, however, unlike the quail, will usually rear their own young. Some breeders allow them to do this, as they do not usually lay a second clutch in a small enclosure, though sometimes they 


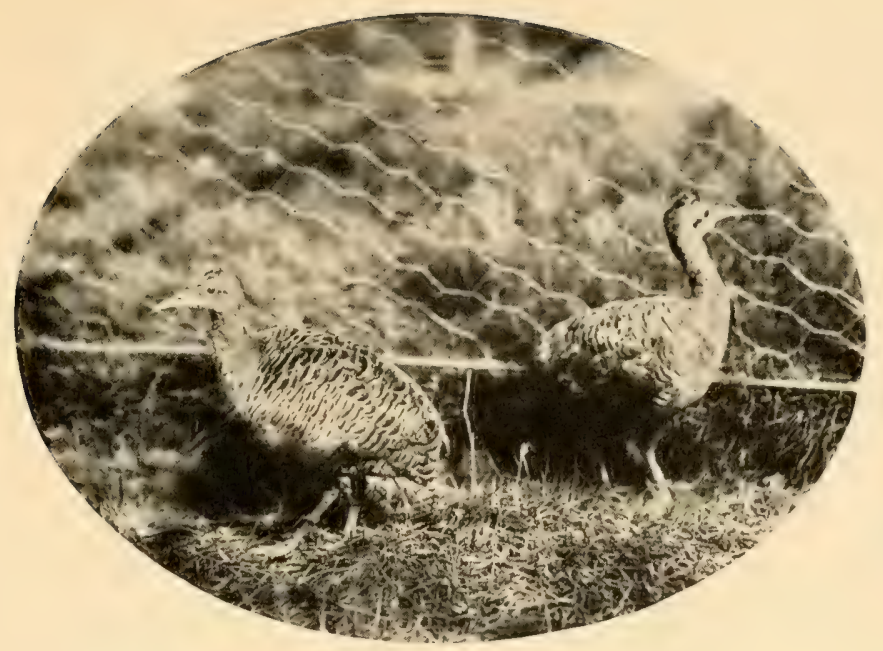

Tinamou, the South American species bred by William Rockefeller

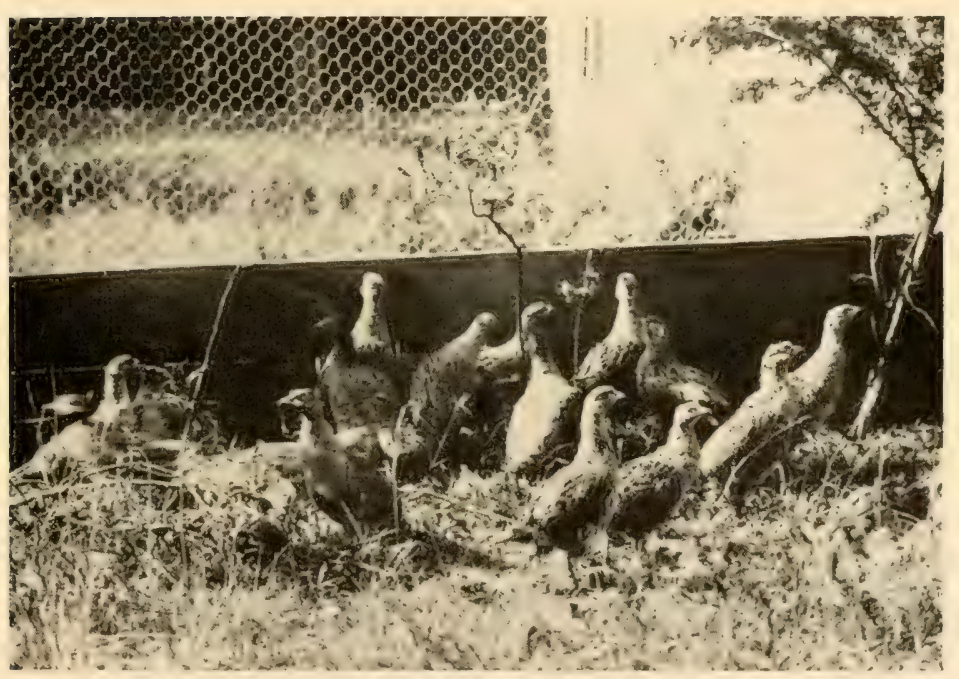

Gray or "Hungarian" partridges 


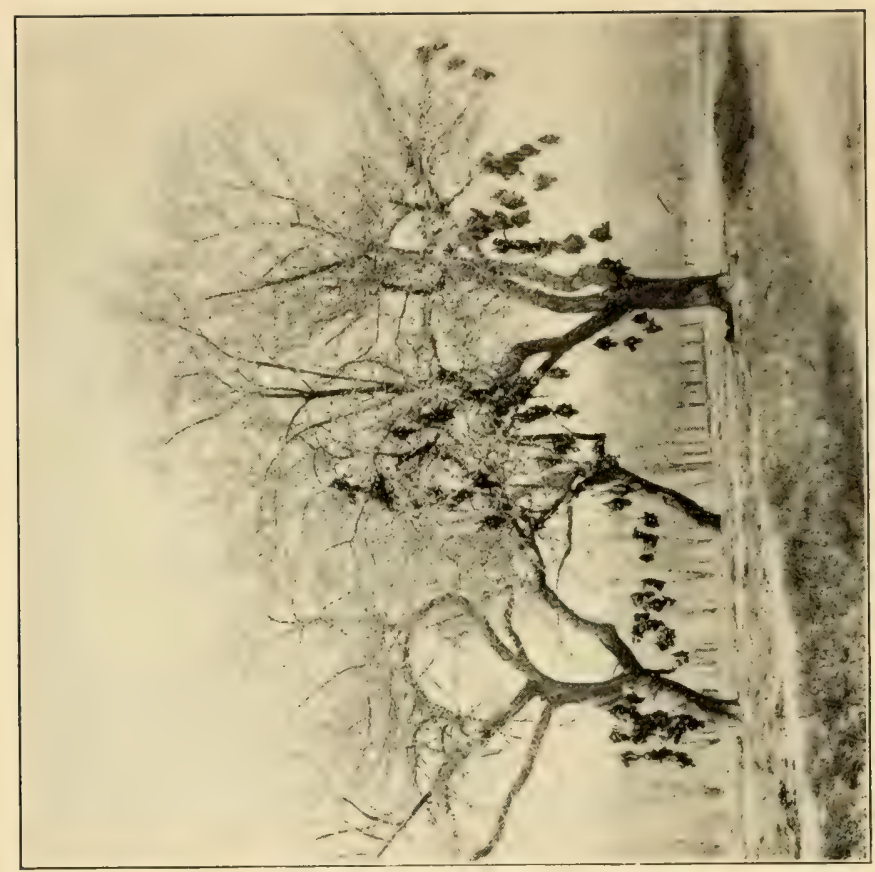

을

5

ڤ

$\stackrel{50}{\Xi}$

כ

$\stackrel{\breve{J}}{3}$

苋怘

$\Xi$

है

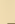

ง

ล

苛

总

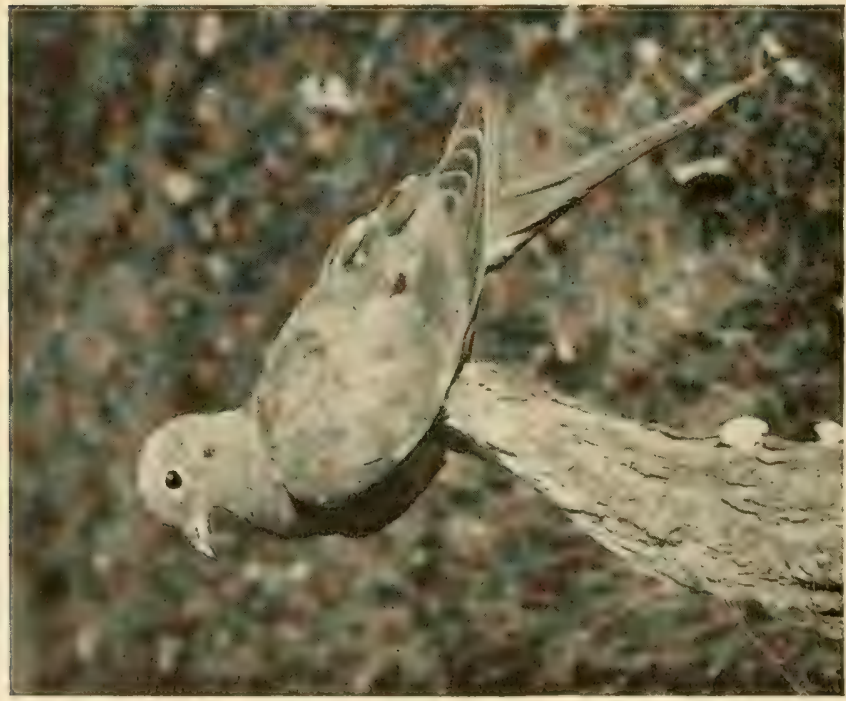

Oี 
do this in a larger fenced field. On the other hand, the young will thus grow up as shy as the parents. So if it is desired to secure tamer stock which will breed better in confinement, and be more inclined to stay on the land where they were raised, it is well to rear the young with bantams.

German System. In Germany, on game preserves, where there are plenty of these partridges in the wild state, they have a very effective system for large increase of their numbers. It is also used with another species, called there "wachtel," comparable to our bob-white, and it would be well worth trying out in America in connection with quail propagation, especially on Southern preserves where the birds breed commonly. It was described to me in detail by Ludwig Seidler.

The unit of the system is a five-acre fenced field. Vermin has been thoroughly trapped in the vicinity, and a fence 5 feet high is used. The ground should be arable agricultural land, and it is fully planted with various garden crops best adapted to supplying both vegetable and insect food to young birds. While these are growing, nests with eggs are hunted out afield. Trained dogs are used to locate them and rewards are offered or finding them. Only fresh sets are taken, so that the birds will lay again. It is preferred to find the nest while the bird is still laying, in which case a couple of eggs are left in the nest, and the birds will often continue laying indefinitely, as the eggs are regularly removed. These eggs are hatched in incubators, and the chicks are then given to bantams which are kept sitting for that purpose. Of course the bantams could be used to hatch the eggs if desired, which is preferable if there are enough bantams on hand

After the young have learned the call of the hen they are placed with her in a coop in the cultivated enclosure and are 
allowed free range with her. Grain is given to the hens, but the chicks receive no artificial food. With such rich forage there is ample natural supply for them, which obviates danger of disease. When they begin to fly over the fence, they are put back. Those that get out run along the wire and are easily caught, especially after dusk, with a little electric flash-light which blinds them. When they have all learned to fly out, the bantam gets lonesome and flies over to join them. They use light-weight, active bantams, which travel about with the young and care for them on free range, not returning any more to the rearing-field, which avoids the danger from fouling the ground. This, of course, would be impracticable without skilled handling of the vermin. By autumn the bantams become as wild as the partridges, and often can be caught only by shooting. In each such enclosure from I,000 to I,200 birds are reared, and losses are slight. Such fields can be duplicated as desired, but there must be a keeper for each in attendance. Toward spring, when the breeding season approaches, in order to scatter the birds over the preserve and break up the coveys, the keepers chase them with horses and dogs. The whole system is worked out thoroughly in every detail. They know very nearly how many birds there are, and where each covey is located. In the hunting season they kill only so many, and leave the desired number for the next season's breeding. No wonder that they have game under such management.

Adaptation to America. Such a system, with slight modifications to fit local needs, would seem to be an excellent one for quails. It might possibly be adapted to the establishment of the gray partridge in this country. Occasional reports give some hope that the species might become naturalized, especially through careful scientific methods, based 


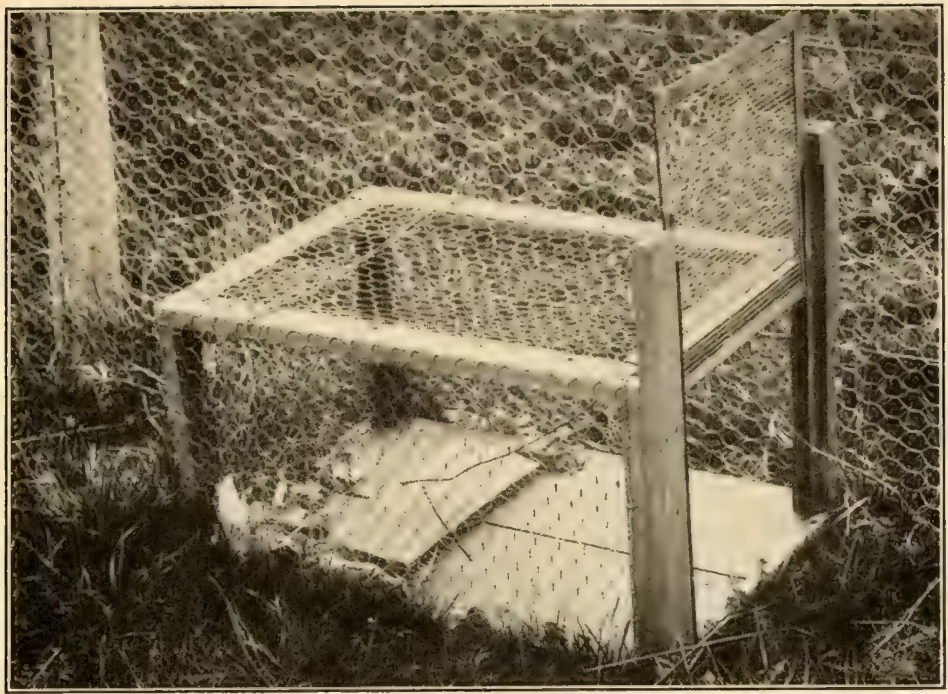

Box trap invented by Wallace Evans. Note spring-pan in centre and wire blocking door

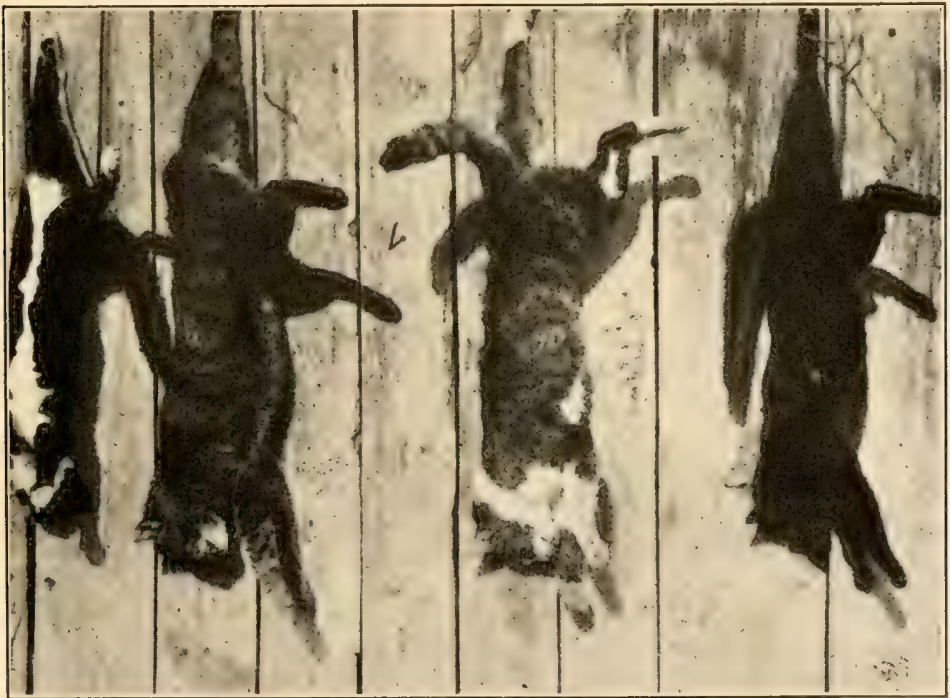

Four of the predatory cats shot by Harry T. Rogers after months of watching, which he estimates cost the State of New York $\$ 1, \infty 00$ in the young pheasants which they destroyed 


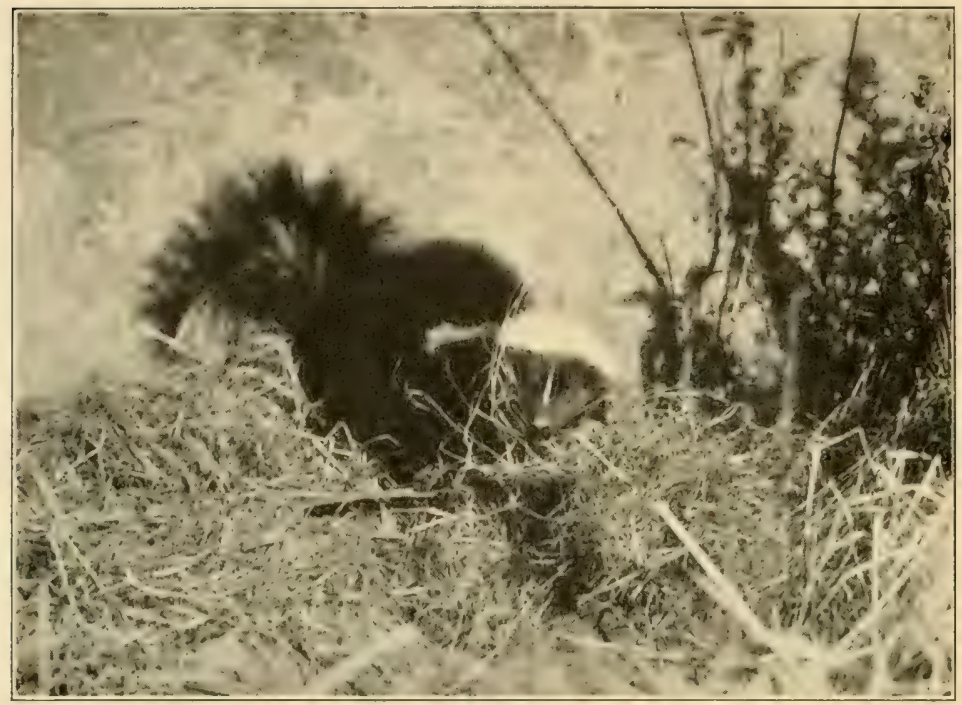

Skunk in trap

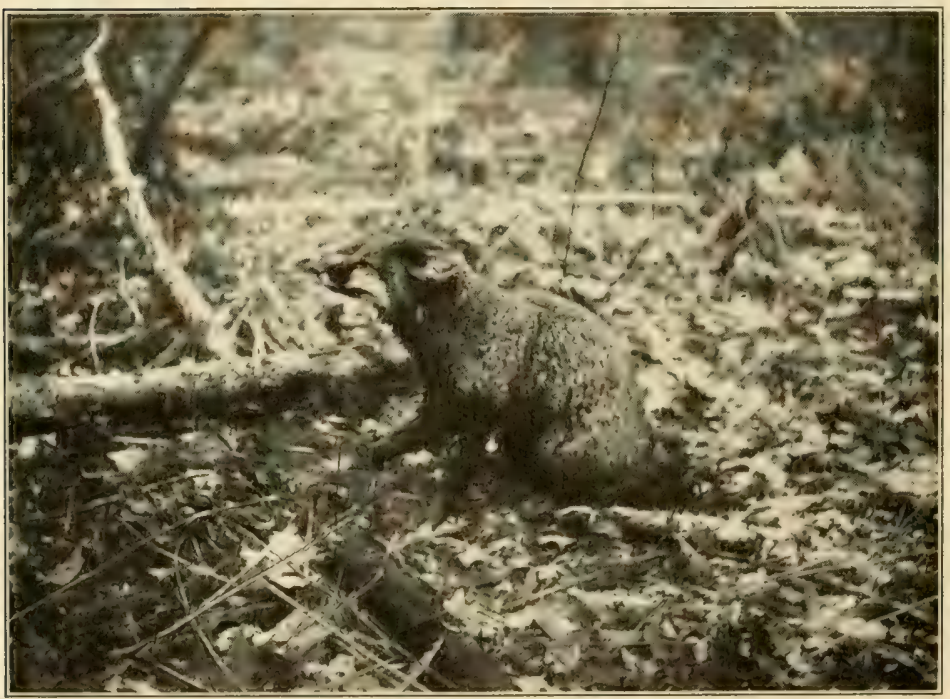

Gray fox in steel trap caught by front paw 
upon study of the needs of the species. William L. Finley, recently chief game warden of Oregon, says that it is increasing in his State in the Willamette Valley. On a large, suitable preserve, consisting of considerable agricultural land, and where grain was planted, with winter feeding and also trapping of vermin, together with the above method for them and for quail in conjunction, the thing might be worked out. Stock properly liberated, as above, would breed in the vicinity. The nests could be found and the rest of the method carried out. Young birds raised with bantams and thus cared for would tend to outnumber the sources of destruction and remain upon the land. After a few generations the species might secure the adaptability to maintain itself, especially as it is hardy and vigorous. 


\section{CHAPTER VII}

\section{PIGEONS AND DOVES}

Lesson from Passenger Pigeon. What is supposed to have been the last surviving passenger pigeon on earth died in the Cincinnati Zoölogical Gardens, September I, I9I4, and thus another notable species has evidently perished from the earth. Had "applied ornithology" been in vogue even thirty years ago this notable bird might have been saved to posterity. It was easily kept and propagated in confinement. At the least, it might have been saved like the buffalo, and with determination even more might have been done. It is too late, but there are still other species of this Order of Columbae.

Mourning Dove. The mourning dove is an allied species so similar in appearance to its extinct relative that many people still mistake it for the latter. It is still found over much of North America, though often in small numbers. Thirty years ago it was a popular game-bird, but the fate of the passenger pigeon has so alarmed the public that in many States it cannot now be lawfully hunted. Despite protection in some quarters, it is evidently shot ruthlessly elsewhere, or in defiance of law, for in some regions, especially the Eastern States, it is scarce and waning.

An Experiment. This species could probably be made abundant artificially if the laws permitted and if the birdloving public were encouraged to assist. Recently I talked with Ernest A. Watts, keeper of the great aviary of Mrs. F. 
F. Thompson at Canandaigua, New York. He was breeding successfully a number of foreign kinds of doves and pigeons, but no American species, because the laws forbade. As a matter of curiosity he had in time past elsewhere experimented with the mourning dove on a small scale. Taking some eggs of this species, he had substituted them for those of tame pigeons. The birds hatched and raised these young doves, and he found them just as amenable to artificial conditions as other kinds. They are fed like other pigeons on small grain, are hardy, and without doubt would breed well.

The next stage would be to let some go free, and experiment to see if they could not be made to breed on the premises in the natural state, holding them to the vicinity by regular feeding. They are hardy, and might not migrate if fed. In case they did, the natural homing instinct would be likely to bring them back.

Other Species. Another interesting species is the bandtailed pigeon of the Pacific Coast and the Southwestern States. It is a large and valuable species, and must be quite hardy, as it is found as far north as British Columbia. The terrible slaughter to which it has been subjected has aroused general indignation. Here is another species notably worthy of practical interest.

A number of other species, probably less hardy and not suited to northern climes, are found in southern Florida and on the Mexican border. The tiny ground dove, which ventures regularly as far north as North Carolina, is a tame and gentle little bird, and in the South could doubtless be readily propagated.

Foreign Species. Various foreign species are bred in America in aviaries. Wallace Evans, William Rockefeller, and others breed the wood pigeon of Europe, which is a 
large, hardy species. It is problematical, of course, what would become of them if liberated.

Elastic Laws Needed. Protective laws are valuable and important, but should be made elastic enough to encourage all reasonable and proper efforts to increase wild birds. 


\section{CHAPTER VIII}

\section{CONTROL OF VERMIN}

A Popular Fallacy. A popular fallacy is that all that it is necessary to do to increase bird life is to set apart a tract of wild land as a refuge, and prohibit trespass and shooting. At the start there are probably few birds, and after ten years there might not be any more. One reason is that the average wild land abounds with destructive vermin Hawks and owls, which are the principal natural check upon the smaller mammals, have been so reduced in numbers that rats and other vermin abound. True they kill some birds, but they eat more of the enemies of the birds. Because we have upset the balance of nature, we have to help restore it by checking the abnormal increase of vermin.

Practical Suggestions. This chapter does not pretend to be a complete treatise on trapping, but only is intended to point out some of the accepted practical methods by which vermin is controlled on successful preserves and estates. Traps, guns, and poison are the implements of war which are effective mostly in proportion to the knowledge and discretion employed in their use.

Hawk Traps. Notwithstanding the fact that raptorial birds destroy much four-legged vermin, we cannot sit idly by if they are actually invading our premises and are destroying the birds we are trying to produce. The easiest way to catch marauders of this class is based upon the fact that before pouncing they usually alight upon some commanding 
site nearby. Small round steel traps set upon top of poles by breeding-pens, rearing-fields, or other open places are very effective. No bait is required. These should not be set in summer, as they will then catch useful small birds. Wind the jaws with cloth or rubber, so as not to break the legs of birds caught. Hawks that are persistent in summer are quite sure to be nesting in the vicinity. The nests are platforms of sticks in tall trees in the woods. If these are hunted out and destroyed, the disturbers will usually depart.

Box Trap. Where there are wire fences, vermin will usually follow the wire, trying to enter. Where ducks are kept, which do not get out, steel traps can be set just outside the wire. This will not do where there are gallinaceous birds which fly out and try to get back. In this case box-trap arrangements are best. Evans and Rogers both use a similar device, the principle of which Evans invented. The following is the model used by Rogers: The trap is rectangular in shape, a frame covered with wire. One end is occupied by a drop door, sliding up and down in metal grooves. About the middle of the trap inside, extending nearly across, is a metal sheet, about 6 to 8 inches wide, which is hinged at the bottom. A piece of stout wire attached to the upper edge of this, in the middle, is cut just long enough so that when this sheet or pan is raised, sloping back at an angle of about $30^{\circ}$, the wire will just reach up to block the bottom of the door when fully raised. If anything enters and steps on the pan, forcing it down, this will pull the end of the wire out from under the door, which will then drop and imprison the creature. Escaped birds can be caught with this as well as vermin.

Another. The model in use on the Evans' Game Farm is similar to the above, except that when the intruder steps on the pan, instead of pulling the wire directly from the door, 
it releases the bottom end of a vertical rod, which has a horizontal extension from its top to block the door, as with the other model. From the junction of the vertical with the horizontal rod a spring is attached and to the back of the trap. The bottom of the perpendicular rod has a tooth or groove which is held by the spring against the pan. When the pan is forced down the lower rod is released, so the spring can pull back the horizontal rod and let down the door.

Pitfall. Another device which Evans uses along his wire fence is a pitfall arrangement. A pit $4 \frac{1}{2}$ feet deep is dug just outside the fence. Over the part closest to the wire is a wooden covered passage. At each approach is a balanced board weighted at the outside end. These boards meet in the middle of the passage over the centre of the pit. The animal gets past the divide and the board tips down and drops the victim into the abyss, springing back into place. Outside the passage the pit is boarded over by a trapdoor, through which to remove the captives. Some mornings there are strange collections of uncongenials in the pitcats, rats, skunks, and what not, too much scared to fight.

Clover-leaf Trap. Another effective device, which might be called the "clover-leaf trap," is used by Frank Hopkins, A. G. MacVicar, and others. It is a wire mesh labyrinth, in the shape of a four-leaf clover, the lobes almost meeting in the centre. At the bottom of one of these indentations there is a small opening at the ground, just large enough to admit whatever vermin or birds one expects to trap. It need be only 2 feet high and about 6 feet across, the wire being held in place by small stakes. It is covered on top, but has there a door, through which to reach captives. Bait is put inside, and for birds a trail of grain is laid to the entrance. The victims enter readily, but seldom discover the 
way out. This can be used to capture escaped birds as well as vermin.

General Trapping. Whether there are wired enclosures or not, there should be a plan of general trapping carried on. Burrows of skunks should be hunted out and steel traps set in them. Skunks and foxes like to run in furrows, and a plough can be run around and steel traps set in the depression. A very good way to outwit the fox, so suspicious of traps, is to select warm spring holes or pools in the woods, and out in the middle, or about a yard from shore, put a bit of meat on a stake, just out of water. About a convenient step from shore set the steel trap just below the surface, placing on the pan a piece of moss which projects from the water like a little island. The fox does not like to wet his feet, and is very apt to step out on the moss to reach the meat. This might interest Mr. Coon also. The raccoon is a great destroyer of nests of eggs and young, and is always hunting for them. If there are coons about, they can also be hunted with dogs at night.

Mink Trap. Weasels and minks are destructive, bloodthirsty creatures, destroying for the mere love of slaughter. If one gets into a coop or pen it may kill everything there before it leaves. Minks are caught by the professional trappers, especially along brooks, by setting steel traps under water by the margin, putting bait of apple or meat handy on a stick or under a steep bank, arranging matters so that the animal has to go through where the trap is to reach it.

Weasel Trap. Weasels like to run through holes and dark passages and are apt to have regular runways. These can be detected best by their tracks after snowfalls, and traps can be set. A good way is to pile up some brush and leave a covered passage or hole through it underneath. A trap used very successfully on the Childs-Walcott preserve 
is constructed as follows: Four rather narrow boards about a yard long are nailed together to make a narrow conduit or passage. A board on a pivot, like a teeter, is balanced in the middle and is set with the end resting down at the front entrance of the trap, making an inclined walk uphill. Under the near end is a short piece of strong wire, loosely hung, and lying flat when the board is down. This trap is set in the tunnel under the brush heap or in the weasel runway, with a slight fence or obstruction built off on each side. The weasel runs in up the board, which tilts down when it crosses the middle, raising the front end of the balanced board up to the top of the passage, closing the entrance. The recumbent wire hangs down and keeps the board from going back. There is wire mesh across the farther end, and the weasel is shut in. On the above estate they caught with this device large numbers of weasels.

Hole-in-fence Trap. An excellent adaptation of the principle of this weasel trap was suggested to me by Ludwig Seidler, who also introduced the above trap from Germany. The idea is to cut a hole in the wire fence of the pen or rearing-field leading into a wire chamber. This trap, or one of larger size, is placed at the entrance to this chamber. Of course some other box-trap arrangement could be used instead. A fox following the wire and seeing a box trap set beside the fence is apt to go around it. If Reynard, however, sees a hole in the fence, he joyfully enters and gets caught. This device is said to be very effective with all sorts of fourlegged vermin.

Stone-pile Trap. Mr. Seidler has furnished also the description of another trap in use on German preserves, said to be especially effective for weasels, rats, and small vermin. Along hedges, in corners of the preserve, or in woods, are the places to locate it. Select a slight elevation, or make one, 
only high enough to avoid flooding in rainstorms. Either out of weather-beaten boards or flat stones, on top of this elevation, make a rough box or chamber, just large enough to hold comfortably the sort of animal it is designed to catch. The top should be broad enough to keep out rain, and should be removable, either a flat stone or a wide piece of board with stones on it. Stones are piled around the box, to suggest an ordinary stone-heap, but there should be passageways built through the stones leading up to entrances to the chamber near the top. Chaff is placed on the floor, and a steel spring-trap is set in this. The animal follows the tunnel, jumps down into the chamber, which is not deep, and gets caught. No bait is needed. The trap is examined by lifting the cover. This will work well also for animals the size of skunks, if the trap is made large enough. A number of such traps should be maintained over the preserve.

Stray Cats. The domestic cat is one of the worst kinds of "vermin" with which one has to deal in increasing birds. The various devices suitable for such animals will usually reap a harvest of felines. It is astonishing how many cats have taken to the woods, and are running wild and raising wild offspring. On the Howell preserve, in a very remote and mountainous section of Connecticut, eleven miles from the nearest large town, Winsted, the keeper, William Whisker, told me he had killed nearly 200 of these semi-wild cats. Many people would be astonished if they knew how many miles their pussy, so quiet and demure in the daytime, had roamed by night, and how much game it had killed in a year.

Humanitarian Movement. The growing movement to limit and control the number of cats is not a crusade against pets, but is based upon motives of humanity and mercy. There are thousands of homeless, hungry cats, in city, 
town, and country. These are giving birth to multitudes more, born to a wretched, suffering existence. Many people move away and leave their cats uncared for in town in summer, or abandon them at their summer place when they return to town. Such practices are barbarous and reprehensible. Not only are they cruel to the cats, but they are contributing to the destruction of the valuable bird life of the nation. It would be eminently proper and merciful to have cats licensed, the number limited which a person is allowed to keep, and organized effort made to put mercifully out of the way the unowned residue.

Rat Nuisance. Another nuisance and menace is from rats. These have proved the undoing of many an effort to propagate wild birds. It is hopeless to try where rats are abundant. Cats have their proper place in the domestic economy to reduce this pest, yet well-directed trapping and poisoning can usually be made effective. The time to get after rats is in winter, when they are driven into buildings by the cold. In warm weather they scatter out into fields and woods, where it is next to impossible to catch them. They prove the despair of the keeper who does not attend to them in winter while they can be reached. There are various good rat traps on the market accessible to all. A bulletin on the destruction of rats, by E. H. Forbush, giving full detail of methods of destroying rats, is published by the State Board of Agriculture, State House, Boston, Massachusetts. See also Farmers' Bulletin No. 369, "How to Destroy Rats," by the U. S. Department of Agriculture, Washington.

Points from Evans. Wallace Evans made the suggestion to me that rats often refuse to enter a trap which is out in plain sight, whereas they would enter if it were covered over with a pile of burlap or nearly any other obstruction. Be- 
sides their being in buildings in winter, he finds large numbers of them in stacks of straw, grain, hay, or piles of rubbish. When he removes one of these in winter he has his trained dog on hand and several men with clubs. The rats run out and are struck or caught by the dog. Sometimes they kill a large number in this way.

Method of Rogers. A good dog is useful to trail marauding animals to their dens. Harry T. Rogers has such a dog which is an expert in this line. He finds dynamite also a good ally, as in the case of persistent weasels, which keep returning and destroying numbers of his pheasants. The dog trails the weasel to its hole, which is apt to be near a tree, with the den usually under the outer ends of the roots. Estimating where he thinks the den is, with a crowbar he punches four holes, in a square of about 6 to 8 feet. In each of these he sets off a pound stick of dynamite, and he says he has never had the animal return after such treatment. This is usually in summer when the weasel has young, and thus he destroys the family.

Methods of MacVicar. I was shown by A. G. MacVicar the methods by which he cleaned up a preserve which had become infested with rats. In brief, he began in early winter a systematic campaign, with steel and box traps and ferret. First he searched out rat-holes, in which snowfalls helped, revealing the tracks. When the rodents get used to one sort of trap, he changes to another. His tame ferret proves the most effective agency of all. He described how, when he first put it under the house, the rats poured out like a swarm of fleas. A well-trained terrier he finds very useful on such occasions. An energetic campaign of this sort, when one makes a business of it, works wonders.

Get after Vermin. A system for general wholesale poisoning has been described in the chapter on the wild turkey. 
Such a plan should be tried, if at all, only in very wild regions, and not where it is contrary to law. In general, however, too much stress cannot possibly be laid on the destruction of vermin. Persistent, unremitting pursuit will yield surprising results, and will often cause the desired species of birds or game to become more abundant in a comparatively shorter time than one would have believed it possible. 

PART II

THE PROPAGATION OF WILD

WATERFOWL 



\section{CHAPTER IX}

\section{WILD DUCKS}

\section{a. Methods with Adults}

Delight of Breeding Wildfowl. The keeping and breeding of various species of wild waterfowl, especially wild ducks, is one of the most fascinating of all forms of applied ornithology. Usually these wildfowl are considered so exceedingly shy that nothing more can be expected than a distant glimpse as the flock, keenly alive to approaching danger, springs from the pond or marsh, and swiftly vanishes into the gathering gloom of the evening sky. The high passing wedge of wild geese, heralded by weird honkings, as in early spring it passes poleward, seems a thing of mystery, almost like a glimpse from the spirit-world. Yet these same frightened ducks can be made to swim trustingly and happily before one on the little pond, and those wild geese to breed contentedly in the farmer's meadow and eat corn at his feet.

Feasibility. The simplicity of the keeping of wildfowl is one of the delightful surprises in store, though it must be borne in mind that there will be failure unless certain fundamental principles are carefully carried out. About all that is needed is a little pond or brook, especially in a quiet, sheltered place and with some marshy ground, perhaps a simple open-front poultry-shed, and a cheap wire fence. The food also is simple and easy to provide. It is easy to maintain the birds in health, when properly handled, for 
they are hardy, and seldom have epidemics comparable to those of the gallinaceous birds, though similar disasters may occur if the water is allowed to become foul and stagnant, and reasonable sanitation is not observed. The young also are comparatively easy to rear. In suitable surroundings, particularly on large estates, wild ducks can be maintained in the natural wild state, free to come or go, and yet be induced to remain and partake of their 'master's bounty. By certain methods the flying wedge of certain varieties of wildfowl may be made to descend to feed at the owner's feet, and later will pair off and lay eggs in their downy nests in the grass by his pond, or in the boxes, as in the case of wood ducks, which he may put up for their convenience.

Any one who has even the facilities of a city backyard, with a cement basin and a little shrubbery could have a few pairs of pinioned wild ducks which would breed in happy contentment. F. N. Manross, of Forestville, Connecticut, has a little artificial basin under the windows of his factory, surrounded by some thick low shrubbery and a wire fence. There a pair of beautiful wood ducks, regardless of noise or human presence, each year raise a brood of young, and furnish their owner delightful distraction from business cares. Asteam pipe keeps the water partly open in winter, and there they live the year round, with no shelter other than shrubbery and a small box. In another part of the same yard he has a couple of pairs of Canada geese, originally wild, which live there in perfect contentment.

Types of Wild Ducks. At the outset, for the sake of clearness, it will be well to state that there are two main and distinct classes of ducks, which have strong diversities and require somewhat different methods of treatment. The A. O. U. Check List gives them as River Ducks and Sea Ducks, though the latter are not confined to the sea nor the 
former to fresh water. There are also other popular designations, such as, for the first class, fresh-water, pond, or marsh ducks, and, for the second, salt-water, bay, or diving ducks.

Classified. Following is a list of our native wild ducks, classified as above:

River Ducks: mallard, black duck, Florida duck, gadwall, baldpate, green-winged teal, blue-winged teal, cinnamon teal (western), shoveller, pintail, and wood duck.

Sea Ducks: redhead, canvasback, greater scaup duck, lesser scaup duck, ring-necked duck, golden-eye, Barrow's golden-eye, bufflehead, old-squaw, harlequin duck, eider, northern eider, king eider, velvet scoter, white-winged scoter, surf scoter, and ruddy duck. The latter in habits partakes of both classes. The scaups are popularly known as "blue-bills" or "broad-bills," and the scoters as "seacoots."

Edible Ducks. Of these classes, the first comprises most of the edible species. In the second category the canvasback, redhead, ruddy duck, and scaups are esteemed for food, especially the first two. The rest are more or less strong and fishy, though eaten by those who like them. There are also the mergansers, also called sheldrakes or fish-ducks, which are in still another class, and are rather dubious for eating purposes. The river ducks are especially the kinds to propagate artificially, though beginnings have been made with a few of the sea ducks, especially the redhead.

Quarters for Wildfowl. A small pond of some sort is the key to the situation. If only a few ducks are to be kept, it may be very small, a mere puddle. It is well, however, to provide for change of water. Stagnant water in hot weather is not good, and is more likely than anything else to start distemper, especially if the birds are at all crowded. An ideal arrangement is a small pond with an inlet and out- 
let. Not only is the water thus kept pure, but the flow brings in small water-insect life, upon which waterfowl especially thrive. For a few fowl a section of a brook may be wired off, together with some surrounding land. In this case care must be taken to sink the wire mesh in the stream to the bottom, to prevent the birds from diving under the wire. Another arrangement may be to dam a stream, and excavate, if necessary, a small pond. If there is no natural water supply, this can be supplied by artificial means.

A Small Pond. For an undertaking to breed or keep wildfowl, a small pond is much better than a large one. A large pond is apt to harbour large turtles, which are death to ducklings, and even attack ducks of good size. Large fish, especially black bass and pickerel, and blacksnakes are also dangerous. A small body of water may be drained off if necessary, dynamited, or otherwise freed from enemies, though in such a place enemies are less likely to be found. With a large area of water it is harder to keep track of the birds or to find their nests in breeding time. A pond covering an acre is a good size, and three acres is amply large. About fifty breeding ducks to each acre of pond is enough.

It is a great advantage if the pond is partly surrounded by marsh, or at least has some marsh on part of its border. There should also be growth of long grass and weeds adjoining, and also some shrubbery. About two acres of such to an acre of water is about right. A pond with a moderate area of reeds or flags growing from the water is a treasure. The deep-water or diving ducks, such as redhead and canvasback, habitually build their nests in such areas, out in the water, on floating bogs or amid aquatic vegetation, and in such surroundings they are much more likely to breed. If there is no aquatic vegetation in the ponds, it is an excellent plan to transplant it from some other marsh. If natural 


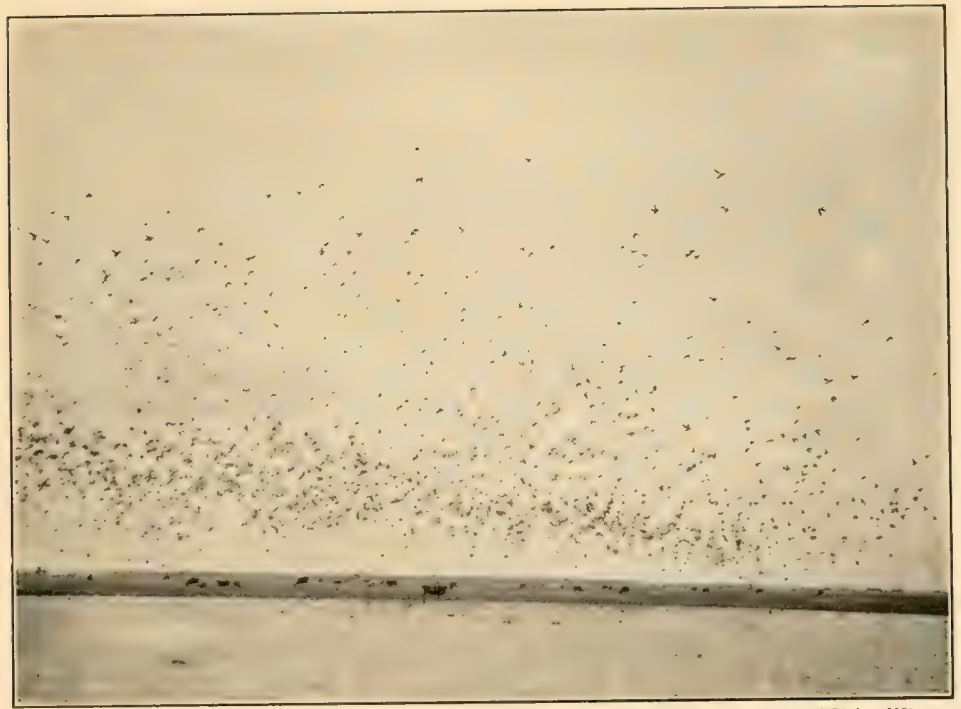

Vild ducks in Texas, showing opportunities for protection

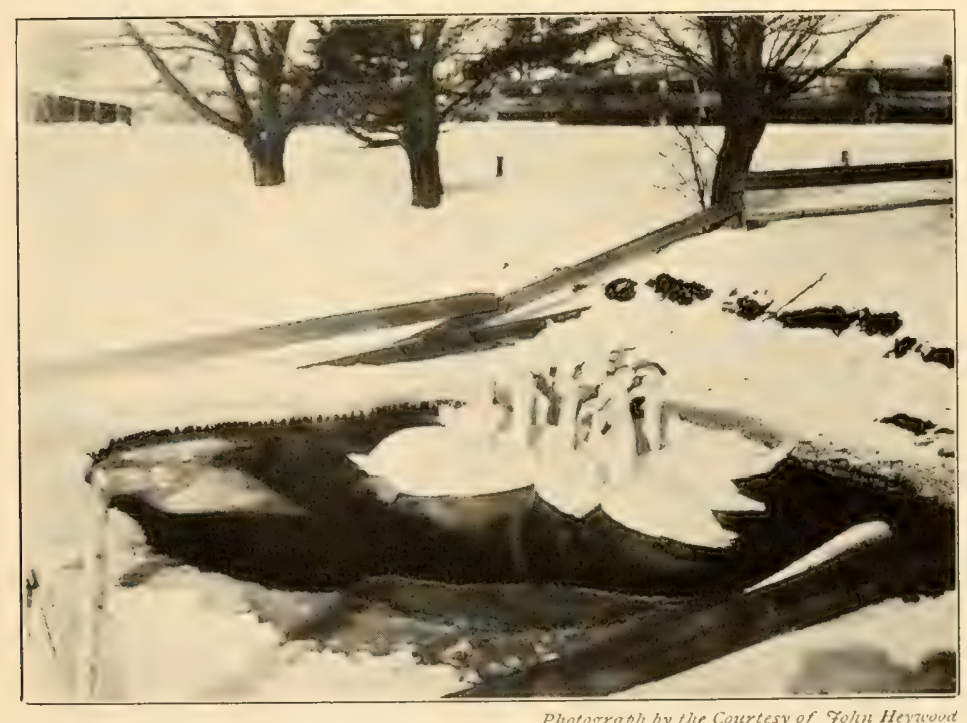

Swans in winter on Heywood Estate, Gardner, Massachusetts, showing how waterfowl keep open a hole in the ice 


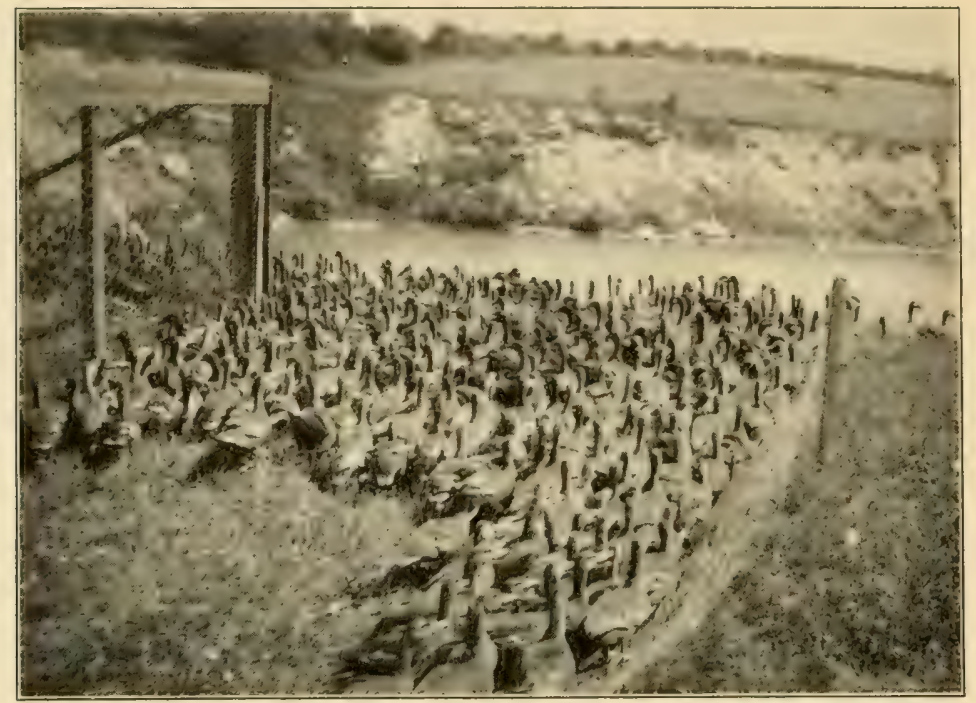

Mallards at feeding time, Clove Valley Club

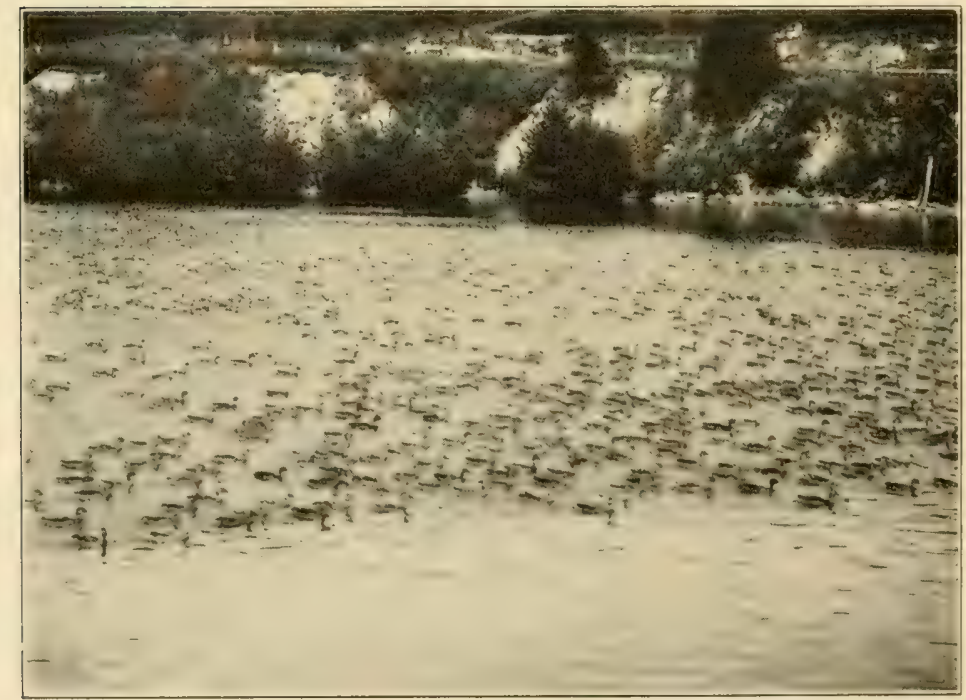

Young mallards raised at Clove Valley Club, New York, I9I4 
duck-feed, like wild rice or wild celery, can be started, so much the better, though ducks on a small pond are apt to exterminate it.

Islands. Out in the great wildfowl-breeding country of the Northwest there is no location more certain to harbour the nests of wild ducks than islets in lonely lakes, preferably overgrown with a tangle of low vegetation or thick grass. On one such grassy island in a large lake in Saskatchewan A. C. Bent and I found, in June, I905, over one hundred wild ducks' nests. In the grass or under low bushes were nesting the pintail, mallard, gadwall, baldpate, shoveller, blue-winged, green-winged, and cinnamon teals, greater and lesser scaups. White-winged scoters and American mergansers were flying about and certainly had nests. In the rushes just out from shore we found nests of the canvasback and redhead, and the ruddy duck also was nesting there. On the island I saw a brood of young Canada geese with their parents. So here, on one rather small island, were nesting sixteen species of native American wildfowl.

Islands are naturally so popular as nesting-sites that in a pond for artificial rearing it would be an admirable feature if there could be at least one island overgrown with thick grass and weeds. Where there are no islets, such might be constructed or some substitute afforded. An ingenious device is used on the Walcott estate in the main wildfowl pond. Here and there posts have been driven in the water, some rods out from shore, and board platforms have been built, just far enough out of water to be safe from flooding in heavy rains. Sloping boardwalks lead up from the water. The platforms resemble islands, being fixed up with cornstalks, rushes, grass, and brush. They prove to be popular nesting-places for both ducks and geese.

Avoid the Artificial. About the worst possible arrange- 
ment for a wildfowl breeding pond is to have the banks stoned up and steep, and all the surroundings cleared up for ornamental purposes. Waterfowl like to wade ashore in shallow water, and most kinds nest in low, thick cover.

Shelter. At least part of the pond should be sheltered from the cold winds, from west to north. Here a protecting bank is all right. It is well if the pond lies under shelter of woods or a grove. Otherwise thick hedges, say of evergreen or other tangle, should be planted, just back from exposed shores. These should not, however, be continuous, as opportunity should be given for breeding birds to retire into thick grass or weeds back from the shore, as some kinds normally nest in such locations.

Fencing. As would be expected, the area in which the ducks are kept must be fenced with wire, with a view, in this case, nearly as much to keeping out vermin as to retaining the ducks inside. Ordinarily the stock is either pinioned or wing-clipped, which will be discussed later. There is no necessity, as with gallinaceous birds, to alternate the ground, if overcrowding is avoided, so the fence may be permanent. Though a very low fence will keep in waterfowl, foxes can jump or climb six feet, and occasionally more. Eight feet is a good height, though some risk it at five or six. For other details of fencing, see Part I.

Ground Around Pond. The fence should never be built close around the pond, but always some distance back, preferably concealed by underbrush. Various species of ducks, notably the pintail, shoveller, gadwall, widgeon, teal, and others, in the wild state nest preferably in thick grass, weeds, or low brush, well back from the water. On the Western prairies I have found nests of the pintail in the dry grass about a mile from the nearest slough. Hence there should be a good area of open land enclosed with the slough 
or the part of the pond fenced off. At the very least there should be 3 o feet of long grass and tangle back from the shore, and 100 feet would be better. Another good plan would be to have the fence at least 30 to 40 feet back around the pond, and at one end an acre or two of meadow or pasture in the same enclosure.

Winter Shelter. During the greater part of the year waterfowl need no shelter whatever. For the most part they stay on the water, sunning themselves at times along the water's edge. When the pond begins to freeze they gather in a flock, and, by swimming around at night, keep open a small area. Ordinarily a duck is comfortable if it can keep its feet from freezing, and as long as it can stay in the water it is all right. Some owners of waterfowl keep their birds entirely in the open throughout the year. Usually the birds prefer to stay in the water, and will not go voluntarily to any house or shelter unless driven out of the pond. When there is an inlet or outlet, and hence a current, the water does not freeze readily, and the fowl will take advantage of this and select such a spot to keep the water open.

Extreme Cold too Severe. During some winters, however, there are very severe spells, during which it is exceedingly difficult to keep ducks from freezing in the ice during the night. In January and February, I9I4, there were two such spells in Connecticut and elsewhere, when the temperature dropped well below zero for several days. On several estates a number of the smaller or weaker ducks perished. On the Childs-Walcott estate, Norfolk, Connecticut, at high elevation, where the mercury dropped to $30^{\circ}$ below zero, the shovellers, which have a long fringe of bristles on the upper mandible, had their bills freeze up every time they dipped them in the water, and they were all lost. The stock was kept out in water where a brook flowed into the pond, 
but even here the keeper had to keep breaking the ice to free the ducks. At the end of the last spell they were nearly exhausted. Wild ducks, starving, came in and died on the pond. Finally an epidemic of pneumonia broke out, and a large number died, predisposed to disease by exhaustion and weakness.

On the seacoast, and in latitudes where the climate is moderate, it is well enough to keep the fowl out on the water all winter, as they remain hardy and in good condition to breed. Where the climate is very severe, even though the ducks come through the winter, their vitality is sometimes so exhausted that it seems to give a setback to breeding.

Learning from Experience. This winter, I9I4-5, at Norfolk a different plan is being tried. A sheltered paddock has been constructed, just inshore from where the ducks have their swimming-hole. A grove backs it to the north and west, and in addition a high fence of cornstalk thatch has been made. Close up under this fence, facing south, are low thatched shelters, with litter on the ground. Now and then the fowl are fed under these shelters, and food is left there for them. They have learned now to use these of their own accord in severe weather. The keeper closes the gate at night, especially to keep out foxes, and, when the weather moderates, breaks the ice for them. Already the temperature has been $24^{\circ}$ below zero, but not a duck appears to have suffered.

On the estate of E. C. Converse at Greenwich, Connecticut, the stock of young wild ducks, which stayed out on the pond through the severe winter of I9I4, mostly survived, but seemed weakened. This winter E. Aubry, in charge, is treating them like his Pekin ducks. Canvasbacks and all have learned to go of their own accord into a house, and are let out to swim during daytime. They are receiving a stimulating diet, and are looking splendidly. 


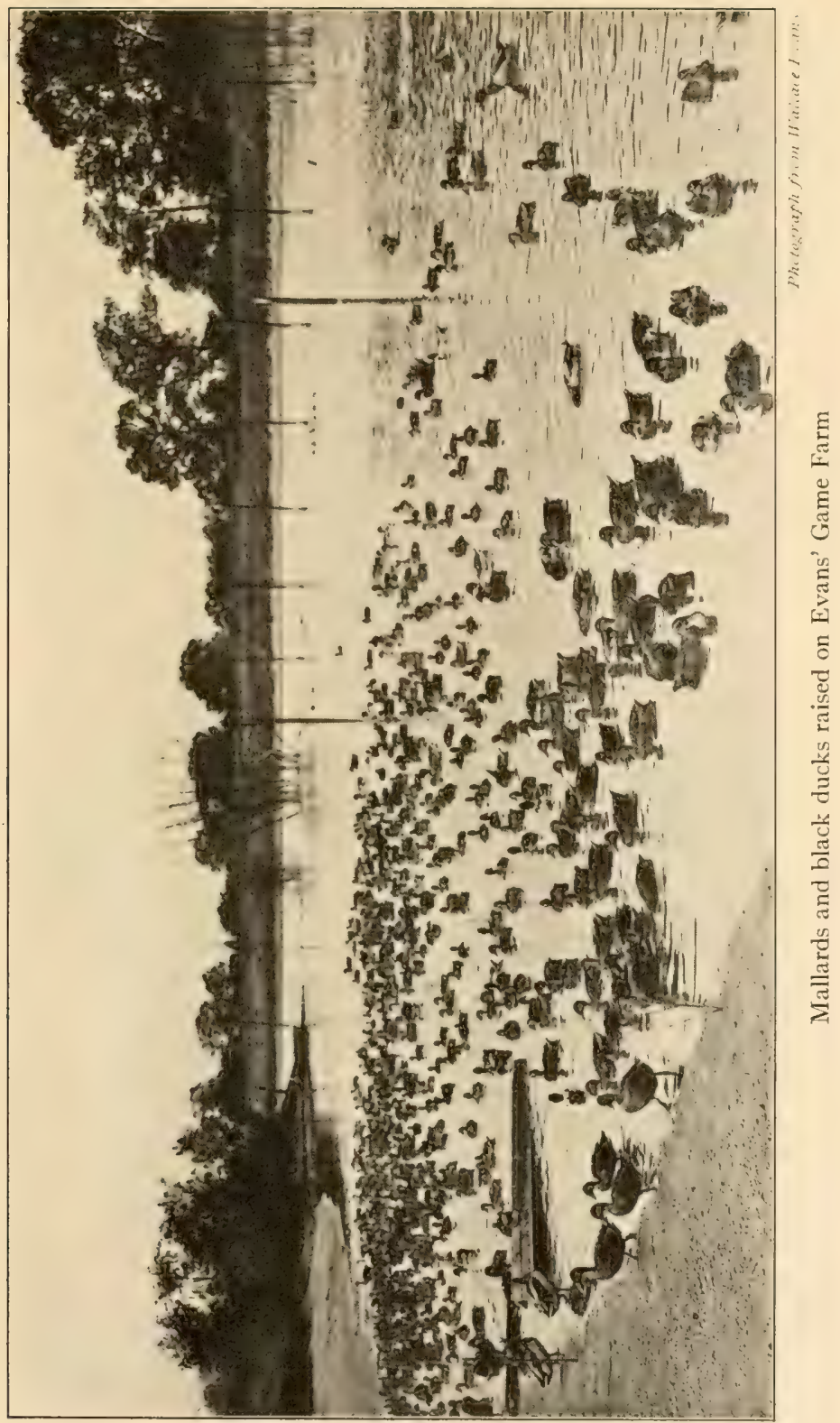




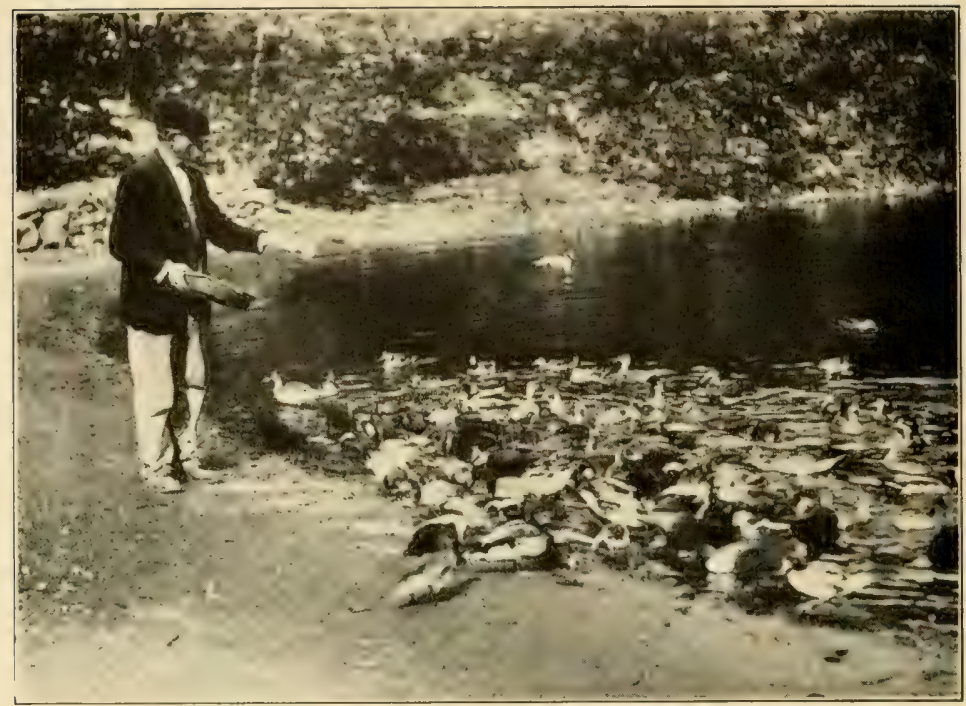

Henry Cook feeding some of his wild ducks. In this pond at this time he had nearly 200 ducks, representing twenty-six species

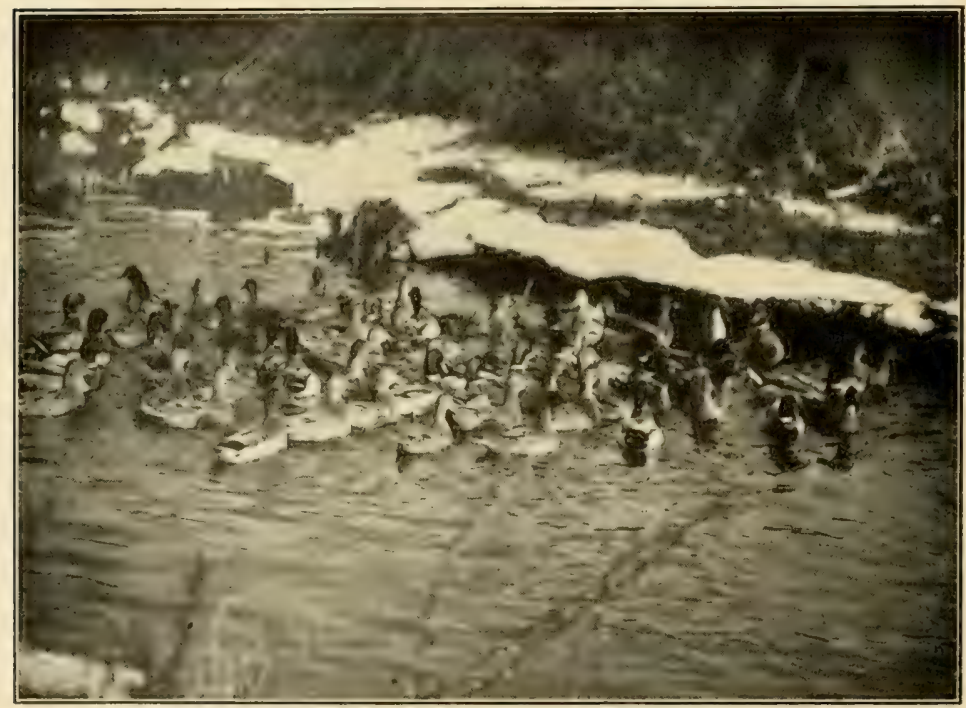

Mallards raised by a farmer in Connecticut, adding to revenue of the farm 
Method of Henry Cook. Henry Cook, of Woodbury, Long Island, New York, who has a fine collection of some thirty kinds of wild ducks on a small pond, has adopted such a method. Finding it hard to chase them out of the water, especially the diving species, he has, at the north end of the pond, a stone wall built out into the water, enclosing a very small area of the pond, only enough to allow the couple of hundred ducks he has to be all in the water at the same time. There is a gate connecting with the pond. Before very cold weather he begins feeding the ducks inside this enclosure. When the pond begins to freeze he closes the gate when the ducks are in to feed. Then he can wade out with rubber boots and drive them all out of the water and into the poultry house in the same yard, which faces south. No artificial heat is used. The ducks are kept in a rather small apartment, so that they will huddle together. On the floor it is well to have litter or chaff so that they can protect their feet, which are the vulnerable parts. In the morning, after the sun is well up, he breaks and scoops out the ice which has formed during the night in the small enclosure, and lets the ducks have their swim during the day. When the weather is moderate they are allowed to spend the night in the water, the house being used only for emergency. In this way the losses in wintering are small. Some such plans as these for our northerly districts, with their great extremes of cold, are doubtless correct.

Delicate Species. Only a few kinds of ducks are unable to endure low temperatures. Of our native North American ducks the blue-winged teal seems to be the most delicate, and the gadwall is rather tender, though with some shelter it survives Northern winters. Sometimes they get through the winter if they are housed at night, but they are apt to die off merely from the cold. Mr. Cook finds that though 
the adult tree ducks, from Mexico and farther south, are hardy enough to stand the cold, their full-grown young, which he raises, sometimes die in severe cold snaps, even in the house. Other kinds stand the cold quite well.

Of course a house might be arranged so it could be warmed slightly in severe weather, but ordinarily this is unnecessary, and such coddling, except for the few tender species, is liable to be overdone, and to make the stock less hardy. Everything depends upon local conditions whether shelter is necessary. It is always well, however, to have near the shore some covered frames or evergreen thatch, in case the fowl should need to use them.

Securing Stock. Stock should be obtained in late fall or early winter, if the birds are to breed the following season. At this season dealers can usually supply moderate numbers of various kinds of ducks and geese. Mallards are cheapest, from $\$_{3}$ to $\$ 4$ a pair, pintails and black ducks a little higher, other kinds ranging up to $\$$ I 5 or $\$ 18$ a pair, and occasionally more. Most of the native stock, except mallards and wood ducks, consists of adult birds captured wild, which are much harder to breed than birds raised in captivity. Eggs of wild ducks hatch well in incubators or under hens or tame ducks, and the young of most kinds are not hard to raise when one knows how. All such enterprises should be conducted under lawful regulation, securing more adequate legislation, if such be needed.

Monogamy vs. Polygamy. Ducks in the wild state are normally monogamous, so in purchasing stock even numbers of males and females should be secured. A seeming exception is in the case of the mallard. The ordinary stock is distinctly polygamous, and can be bred three to five females to one drake. This is in common with domesticated breeds of ducks. I am inclined to believe that all mallards which 
are polygamous have in them more or less of the domesticated strain. Some English records, according to Mr. Walcott, indicate that other species also of wild ducks tend to become polygamous in captivity.

Polygamy Abnormal. Henry Cook and his son-in-law, A. N. Frey, who have for years kept wild ducks of more than thirty kinds, including mallards caught wild, and have bred about twenty species of these, unite in testifying that they have never observed a single case of true polygamy. Mr. Frey writes me: "We have both failed to notice this habit (polygamy) even among the mallards (birds caught wild). Like all wild ducks they are strictly monogamous. It may be that the trait you mention could be developed in our own mallards under protracted domestication, since it obviously exists in their distant relatives, the barnyard mallards. On the other hand, a hybridizing tendency, such as a cinnamon teal leaving its mate for a wood duck, and females in want of males of their own species seeking the male of another, only to be refused, attracted our attention. In short, we have not noticed one instance of polygamy."

Receiving Stock. All waterfowl stock will come either pinioned or wing-clipped, so there is nothing further to do in that line. The one caution to emphasize is that for at least a week or ten days after shipment fowl should not be turned out on the water. The plumage is then dried out and disarranged, and it takes some time to restore it to the normal waterproof condition. If allowed the usual aquatic privileges at first, the birds are liable to become bedraggled and chilled. In case they arrive in poor condition, they should be kept from water for a longer period, sometimes three weeks, until restored. Give the new stock at first some extra nourishing food-some mash, scraps of raw meat, or green food. If they need to clean themselves at first, 
they may have a pan of water on a sunny morning, when not too cold, and later more frequently, until let out on the pond.

Pinioning vs. Wing-clipping. The problem with waterfowl hinges upon inducing them to breed under artificial conditions. Some species have never yet been known to produce fertile eggs in captivity, even though they may mate. Anything which would tend to prevent or retard the breeding function should be avoided. There is no question but that the operation of pinioning, or removing the last wing-joint permanently to prevent flight, does this to some extent. It affects the female more than the male, and often prevents her from breeding the next season when it does not affect him. In the case of species hard to breed, it is best to err on the safe side. The flight feathers are shed and renewed only in mid-summer. As they keep growing out, it may be necessary to repeat the clipping. At best catching ducks is a troublesome undertaking in a pond of any size, so many prefer to pinion the stock, but there is wide divergence of opinion in this matter. It makes no difference with the ordinary mallards, for they are sure to breed anyhow. Some experimenters who have been successful with various other species say that by judicious forcing methods of feeding the bad effects of pinioning can finally be nullified, among whom are Messrs. Cox and Cook. The young are in no way injured by pinioning.

How to Pinion. To pinion an adult bird, raise the little bastard wing or thumb of the wing, and tie a cord tightly around the bone of the wing at the last joint, well up under the thumb. Have ready some tannic acid, which is in powder form. With a pair of stout sharp shears or scissors clip off the bone close below the cord, removing all, or certainly nearly all, of the primary quills. At once take a pinch of the tannic acid and press it firmly into the wound, to check 
the bleeding. Some use boric acid or powdered calomel. The cord should be removed a few days later, when the wound is healing. Some advocate removing only part of the joint so as to leave about half of the primaries, allowing the bird to fly a little, though not high. This is so it can escape better from enemies, and is on the theory that it will feel more contented and be more likely to breed. I confess to being rather dubious about this, as birds partly pinioned are more apt to escape and perish.

Pinioning Young. Pinioning the young is a very simple affair. The best time to do it, if they are in good condition, is when they are from four days to a week old. Should they seem delicate, it is better to wait till they are thriving. At the early period there is hardly any blood in the wing, and most operators simply snip off the joint, dip the end in the acid preparation, and let the bird go. Hardly a drop of blood escapes, and the youngster seems to suffer very little pain or inconvenience. Some use the ligature as above, and this must be done if the operation is much delayed.

Trapping. General trapping of vermin in the vicinity should be carried on, and traps set outside the wire, as described in Part I. A few of the posts of the fence should be continued to the height of about a dozen feet, and small round spring traps set on top for visiting hawks and owls. The great horned owl is very destructive of ducks, and one should get busy at the first sign of his presence.

Food for Adults. All breeders use grain as the principal food, with some variations, and usually some forcing food during and before the breeding season. This is frequently a rather rich mash with some beef or fish dried scrap, or else some form of fresh fish food, and green vegetation also. Adult ducks are commonly fed morning and night.

The grain used may be ordinary mixed grain or scratch- 
feed. Components used by various workers are wheat, barley, buckwheat, whole or cracked corn, kaffir corn, whole oats, sunflower seed. It is not well to feed corn very heavily, but more can be given in cold weather, especially whole corn at night. Grit should always be on hand, mixed with a little ground charcoal, and also ground oyster shells.

Care in Feeding. Care should be taken to give only as much grain as will be eaten up clean when fed. Letting grain lie around is a very bad practice. It sours and is bad for the ducks, causing disease, and draws rats from near and far. Cracked corn sours especially soon, and should be fed in moderation and kept cleaned up. A good practice is to feed the ducks in shallow water near shore, at a depth of not over a foot and a half, where the shoal-water ducks can reach it by tipping up, and any remaining grain is visible to the keeper. Though rats can get grain from under water to some extent, a little there is not so conspicuous as on shore, and will not attract them so much. It is believed, moreover, that it is well for the health of ducks to get water with their food.

Following are some receipts for feeding, or hints from various sources, which give a good idea of methods in general use:

Receipts. New York Zoölogical Park: Wheat, barley, buckwheat, and kaffir corn or ordinary cracked corn, mixed in even parts. A little chopped raw meat and fish are used, three times a week, especially in severe winter weather or at the beginning of breeding. For the meat, any sort handy can be used, such as liver or other inwards, or, on game preserves, ground-up bodies, such as rabbits, hares, cats, or captured vermin. On the other alternate days, at such times a mash of Spratt's wild-duck meal is used. In winter they also give cabbage or cooked beet every day if they have 


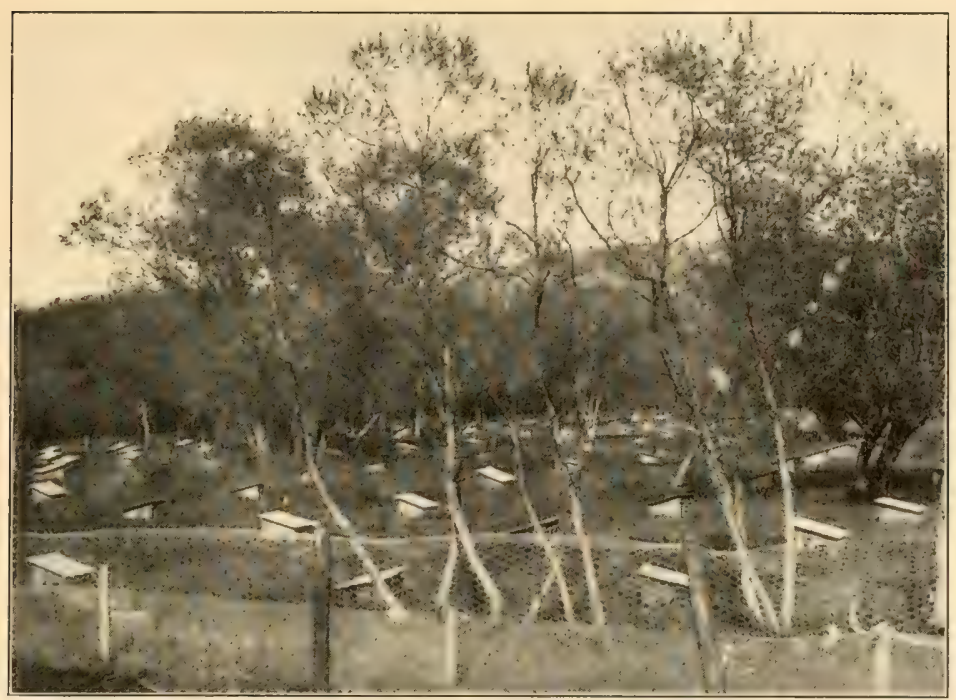

Whotorrath by Thorn L Germus

Rearing-field for mallards, Clove Valley Club, New York

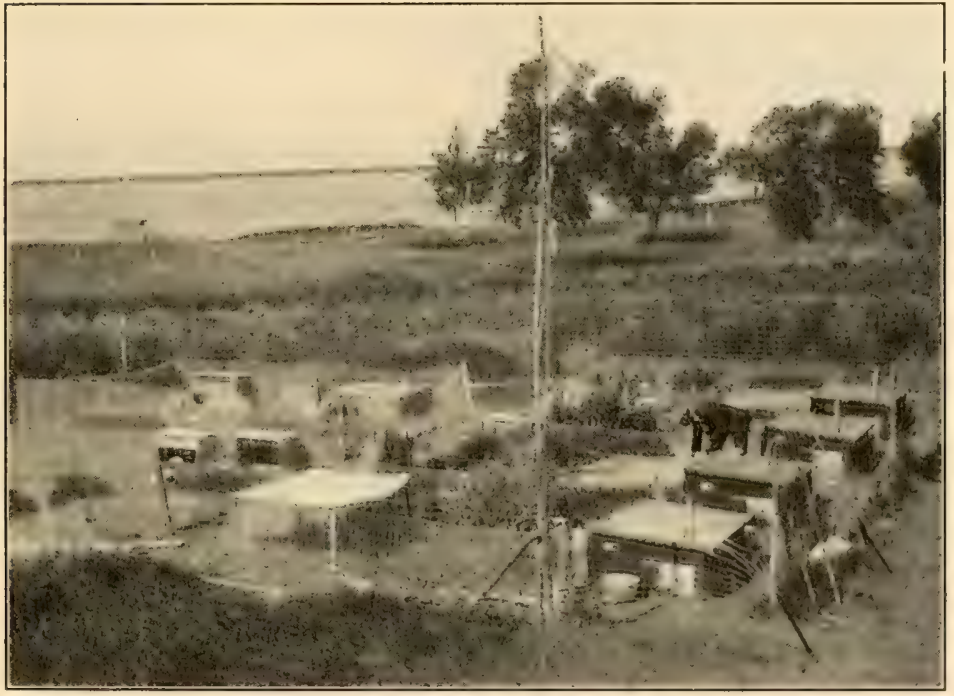

Our "duck farm" in Manitoba wilderness, the author feeding ducklings in brooder yards 


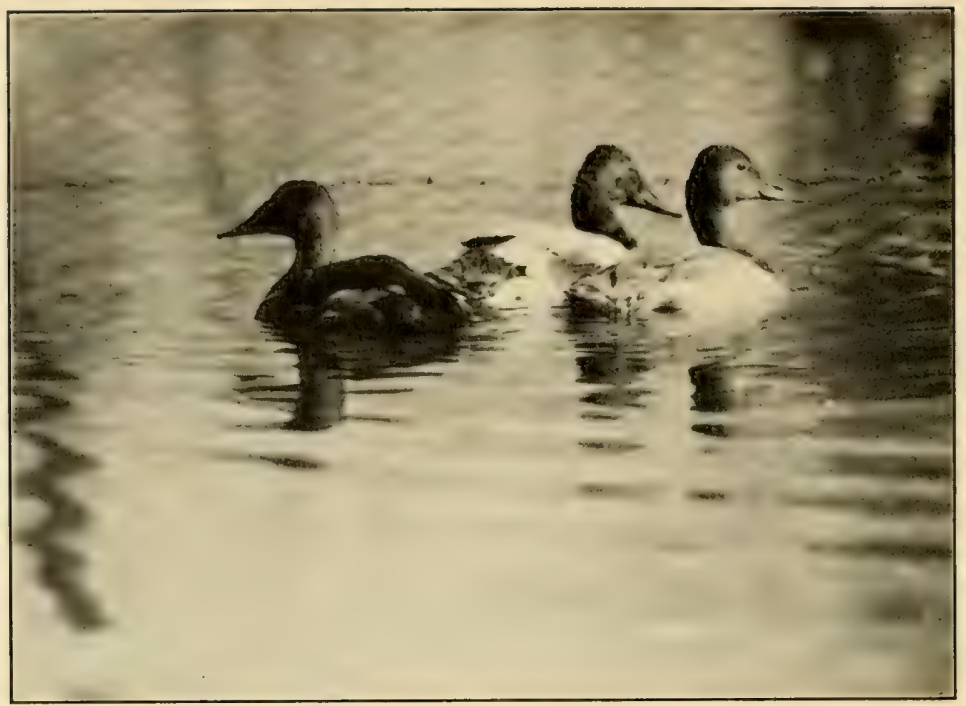

Canvasbacks in artificial pool, winter quarters

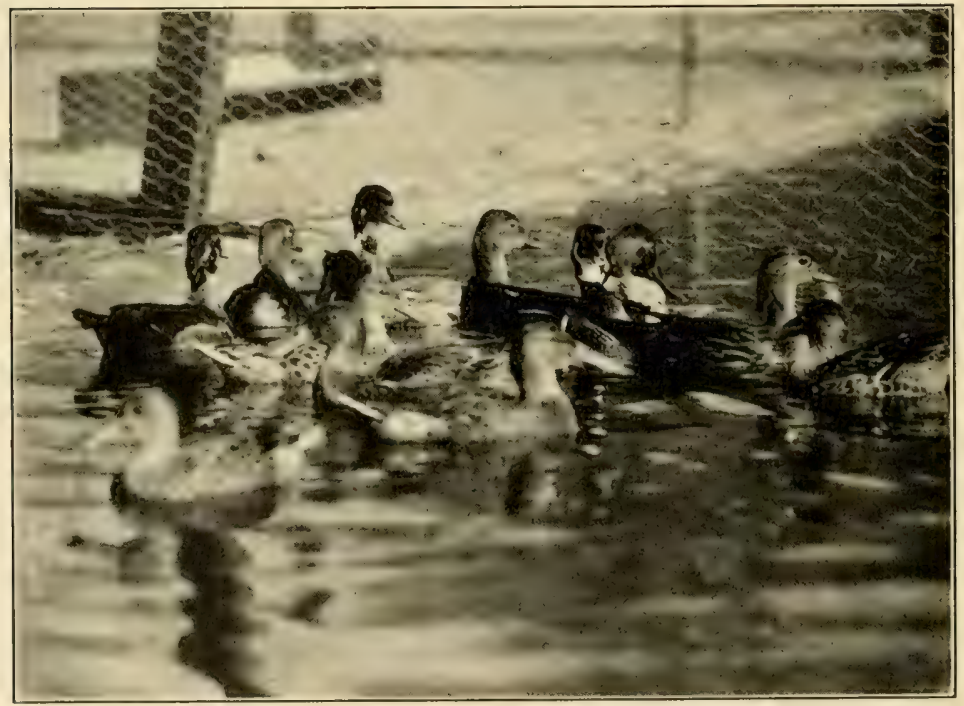

Wild ducks in winter quarters: Wood ducks, shovellers, canvasbacks, and pintails. All but the wood ducks are young raised on Manitoba Expedition 
enough. A variation on this grain receipt is employed by Colonel Kuser, Bernardsville, New Jersey, in which during summer the corn is left out and more buckwheat substituted. Others use only corn and wheat or barley for grain.

A. G. MacVicar, on the Walcott estate, for a winter diet is feeding the ducks and geese mostly whole corn for the grain ration, but gives a change once a week to wheat, buckwheat, and barley. Barley he considers an excellent food for ducks. In the warm season, of course, not so much corn is used. Besides the grain, he feeds chopped turnip and cabbage, giving this in the water, so it will not freeze. In spring he begins giving mash, of barley meal, Spratt's pheasant and duck meals, and crissel, the latter not over Io per cent. These are mixed and scalded together. Another mash, used for variety, is of cornmeal, bran, middlings, and crissel. He feeds the mash mornings and the grain at night. On cold mornings in early spring he delays giving the mash until it warms up enough not to freeze. He does not give crissel separately, nor allow dry mash to stand before the ducks, thinking that they get too fat.

Henry Cook uses a grain mixture of wheat, kaffir corn, corn, buckwheat, barley, whole oats, sunflower seed. In winter he also gives cabbage, and sometimes has ground-up raw carrots, though they do not care so much for this. He also gives lettuce in season, watercress, or other succulent growth. In winter and spring he also gives clear beef-scrap, scalded and soaked, in a trough, renewing it when eaten up, and keeping it before them most of the time. If it freezes he pours hot water on it. They eat only a little at a time thus, and it never has hurt them.

Neil Clark, of the Clove Valley Club, New York, keeps the mallard breeding-stock out on a marshy pond and connecting brook all winter without shelter. They pick up a good 
deal of natural food, and he gives them only wheat and cracked corn in addition.

E. H. Austin, Gaylordsville, Connecticut, from October and on, gives mixed grain or scratch-feed, sometimes with a little dry beef-scrap mixed in. The ducks spend the day in a brook and meadow area fenced off, and in winter are driven up at night and shut in an ordinary poultry house.

Forcing Foods for Laying. The following are some of the feeding receipts for help to egg-production. Usually the change of feeding is begun quite early in the spring, generally early March. Mashes should preferably be scalded and left for about half an hour to swell, being mixed only crumbly moist.

Mr. Austin's receipt is: shredded alfalfa, 6 quarts; ground corn and oats, 2 quarts; beef-scrap (never any but best grade), 2 quarts; a handful of linseed meal. He keeps this before them all the time.

The forcing-mash used by E. Aubry, poultryman of Edmund C. Converse, Greenwich, Connecticut, is as follows: Ground oats, Ioo parts; bran, 50; cornmeal, 20; linseed meal (old process), 20; gluten, 20; sifted beef-scrap, 25; alfalfa meal, 25. Two or three times a week he puts in a little cracked corn, at the rate of a handful for half a dozen ducks. Unlike most breeders, he gives this mash practically the year round, but in winter doubles the cornmeal to 40 parts, reduces the ground oats half, to $5 \circ$, and reduces the beefscrap to ${ }_{5} 5$, in severe weather 20 . Too much of the latter at this season brings on liver troubles. He uses Swift's beefscrap. A. G. MacVicar does not use beef-scrap in winter at all. The mash is given in the morning, and grain at night, sometimes only cracked corn, especially in severe weather. He also makes a practice of keeping always before the ducks, in troughs on the shore under shelters, 
this mash in dry form. I have watched the ducks and noticed that all kinds, even the canvasbacks, at frequent intervals go ashore and eat a little.

Following is the forcing-mash used in spring by Neil Clark: Cornmeal, bran, mixed feed (of bran and middlings), cracked corn, wheat, Spratt's duck meal, and crissel. Adam Scott, on the Schley preserve, uses simply ground alfalfa, scalded and soaked, for extra forcing just before laying time.

Problem of Wildfowl Breeding. In the case of the gallinaceous species, the most difficult practical problems are in rearing the young and avoiding epidemic diseases, rather than of inducing them to breed. With waterfowl the opposite is true. The young are not hard to raise, and, with reasonable sanitary precautions, epidemics are unusual. With most kinds, the one troublesome problem is to make them produce fertile eggs. The mallard, however, is the notable exception to this rule, for they breed almost as readily as poultry. The degree of difficulty in this matter varies with different species or groups, as will be described.

Breeding Mallards. When reference is made to breeding wild ducks, it commonly refers to mallards, as the great majority of wild ducks raised are of this species, both in America and abroad. This species, therefore, truly stands in a class by itself. The mallard has been bred for generations, and has become thoroughly domesticated, some strains having become mere barnyard fowl, unable to fly, fit only for food and market purposes. There is plenty of stock, however, which has all the traits, form, and activity of true wild birds, and yet is easy to breed and control. But constant care must be taken to introduce into a breeding-stock fresh blood by changing drakes, or it will degenerate into the clumsy barnyard type.

Mallards captured wild are reluctant at first to breed, 
though I think rather less so than other kinds. But the usual hand-reared stock breeds regularly and easily. All that is needed is the usual small pond, with arrangements as previously described, including feeding. Any sort of land around the pond will do. Dry land is as good as marsh, and there need not be so much of it as for some ducks. They will lay almost anywhere, using any sort of shelter, such as brush-piles, boxes, coops, wicker baskets, logs, stumps, grass, or other growth, and the like. To some extent they may drop eggs around the pen, or even in the water. They are not easily disturbed, and eggs can be collected from the nests daily, if desired, leaving a couple for encouragement. With other species nests should not be disturbed until laying is completed. Laying may begin about the first of April or earlier.

Wood Duck. Another species which it has proved not difficult to breed is the wood duck, which is one of the most elegantly coloured of our North American birds. It is a gentle, docile species, and is very easily kept in captivity. Strange it is that until quite recently it was bred very little in this country, but in large numbers abroad, particularly in Holland and Belgium, so that nearly all our breeding-stock for sale came from those countries. American dealers made trips there, bought up these birds from the farmers, and shipped them over here. Now they are bred and raised here quite extensively, yet there is such demand for them that prices still remain high, and rearing them is very profitable.

Breeding Methods. The methods employed for feeding and breeding them are not different from those with other species, except in regard to their nesting. In the natural state they breed in hollow trees, and in captivity in elevated boxes. The best way is to drive a post out in the water, 


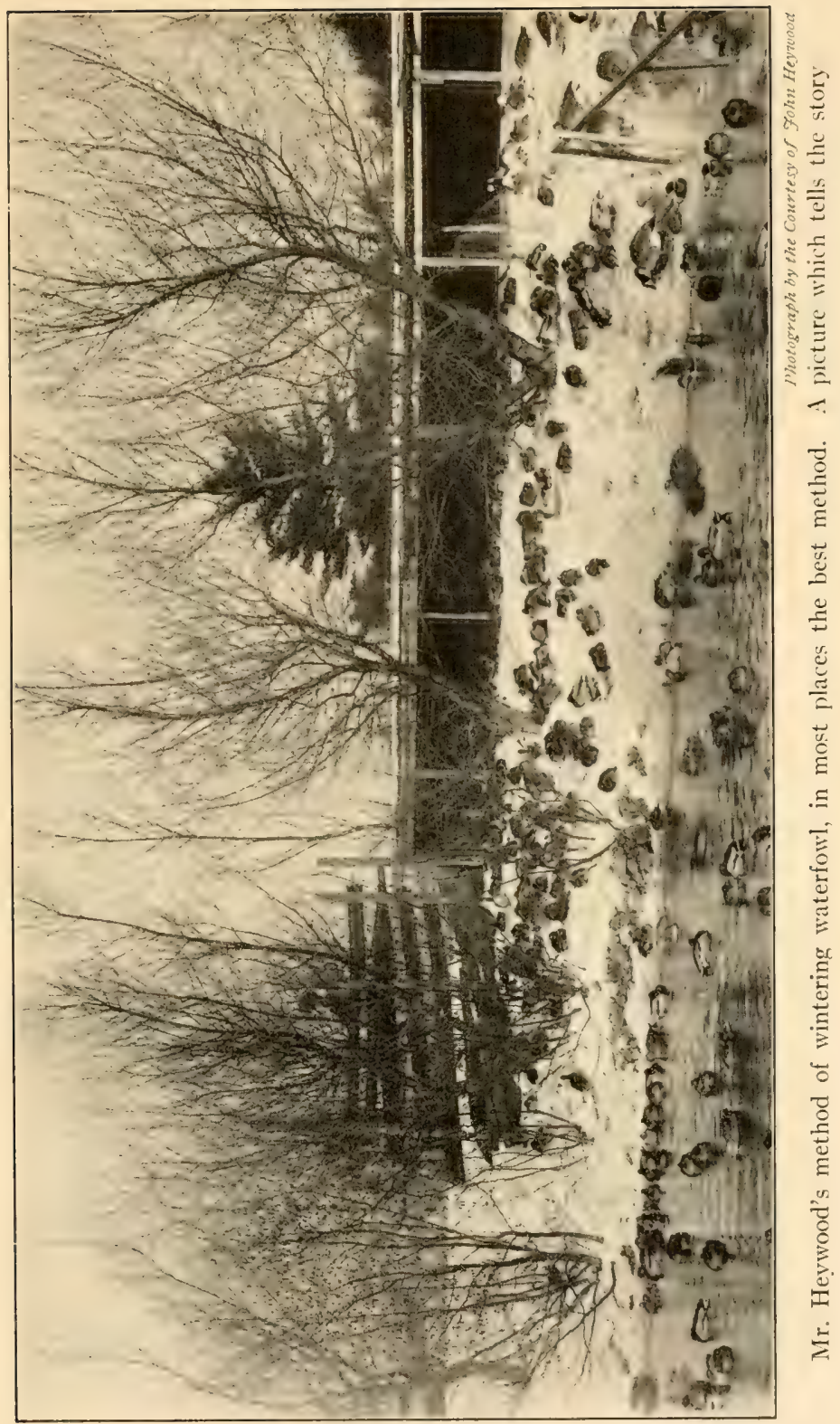




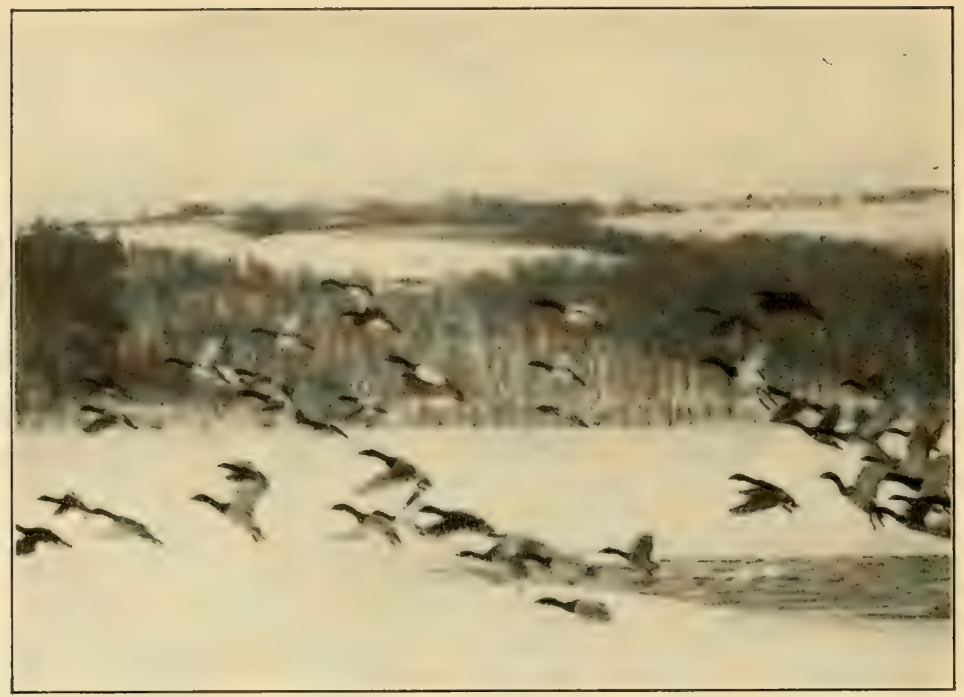

Photograph by Verdi Burck

Canvasbacks at Branchport, New York, March 3, I9I4

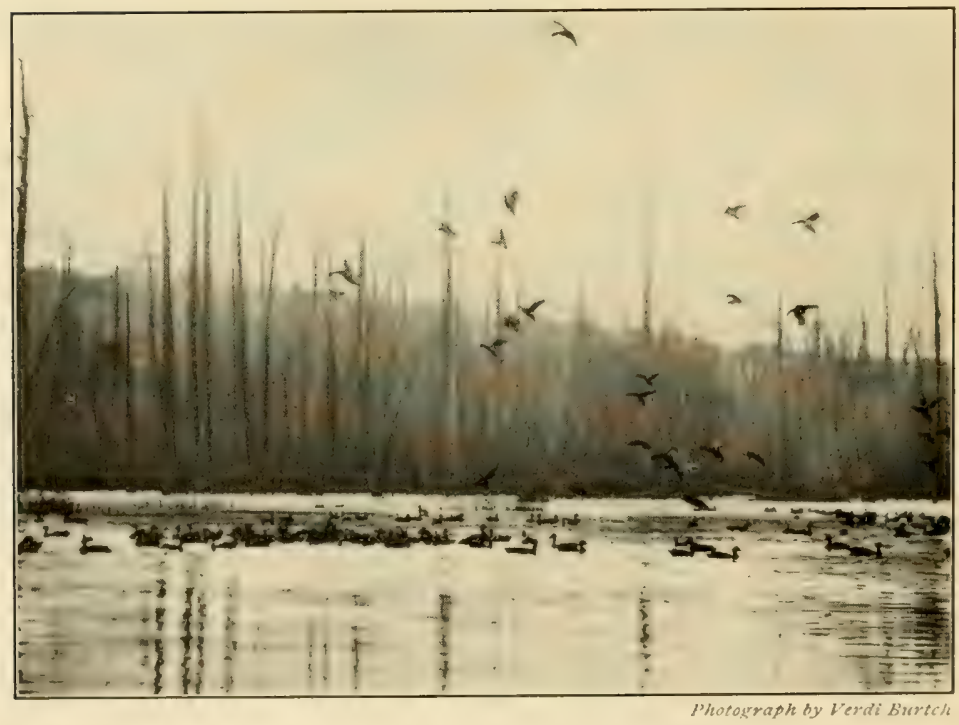

Canvasbacks at Branchport, New York, March 3, I9r4 
projecting any moderate distance, say two feet. On top of this the box should be nailed, with an entrance hole in one end, and a boardwalk leading up to it from the water, with small cleats nailed across it, to furnish an easy ascent. Some locate the box on shore, in which case it is well to have the board leading up from the water, though it may be back from the shore, especially under trees. I advise, however, placing it out in the water, on the principle that the birds feel, and doubtless are, more safe there from vermin, particularly the common brown rat. On the same principle, for most ducks a small island, with thick vegetation, is the most attractive possible location, for there they feel safe. The first set should be taken as soon as finished, and set under a bantam or small hen. Then the duck will usually lay a second, which she may be allowed to hatch if the pond is small and free from vermin. These ducks are so docile that they do not teach the young to be very wild.

If young are allowed to fly, as described farther on, boxes can be put up in trees, near the edge of groves or woods, just back from the pond, either plain boxes or the hollow $\log$ of the Von Berlepsch type. Even the pinioned birc's will breed in boxes low down in trees, as on sloping willow trunks near the shore. A number of such are used by wood ducks on William Rockefeller's estate.

Boxes should have an opening of about 4 by $4 \frac{1}{2}$ inches, which is the right size to admit the wood duck, but will keep out larger kinds, especially the mallard. The hole should be near the top of the front. A suitable size for the box is about one foot square, with hinged lid which slopes a little to shed rain. This model is employed successfully on the Walcott estate.

Black Duck. The black duck, sometimes also called "black mallard" in distinction from the regular mallard, 
which is often known as "gray mallard," is the common resident wild duck breeding in Eastern districts. It is of a naturally shyer disposition than the mallard, and does not breed as readily in captivity. Black ducks, however, frequentlybreed when enclosed in a good-sized marsh or swamp, with plenty of low cover, preferably from two to four acres, and given almost absolute privacy. Ordinarily wild stock will not breed under "civilized" conditions which satisfy the mallard and the wood duck. It seems to fail to breed largely because of its shyness, though perhaps partly from lack of certain food elements.

The Pintail. The pintail is a good example of individual difference in closely related species. It is very docile in captivity, and apparently comes next to the mallard and wood duck, among native species, in readiness to breed. It needs, however, a little special treatment, especially in the way of natural marsh and grass, for "grazing" and catching insects, supplemented by receiving artificially more animal and other stimulating food. This species, I believe, is destined to become one of the most popular wild ducks to propagate.

Two Main Difficulties. Clearly the two main obstacles to successful breeding of wild waterfowl are, first, lacks in natural food elements conducive to fertility, and, secondarily, docility or mental state. The latter is usually overcome after a period of captivity, but the other is the real problem.

Mental State. That docility, or mental state, is also an important factor is shown by the fact, recognized by breeders of wildfowl here and abroad, that young hand-reared stock is almost sure to breed under proper conditions. The main practical need is to get started stocks of hand-reared young birds of the various species, which would tend to breed more and more readily through successive generations. In time, 
no doubt, many species, particularly of the "river ducks," could be domesticated like the mallard. In case of some species, as has been done in Europe, such stock could be started from wild eggs under legal regulation. Some kinds, however, nest in rather inaccessible northern wilds.

Wild vs. Hand-reared. An illustration of the difference in willingness to breed between adult ducks captured wild and young of the same kind reared by hand is the following: A single female pintail was hatched by E. H. Austin from a setting which I sent him by express from the Northwest to New Milford, Connecticut. This duckling became the mascot of the farm, flying around at liberty, yet running after her master like a dog, and never thinking of leaving. He got a mate for her the next spring, which hurt its leg and went lame. The duck made a nest in the grass near the house and laid six eggs, which proved to be infertile. Adult pintails captured wild, on the other hand, though they have in time bred in captivity, have to be managed very carefully. Under the above barnyard conditions their breeding would have been inconceivable.

Immediate Problem. The more usual facilities, however, are through breeding captured wild stock, which can generally be obtained from dealers. The immediate problem, therefore, is so to handle and feed such stock that fertile eggs can be secured. Though wild captured birds do not breed readily, in many cases, through care and patience they have been made to do so. Probably all our "river ducks" have been thus bred on a small scale. The marine ducks present a harder problem, but the redhead and scaup have been bred in this country, and the related pochard, the tufted duck, the eider, according to Mr. Walcott, and perhaps others, have been raised abroad. No one as yet seems to have bred the canvasback, but, since it is so similar 
to the redhead, there seems to be no inherent reason why this may not soon be accomplished. It is best to start with a small stock, and increase it by careful breeding.

Long-sought Methods. After years of experimentation methods have been discovered by which wild ducks of various kinds have been made to breed successfully. One of these methods has been demonstrated by the late Wilton Lockwood, the artist, and by John A. Cox, on neighbouring estates on Cape Cod, Massachusetts, at South Orleans and East Brewster respectively, and also in part by Henry Cook, already mentioned. By this method the ducks are kept on a natural marshy pond, with aquatic vegetation, preferably small overgrown islands, and plenty of marsh or pasture land in the enclosure with the pond. Early in the spring, when they show signs of mating, they are given minnows or any small fish alive about twice a week. Wallace Evans feeds small fish twice a week, two feeds each time. The most approved method is to give them in a trough, in water. They can be caught on the seacoast or in rivers or lakes in set traps or nets. Small-mesh nets are baited, set in shallow water, and drawn up when the school of fry is after the bait. This method is also quite frequently employed in England.

Horseshoe Crabs. Besides the minnows, Mr. Cox also secures, on the flats of Cape Cod Bay, horseshoe crabs, which he says can at times be gathered by cartloads. In spring the female crab is full of eggs and other gelatinous matter. Only females are used. They are cut open underneath, and the ducks allowed to help themselves, which they do eagerly.

Species Bred. This system is so successful that nearly every species experimented with bred, except canvasback and lesser scaup, which did not, however, have a fair chance, from lack of stock. Mr. Cox has bred numbers of the fol- 
lowing American species of ducks: redhead, pintail, gadwall, widgeon, shoveller, green-winged and blue-winged teals, wood duck, black duck, mallard, besides the mandarin duck and other foreign species. He had but one pair of canvasback and one of lesser scaup. The above did not merely have one brood or an occasional one, but they all bred every year, and did well. Of some kinds he reared as many as fifty young in a season. It was not from choice selected hand-reared birds that he bred, but from ordinary wild stock, mostly pinioned, which he bought in the general market from the regular dealers, doubtless wild trapped birds. The eggs were usually nearly all fertile. A large percentage hatched, and he raised most of them to maturity by methods later described.

Pond and Enclosure. The pond and enclosure comprise about four or five acres. Here the ducks remain outdoors all winter without shelter other than bushes on the shore. The climate on Cape Cod in winter is raw and chilly, but the mercury seldom reaches zero, and there is not much snow. The pond was partly excavated, and small elevations were left to form islands. These were planted with a common yellow garden lily which thrives in moist places and grows very rank, making admirable cover to conceal nests. The redheads were fond of nesting under it, just up from the shore, where they could slip off into the water, as is characteristic of the diving ducks, which walk awkwardly. The field ducks, such as the pintail, shoveller, teal, and others, nest well back in the grass. Most of them usually laid a second set when the first one was taken fresh, though not all. None of them was known to lay a third set, as domesticated mallards will do.

Young Valuable. The young he raised were in great demand for breeding-stock. An advertisement in Country 
Life in America brought requests from nearly every State and from abroad, and all he could spare were sold at good prices. He bred them for a number of years, and each year the result was about the same.

Methods of Lockwood. Mr. Cox described the methods and success of Mr. Lockwood as identical with his own. This was confirmed by a letter from Lockwood, written shortly before his death, to F. C. Walcott, which Mr. Walcott kindly let me read. He fed the live minnows to his ducks, like Cox, but did not mention the crabs. The pond and swamp enclosure, with islands in the pond, was about the same in size, four acres. He mentioned that the fence enclosing was 6 feet high, of $\mathrm{x}$-inch mesh, with an I8-inch overhang, to protect the ducks, which were pinioned, from cats and minks climbing over. He also had traps on poles. He advised planting areas of cat-tails, and emphasized avoiding overcrowding of ducks on the pond. All kinds were in together, as with Messrs. Cox and Cook. Breeding began about the first of April.

Tank of Minnows. The tank in which the live minnows were given to the ducks was six feet long and one foot deep. The ducks, especially the diving kinds, in their eagerness made the water fairly boil.

Protection. If the pond has no good cover near it, he advises making an arbour, about I $_{5}$ feet square, beginning a couple of feet from the water, covered over with brush. The ducks use it for shade and to hide from enemies. He warns against turtles and rats, and advises dynamiting the pond if it harbours anything which attacks ducks.

Species Bred by Cook. The methods of Mr. Cook are similar, but his pond is not so good, being without marsh adjoining it. Hence, the laying is more irregular, and fewer birds mate and lay, though he has secured at least some eggs 
from nineteen species of a total of thirty-two in his collection. Most of those that breed lay their eggs under bushes and sprouts in a strip of woods, and some kinds, such as pintail, shoveller, and teal go back of this into a strip of open grass and weeds, formerly a cultivated field, where they nest. Mallards, black ducks, gadwalls, and various foreign species nest in the wooded strip, among bushes, beside stumps or logs, or in rotted-out hollows in stumps. Redheads lay on grassy banks close to the water. Wood, mandarin, and tree ducks nest in boxes or in hollow stumps. Besides the above species, the following also have bred: green-winged, cinnamon, pampas and warganey teals, red -billed and fulvous tree-ducks, European widgeon, Bahama duck, rosy-bill, spotted-bill, and Australian duck.

Live Food. Mr. Cook feeds his ducks some live minnows in spring. Also at times he brings them watercress and other pond weed which frequently are covered with waterinsect life. Such insect life he thinks is a considerable factor in the breeding of wild ducks. He has found that when captive wild ducks are put in a new pond, where such life abounds, the laying is materially increased. After a season or two, unless a stream enters the pond, the insect life is depleted, and egg-production decreases. He believes that the breeding of wild ducks is largely a matter of having proper natural food, especially animal food, which must be supplied in some form.

Fish Diet as Stimulus. The value of a fish diet as stimulus to reproduction is indicated by an experience of which I was informed. On a commercial duck farm, where Pekin ducks were raised, it was the practice in late winter to secure fish heads and other remains at the wharves where incoming fishermen dressed their fish. These were freighted by the barrel to the inland farm, and boiled in cauldrons until the 
bones dropped apart. Then the entire mass was given to the ducks, who stripped the bones of every vestige of flesh or skin. It was said that this started the ducks breeding a month earlier than usual, and the eggs averaged much higher in fertility than early eggs are apt to do. This resulted in a stock of early broilers ahead of the season, at highest prices. The fish diet, however, Wallace Evans says, can be overdone and cause indigestion. About two good feeds a week seems the consensus of opinion, but the more green vegetables that can be grown the better.

Cases of Skipping. For the encouragement of any who try these methods without immediate success, a few further suggestions may be of value. Even under the best of conditions some fowl will skip laying, especially the first season. Mr. Cox found that stock imported from England was harder to breed than freshly caught wild birds over here. Moreover, some species are probably slower to adapt themselves to changed conditions than others. Mr. Lockwood wrote, for instance, that redheads which he purchased usually did not lay till the second season after. Again, ducks which have been kept for years without breeding, owing to unfavourable conditions, may tend to have their sexual powers atrophied or retarded. Though perhaps unlikely to breed again, they may do so, as I have known this to occur, even after a respite of several years.

Retarded Breeding. Furthermore, not all young ducks raised artificially breed when a year old. A successful breeder of wood ducks told me that much of his young pinioned stock does not breed till two years old, though broods hatched early and fed carefully would breed the next season. Lack of active exercise in flight and of the normal amount of insect and other food which they would have secured in the wild state probably causes slower development. Hence 


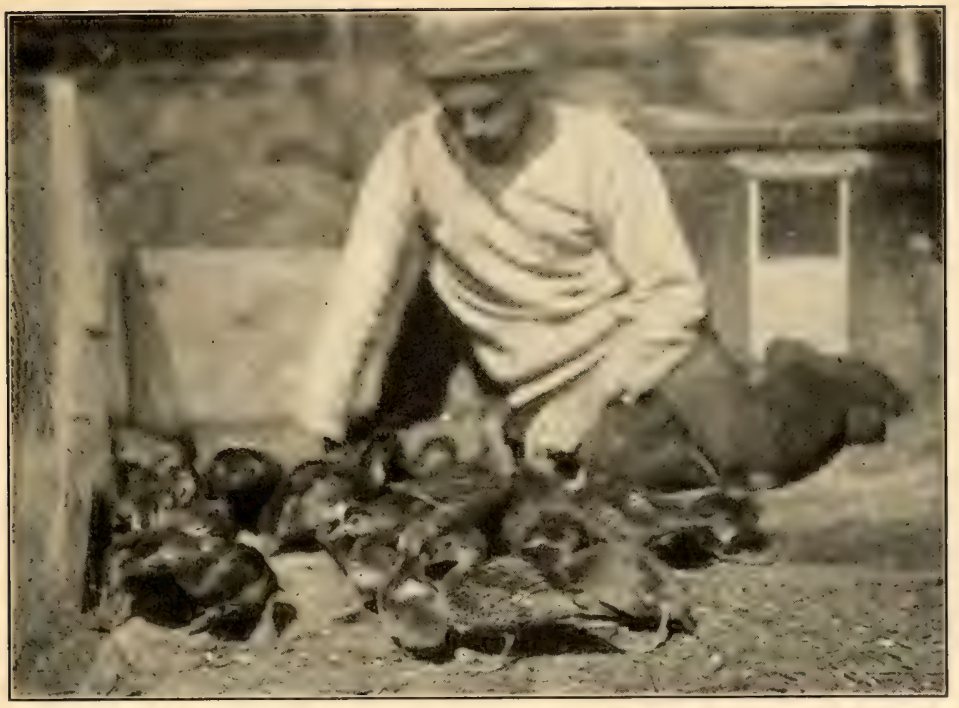

Son of author, G. Curtiss Job, on Manitoba expedition, feeding "wild" ducklings-gadwalls, redheads, scaups, etc.

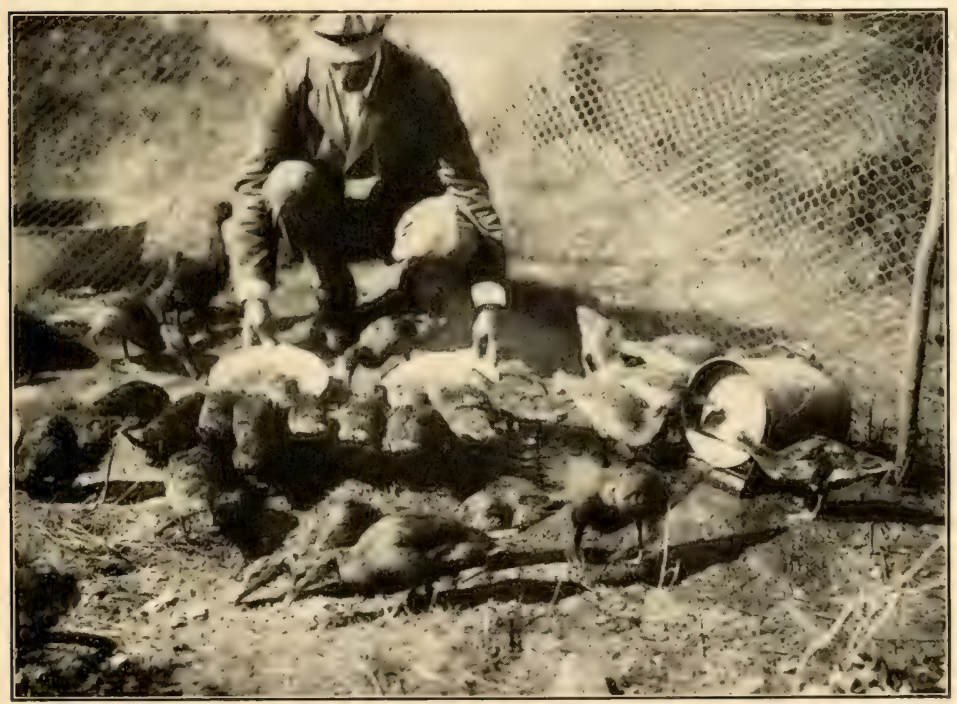

Author feeding young wild ducks in Manitoba, nearly full grown 


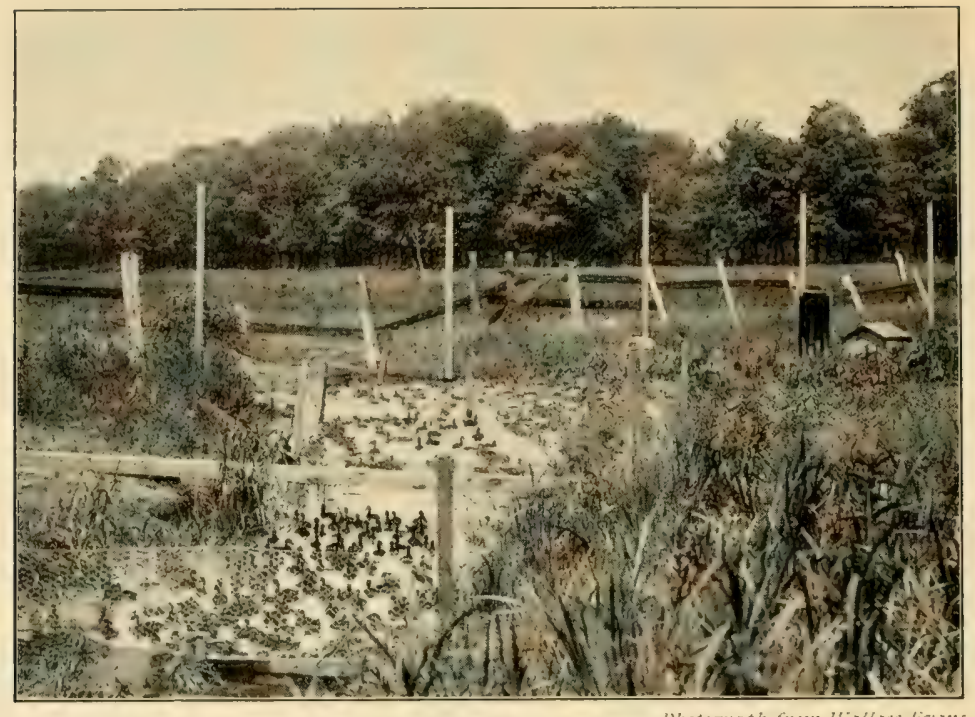

Method of rearing young wood ducks on Evans' Game Farm

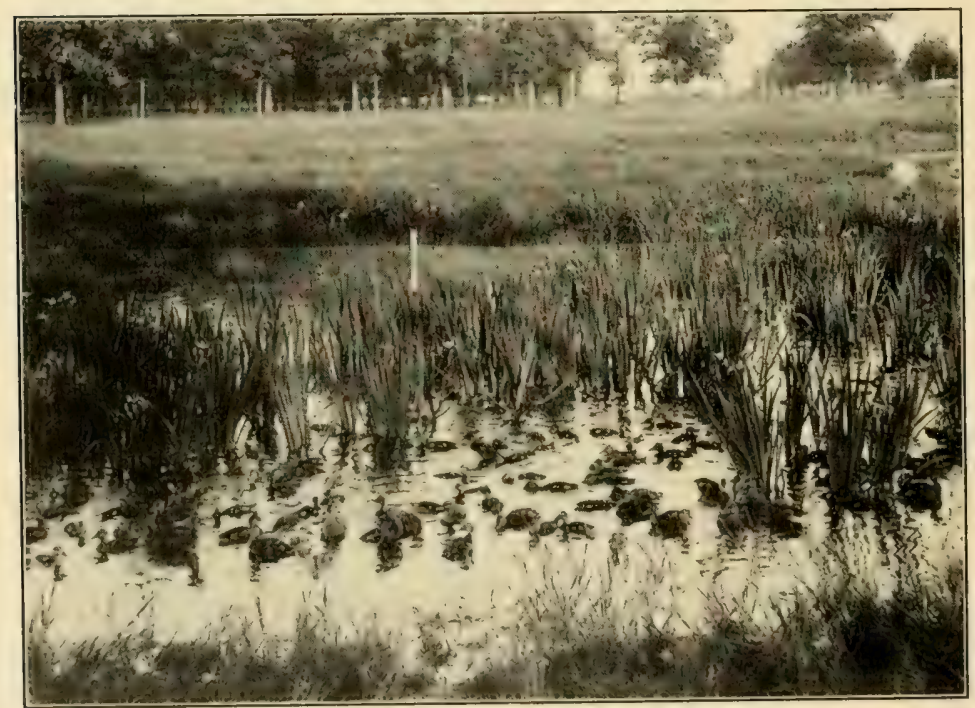

Good-sized ducklings in fenced marshy area on Evans' Game Farm 
one should not become discouraged too soon. That handreared ducks of practically all kinds will breed is proved by experiments in England, as well as by those of Lockwood and Cox; the natural food, the condition of the water, and the climate being important factors.

How Overcome. As a case of ducks breeding after years of intermission, and of the means of bringing this about, the experience of Dr. A. F. Warren, of Chicopee Falls, Massachusetts, is instructive. Doctor Warren came into possession of about five green-winged teals, which he kept in a city backyard. To make proper quarters for them, he made a cement pool, set out shrubbery and various plants around the shore, and back of this allowed grass and weeds to grow rank. Also he had a small shelter-house for winter. For the first years there was no sign of breeding. Thinking that animal food might start them laying, he began giving them a considerable quantity of earthworms. In the fall he accumulated a quantity of these, kept them in earth in the cellar, and fed them to the ducks during winter. In the spring of $19 \mathrm{I} 3$ a male and female paired and built a nest, but did not lay. Next year this pair made nests and produced several eggs which were fertile, but had shells too thin to stand handling, owing to lack of lime constituents in their food. The other female would probably have bred, but the other drakes would not have her, one being vainly infatuated with the mated female. Doctor Warren watches them for hours and days from concealment, and he has material for a wonderfully interesting monograph on the courtship and mating habits of this species. Barring accidents, he will probably next season breed and raise wild ducks in a tiny city backyard, and that, too, adjoining a most noisy industry, well calculated to terrify anything wild.

Keeping Marine Ducks. Certain marine or fish-eating 
species have seldom been kept successfully in this country for any length of time, such as scoters, eiders, mergansers, and the like. F. C. Walcott, however, who has visited various English preserves and experimenters with wildfowl in Great Britain, tells me that all such species are kept there without trouble, being fed partly on fish and ground-up crustacea and shellfish, and also on grain, which they all learn to like. Even sheldrakes will eat grain with eagerness. In feeding grain to mixed flocks of ducks I myself have noticed that canvasbacks, redheads, and scaups are just as eager for the grain as any others. Mr. Walcott says that English experimenters have even bred the eider, though no one has yet done so with the canvasback, probably owing largely to inability to secure stock.

Possible Experiments. Doubtless some interesting experiments could be worked out on the seacoast. For example, I have heard that on the coast of Maine eiders have been tamed sufficiently so that they could be let out to pick up their own food on the sea beaches, along with domestic ducks. I have no doubt but that any of these maritime species could be made to breed, certainly after one season of restraint, by a plan somewhat as follows: Fence in with wire a few acres on the edge of a fresh or salt marsh near the coast. If it is on tidewater, some high and dry land should be included, in case of flood tides. There should either be a small pond or part of a ditch or creek included. Probably the best location would be where there was a direct connection with the sea, to bring in minnows and other sea food. At any rate small fry could be netted and fed to the ducks in a pool spaded out in the marsh. Snails, mussels, clams, shrimp, crabs, and various other food would be easy to get, also sea-weeds. I have often watched flocks of scoters diving and feeding on submerged mussel beds. They eat small 
mussels, shells and all, which gives some idea of the varied diet of these species. The main secret of feeding any of these marine species seems to be to give them, besides grain, occasional special feeds of a diversity of animal or other food. Table scraps would doubtless serve well. The salt in such will do no harm, but rather otherwise, as marine species, of course, get considerable salt from the water. Salt now and then in mash would be good, this being regularly done in England for sea ducks. Fresh water should be supplied if lacking. Stock could be secured from the various "pensioners" along shore partly disabled by gunners. While wounded ducks are apt to die in time from the effect of wounds, many would recover, and probably some, in time, would breed. Some of Mr. Lockwood's stock was secured in this way. Once get a young stock started, especially some hand-raised females, further success would be quite probable. Males of wild ducks captured are found to breed more readily than such captives of the other sex.

Plan Succeeded. Since writing the above I learn from O. R. Austin that in a salt-marsh pen on a creek, as above, he bred scaup ducks successfully, and sold the young. This was in Rhode Island.

Starting a Stock. How matters work out with wild stock is illustrated by the experience of $\mathrm{E}$. H. Austin with the black duck. This species when wild has a shy, nervous temperament, and does not breed readily unless in large, marshy enclosures. Mr. Austin, after considerable effort, got a few settings of eggs from captive wild stock in this way, which he hatched and raised with hens. These young when reared proved quite tame. Early in the spring, in a poultry yard, they mated, and one made a nest in the shed. They were then put out in a meadow and swamp enclosurewith a brook, and laid splendidly. Unfortunately their nests were not 
hunted out in the tangle, and they brought off their own broods, which were mostly destroyed by turtles or other vermin. The safest way is to gather the eggs and rear the young with hens or tame mallards in safe quarters. The presence of strangers is apt to keep shy ducks from breeding. They should have absolute privacy during the mating and laying period.

Whealton's Method. J. W. Whealton, on Chincoteague Island, Virginia, breeds black ducks by keeping a flock of them in a paddock of four acres, with small fresh ponds and marsh. Besides grain, they are given lettuce and eel-grass, of which they are very fond. The place is a thicket of tall weeds, grass, and bushes. The ducks breed under the tangle, and are allowed to raise their own young. In common with the experience of others, he finds that captured black ducks are of shy and nervous temperament, and that it is hard to make them breed save in a large area of this sort. Vermin are kept down, and usually he raises a good number of young. One year he tried keeping a pair of Egyptian geese in the paddock, but the murderous gander hunted out and killed all the seventy-five young ducks.

Ducklings with Adults. In the case of some ponds, such as artificial ones where there is little natural food, it sometimes happens that nests escape observation, and ducks bring off broods. It is difficult to capture the brood without frightening the stock and perhaps preventing laying. On the other hand, the large ducks clean up the food so thoroughly that the young are likely to starve. A plan to obviate this is to build an enclosure of 3 -inch mesh wire, partly on shore and partly in the water, and place proper food for the ducklings within it, close to the water's edge. They will learn to go there for food, which is reserved for them, since the larger ducks cannot get through the wire. Under such 


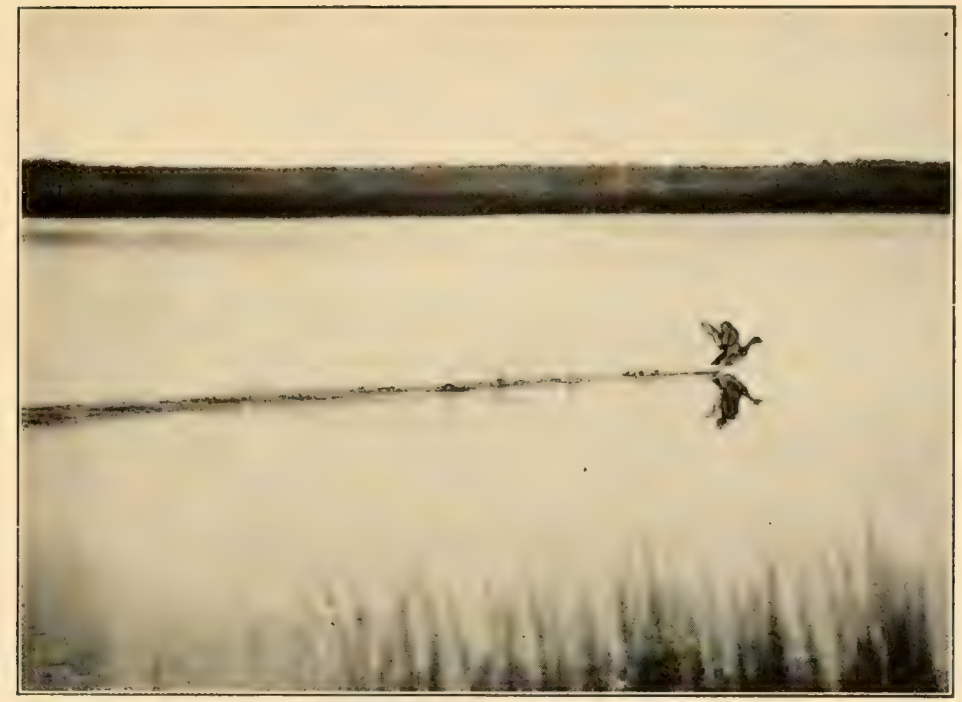

Female lesser scaup duck fluttering from nest on shore of western lakelet

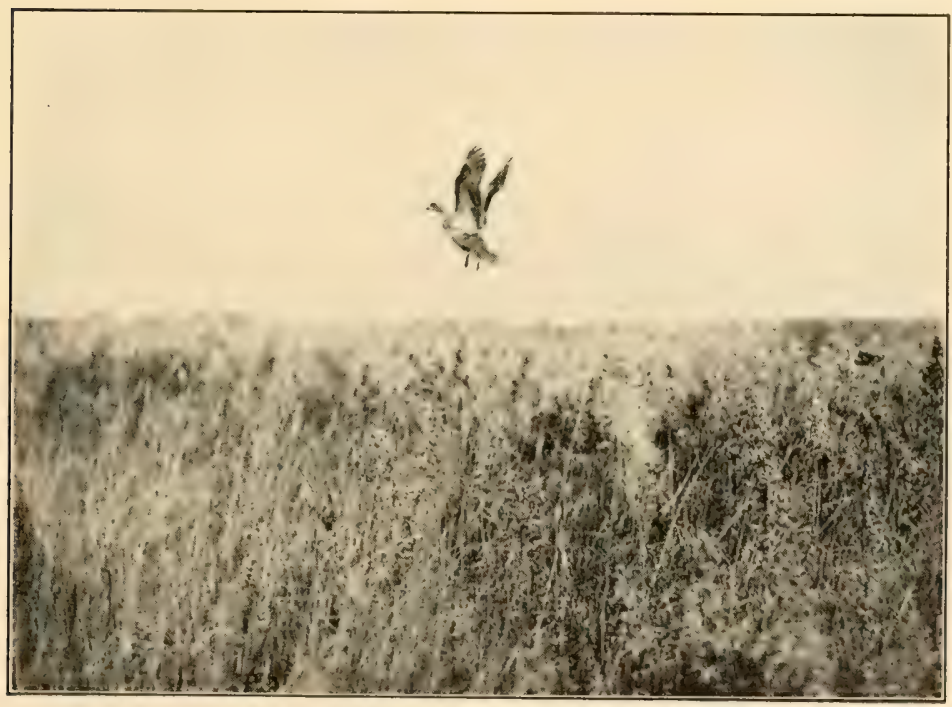

Gadwall flushing from nest in prairie grass 


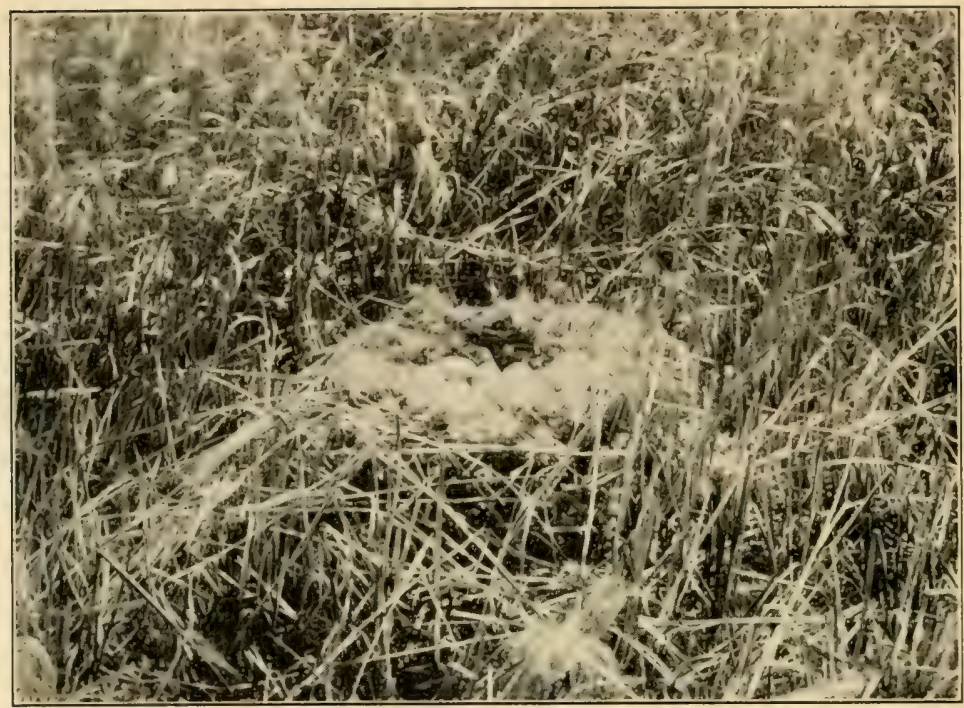

Nest of canvasback in tract of old sedge built up in water one and one half feet deep, Nanitoba

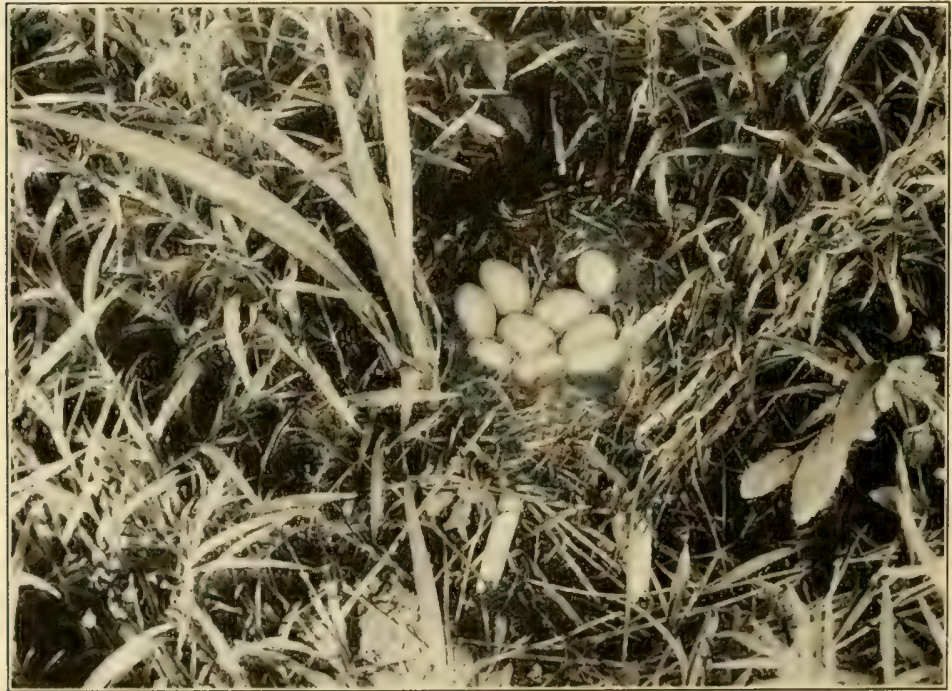

Nest of lesser scaup duck in rank vegetation ten feet back from shore of marshy lake, Manitoba 
conditions, though, it is best to try to gather all the eggs and rear the young with bantams.

Control in Free Range. Under some conditions it is possible to maintain wild ducks in freedom of flight, yet under artificial control. This plan is especially applicable to large estates, where there is abundant space of water and marsh, and with species that normally breed in the general region. Such undertakings are particularly the province of State game officials, as wildfowl thus raised will naturally spread to surrounding localities and benefit the general public. This mode of procedure is based upon the fact that young ducks reared artificially, even if allowed powers of flight, will resort to the places where they are fed, often remaining through the winter if any water can be kept open for them. Even if attracted away with migrating fowl, they often return. Most of them tend to remain or return and breed in the neighbourhood of their birthplace, following the homing instinct which seems to be strong in most birds. It is upon this natural instinct that the migratory impulse seems to be based, causing birds to return to the region of their birth. The more readily a species is tamed in captivity the more successfully does it respond to such a plan. The mallard and wood duck have thus far been most readily controlled, but the plan also works with the black duck, and, according to Mr. Walcott, with the pintail, and probably it will be found to with any species which is hardy enough to winter in the region where the plan is attempted.

How It Works. A bunch, say, of a hundred or more young mallards, is reared in a large preserve. Their wings are allowed to grow out, and at the age of three months they are in full flight. Parties of them fly from one pond or marsh to another, like veritable wildfowl, but return home at regular feeding times. Thomas A. Howell has his mallards range 
in this way. They are fed in a covered wire enclosure, to which at call they come trooping in, and they can be shut up if desired. In winter they are driven into a shed at night. As many as are needed for breeders have their wings clipped. Otherwise the ducks would pair off and mostly breed in the wild state in the vicinity, if the conditions were favourable and the food sufficient.

Wood ducks do well by this plan, being naturally docile and hardy. They fly about in the woods and swamps, but return to the regular feeding place. Dr. John C. Phillips, of Wenham, Massachusetts, says that his wood ducks seem to lose all migratory inclination, and stay on his place the year round. Obviously such birds perish in winter if not fed.

On the Walcott estate the wood ducks, raised in confinement and allowed to fly, migrate but return and nest in boxes put up for them along the shores of a lake. It is quite an idea that just as we can have bluebirds and wrens in our bird-houses, so we can have wild ducks. Moreover, we can regulate the supply of wild ducks at pleasure, while with the song-birds other factors largely control the supply.

On this estate young black ducks and mallards were also liberated. The birds were not banded, and it was not possible to recognize individual birds. Some left during the worst of the winter. It was obvious that many of them returned, perhaps with other wild birds, for the number that returned was said nearly to equal those that had left, and a considerable number nested in freedom on the estate, some resorting to the wire enclosures. It is evidently possible to establish wild ducks breeding permanently in a locality by such methods.

Wood Ducks on Walcott Preserve. That wood ducks breeding in the wild state are now established in numbers on the Walcott preserve in Norfolk, Connecticut, after only 
two years of effort is a remarkable demonstration of what the system above described can accomplish. Two years ago Mr. Walcott bought three pairs of pinioned wood ducks from Wallace Evans, probably stock raised on the Evans' Game Farm. The first season, r9r3, forty-five young were hatched of which twenty-six were raised. The first clutches laid were hatched under bantams, but the ducks were allowed to hatch their second layings. Only a few of these were pinioned. The rest migrated away for the winter, but mostly returned in the spring, and nested in the woods adjoining the lake where they were reared. In the autumn, I9I4, about seventy of them were staying about this lake. I write these words on the Walcott place in mid-December, I9I4. The full-winged wood ducks and some of the mallard and black ducks have migrated away, but there are a good number of ducks, about two hundred, keeping a hole open in the ice. Some of them are wild birds which have joined the flock. Flocks of each kind keep flying up, winnowing over the frozen lake and the woods, and then splashing back in showers into the open water, wild birds, too, even when I am standing but a few rods away.

The Lanier Experiment. It is further possible, by a slight assistance to nature, to establish the breeding of wild ducks in a favourable locality, even without artificial propagation. This has been done in a notable experiment by Charles $\mathrm{D}$. Lanier, at Westchester, Connecticut. He owns a tract of some 3,500 acres of wild land, mostly woods and swamp, in a retired locality. By judicious damming of brooks, areas of swamp have been overflowed, and a chain of flooded marshes and ponds created. Timber in the flooded areas has died and fallen, leaving considerable open water, in which pond lilies and other aquatic plants have taken a start. The place, naturally attractive to ducks, has become still 
more so, and wild ducks have resorted more and more to it. Each year a number of pairs of black duck and wood duck have raised their young on the premises. This makes quite a gathering of native ducks by the end of the summer.

In late August each year, or by September I, systematic feeding of the ducks is begun, by the placing of quantities of whole yellow corn in two of the ponds in shallow water and on the shore. The presence of the native stock contentedly feeding draws in every other duck that flies within sight, and by October there are literally thousands of them. Especially early in the morning, when I have startled the assembled throngs, it has seemed that the whole pond was being lifted bodily as they rose. The owner, who is experienced with wildfowl, estimates that in the height of the migration there have been as many as I5,000 ducks on the place at one time. Large and increasing numbers remain to breed, mostly black ducks, but also numbers of wood ducks. The starting of additional duck-food plants would further enhance the effectiveness of such a place.

It is now well proved that the presence of resident or captive ducks in a suitable locality, such as the above, serves to attract and even hold ducks in the strictly wild state. On the Childs-Walcott place each fall and winter the pinioned ducks on the pond are joined by considerable numbers of various species. Even wild canvasbacks, redheads, greenwinged teal, and others spent most of the winter there, even when the water was frozen, except for a small area kept open by the captive ducks and geese. Many wild black ducks, wood ducks, and mallards undoubtedly were induced to remain and breed in the vicinity, attracted by the captive ducks and their free offspring which bred all about, as well as by the planting of wild celery and other food-plants, by methods described farther on. 


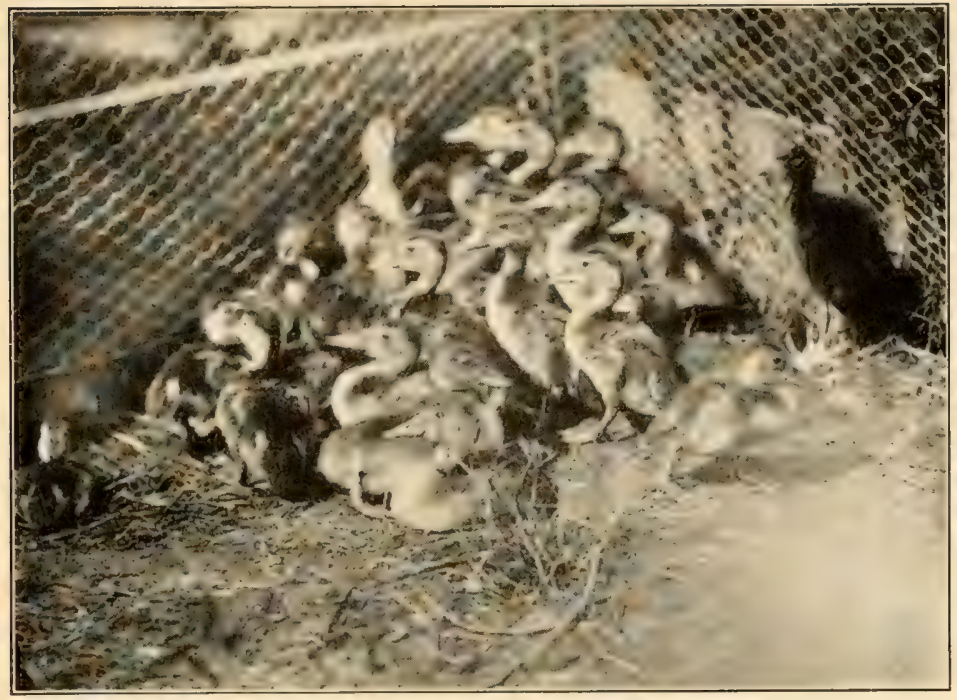

Young canvasbacks hatched and raised to maturity by author in camp in northern Manitoba. Probably the first canvasbacks ever reared artificially

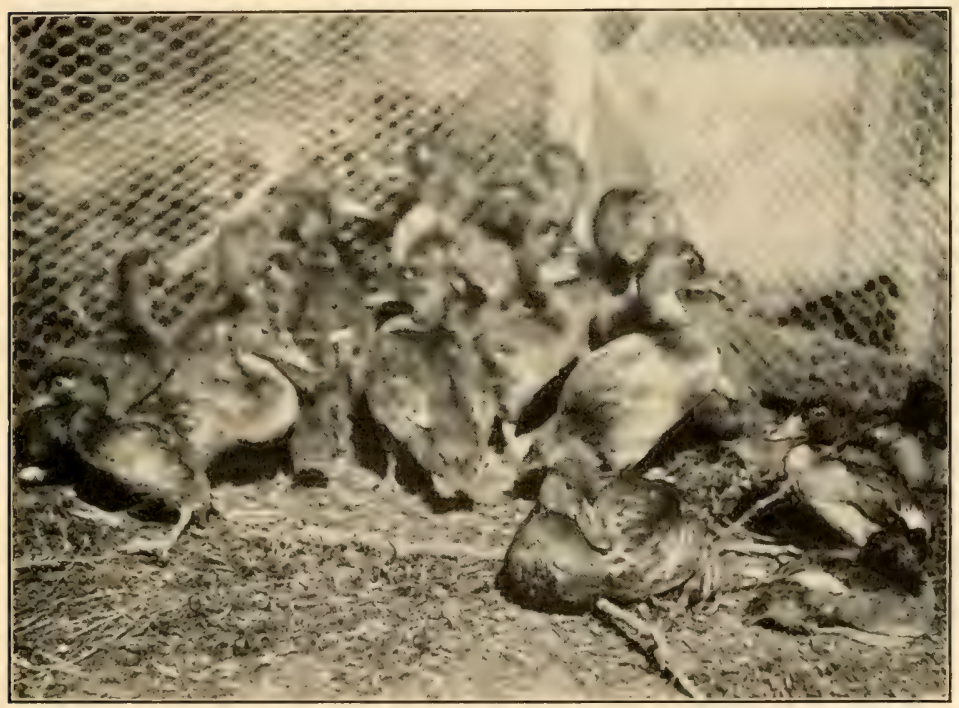

Young canvasbacks, redheads, and golden-eyes, raised by author on Manitoba expedition 


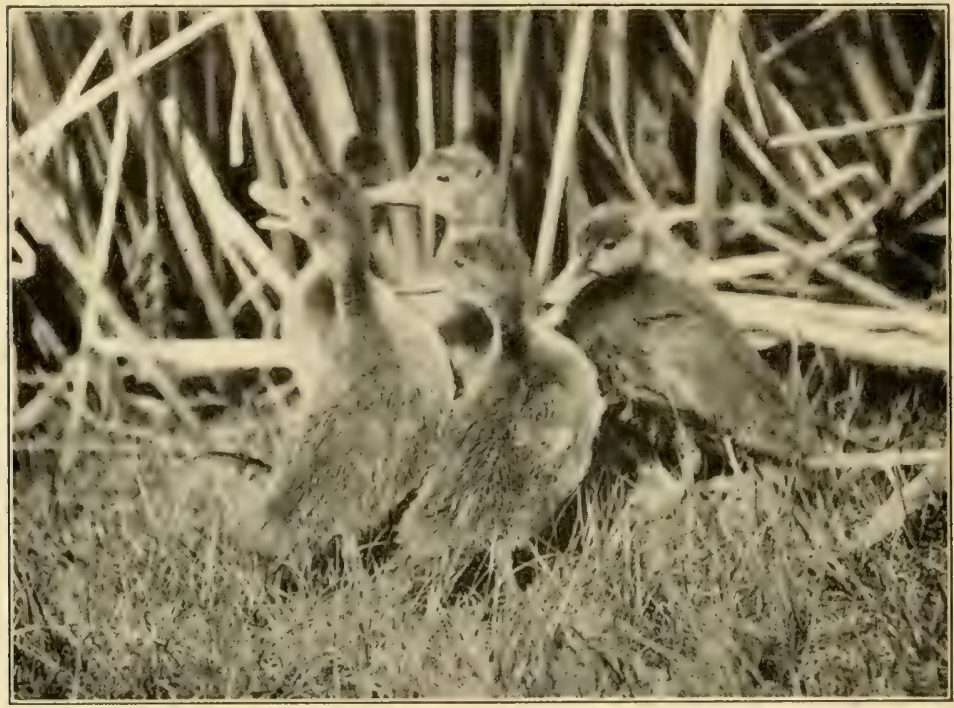

Young redheads, Manitoba expedition

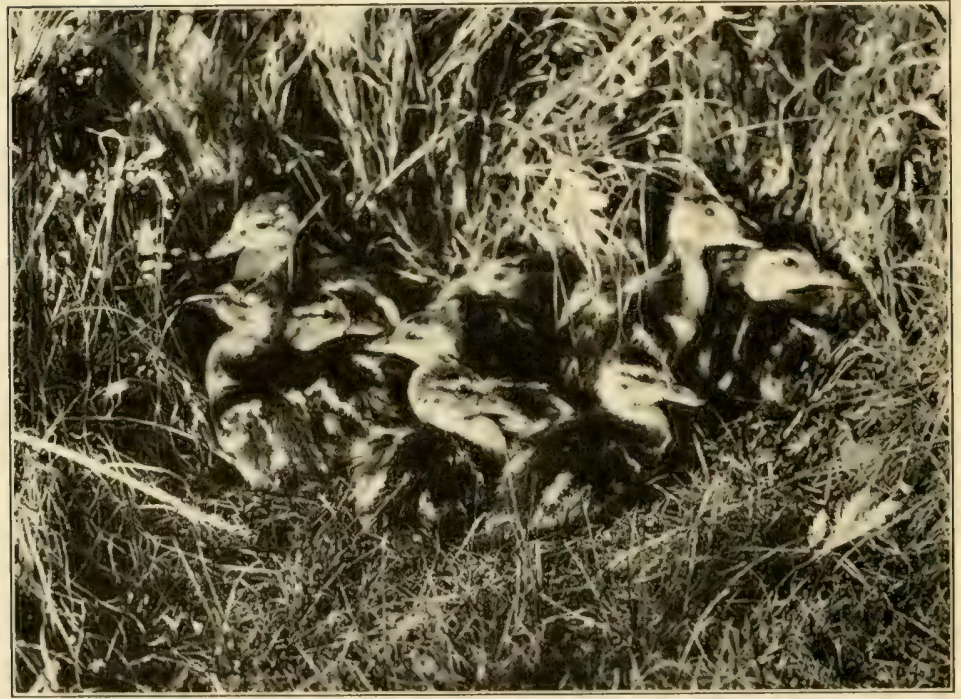

A brood of gadwalls, Manitoba expedition. Of a clutch of thirteen eggs, all hatched in an incubator, and eleven ducklings were raised to maturity 
Hence a good way to get wildfowl breeding abundantly on a suitable large wild area, properly protected, is to keep a nucleus of captive ducks, especially mallards, breed them, and liberate some of the young, which will breed naturally in the vicinity. This will draw other ducks and induce them to breed. The captive breeding-stock will be kept strong by new infusion of wild blood, for wild drakes in the vicinity will fly into the wire enclosures and mate with the pinioned or wing-clipped females.

Such estates as the above are doing great public service in restoring and increasing valuable species of wildfowl in regions where they have long been on the verge of extermination. The overflow from these places breed in other suitable localities, and tend to restock whole States.

An English Breeding Method. A remarkably ingenious method for making wild ducks breed has been worked out in England through experiments by enthusiasts who have gone far ahead of us here in America. An account of this method is given in The Estate Magazine, published in England, November, I9I I. Evidently it is well-known in England, and it was elaborated for us by Lord William Percy during a recent visit to this country. Mr. Walcott, during a recent trip to England, saw the results of it in full operation. On certain large estates he saw nests galore with eggs of many species of wild ducks.

The method employed is as follows: In the fall migration large numbers of wild ducks, even thousands, are caught by funnel-shaped net traps, into which the flocks of ducks swim, attracted by bait and live decoys. The wild birds are caught, one wing is clipped, and they are put for the winter into fenced enclosures. In these there may be a small shallow pond, or simply holes dug in the marshy ground, in which a little water will gather. The flight feathers are renewed 
only once a year, in late summer, but new feathers will grow out within three to four weeks after the old quill stumps are pulled out by the roots. The time required for the complete growth of a new wing quill is usually from twenty-one to twenty-four days.

The time selected for the operation is, thus, about three to four weeks before the normal breeding time for ducks, in England about the middle of March. The ducks are then caught up, the stumps of the old clipped quills are pulled out with pincers, and the birds returned to the enclosures. When the wing has grown out they are allowed to fly over the fence. By this time the wild migrants have gone north, the breeding impulse is on them, and they usually remain and nest in the vicinity.

Sometimes, however, they depart to neighbouring estates, so the following modification has been devised: The female only has the stumps of her quills pulled out, and both sexes are put into a large marshy enclosure. Flight invigorates the female, usually the more backward to breed in captivity, so that she is ready to lay. Already she is mated to a male in the pen. He cannot fly, but she is unwilling to leave him, and mates with him and nests nearby, sometimes even in the enclosure. The ducks usually rear their own young wild, and no attempt is made to restrain them, or to prevent the males from leaving when their flight feathers are renewed. For the next season stock is trapped wholesale, which is less trouble.

According to Messrs. Walcott and MacVicar, the plan has been worked successfully in England with the pochard, tufted duck, gadwall, widgeon, pintail, shoveller, teal, and perhaps others. That it is based upon traits natural to wildfowl is shown that in the wild state uninjured ducks are cometimes known to refuse to desert their wounded mates, 
and breed there out of their normal range. MacVicar has seen cases of this with black duck, mallard, teal, and Canada goose. I was told by a fisherman at Chatham, Massachusetts, that he had seen a female old-squaw with a brood of young near Strong Island, Chatham Bay, which undoubtedly was a case of this sort.

How the plan works out is indicated by the account by Mr. Walcott of a shoot one recent autumn on an estate where this method was employed. More than I,700 ducks were killed in one day by eight guns, largely those reared on the estate. Very few of them were mallards, but mostly the kinds usually considered hard to breed, such as pochards, pintails, gadwalls, widgeons, shovellers, teal, and the like.

It is said, however, that the method is not so successful with wildfowl that are very northerly in their range, at least for any permanent result in establishing a new breeding habitat for a species, but is especially applicable to species that normally breed in the same latitude. There is no reason why these methods should not work in America as in England, in localities where there are suitable large marshy areas. There is this difference, however, that in England it is not so cold, so that some water remains open all winter. Here in the Northern States everything is likely to freeze up hard at some time each winter. There the ducks remain the year round, but here they would be compelled to migrate away, unless artificial methods and feeding were used. The above method should be employed with the greatest discrimination and only by experienced persons, and with the consent of the State authorities, as otherwise it would be liable to result in much cruelty and waste.

Reasons of Failures. There are many persons fond of wild waterfowl who for years have kept wild ducks, hoping that they would breed, but with little result. In most cases 
the causes of failure are not hard to discern. In the first place, the quarters usually are not suitable. In my various explorations I have found the nests of twenty species of American wild ducks, including hundreds of nests. In every case the nest has been most carefully concealed. Never is it out in open view, but always hidden with the greatest care. Seldom have I found the treasures without flushing the mother bird. She is wonderfully hidden in the tangle of grass or bushes, and it would take the sharpest of eyes to discover her. She will sit motionless until almost stepped on. When she leaves the nest of her own accord to feed, she covers the eggs with a blanket of down plucked from her breast, and often, in addition, scratches over them the surrounding debris. When she returns she sneaks through the grass with the greatest caution, and no eye sees her. If flushed, she is apt to stay off for hours before she dares to creep back. Nesting with a wild duck is her most precious secret. How in the name of commonsense can she be expected to breed when kept in a prim artificial pond with elegant stone curbing, the grass around it closely trimmed and raked, and the shrubbery neatly groomed! After all, in her desire for privacy she is considerable of a lady!

And, speaking of privacy, how can they get it on a little pond, with bare surroundings, crowded with ducks, usually with plenty of tame polygamous mallards that will chase away every other duck and interfere in all its affairs. Another trouble is wrong feeding, insufficient in certain elements. Wild ducks can exist on a grain diet, but grain alone is not conducive to fertile eggs.

\section{b. Laying and Hatching}

Egg-production. Only one wild native species, the mallard, usually lays eggs at all continuously like domestic 
poultry. They average about twenty-five to forty eggs per duck in a season, and individuals go considerably higher. When it is realized that mallard eggs from pure wild stock sell readily at 20 cents each wholesale and 25 cents retail, it will be seen that a duck, worth, say, three dollars, which lays ten dollars' worth of eggs a season, is not such a bad boarder! Wood ducks, properly handled, usually produce two clutches of eggs a season by having the first laying removed as soon as complete. With other kinds, at the present stage of progress, we are delighted to get even one laying, and are overjoyed at two. Wild ducks lay from seven to sixteen eggs to a clutch, eight to eleven being the usual numbers. I once found 22 eggs in a redhead's nest, in Saskatchewan, but this is extraordinary, perhaps the layings of two ducks. E. A. McIlhenny, however, has just informed me that he has bred the blue-winged teal and the gadwall in captivity and secured eggs in considerable numbers, teals having laid as many as sixty eggs in a season.

Date of Laying. Both in the wild state and in captivity the mallard is a very early breeder. On preserves in the latitude of New York City they begin laying early in April, or sometimes in March. The pintail is another early duck. In the Canadian Northwest I have obtained young pintails nearly able to fly, nine or ten weeks old, on the 25 th of June. The eggs, therefore, must have been laid in early April, when it is still winter in that region where ice stays in the lakes till the middle of May. Next out there comes the canvasback, with eggs early in May. The teals and shoveller begin incubation toward the end of May, the redhead in early June. The ruddy duck, gadwall, widgeon, and scaups are late, averaging about June Ioth, while the whitewinged scoter seldom has eggs before the last week in June. The wood duck, both wild and captive, usually lays in late 
April or early May in Connecticut. In Mr. Cox's experiments the black duck and mallard lay eggs beginning early in April, the wood duck, mandarin, pintail, widgeon, shoveller, and others late in April or in May, and the redhead and teal in June.

Incubation. Ordinarily it is not best to allow the ducks to incubate their own eggs, certainly not the first litter, so as to make them lay a second one, which is so much clear gain. With most species it is hard to manage and protect the ducklings with their natural mother. Of our native species only the mallard and wood duck breed readily in a small enclosure. A brood hatched on a large marsh or pond is in great danger of natural enemies, such as turtles, snakes, large fish, minks, and others. In the wild state broods are often seriously diminished by these causes. On the marshes of Lake Manitoba, where many waterfowl breed, I found the Indians netting fish, such as pike and large pickerel, in the stomachs of which were frequently found young ducks, grebes, and coots, swallowed whole. I have seen broods on these marshes reduced to one duckling, from these causes or perhaps the effects of cold storms. A larger number will usually be reared where they can be controlled. Moreover, the ducklings raised by the mother are wild and harder to manage later, whereas it is desirable for future breeding that they should be as tame as possible, in view of the problem of shy ducks failing to breed.

In the case, however, of only a pair or two of wood ducks or mandarins in a tiny pond where there is certainly no vermin, it is proper to let the ducks raise their second litter, especially in view of the fact that ducklings of these species are peculiar and harder than others to raise. The mother duck, under favourable conditions, is usually able to raise them, whereas unskilled human efforts often fail. On the 
other hand, even the mother duck does not always succeed. Dr. John C. Phillips who has raised many wood ducks, usually letting the ducks rear their own young, informs me that some years they raise large broods and other seasons almost completely fail, the cause of which he has not been able to ascertain.

Taking Eggs. Except with mallards, which usually will lay anyhow, it is best not to disturb a nest or remove any of the eggs until the duck has nearly completed the set, and till a sitting hen is ready for them. The chances are that the mother bird will have incubated a day or two before it is known that she has finished laying, and this is enough to spoil the eggs if they are allowed to get cold. In the case of mallard eggs collected daily, or of others known to be fresh, they should be kept in a fairly cool place, stood on end in bran, not touching, and reversed daily. It is best not to keep them over two weeks, or three at most, before setting. Ducks' eggs are fragile, and must be handled carefully.

Transporting Eggs. That wildfowl eggs, even at the most critical stages of incubation, can be transported a few miles when carefully handled, I have proved by experience in the Northwest. On the contrary, I have had no luck at all in sending eggs by express, or carrying them myself with utmost care, on long railway journeys. These eggs I had collected myself, taking only incomplete sets which I knew were fresh. When set, after the journeys of more than 2,000 miles, not an embryo, in most cases, started. In one case two eggs hatched, a pintail and a lesser scaup. In one instance I hatched out several blue-winged and green-winged teals, but they had no stamina and soon died. Furthermore, eggs of wild ducks are seldom found except by flushing the mother from the nest, almost always after incubation has begun, even though it is imperceptible to the eye, and the 
eggs spoil. These experiments I tried out under government coöperation, and I give these results that the public may not waste wild life, to say nothing of their time and money. Game farms, however, with conditions favourable, are able to make quick shipments of fresh eggs to considerable distances with quite good results.

Modes of Incubation. There is, fortunately, much more latitude with incubation and rearing in case of waterfowl than with the gallinaceous birds. In this case incubator methods are quite feasible. The first choice, however, is to hatch and rear with bantams or small hens, and these are usually considered preferable even to tame ducks, though the latter are sometimes used. The duck, however, in order to keep clean, needs frequent bathing, which is dangerous for ducklings of delicate species, especially in cold or wet weather. The hen, too, is less likely to kill ducklings of other broods that may happen to come to her.

Any ordinary hen of medium weight that is docile will answer the purpose. Wild or very heavy hens are liable to crush these fragile eggs. Bantams are rather better for eggs of wood duck, mandarin, shoveller, teal, or other small species. For an ordinary hen twelve eggs of the larger species makes a good setting, or eight for a bantam, but the number used will vary with the size of the eggs and the hens. The main thing is never to give a hen more eggs than she can easily cover. Efforts to cover too many are apt to result in breakage, as well as failure to hatch.

Moisture. The eggs of waterfowl require so much moisture that it is best to set them on the ground. Outdoor hatching coops such as have been described may be used. In the wild state the duck moistens her eggs when she returns from the water. As the hen does not get wet, it is well to sprinkle the eggs with warm water toward the end of 


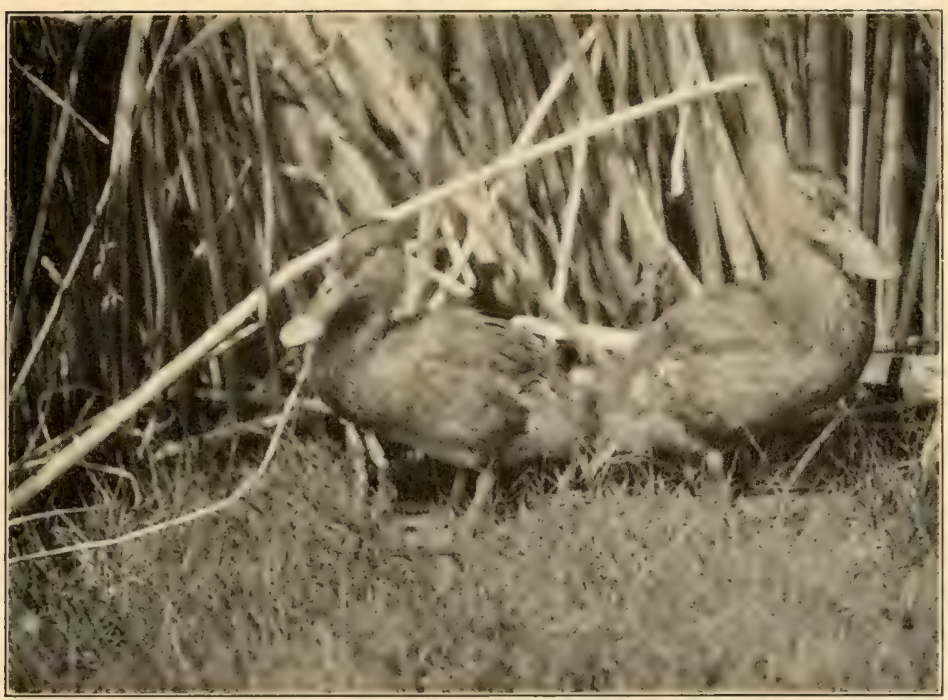

Young shovellers or spoonbills, Manitoba expedition

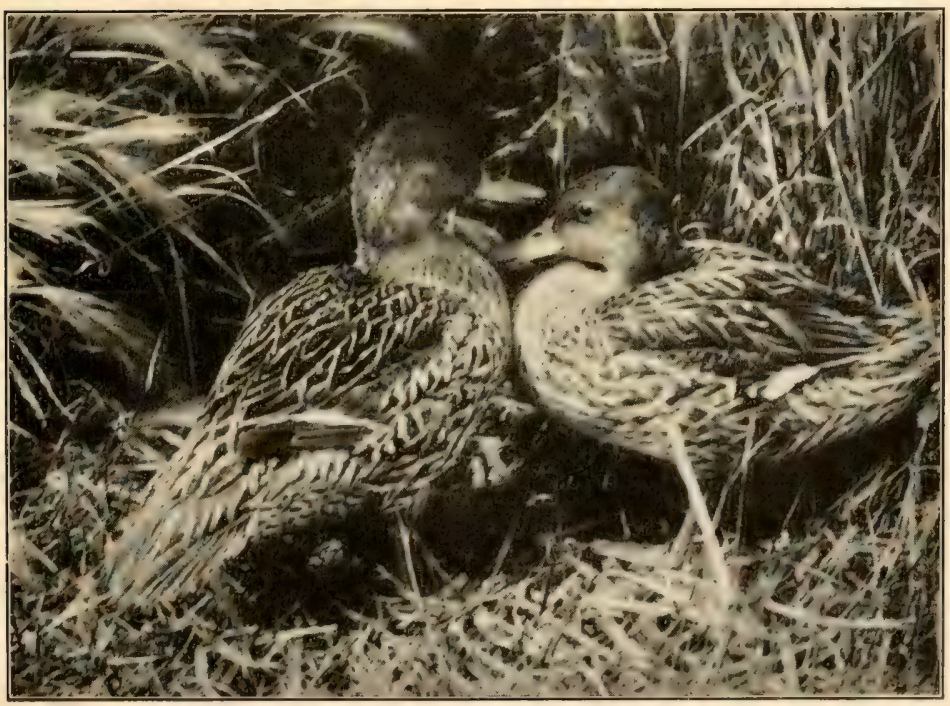

Young pintails raised by author, Manitoba expedition 


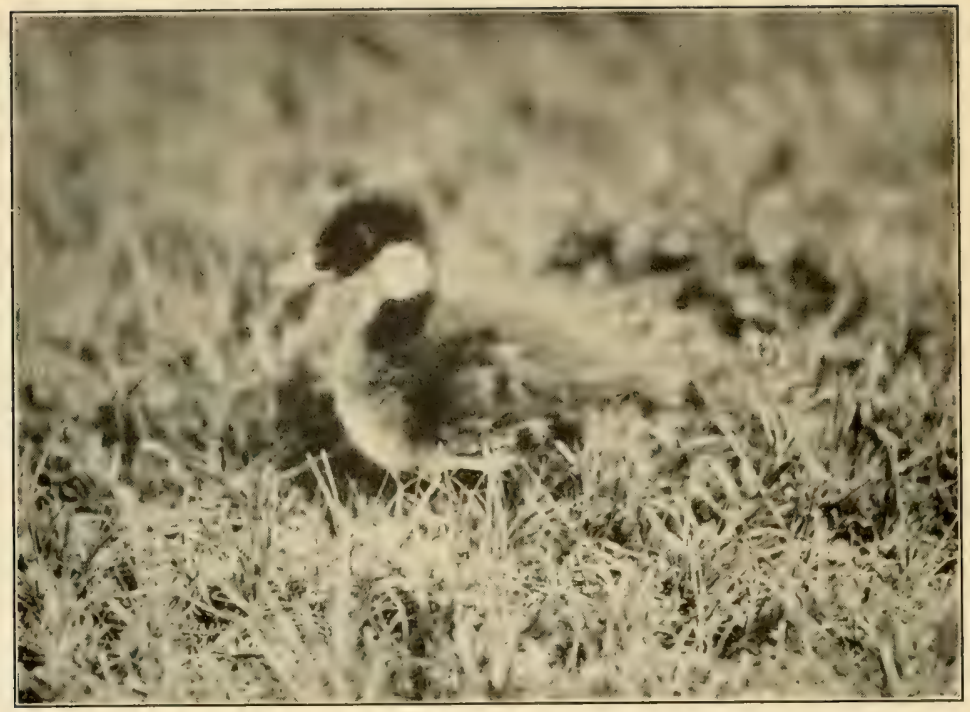

Young white-winged scoter, popularly called "sea-coot," Manitoba expedition

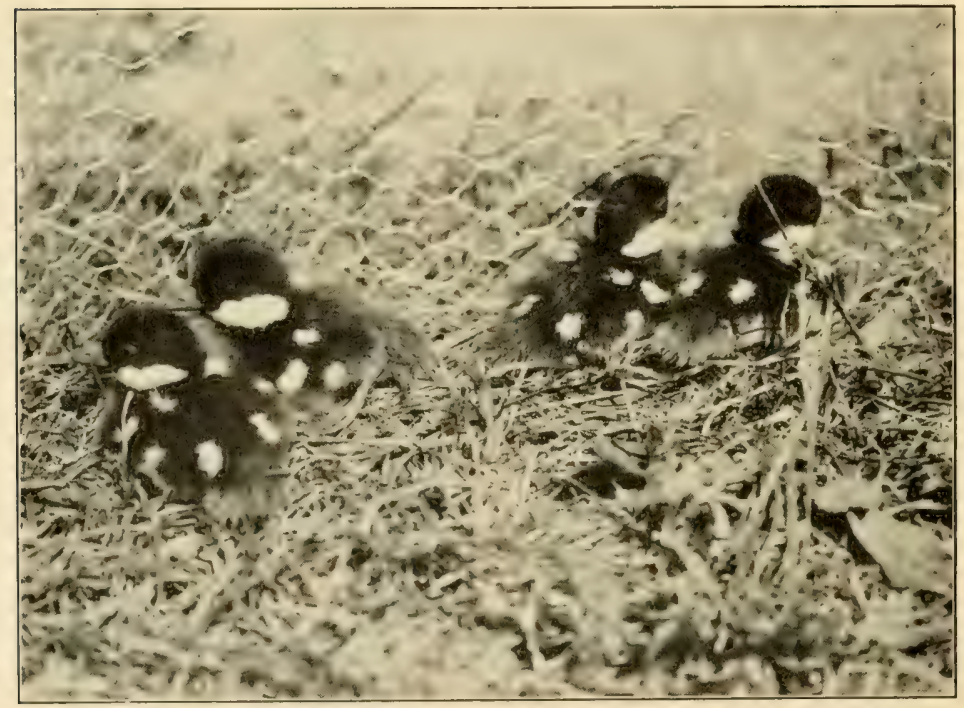

Young golden-eves or "whistlers," Manitoba expedition 
the hatch, even though they are set on the ground. They could be set on the ground in a shed, provided the ground under the nest be kept moist. Some breeders of mallards, however, use tiers of nest compartments in hatching-houses, construct the nests of sods, and soak them with a wateringpot each day, which seems to answer the purpose.

Period of Incubation. I had hoped in my experiments in hatching wild ducks' eggs in camp in the Northwest to learn the exact periods of incubation of the various species. The few incomplete fresh clutches found were shipped East and did not hatch, and those hatched on the spot were all more or less incubated when taken. Careful incubation records of most species are hard to get, but Henry Cook has kindly supplied a good list from records of results on his place at Woodbury, Long Island, New York, as follows: mallard, 27 to 28 days; black duck, 26 to 27 ; wood duck and mandarin duck, 28 to 30 ; gadwall, 28; redhead, 28; European widgeon, 24 ; shoveller, 22 to 24 ; all teals, 2 I to 23 ; fulvous and redbilled tree ducks, 26 to 28 days. Wallace Evans, who has hatched thousands of wood ducks, says that the above period for this species is correct. Captain Oates, in his book on mallard breeding, says that the period for this species he has known to vary, according to conditions, from twenty-three to twenty-nine days, but that the average is about twentysix days. Doubtless there is considerable variation with all species, according to weather, temperature, closeness of sitting, and perhaps age of the birds producing the eggs.

Artificial Incubation. Though the general practice with fanciers is to use hens, there are some who use incubators and brooders. This, in fact, is commonly the method of commercial duck farms, where Pekins, mallards, and others are raised in quantities for market. These species are hardy, eggs are abundant, and it is cheaper on a large scale, even 
if losses are somewhat larger. Different workers claim to hatch with machines from 60 to 75 per cent. of the eggs set, or about 80 per cent. of the fertile eggs. In such cases they usually have large brooding-houses and all facilities. Where it is a matter of operating single outdoor brooders, with a moderate number of ducklings, it is saier and far less trouble to use hens.

There is no question, however, that wild ducks' eggs hatch very well in incubators. On two expeditions to Northwest

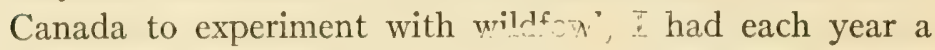
hatch with Cyphers incuvatioro vi ýz per cent. of the total number of eggs, including about a dozen species. These were eggs of wild ducks gathered in the marshes. Nearly all were fertile, owing to the vigour of the wild stock, and in most cases every egg of the set hatched, or all but one. The young were reared in brooders. It was necessary to manage in this way, as in the wilderness it was impossible to secure hens, particularly broody ones.

My method, which is the usual one, was to run the machine at $103^{\circ}$, raising to $104^{\circ}$ during hatching. The eggs were gathered in all stages of incubation. When a set was pipped, the eggs were usually transferred to a separate machine with higher temperature. Some sets, however, hatched in the general machine at $103^{\circ}$ and the young seemed to do just as well. The eggs were well sprinkled daily with tepid water which felt slightly warm to the hand, were turned, and were aired till the temperature felt neutral when the egg was placed against the eye. Two towels dripping wet with warm water were at this time placed in the bottom of the machine.

The German method used by Ludwig Sëidler, similar to others as to temperature, in the incubation of ducks' eggs uses all possible moisture, as near to saturation of the air as 
possible, throughout the process. Two pans of water, besides wet cloths, are used. The hygrometer reading is kept up to $75^{\circ}$ and to $90^{\circ}$ if possible. The higher the elevation of the locality, the harder it is to keep up a high degree of moisture. Before hatching begins, the water should be removed from the bottom of the machine, so that the ducklings may drop down there and dry off. The tray and shells should be removed after hatching, and the young left in the machine for the above-mentioned period. Where hens are employed, the handling should be as described for gallinaceous birds, never relaxing guard against insect pests and vermin.

The incubator can be used as an adjunct to the hens. When a set is pipped under the hen, it may be transferred to the incubator, running at $104^{\circ}$, and the eggs allowed to hatch. This will save the trampling of the young or their being crushed against the unhatched eggs. A few poultry eggs can be given to the hen to keep her sitting.

\section{c. Methods with Young}

First Handling. When the hen is hatching she should not be lifted from the nest, as she is liable, in settling back, to crush the young. Eggshells should be removed by putting the hand carefully under her and raising her slightly. If the incubator is used just for the hatching period, when the ducklings are dried off they should be put under the hen, so as to learn to brood before being taken to the field. If several broods hatch at the same time, the young can be divided equally among the hens.

The methods in general are similar to those described for young quails, the coops and apparatus being the same. The ducklings are transferred and handled as there described. If the weather is cold or wet, they should be kept in the coop 
with the hen until it is reasonably safe to let them out. They need air and exercise as soon as feasible, but they must not at this early stage get wet or chilled. Three-fourthsinch mesh wire will keep in ducklings of the larger species, but for wood ducks and other small species the $\frac{1}{2}$-inch size is necessary. The young of the wood duck and other treenesting species climb, which the others do not, and for these it is important that the run be covered above at first.

Hot Sun Dangerous. Hot sun is a danger for ducklings to be avoided as carefully as cold. There must always be cover so that they can get in the shade, which they know enough to seek. A surprisingly short enforced exposure to hot sun will cause sunstroke. Hence in the pens in front of each coop there should always be either an awning or a frame covered with foliage, preferably evergreen, or stalks.

Popular Fallacy. Mallard ducklings and those of a number of other species, especially of the "Anatinæ" or "river ducks," are much easier to raise than quails or pheasants, in that they are not nearly so liable to epidemic diseases and do not require free range. The process, however, is not so simple as is commonly supposed. The popular idea is that young ducks are all right if they have a pond to swim in. This is a most mistaken notion when applied to ducklings under artificial conditions. Without the mother duck, their plumage is not properly oiled, and they quickly get soaked and die of cramp. Moreover, various aquatic enemies devour them. The practical fact is that water is dangerous, and it is safest to rear them on dry land, with certain partial exceptions which will be discussed later. The generally accepted method, notably with such species as mallards, is to rear on dry land till the young ducks are about eight weeks old, when their bodies have become well feathered.

Common Method. At first the young are kept with the 


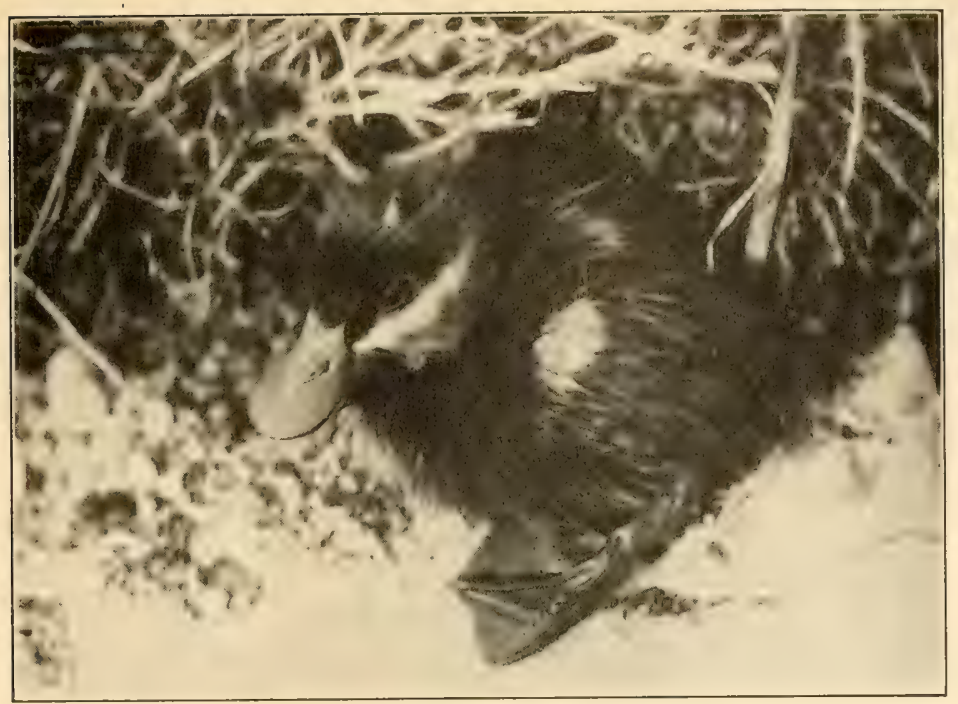

Young ruddy duck, a most peculiar creature, Manitoba expedition

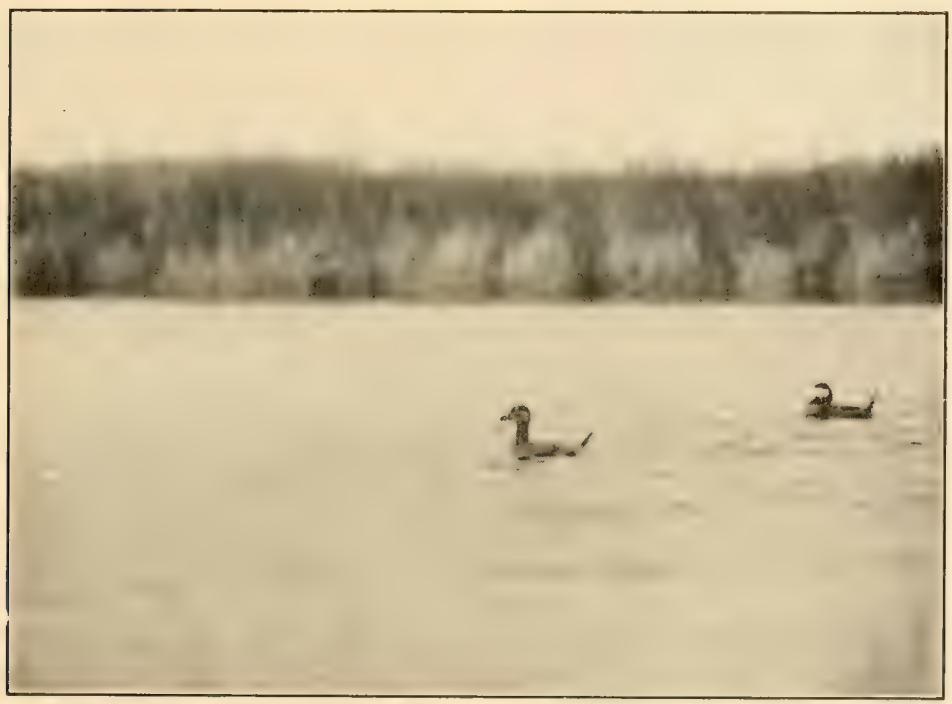

Pair of adult ruddy ducks in marsh near nest, Manitoba 


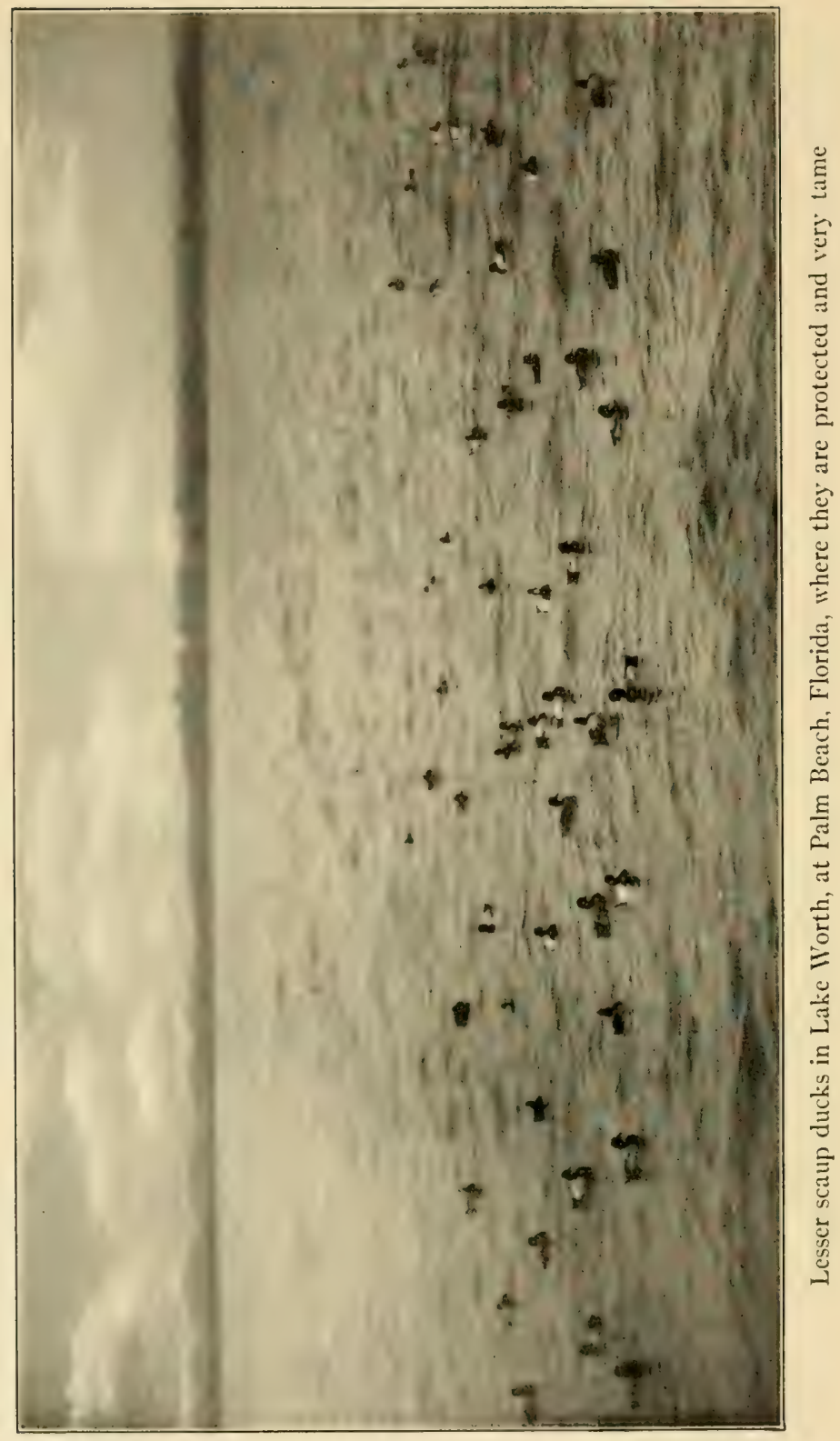


hen in a bottomless coop with a small yard, preferably on turf, which should be shifted to a fresh spot frequently, say every other day. After they are a week old they should have a pen at least about 8 feet square, better larger, and the ground should be changed about once a week. If there are only a few broods, this can be continued for each until they are old enough to take to the water.

Larger Scale. Another plan, when rearing is on a considerable scale, is to have a rearing-field somewhat on the pheasant plan. The coops are placed about 40 feet apart, the hens kept shut in, with frequent change of ground for the coop, and the young allowed to range about in the field. It is well to group the coops to have young of the same size together. Though hens may occasionally peck at ducklings different from their own, they are not so bad as ducks in this respect. This field arrangement is excellent for the ducklings, as it keeps the ground fresh and gives them exercise.

The following method for young mallards is used by Adam Scott: Hens and ducklings, six broods, are placed in an enclosure about 50 by 75 feet in size, using I-inch mesh wire, 2 feet high, this, of course being simply a section inside a high fence. The coops are 3 by 6 feet, without bottoms, but false bottoms are used for the first few days, to prevent the ducklings getting stepped on in hollows. There is a sliding slat front for use during the day, and there are ventilating openings near the top. In quarters of this size no change of location is necessary. In I 9 I 3 by this system $I, 500$ young mallards were raised on two acres of land. New ground is used each year. The ground used for rearing is thoroughly limed, ploughed, and seeded down in the fall. At the end of the third week Mr. Scott removes all the hens, leaving the ducklings to run together. They have no water standing, but only what is given them in troughs three times a day. 
They are fed in similar troughs, all being 3 inches deep, 6 inches wide, and 8 to ro feet long. Feeding troughs must be cleaned thoroughly. They are fed only what they can clean up in a few minutes. For shade he uses light tables in front of each coop, 18 inches high and 3 by 6 feet in area.

This matter of shade for ducklings is of great importance. In a rearing-field there should be, if possible, some trees and shrubbery. If not, shade must be provided, either by arbors, awnings, brush-piles, or other such devices. At the Clove Valley Club the rearing-field is in a sort of open grove, so there is good shade and sufficient sunlight. For the first week the ducklings are kept in small yards with the hens. Then they are allowed to run all together. At night the i.eeper evens them up, if too many go to one hen. When they are two months old they are driven, on a warm morning, to the pond where they are to mature. It is a flooded 1 ine, and has little or no natural feed, but it answers the purpose. At first the ducks get badly soaked, so the first days they are not allowed to stay in the water long, but are driven out into an enclosure. As soon as they get oiled up they stay on the pond nearly all the time, also bask on the banks, and come to feed morning and night when called. When they learn to fly they do not leave, especially as the flock of twelve or fifteen hundred creates a good social nucleus. They fly about some, but are on hand to feed. They are easily caught by feeding them inside a covered pen.

Brooder Method. Young wild ducks can be successfully hatched in incubators and reared in brooders, as I have proven by raising a dozen different kinds in this way. The keeping of proper temperatures, however, is so exacting a task, requiring incessant vigil day and night, that I should never recommend it, or employ it myself, except in case of necessity, as I did in the wilds of the Northwest where it 
was impossible to get broody hens. In case, however, some one should need the information, I will describe briefly the procedure with brooders. For the first three or four days I keep the temperature from 95 to $100^{\circ}$. Then, till the ducklings are about three weeks old, gradually reduce it to about $85^{\circ}$. For a week or two longer, or according to the weather, $80^{\circ}$ at night will be enough. In the daytime young ducks after the first three weeks do not need much or any artificial heat, unless during cold storms. When they are about five weeks old, or even younger, if the climate is warm, they can sleep in ordinary coops. On bright summer days the danger is more from overheating. Be careful that the brooders do not get too hot in the sun and smother the ducklings. Usually at such times it is best partly to raise the covers. Brooder lamps should be trimmed and filled every day with regularity, lest there be accidents by smoking or going out at some critical time.

Modified Methods. Experiments with various kinds of wild ducks reveal the fact that something is lacking in attempting to rear certain species entirely without access to water. Young wood ducks, mandarins, golden-eyes, scoters, and doubtless most of the sea or diving ducks, are hard to bring through the early stages by this method. In my successful experiments with rearing young canvasbacks I found that when they began to feather, at the age of about one month, their growth seemed to be retarded, and they did better when I gave them even a pan of water. Scoter and golden-eye ducklings were notably retarded in growth. For these marine species, also for wood ducks and mandarins, or any ducklings which do not appear to thrive, I would recommend judicious and careful use of the following methods. Even with such ducklings as mallards, whenever their plumage becomes fouled, it is well to let them bathe in 
a pan of shallow water for a short time on a warm, bright morning.

Young Wood Ducks. The success of Wallace Evans in his method of raising young wood ducks is instructive. These ducklings have sharp claws and are great climbers. When kept on dry land, at first they appear wild and restless, paying little heed to the hens, and are continually trying to climb out of the pen. They seen to worry themselves to death, and it is common to lose half or even all of them. With the mother duck, however, even in a small puddle, they seem perfectly content, and seldom try to escape. They are constantly dabbling, sifting mud and water through their bills, and usually nearly all of them thrive.

Mr. Evans takes the hen and brood to a rearing-coop placed upon dry land, but near a bit of shallow water, which is included in their enclosure. Some of these pens were along a marshy lake, others along a shallow ditch or canal which was divided off into sections, each yard having in it a strip of the ditch. They are allowed to take a brief bath soon after they are placed in the rearing-coop. This must be only when there is warm sunshine, and in warm marsh water, also in time to dry off before night. If the first day is cold, they should bathe only as conditions are favourable. His theory is that for a time after the ducklings are hatched their plumage has in it considerable of the natural oil, which soon dries out if they stay out of the water. The first bath must be a brief one, after which they are shutin with the hen. The little ducks should not get bedraggled, and should avoid getting their backs wet at first. If a shower comes up they are shut in the coop. It is bad for them at first to run through long wet grass or weeds, as this forces the water into their plumage. Hence vegetation in the enclosure is 
kept short. Evidently they oil themselves, and the time they are allowed in the water is gradually extended.

Another element in this theory is that by dabbling about and sucking mud and water through their bills, the ducklings secure some food element which is important, such as minute larvæ, infusoria, and other insect life. This I know, that Mr. Manross raises almost every one of his annual brood of wood ducks practically without feeding them. The little artificial pond in the factory yard is only some 25 feet in diameter. A little grain scattered on the shore for the old birds is the only artificial feeding. The young do not touch it till they are well grown, and live on what they pick up in this small body of water.

Method with Pan. The soundness of Mr. Evans's theory and method was proved abundantly to me by more than 600 young wood ducks nearly grown which I saw on his place in August, I9I4. He considers that he has only just begun to raise them. He says that if there is no suitable marsh available, the following method will answer. Place in the enclosure a good-sized baking-pan. In it lay green turf, grass side up, and fill it with water just a little over the roots of the grass. This prevents the young from getting wet above, but keeps them busy "sucking mud" and nibbling green vegetation. The pan can be removed when it is not best for them to bathe. This method with the pan was also habitually employed by Lockwood and Cox, and by others. During the first few days some fill in the pan with pebbles, to keep the little ducklings mostly out of the water, so they can get only their bills in, and gradually remove the pebbles as they grow older, later substituting quite a deep pan.

Avoid Chill. The main thing in allowing young ducks access to water is to do it with discretion and plan things so 
that they do not get soaked and chilled, especially in cold weather or at night.

Keeping Clean. Another advantage gained by judiciously allowing bathing is that the ducklings are then able to clean their plumage. One of the most serious difficulties in raising young ducks on dry land is that they run over one another and get their backs fouled. In trying to rub it off they get their necks, heads, and eyes stuck up, and are likely to die. Sometimes I have spent whole mornings, on warm days, cleaning ducklings by hand, with warm water. By the above plan they will attend to their own toilets.

Method of Cox. The method of Mr. Cox in handling ducklings is as follows: He never lets ducks rear their young if he can avoid it, but always rears them with bantams. Sometimes he sets eggs under ordinary hens, occasionally as many as sixteen, and when they are nearly hatched, or as soon as broody bantams are ready, he gives them to the bantams, about eight apiece. Thus they are less liable to be trampled.

At first he keeps the bantam and ducklings in a Hodgson's coop No. 5, with a little wire run. In the case of the young wood ducks and mandarins, which at first are determined to climb out, this run is covered. In five or six days they learn the call of the hen, after which they are not so anxious to leave her. One-half inch mesh is used for these small ducklings. He has large flower-pot saucers sunk in the ground, and lets the ducklings bathe from the first. In cold or wet weather he takes this water away, gives them drinking-water only in fonts, and mostly keeps them shut up in the coop.

When they are a few days old he removes the small run and lets them out in grassy yards about 8 feet square, one brood in each, using the same coop. He has large sheet- 
iron pans made to order, about 2 inches or more deep, which he sinks in the ground and fills with water. Whether he changes the ground during their growth he does not state, but obviously it is desirable to do so, certainly as often as there is any suggestion of fouling and when the vegetation is consumed. When two thirds grown, say eight weeks old, they are put, a number of broods together, into an enclosure at the corner of the pond which has been wired off for them. Here they are kept till fully matured, when they are let out into the pond with the older ducks.

In the experience of Mr. Cox, the young ducks usually breed when a year old, though in a few cases they wait two years. He notes that the young redheads regularly breed at the age of one year.

Feeding of Young Ducks. Fortunately, with most species of wild ducks the matter of the adequate feeding of the young presents no especial difficulties. The young of all our native Anatinæ, or river and pond ducks, except the wood duck, are easily raised, which is also true of some of the Fuligulinæ, the sea or diving ducks-namely, the redhead, canvasback, and the scaups. The others require special treatment.

In my own experimenting with wild ducks in the West, I have, by essentially the same feeding method, raised by hand, from egg to maturity, young of the following species: canvasback, redhead, lesser scaup, pintail, gadwall, shoveller, blue-winged teal, green-winged teal, and mallard. The baldpate, cinnamon teal, black and wood ducks come under the same category, only I did not then have any. Following is the method which I employed:

Preliminaries. When the ducklings are a day old and are removed to the coop or brooder, it is time for the first feed. Fine grit, mixed with a little ground charcoal, should 
be before them from the very first, also water in drinking fonts in which they can dip only their bills. It is astonishing how soaked and bedraggled small ducklings can get with little opportunity. The ordinary commercial chick fonts are apt to be too large at first. I found the best way was to take a small opened tin can, punch two holes on opposite sides about half an inch from the bottom, fill the can with water, and stand it reversed in a close-fitting, rather deep saucer or small dish. The can supplies water in the dish to the level of the holes in the can, and the ducklings can only insert their bills.

First Feeding. At the very first I began by giving them, in a small dish, a little hard-boiled egg, finely ground, mixed with cracker crumbs or rolled oats, just crumbly moist, and a little sand. They soon get to feeding. If one picks up a duckling and sticks its bill in the water, it likes the sensation and will experiment for itself, the others soon copying. To get them to eating, it seems to expedite matters to stick some of the egg against the tin water can, about as high as they can easily reach. Somehow they like to pick at things which are elevated, and they soon sample the egg, and usually are eating in the course of an hour. When they are with the hen, she will soon instruct them. The hen should be fed with grain, which the ducklings will not touch, to prevent her from gobbling up the egg. When the young have learned to eat they can be fed from a dish outside the coop, keeping the hen shut up behind the bars. Some persons throw food on the ground, but, especially where the same ground must be used for some time, it is better to use a dish or trough, keeping everything clean and sweet, which is most important.

Feed Moderately. Feeding at the very first should be often, a little at a time, about five times a day. While they 
are learning to eat they should be given plenty of time to get what they want. After a couple of days, when they have become the little hogs that they are, and fairly shovel down the food, four meals a day are enough, say at 6 and Io A. M., and 2 and 6 P. M., which is every four hours. They should have all they will eat with eagerness. After all begin to quit, and the weaker ones have had their chance, take away the dish. Water in the shade, and the grit and charcoal, should always be accessible.

Subsequent Feeding. When they had learned to eat, after the first day I fed the following: Mix three parts oatmeal or rolled oats and one part wild-duck meal, as prepared by dealers, scald with hot water, only crumbly moist, not sloppy. Then sprinkle in coarse, sharp sand, say a handful, or about 8 per cent. of the bulk. Grind up hard-boiled egg, shells and all, and add a moderate amount of this to the mixture, perhaps a quarter of the feed being egg. This can be continued for a week, and then the idea is to reduce and cut down the egg. When the ducklings are two weeks old egg can be given only once a day and be discontinued entirely when they are three weeks old.

Crissel. At this time may be begun the addition of crissel or high-grade beef scrap, at first just a little in the mash, say a small handful, perhaps ro per cent, then increasing it to 5 per cent., giving this but once a day.

Diluting. After the first week the proportion of wildduck meal in the mash may be increased, say two parts rolled oats to one part duck meal. This is on the theory that it is rather rich undiluted for small ducks. Later, besides the oatmeal, barley meal, bran, and middlings may be mixed in for economy. Barley meal tends to constipate and check diarrhoea, and a little may well be used from the first, the coarse grade preferably. 
Ants' Eggs or Angleworms. Another useful food, especially for the more delicate species, is the commercial ants' eggs, which helps to supply the natural insect element. Usually during the earlier stages I gave the ducklings some in the mash, on the Northwestern expeditions. When I ran out of it, however, the ducklings did just as well without it. It is expensive, so in practice I should use it mainly in starting young broods, and for the species hard to rear. Chopped angleworms make an excellent food for such purposes, and are usually easy to get.

Begin Grain. On the expeditions above-mentioned I ran out of duck meal, but got along all right by substituting cornmeal and bran, about half and half. Also, when the ducklings were three weeks old, I began giving them ground mixed grain, or commercial chick-grain, in the mash, a little at first, increasing the quantity as the ducks grew.

Green Food. Green vegetable food is also important from the first. About any succulent foliage or growth will do, according to what is accessible. Lettuce, or chopped garden stuff, if available, is always good. When I was in the wilds I used roots of water plants, the inside stems of reeds and rushes, and the like, finely chopped. On one expedition our best source for this supply was when we discovered areas of wild celery in the lake. We gathered this by bushels, and gave the entire plant to the young ducks, then half grown or more, in pans of water. They were eager for it, and devoured every part, from root to blossoms. This made their mid-day meal, for at the age of about six weeks they were cut down to three meals a day. They were kept on dry land, in pens, and for water had the drinking fonts, now of large poultry size, always before them, and the large pan of water, for celery and bathing, in the middle of the day. 
Various Receipts. As most kinds of ducklings are hardy and free from disease, they will thrive on quite a variety of feeding. The following methods of different successful raisers of ducks will be of interest for comparison.

Evans. Wallace Evans starts ducklings on egg-and-milk custard, cooked hard, and grated through a sieve. After a few days he mixes in his own prepared foods, such as he sells, finally substituting these entirely for egg. That green food, grit, and water are supplied, in all these methods, is, of course, understood.

Clark. Neil Clark uses the following for mallards: At first he beats up raw egg and mixes this with Spratt's wildduck meal, scalded. When the ducklings are one week old he adds a little bran and middlings. The egg is left out after ten days. At two weeks a little cornmeal is added, but sparingly, for too much is liable to cause convulsions. At three weeks a little crissel is begun, and increased from time to time. For green food he has used rape leaves a good deal, ground up in a hay-cutter, and given in a trough of water. After three weeks he adds wheat and cracked corn, increasing these cereals and cutting out the duck meal. $\mathrm{He}$ gets them on to grain when full grown, but gives some mash until along in the fall. Occasionally he puts grit in the food, to make sure they are getting enough to aid digestion.

Rogers. Harry T. Rogers, as with pheasants, starts ducklings on ground hard-boiled egg mixed with crumbs of cracker or parched bread. After a few days he begins, besides this, using a mash of middlings, a little bran, a little cornmeal, corn and oats ground together, and a little crissel, about one sixteenth. This mash he gives twice a day at first, alternating with the egg, and after a while gives it entirely, probably at about three weeks. 
Cook. Henry Cook for the first week uses stiff, grated custard as above. During the next week he mixes this with Spratt's wild-duck meal. Then he drops the custard, and feeds only the duck meal, scalded. At three weeks, or when the first feathers show, he begins to use chick-grain mixed with the duck meal. In regard to using the commercial duck meals full strength, some consider them too rich, but more dilute them for reasons of economy, finding that the ducklings do just as well in this way.

Seidler. Ludwig Seidler begins with a little egg, but soon feeds on barley meal and Spratt's wild-duck meal, half and half. He also adds oatmeal to the mash at two weeks. At three weeks he grinds up various grains quite fine, not much corn, not over one fifth, and mixes it with the mash, also a little crissel. Of the latter he uses a double handful to a fourteen-quart pail of mash, once a day, in the morning.

Barley Meal. The use of barley meal as an ingredient is particularly an English method. F. C. Walcott, on his visits to the English preserves, found the most successful breeders and experimenters using this, and very insistent upon it. They consider it especially important for marine ducks, and for the young of kinds hard to raise. Captain Oates in his book says that barley is apt to cause indigestion unless begun gradually. He suggests at first using four to one duck meal to barley meal, increasing to half and half, also diluting the barley meal with 25 per cent. of bran. A. G. MacVicar advises using the coarse grade, not the finely ground.

Cox. John A. Cox has a most original method, not generally applicable from lack of the material. He was very successful in raising rare kinds of young ducks by feeding them entirely at first on female horseshoe crabs, raw. These 
were cut open, and the ducklings greedily devoured the eggs and gelatinous matter inside - a cheap food, certainly! He kept the crab always before them, but avoided overfeeding by not replenishing till they had picked off every last vestige of meat, which kept them busy and gave exercise.

Finding that the young wood ducks and mandarins did not digest crab very well at first, he started these with the firm, grated custard. In a few days he added Spratt's meal, No. 5, which was rather coarse, so he ground it up finer. When they were about ten days old, he began giving them crab, sprinkling the custard and meal on the inside of the crab, and thus he got them eating it. These ducklings seem harder than most to learn to feed, and he found it helped them start to scatter a little grated custard on the grass and weeds, to stick to the stems. They hunt around among the vegetation, and pick up these bits better than from dishes. He has tried these methods for a number of years, and finds them always successful.

Starting Shy Ducklings. To add to his suggestion about starting ducklings which are reluctant to feed, especially small ducklings captured wild, I had some interesting experiences on the western expeditions. The young of the American golden-eye and the white-winged scoter were harder to start than the others. Sometimes also young lesser scaups were a little backward. I found it a good plan to put in with them one or two small ducklings of other kinds which were tame and had learned well how to eat. These were not enough to awe the timid ones or monopolize the food, but usually they soon taught the others proper table manners, which, for a duck, consist in being as greedy as possible.

Captured Ducklings. Small ducklings captured wild in the marshes were often a difficult problem. When put with 
other ducklings, some would learn to eat, but others would refuse food and exhaust themselves trying to escape. The young Anatinæ, or river ducks, usually got straightened out, but ducklings of the diving species, if captured when small, were hard to save. If they were caught older, when they had vitality to survive a period of "sulks," they came through all right. The best way with such, I found, was to feed live flies or other insects, especially in a pan of water. They were not interested, usually, unless the insects moved. Hence flies captured had to be crippled or soaked, so they could not take wing. They liked worms also. Sometimes, however, in the cold, rough weather of the region of Hudson's Bay, it was very difficult to find insects, frequently at critical times when they were badly needed. It would be well to keep worms on hand, and also flies in traps.

Ruddy Duck. One kind of duckling, the ruddy duck, I could do nothing with. This species is in many ways most peculiar. Though a small species, the eggs are larger than those of the mallard or canvasback. We hatched out one small brood and caught young from another. These ducklings are round, fat, helpless things, almost unable to stand up on land. During the early stage they seemed utterly stupid, refusing to eat or to notice anything. If found with the old duck in the marsh, unlike the spry skulking young of other species, they made little effort to escape, and allowed themselves to be picked up. At that time I had not had experience with these ducks difficult to rear, and could do nothing with them. They would not take food, and refused to swallow any that was put down their throats. I made an attempt to feed them in water, but had no insects, the weather being bad. Some died from chill, and none survived beyond the fifth day. Examination showed the abdominal cavity still full of yolk of egg, 
unabsorbed. Probably at first they should be kept quiet and warm, and then be allowed to swim in warm, shallow water, in which live insects could be put. Perhaps they might do better with a hen, and with patient handling get a start.

Food for Delicate Species. Experiment showed that ducklings of certain species, even when eating heartily, were not properly nourished by the artificial food which answered well for most kinds. Such species are the whitewinged scoter and the golden-eye. The little black-andwhite fellows, after learning to eat, seemed perpetually hungry. They would stay at the dish after the others had finished, and load themselves up. For all that they gained little. Stunted in growth, some died, and the few that got fledged were under-sized, and the last died when frost came. From the voracity of all the young ducks for insects, it is evident that this was what they needed. When I returned from the marshes and stepped into the duck pens, my clothing almost covered with mosquitoes, the ducklings of all kinds almost mobbed me, eating off the insects. This is what they live on in the sloughs-insect life, worms, and aquatic vegetation.

Besides catching insects for such ducklings, worms could be dug for them. These would have to be chopped up at first, if large. Maggots could also be raised to get them started. A little later chopped liver or meat could be fed to them, and some fish. W. W. Grant, who visited English preserves, writes that the keepers tempted shy ducklings with vermicelli in water, which resembles worms. The ordinary duck foods could also be given to supplement, finally even grain. Mr. Walcott found that in England, where experimenters keep various sea ducks, the adults at least do well on a varied diet, and eat grain and corn, 
even fish-eaters like mergansers, which would indicate that the young also may be considerably omnivorous.

Raising Eiders. Young eider ducks were raised successfully in Scotland for several seasons by Donald MacVicar, according to his son, A. G. MacVicar. The eggs were brought from the western Hebrides. He used to go to the shore, gather limpets and various shell-fish and crustacea, and pound them up for the young eiders, which thrived upon them. Doubtless this diet would be equally effective for other marine species or those hard to raise.

Further Details on Wood Duck. In reference to raising wood ducks, A. G. MacVicar has some further interesting details of method. For diet he emphasizes angleworms and lettuce, especially the former. These ducklings are nervous in temperament, and should be kept as quiet as possible, being shut in with the bantam in a covered run for at least the first week. If their claws are clipped slightly they cannot climb up boards or posts, though they still can scramble up wire. After the first week their claws become blunted naturally. He gives the brood a pan of water nearly filled with sand and pebbles, on warm days only. They dabble in this, and eat grit, to their good. He prefers cochin bantams for them, as they are good callers and keep chattering to the restless young, controlling them better than other kinds. Silkies, though quiet, are poor callers and thus not good disciplinarians. Moreover, their hairy plumage gets soaked from the young ducks, and is hard to dry.

Further Experiments. Some further details can be given as based on my experiments with hatching and rearing young wild ducks in Northwest Canada, and subsequently. The species there experimented with, of all of which eggs were secured, were canvasback, redhead, lesser 


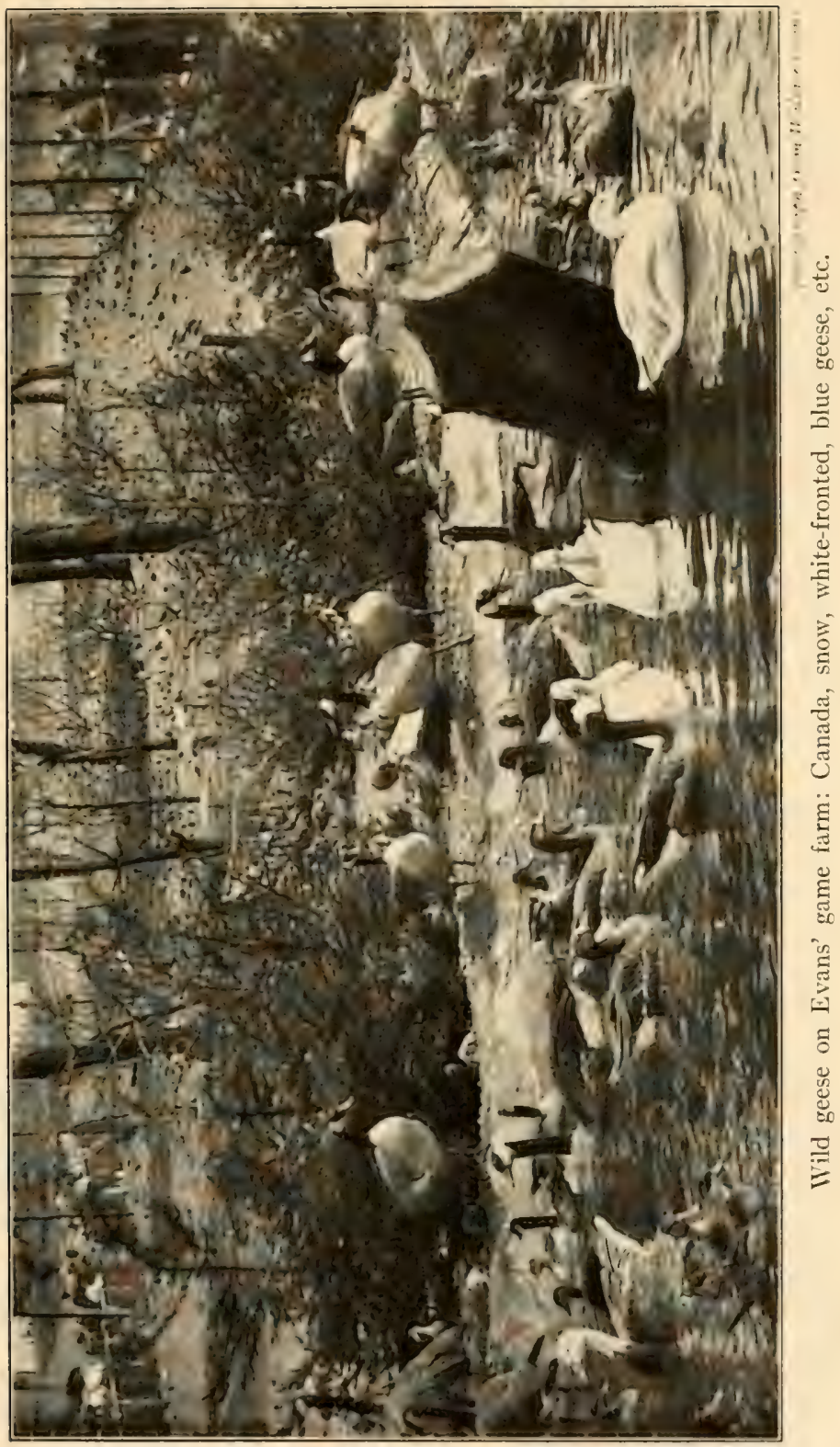




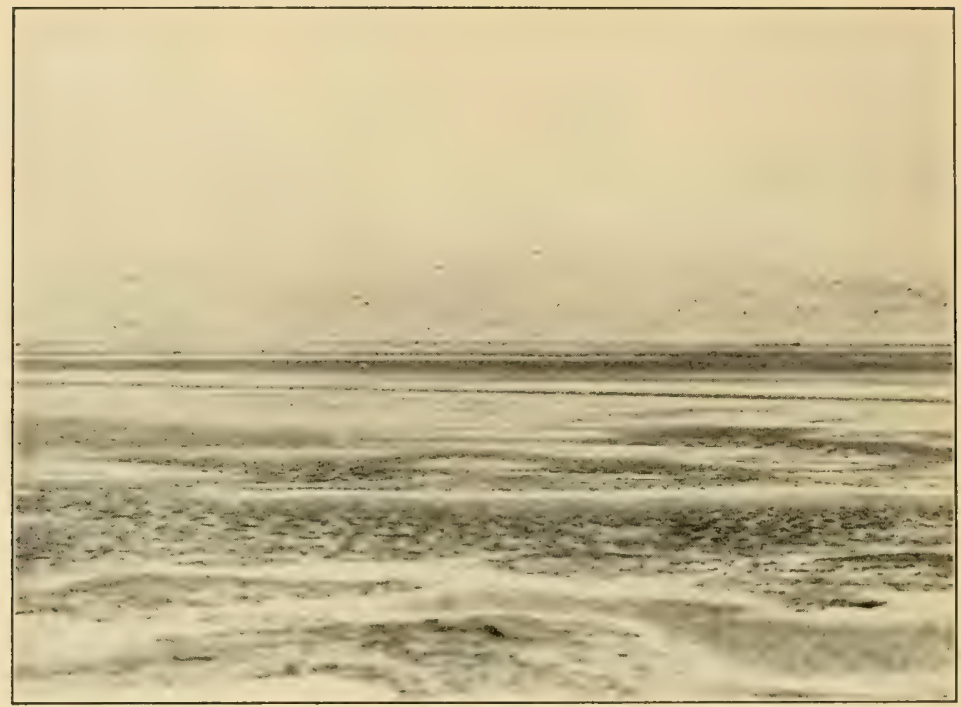

Great flock of blue geese on coast of Louisiana in winter at mouth of Mississippi River. Similar hordes of wildfowl throng on the protected areas

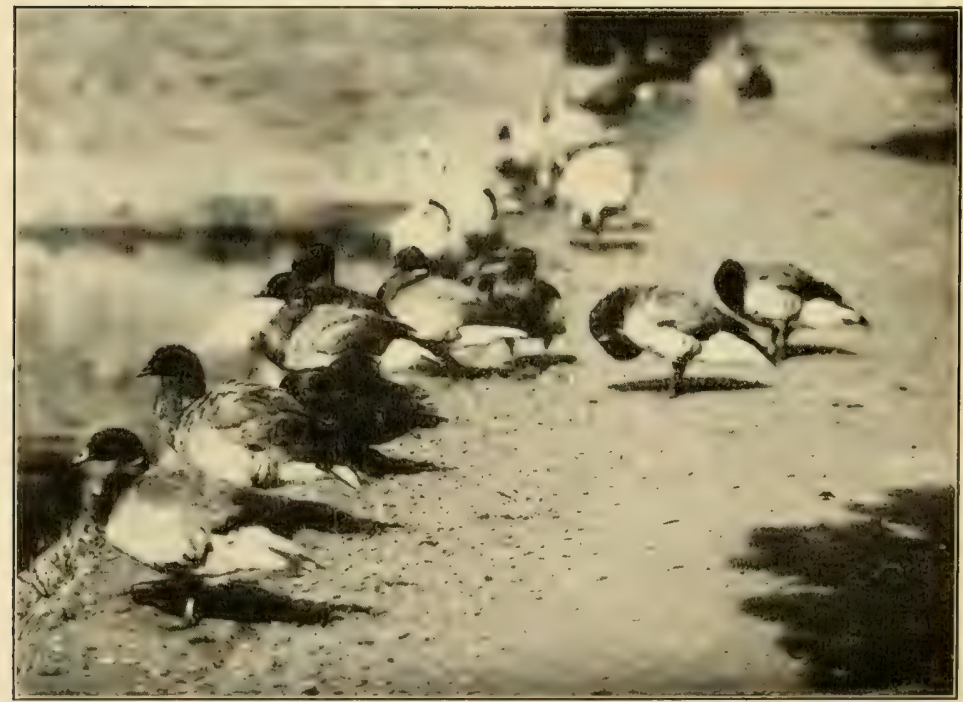

Brants on embankment at aviary of George D. Tilley 
scaup, white-winged scoter, ruddy duck, golden-eye, mallard, pintail, gadwall, shoveller, green-winged teal, and bluewinged teal-twelve species. The eggs of all of these hatched normally, all kinds equally well, averaging 92 per cent. The young of nine species, all but the scoter, goldeneye, and ruddy, were easily raised by the same method, described above.

Peculiarities of Species. The young shovellers and bluewinged teals seemed rather the most delicate of these nine, perhaps partly owing to their small size and being trampled by larger ducklings. On the other hand, the few greenwinged teals were more easily raised, and seemed to have so much vitality that nearly all grew up, though they were trampled and plucked almost bare. The pintails were just as hardy, and in two seasons we did not lose a single one. The mallards also were very hardy. Gadwalls did well, and are very nice ducks, easy to raise, though some mortality in winter made it appear that they are not so hardy as the three above mentioned. E. A. McIlhenny, however, is very successful in rearing young gadwalls and bluewinged teals. The redhead is easy to raise, hardy, and docile.

Canvasback. As far as I know our young canvasbacks were the first ever reared in captivity. They thrived on the ordinary food, were easily handled, and we raised a good number. Apparently they were of a more shy and nervous temperament than most of the others, decidedly more so than their near relatives, the redheads. When once frightened, it was hard to get them over it. One batch which had a bad fright in some simple way when small never forgot it, but would have a mad stampede if any one near them made a quick motion. When care was exercised, however, they were tame and gentle. During the period 
when they were feathering, they seemed to have a period of not growing well, and now and then one died from a "goinglight" trouble. A few even of the older young mallards had it. It was clearly caused by overcrowding, being kept on the same ground, which got foul, and not having access to water, these inconveniences being unavoidable through lack of dry ground and sudden great changes in the level of the big lake in storms, so that we could not keep the ducks along shore. The canvasback, with legs set far "aft," is an awkward bird on land, being built for the water, and handicapped when away from it. They all did well after their arrival in the East when turned out in ponds.

Other Diving Ducks. The scaup when first hatched is of a rather restless disposition, and runs around trying to get out. It is, moreover, great on the standing jump, and tries to vault over the fence. In a few days it quiets down and becomes very tame and docile. The golden-eye is particularly wild and restless. Like the wood duck and the southern tree ducks, it has claws especially designed for climbing, and gives much trouble in scaling fences, especially up wooden posts. The scoter is a big but mild and gentlemanly fellow, walking so upright that, in its blackand-white suit, it makes one think of an auk, or even a little man. The study of these young ducks is intensely interesting.

Two Expeditions. It is generally believed, and well established as a principle, that hand-raised young ducks of various species are docile and easy to breed. It was with the idea of securing a breeding-stock for experimentation, as well as for other studies of hatching, rearing, plumages, etc., that I made the two expeditions in I9I 2 and I9I3. One hundred young ducks were brought back the first time, and two hundred the second. Some fresh incomplete 
sets of ducks' eggs were shipped back East as a test, but none of them hatched. The only sure way was the one adopted: to hatch and rear the ducks on the spot, and bring them back in late summer or fall. The journeys were severe, being over 2,000 miles, and lasting four and five days. The first year the ducks were brought back when quite small, and the loss the first week after the journey, from exhaustion, amounted to nearly one quarter, mostly of the ducklings under three weeks old. Hardly any died that were over three weeks old at the start. On the next expedition the return was not made until late in August, when most of the ducks were fledged, and the loss was only nine.

The results of the breeding experiment with the first lot were negatived by the severe winter and imported epidemic already mentioned on the Childs-Walcott estate where the ducks were kept. Most of them were destroyed, and the survivors enfeebled for breeding the following season. Those of the second expedition have survived well, and a few young produced the next season, of pintail and redhead. I have also learned, from both these experiments, with confirmation from other sources, that young wild ducks under artificial conditions frequently fail to breed the first season, till they are two years old. The shock of the long journey, and other initial disadvantages, gave a set-back and made many of them skip laying the first season. Had the forcing methods previously described been employed, it might have made a difference. Some accidents reduced the stock, but the remainder now appear to be in fine condition, and there should be further results in the future.

\section{d. Other Conservation Methods}

Practical Conservation. It is coming to be a great source of pleasure for lovers of wild waterfowl to prepare a proper 
breeding-pond, keep a choice selected stock, and multiply these admirable native species. The young will breed even more readily than did their parents, and with a few generations the problem will be solved and a great need be met. Valuable species may be saved from extermination.

Species in Danger. A case in point is the exquisite wood duck. A decade ago it was characterized in a government publication as a "vanishing game-bird." Now it is being reared artificially by thousands, and in some localities it is again becoming abundant. Would that this could be said of all our waterfowl! The Labrador duck has long since become extinct. The species which at present may be most in danger, perhaps, is the pretty little bufflehead, or "butterball." Around Lake Winnipegosis, Manitoba, only a few years ago they were said to breed commonly. Though the country still remains wild, the duck is now almost unknown there, and I was not able to discover a single one. It is still said to be numerous west of the Rocky Mountains, but in the middle and eastern sections it has waned notably.

Breeding for Profit. It is a very laudable sort of enterprise for people to breed wild ducks for profit, particularly to be able to sell hand-reared waterfowl of all possible kinds for breeding-stock. Very many people will wish to be able to secure such stock, and for a long time prices will be high enough to make this very profitable. These species are so hardy and free from -epidemics that there is not the risk found in breeding the gallinaceous species.

Public Responsibility. Owners of large estates suitably located would find it most fascinating, as well as of public service, to breed various waterfowl, and, by the methods described, liberate numbers of the young which they raise, to breed in the wild state and help to restore these valuable species. Every State should have at least one suitable 


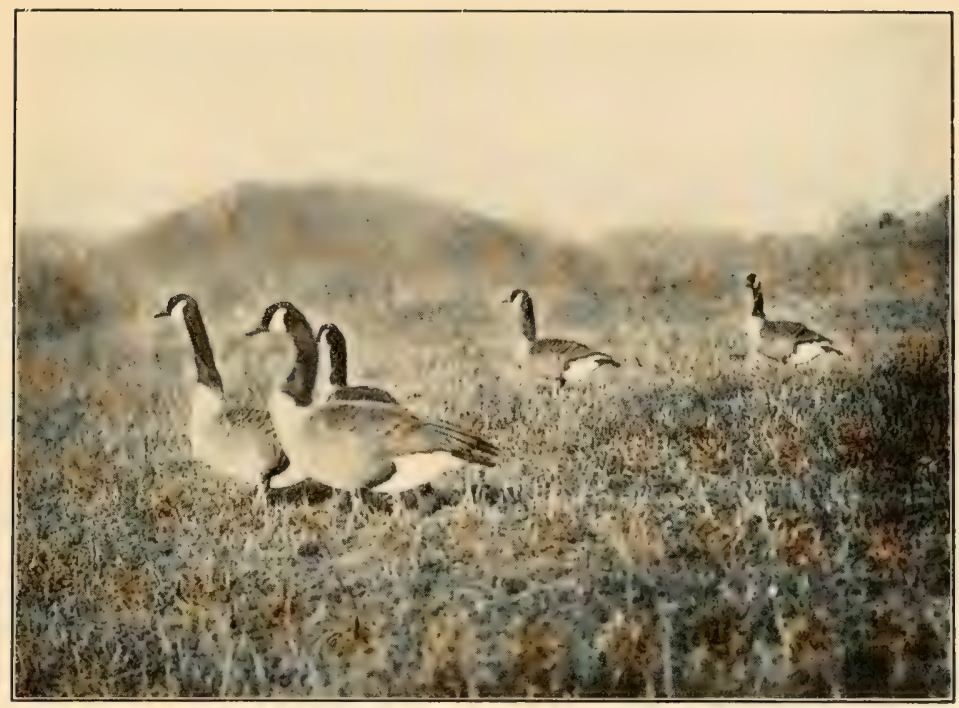

Family party of Canada geese raised by E. H. Austin in Connecticut

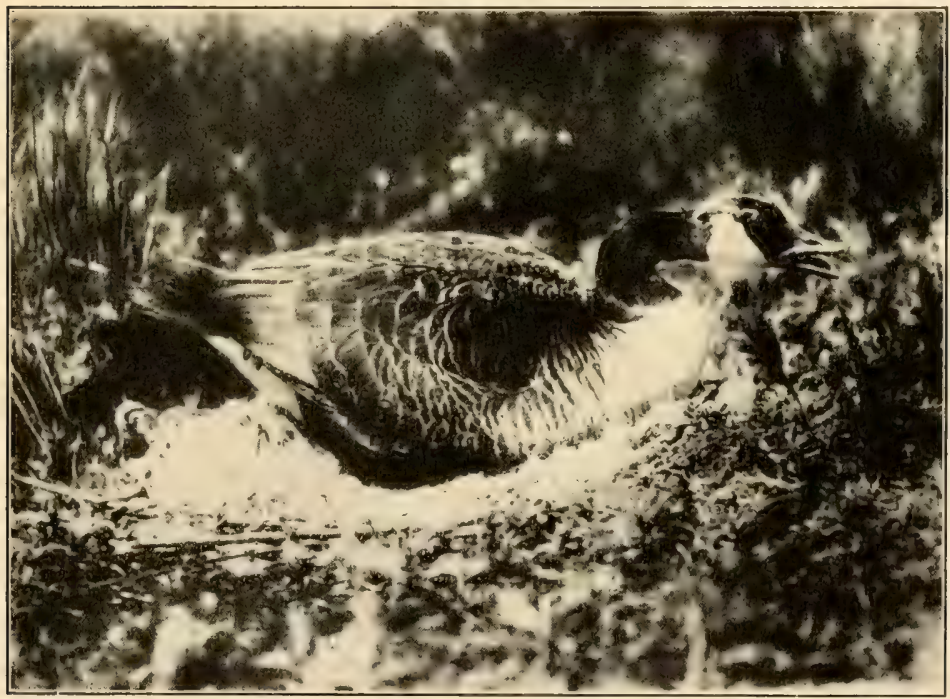

Canada goose incubating on farm of $\mathrm{E}$. H. Austin 


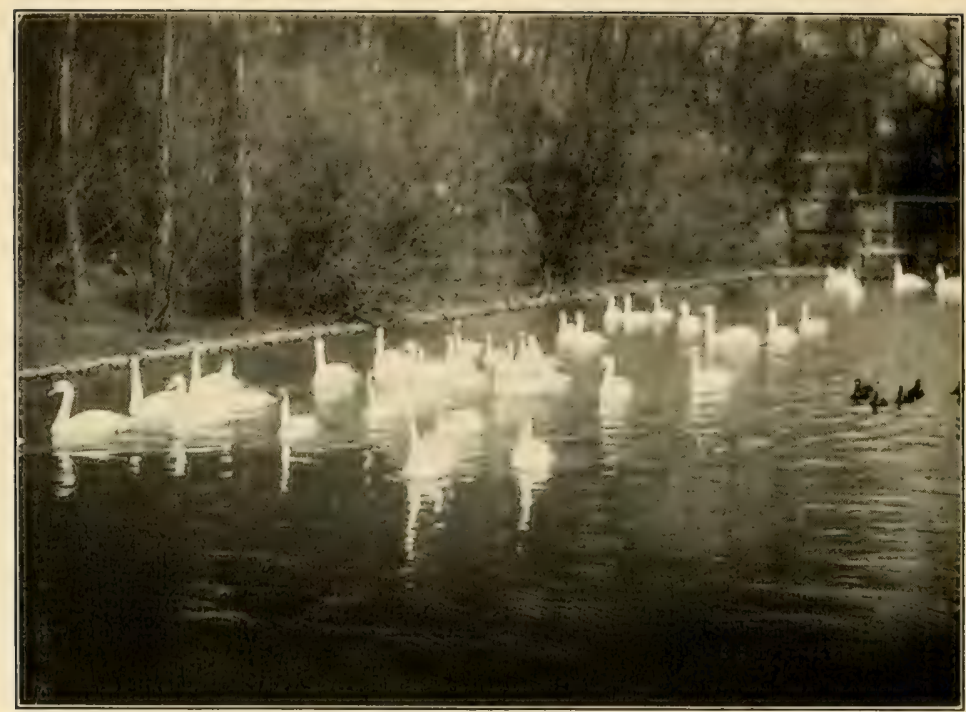

Photograph by H. K. Fo

Swans and ducks at George D. Tilley's aviary, Darien, Connecticut

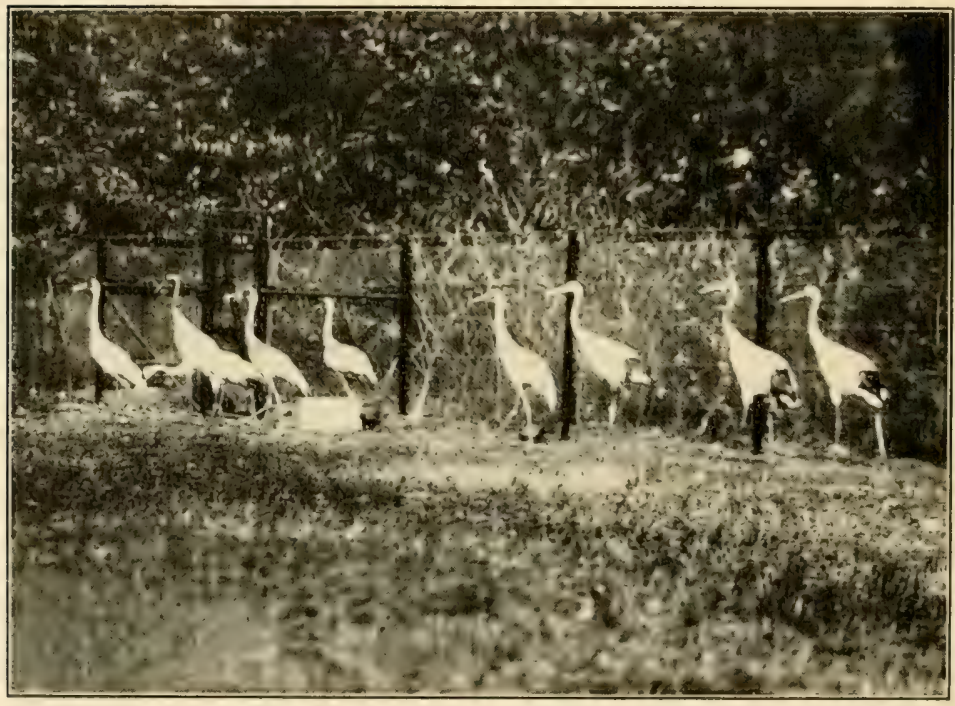

Cranes at aviary of George D. Tilley 
preserve and propagating farm for waterfowl, which would result in great good.

Planting Foods. Another very important line of effort which should be undertaken on large tracts is the establishing of food plants such as are naturally attractive to wild ducks. A great deal of interest in this matter is arising, and many landowners and State officials are experimenting with various species of water plants. With some kinds these efforts have already been successful. The planting of wild rice and wild celery are most in the public eye thus far, and have proved feasible. On the Walcott preserve wild celery has been established in at least one pond. There was trouble in starting wild rice on a pond where pinioned ducks were kept, as these ate up the seed before it could get a start. Commissioner Titcomb of Vermont reports success in his planting wild rice. Mr. Walcott finds it better to plant the roots in the spring than to sow seed in the fall.

Authorities. There is such a large amount of detail in connection with the description of various water plants which attract wildfowl and of the methods of starting them that it is impossible here to discuss it thoroughly. Instead I will refer those interested to two authoritative sources. Bulletin No. $5^{8}$ of the United States Department of Agriculture, entitled, "Five Important Wild-Duck Foods," by W. L. McAtee, describes the Delta duck potato, the wapato or duck potato, the chufa or nut-grass, the wild millet, and the banana water-lily. Some suggestions are also given for propagation.

Clyde B. Terrell, Oshkosh, Wisconsin, has gone very thoroughly into the subject. His father back in 1895 began to distribute wild-duck foods. The son grew up in the business, and has endorsements from Commissioner Tit- 
comb and other well-known people. His publications go into full detail in directing customers as to the sowing or planting of all the important wild-duck foods. Among those which he describes and handles are duck potato or wapato, wild celery, wild rice, peppergrass or watercress, American lotus or water chinquapin, nut-grass or chufa, blue duck millet, and others of the hardy potamogetons or pond weeds.

Wapato. To refer briefly to a few of these plants which are best known and of which ducks are fond, the wapato or duck potato is an excellent food, with its succulent bulbs and shoots, and spreads rapidly by bulbs, runners, and seeds. It grows in shallow water or on moist ground which is annually overflowed. It is best started by bulbs or by transplanting. Mr. Terrell advises about a thousand plants to the acre, six feet apart, in water a foot or less in depth. The proper time to plant is during the summer months.

Wild Celery. Wild celery is an eel grass, growing on mud or loam bottom in fresh or slightly brackish water from $\mathrm{I} \frac{1}{2}$ to 8 feet deep. It is a perennial, and produces seedpods after the second or third year from planting. It also spreads by runners. The best time to plant is in the fall before freezing, the natural time that it goes to seed. It can also be sown in spring if the seed is always kept moist and is stored in a cool place to prevent fermentation. The main reason why people have failed in sowing wild celery or wild rice is that if the seed of these water plants is ever allowed to dry, it will never germinate. About two or two and a half bushels of seed to the acre is Mr. Terrell's advice. He also suggests, especially where the bottom is rather hard, to mix clay with water, make little balls, as of putty, insert a little seed in each, and drop into the water. Plants, he says, should he set out about three feet apart, being set in 
firmly so they will not loosen and float to the top. Waters moving slowly suit it best, but it will grow in good-sized ponds where there is motion by the wind. The depth can be from 2 to 6 feet.

Wild Rice. Wild rice can be sown at 3 to 6 feet deep, on bottoms where there is from 3 to 6 inches of mud, using fifty to sixty pounds of seed to the acre, according to Mr. Terrell. Both grow well in slightly brackish water, but if the water is salt to the taste it is too salt for wild rice or celery. 


\section{CHAPTER X}

\section{WILD GEESE}

Readily Tamed. It is a surprise to many who consider wild geese the type of inherent wildness that in reality they are tamed more readily than almost any other wild bird, even than ducks, submitting even in shorter time and becoming more absolutely familiar. This is notably true of the common wild goose or Canada goose. Wing-tipped geese which are captured will in a short time become so tame that they will hardly get out of the way.

Anomaly. It is a curious anomaly, however, that while the Canada goose, as a species, breeds readily in captivity, all the other species of native wild geese are very hard to breed, notwithstanding the fact that they all become perfectly tame. The snow goose and the white-fronted goose have occasionally, though infrequently, bred successfully in captivity. Even when they lay eggs, these are seldom fertile. The common brant becomes very tame and mates, but $I$ have never learned of an instance of its even laying eggs in captivity. If the same analogy holds as with the ducks, the secret should lie in the matter of feeding and of furnishing suitable nesting-sites, and it ought to be possible to solve the problem. It has, however, been suggested to me as a possible explanation of failure to breed in captivity that some wildfowl are supposed to copulate habitually in the air, and thus might not when unable to fly. Such matters now attract so much popular interest that it is to be 184 
hoped that determined and carefully directed scientific experiments will be made. In view of the fact that pinioning evidently tends to retard breeding, the best way to begin such experiments would probably be to secure trapped or netted birds which have not been injured, and merely clip the wing, repeating this procedure in mid-summer and after completing the moult. If young should be secured, they could be pinioned when small without injury, the same as ducklings.

Keeping Geese. The actual keeping of wild geese is quite simple. All they need is a small pond, marsh, or section of a brook, enclosed with a wire fence. The fence should have I-inch mesh wire at the ground about 2 feet high, to keep out such vermin as minks, which are very destructive. The rest may be of ordinary coarse fencing, high enough to keep out dogs and foxes, at least 6 feet in all. A fair amount of grass land should be in the enclosure, as geese are great grazers. In fact vegetation and its roots, especially grass, forms the chief article of diet. They are also fed grain of any sort, or mixed, and this is all they require. Each fall plant part of the field where they breed with winter rye, which furnishes the best food for them and the young. No animal food is necessary, unless it should be found so in experiments as suggested above. Nor is shelter needed, unless it be a hedge or windbreak on shore, and perhaps a bower to stand under, which, like enough, they would not care to use. Usually they are able to keep a hole in the ice open all winter in which to swim, and they surely can with a little assistance in the worst cold-snaps. They are the hardiest of birds, and cold and storm have no terror for them.

Keep Separate. Geese are quarrelsome birds, and should be by themselves in the breeding season. During 
the fall and winter they can be on a pond with ducks if there is plenty of room, so the ducks can get out of the way of the geese. But in the breeding season geese should be separated by pairs. Particularly will they kill young of other species, and by their fighting will prevent timid ducks from breeding.

Breeding Quarters. They can be allowed to breed in the same enclosure where they winter. Though the ganders will quarrel considerably, there will usually be no serious trouble if there is enough ground so that each pair can nest quite a distance apart. Harry T. Rogers quotes Captain Bartlett, the Arctic explorer, as saying that in the far north he has seen geese nesting in colonies, the nests being quite near together, but these may not have been the Canada goose. At any rate they should have plenty of room. Ground such as an ordinary field or pasture will do, adjoining water.

Mating. Geese are naturally monogamous, and generally mate for life. Nevertheless, captured wild Canada geese, some of which surely must have been mated, after a time usually pair. In such cases the female is more reluctant to breed than the male, and is inclined to delay a couple of years or more before yielding, whereas the male will generally breed the following spring. Usually they begin when three years old, but individuals vary. Occasionally they breed when one year old, but some delay till the fourth or fifth year. There are occasionally those which never mate. They are independent about mating, and cannot be made to pair by shutting up two together. Naturally the young reared in captivity make the best breeding-stock.

A. G. MacVicar once sent a pair of Canada geese to England which did not breed for eight years, when they raised a brood of seven. The following year there were three nests, as some of the young bred when a year old. 
Nesting. Breeding occurs very early in the season, the date depending upon the latitude. On the coast of Virginia, J. W. Whealton's geese are said to lay in February. In the region of New York City and Connecticut they usually lay early in April, though sometimes later in the month in backward seasons. In fact they breed too early, for the eggs are often frozen or flooded. The pairs are fussy about selecting the exact locations for their nesting-sites, and the ganders fight. The first year that geese nest they are timid, and must not be disturbed while they are preparing to nest. When once they select a spot, they use it boldly every year without further trouble. Usually no attempt is made to conceal the nest, though it may be under a tree or bush, or beside a trunk or log. I have seen the goose sitting on her nest out in an open meadow, the most conspicuous object in the landscape. The gander remains constantly on guard, seldom going off more than a few yards. Grain should be placed near him, as some ganders will almost starve rather than leave, sometimes getting so weak they can hardly stand up. In case of intrusion they can put up quite a fight, and they strike powerful blows with their wings. The eggs are from four to seven, five being the most usual number.

Evans Method. Wallace Evans breeds a considerable number of Canada geese. They all live on one good-sized pond, and make their nests some distance apart, and back from the shore. They have access to a grove in the rear, and some of them nest in these woods.

Young. Assuming that the place has plenty of grass and green vegetation, the goslings require no care or feeding other than by the parents. Most breeders do not feed the young at all until they are old enough to eat the grain given to the parents. At first they do not touch it, but 
begin when they are getting their feathers. In the case of a pair in a small yard, it would be safe to offer food, the same as for ducklings, though usually they will not touch it, unless hard pressed. Their natural diet seems to be largely from grazing, and they industriously eat grass and dig up roots. They are hardy, too, and usually thrive without trouble. There should also be shade accessible, either bushes or prepared shelters, as without such they are quite liable to succumb.

Goose Farming. The most successful breeder of wild geese on a large scale in this country is J. W. Whealton, on Chincoteague Island, Virginia. This is a large island, seven by two and one half miles, on a marshy coast, surrounded by shallow bays and sounds which are natural feeding grounds and are resorted to in fall and winter by great numbers of fowl. Many years ago Doctor Whealton picked up some wounded wild Canada geese, as well as ducks, and started to breed them. In course of time he has worked out a most interesting and successful system of wild-goose farming. It is quite unique, but could probably be duplicated on coastal islands under somewhat similar conditions. I have not yet visited the island, but this has been done by C. William Beebe, of the New York Zoölogical Park, who in the New York Zoölogical Society Bulletin for October, I909, has presented a most informing account of the methods employed, from which I glean the following information:

The Stock. Beginning with one pair originally, his stock of Canada geese alone was at that time, I909, some 450 birds. Inbreeding was avoided by introducing wild captive ganders from time to time, which breed at once with the tamed females, whereas wild females might not breed for years. These geese, in flocks of from four to fifty, 


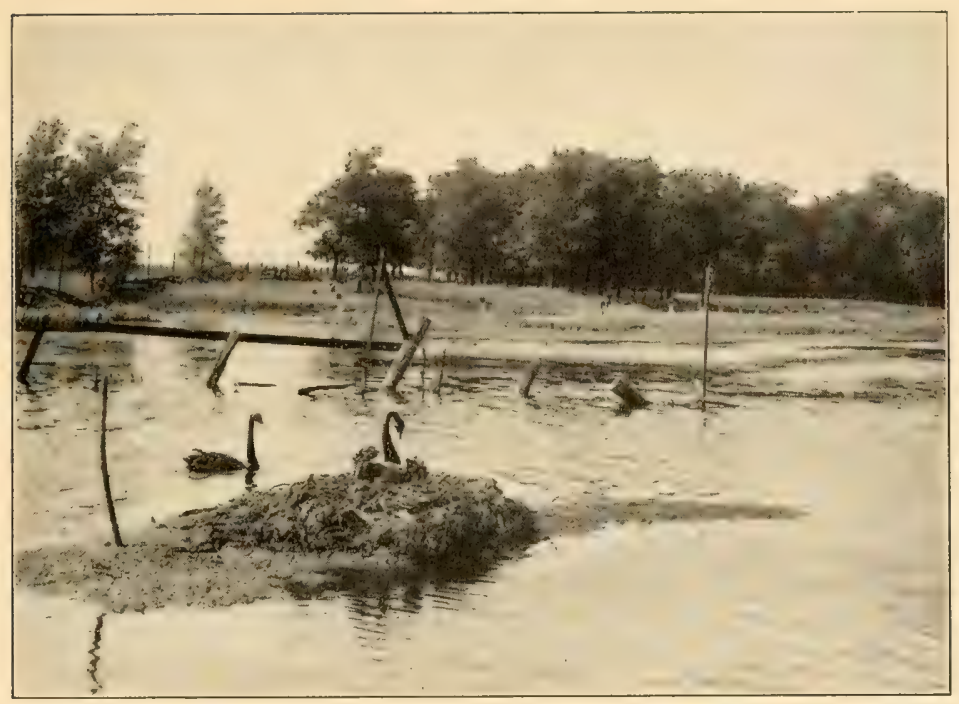

Photograph from Wallice Evans

Black swans nesting on Evans' Game Farm

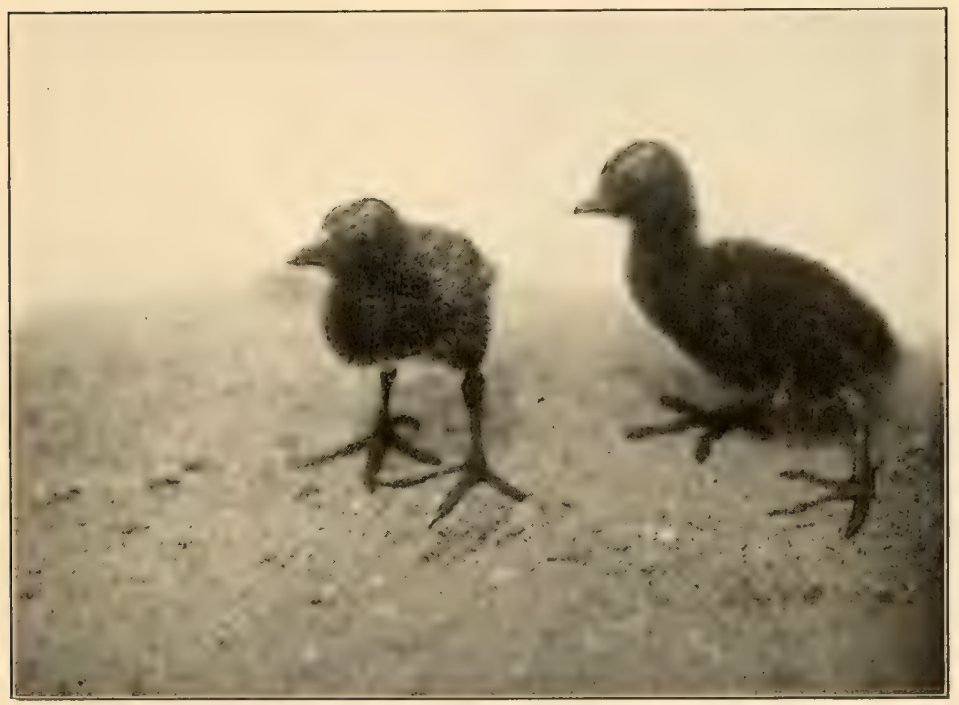

Young coots or "mud-hens," raised on Manitoba expedition 


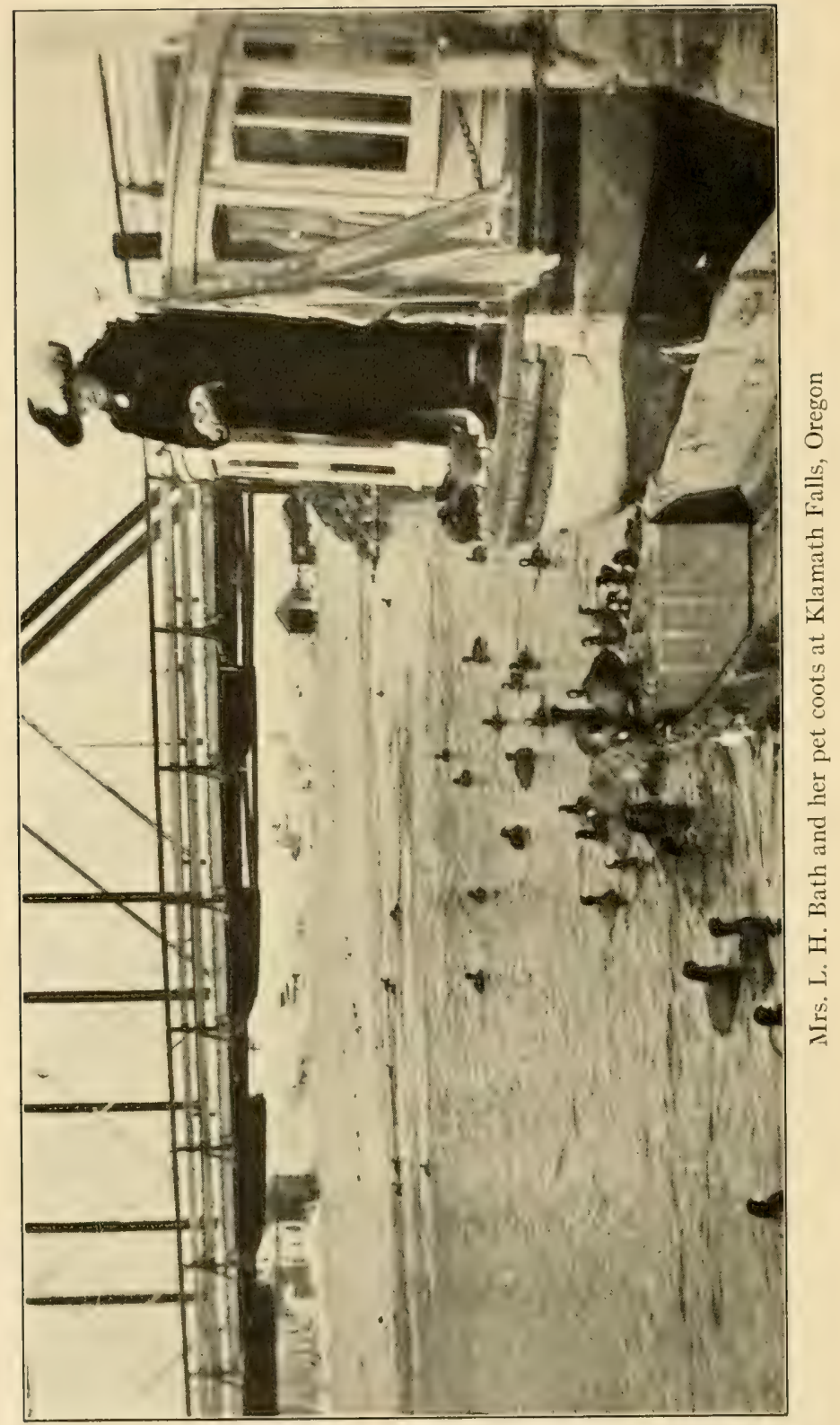


are allowed to roam over this and adjacent islands and waters. Their principal feeding-ground is out on the bays, where they eat eel-grass and sea-lettuce, pulling up plants by the roots at low tide. They get fat on this diet. A little grain is given now and then to keep them tame. Also they are supplied with fresh water in winter.

Mating. On the first warm days in March those not already paired for life secure partners, and there is a general mating. Geese nest in the same spot every year, so these performances take place near the fenced pastures where the goose community is accustomed to breed. They are let in one pair at a time, that they may select location with the least friction, and then they will hold it. There is much quarrelling, however, and some pairs are broken up. The geese are fed grain for awhilebeforelaying, till they are turned out to roam with the young when these are quite large. Neither young nor old are troubled with lice, and it is thought that their feathers contain some element which keeps the pests off.

Breeding-grounds. The breeding-field or paddock is an enclosure of 25 to 30 acres, and has around it a board fence 3 feet high. About 75 pairs breed here, and raise 200 to 300 young annually. There are a few small fresh-water marshes in the enclosure, and here numerous hummocks are thrown up, which are soon covered with grass and low brush. These are favourite nest-sites, and five to seven eggs are laid by each pair. They nest but once each season. When the young hatch they are pinioned and turned into another pasture with the parents. If the goose dies, the gander will rear the young alone, but, curiously, the mother either cannot or will not rear the young if the gander should be removed. Some of these birds are already fifty years old. They breed better when thirty than when even ten 
years old. In spring one familiar with them can tell which will lay by the condition of fatty deposits visible under the skin. If considerable yellow fat is visible about the abdomen, there is no likelihood of eggs that season.

Young Remain. When Mr. Beebe wrote the article quoted he stated that the young geese were all pinioned. F. C. Walcott, however, says that now they are allowed to grow up without pinioning, and have full power of flight. Nevertheless, they do not attempt to migrate away, though flocks of wild geese sometimes associate with them on the bays where they feed. In like manner it is reported that in England Canada geese are bred in numbers on large estates, and similarly liberated. They remain there the year around, breeding in the natural state, and they and their offspring form large flocks.

When one month old they are given their liberty. Usually they do not breed until three years old. They mate for life, and invariably return to the nest occupied the previous spring. A pair, as a rule, will not allow another pair to nest within fifty to one hundred yards. Yet they are erratic in this respect, some letting others nest near, others being very jealous. In summer they feed mostly on the land, in small parties, but in winter they seek their living out on the bays and flats.

On the island foxes are numerous, but do little harm. Minks are abundant and destructive. Dogs are the worst pest. In I 908 twenty-six dogs were shot in the act of killing geese. One year a pair of snow geese hatched four young, the only instance in which this species had bred successfully. When these goslings were half grown they were killed by dogs. Speaking of the snow geese, Doctor Whealton has got a cross from the snow gander and the common goose, and bred back into essentially pure snow geese in several generations. 
Plucking Feathers. They have a system on this island of plucking the geese for commercial purposes. This is done three or four times a year, beginning about the first of May. All contour feathers, except of the wings, tail, and neck are taken. The average bird yields one third of a pound. The down is left, only feathers being used. The first picking occurs when the geese are tending young. This mostly stops the fighting which always goes on at this time, reducing the strength and pugnacity of the birds, besides making it less easy for combatants to get hold. The first and last pluckings yield the heaviest feathers, those taken in mid-summer being lighter. These operations occur about once every seven weeks. 


\section{CHAPTER XI}

\section{SWANS}

Swans are bred and handled much like geese. Food is equally simple, consisting only of grain and what they pick up in grazing. As with geese, under similar conditions, the young do not need to be fed. There is even more trouble about fighting than with geese. The males are murderous fellows. Even a man is in danger from them, and a blow from a swan's wing can even break one's leg. Some might consider this a joke, but I advise them to take no chances. Once when I was talking with the owner of an estate where waterfowl were kept, a swan sidled up to me, and I took no notice. Suddenly the creature raised its wing and hit me a rap across the shin that made the bone ache for a week after. I have an idea that the bone may have been slightly cracked.

Hard to Mate. At best they are troublesome birds to mate. With some species the sexes cannot surely be distinguished, and, if two males happen to be secured, there is apt to be murder. Sometimes swans will not mate at all. When they do mate, each pair must beconfined in a separate enclosure, unless the area of pond and shore is considerable. They are fond of nesting on small islands.

Treatment Simple. Mr. Whealton breeds the trumpeter mute and black swans, and is reported by Mr. Walcott to have bred the whooping swan once. They are simply turned out in pairs, separated from each other. Each enclosure has plenty of forage, but the birds are fed daily on 
wheat and corn. They breed even earlier than the geese. One year a pair of black swans made a nest in February when there was snow on the ground and the ponds were frozen up tight. When the young hatched, a hole in the ice had to be cut for them, but they survived the icy baths, and the four young were reared.

Cox's Method. Mr. Cox bred swans at East Brewster, Massachusetts, on Cape Cod, raised young, and had quite a flock. Each pair had to be kept separate, in a fenced area of meadow, with a brook flowing through it. They fed mostly on vegetation helped out with grain. The young were given no food till they joined their parents in the grain ration. 


\section{CHAPTER XII}

\section{WADING BIRDS}

It is a pity that most birds of this class are not amenable to artificial aids to increase their numbers, particularly the Limicolæ or shore-birds. These birds are largely insectivorous, and all are migratory. The only feasible way to increase them is to secure their adequate protection. In another publication I have noted my experience with a captive woodcock. It weighed six ounces, and ate each day from eight to twelve ounces of earthworms, which was up to twice its own weight of food a day. Being unable to spend so much time digging worms, I hired boys, who became known as my "worm brigade." After a month I was glad to liberate the bird. Imagine raising woodcocks like pheasants!

Coot or Mud-hen. One species of wader, however, I found very adaptable, the American coot or mud-hen. This bird, of the rail tribe, found in numbers in our marshes, and breeding abundantly in the sloughs of the West, is the size of a small duck, and can be handled much in the same way. It is prolific, laying from eight to sixteen smallish eggs, dotted with small black specks, in a floating nest of rush stems, built among the reeds or other water-plants. In the summer of $\mathrm{I}_{\mathrm{I}} \mathrm{I}_{3}$, in northern Manitoba, as an experiment I hatched some of their eggs in an incubator and raised a number of young to maturity in brooders. They are most peculiar-looking creatures, having black down, with red 
hairs growing out from the neck, and are baldheaded. At first they are rather feeble, but they soon become nimble, and are exceedingly tame. They have a raucous voice, and use it vigorously in demanding food, running at the caretaker with insistent shrieks, pecking his hands or feet, and fairly mobbing him. We raised them with the ducks, and, bold as these were, the coots were always in the forefront and got all that was coming to them. They have sharp bills, and in one or two cases hurt small ducklings, though usually they were harmless. All in all they were very amusing. They thrived on the same food as the young ducks, though they were a little harder to start at the very first, owing to their small size.

When they are grown up they swim in the pond with the ducks, and are treated as part of the flock. They are hardy, and stand winter weather in the open as well as the ducks. Now and then I see a few in collections of waterfowl on private estates. From what I have seen of them I think they could be bred and perhaps established in the wild state, especially should it prove that the young would return after migrating.

Henry Cook, on his duck pond already described, has a few of these birds. If the pond were marshy they would probably breed, for in one case, even as it was, a pair built a nest of sticks, since there were no rush stems, out in the open water by a fence, and laid several eggs, but finally quit. In a suitable pond, and with proper feeding before the breeding season, they would probably breed successfully. In such case they should be allowed to rear their own young. When the young were large they could be driven into an enclosure and pinioned or wing-clipped.

Gallinules. Very likely the gallinules, of which we have the Florida and purple gallinule, could be propagated in the 
same way, though it is doubtful if they could endure a Northern winter like the coot, though perhaps with shelter in winter they might do well.

Cranes. The keeping of cranes on estates is becoming quite a fashion, and it is said that there are nineteen species known to be amenable to artificial conditions. These birds are easily tamed and fed, and are of striking and interesting appearance, as, with dignified carriage, they stalk about. The usual practice is to pinion them and let them range in large fenced enclosures. Most kinds are hardy and can endure cold weather. All they need for shelter is an open shed or merely a thatch of evergreen boughs, with a windbreak to the north and west. The food requirements are simple, merely grain of any sorts. L. S. Crandall, of the New York Zoölogical Park, recommends also now and then a feed of raw fish. They also graze a good deal and hunt for insects.

Breeding. Pinioned cranes, especially if kept in small enclosures, usually do not breed. When occasionally they produce eggs these are usually infertile. This is the experience at the above Park, as stated by Mr. Crandall. One pair there laid infertile eggs, and an unmated female for years produced such eggs each season. He states also that the young are hard to raise, because for about the first three weeks they will not eat unless fed by the parents, who catch insects for them and feed them. The only likely way to make cranes breed is to give them access to a considerable tract of grass, where they can secure plenty of insect life and get exercise.

An article by Maurice Portal in the English magazine, Country Life, April 4, I9I4, quotes facts which indicate that cranes are more likely to breed successfully if kept unpinioned and given liberty. As they are expensive, few 


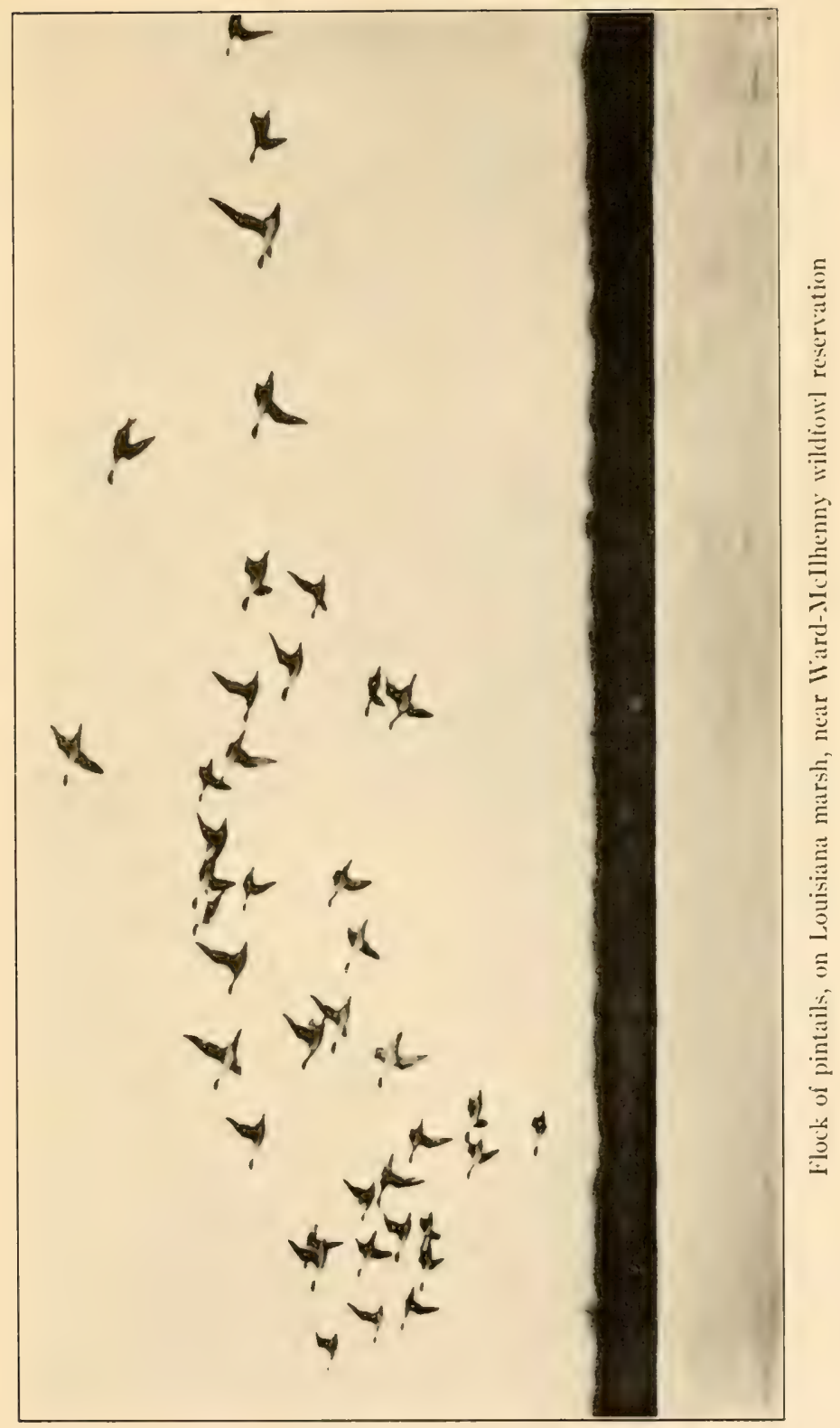




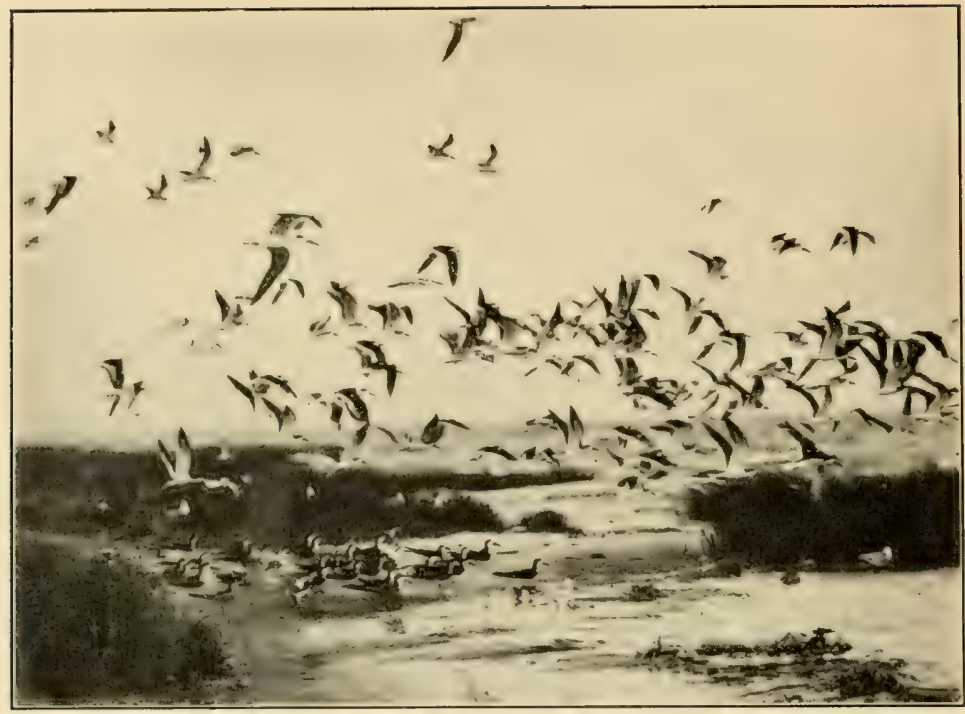

Black skimmers on Breton Island Reservation, Louisiana, patrolled by The National Association of Audubon Societies

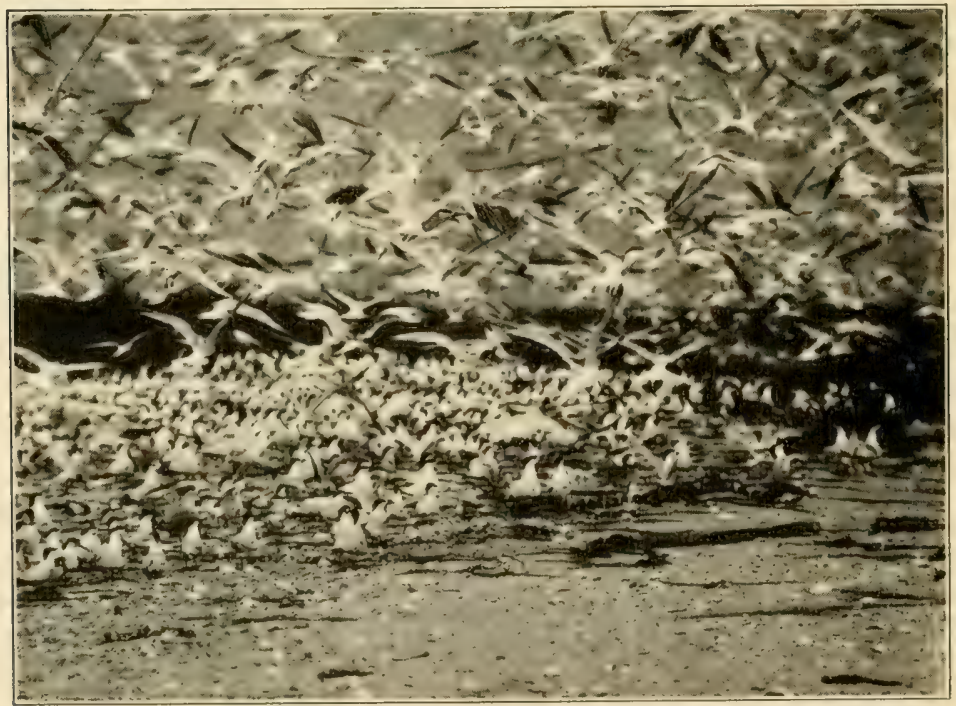

Breeding royal terns flourishing under protection, Breton Island Reservation, Louisiana 
people care to run the risk. He cites two instances in which a pair of cranes bred in England and raised young. In one of these cases, of demoiselle cranes, the young were liberated, but they left the next spring and were never heard from. In I906 six Soudan crowned cranes were imported to England. They were not pinioned and were allowed full freedom, yet did not leave, and stood the winters well. Not until I9I 2 did one pair breed, producing three young, which were killed by a weasel. The following year the same pair again had three young, which died when a month old, it was thought because insects were scarce.

Herons. The idea sometimes put forth of running heron or egret "farms" to produce aigrette plumes for market is simply a fake to deceive the ignorant and serve as a blind for a cruel and nefarious business, a salve for tender consciences. The enormous appetite of herons for fish would make the thing commercially unprofitable, even if herons were induced to breed in captivity. E. A. McIlhenny is experimenting now with herons in a large flying cage, to see if they will breed in captivity. He says that each bird eats $I \frac{1}{2}$ pounds of fish a day on the average, and it has cost $\$$ I 2 per year to feed each bird.

Egret Farm Fake. T. Gilbert Pearson has carefully run to earth this egret farm myth, and exposed the sham. He has secured affidavits from many well-known travellers and explorers in the tropics who have visited many great breeding colonies. They unite in testifying that they have never seen or heard of a bona fide egret farm. The nearest approach to such a thing was when some men "protected" an egret rookery from other hunters that they might shoot the birds themselves.

Starting a Heronry. Under suitable natural conditions it is possible, though difficult, to start a heronry on the de- 
sired tract of swampy land, though it must be said few would think it worth while, or be willing to go to the great 1rouble necessary. The only example of this which I can cite is that of Mr. McIlhenny, just quoted, of Avery Island, Louisiana, who is an ardent naturalist. Desiring to have a heron colony at his home, he took young herons from nests and raised them by hand. These grew up very tame, migrated away for the winter, but returned the next spring and nested in the swamp close to the house. In course of time others joined them and bred, and an immense colony, aggregating many thousands of various kinds of herons, has been permanently established. They build their nests of sticks and twigs, and so large a number were destroying the trees. Mr. McIlhenny therefore began to provide them with building material, and this spring, I9I5, he has had carted in nineteen wagonloads of suitable twigs which the herons eagerly appropiated. This, however, is a very different matter from breeding herons in close confinement so that they could be caught and have their plumes clipped. It should also be borne in mind that plume feathers naturally dropped are worn out, "dead," and are of little commercial value. Even thus they are seldom found. In all my own visits to egret rookeries I have found just one aigrette feather naturally discarded. 


\section{CHAPTER XIII}

\section{REFUGES AND PROTECTED COLONIES}

Attracting Water-birds. In conjunction with the heron colony just mentioned, Mr. McIlhenny has a pond with pinioned wild ducks and geese as a nucleus. No shooting, of course, is permitted, and a host of other wildfowl are attracted in here to spend the winter and feast upon the hospitality of the owner. Some like it so well that they decide not to migrate North, but remain to breed. This sort of thing, in localities naturally attractive to waterfowl, could and should be done more and more, and this instance serves as an instructive practical example.

Wildfowl Reservations. A splendid movement, which has gathered momentum in the past few years, is the establishment of reservations on tracts of marsh and swamp land, unsuited to human occupancy, where wildfowl can gather and feed in winter and be safe from molestation. Well known already are the Ward-McIlhenny tract in Louisiana and that of Marsh Island, donated by Mrs. Russell Sage. Latterly comes the vast tract under the Rockefeller Foundation adjoining the above in this great marsh region. Together these comprise some 500 square miles, and extend for 75 miles along the coast. Already ducks have begun to breed there in considerable numbers, according to Mr. McIlhennythe blue-winged teal, gadwall, black duck, and mallard, and probably others in time will join them. Similar measures should be taken, even if on a smaller scale, in every State of 
the Union. The wildfowl should also be protected on their breeding-grounds, wherever these are located. Some breed in the United States, but most of them in the northwest provinces of Canada, and it is ardently to be hoped that through treaties with our neighbours, both on the north and south, a comprehensive continental protection and conservation of this important and valuable asset may be made possible.

Water-bird Breeding Colonies. This splendid movement dates its beginning from the activities of the National Association of Audubon Societies in protecting the breeding colonies of water-birds, pelicans, gulls, terns, herons, and others, first along the Atlantic Coast, and then more widely. The good work was taken up by the Government, and then protected colonies were made Government reservations, until now there are nearly sixty of such areas under Federal protection at the most strategic points, scattered widely over the country. Since Government appropriations are often lacking to hire wardens and secure boats for patrol, the National Association of Audubon Societies still furnishes wardens and boats for the service of the Government. Various rookeries of egrets and other water-birds which are not Government reservations are guarded by the National Association and have been saved from devastation. Thousands of individuals all over the country are now protecting birds on their own land. The nation is at last becoming awakened to the value and importance of wild-bird life and the need for its conservation, though there is yet much more to be accomplished. 
PART III

METHODS WITH THE SMALLER LAND BIRDS 



\section{CHAPTER XIV}

\section{PRELIMINARY MATTERS}

Title. There seems to be no very good name for the class of birds now to be discussed. Some call them songbirds, but they do not all sing. The term insectivorous birds is not exact, for many other species eat insects. The above title at any rate will suggest what is meant.

Birds That Appeal. While certain of these species inhabit the woods, the great majority are attracted to the haunts of man partly owing to the greater abundance of food, especially insects, which they find there, and also to a degree of immunity from certain natural enemies, particularly predacious birds and some wild animals. Thus they come into especially intimate relations with man. They are the forms of wild life most easily observed, and represent bird life more than any others to the average person. To children they are about the only wild animals, except squirrels or rabbits, that they are apt to see, and, since every child is naturally interested in wild animals, the birds can be made to mean very much to them. There are many adults, especially ladies, who do not go afield, but who watch and enjoy such birds as are readily accessible about the house or garden. The average man, rightly minded, enjoys the presence of wild birds about his home. In fact, within the last few years there has grown an interest in attracting and propagating these songsters and others which has become one of the most popular customs of the day. It may 
be in part a fad or fashion, but it is much more a manifestation of the call of the wild which is fundamental in human nature.

Economic Value. Even if birds have no such attractiveness, it would still be essential to take measures for their increase because of their vital importance to agriculture, in destroying and keeping in check the hordes of insects which otherwise would devastate the land. This is fully recognized, and need not be discussed.

Size No Criterion. The point of view should be widely inculcated that interest in a bird should not be in proportion to its size. To contemn small birds is the materialistic attitude of the pot-hunter, who sees nothing in a bird or wild creature but the amount of meat. Once I was showing a man a set of coloured photographs of wild birds in action that I considered especially fine. With each succeeding picture came the inquiry whether or not that bird was good to eat. If it was, the man expressed pleasure; if not, he gave a grunt of disgust. I closed the interview as soon as possible. Here I would enter a plea for an intensive interest in birds. No one is more fond than I am of a wild goose or a grouse, or a great flight of wild ducks. None the less some tiny bird gives me just as real a delight. When, say, searching about in woods or swamp, I flush from its carefully hidden nest some rare warbler, a gem of bird life, the sensation is thrilling. Some such feeling is aroused by close contact, perhaps at the bird lunch-counter, with some bit of animated vivacity, like a chickadee or nuthatch, with its sparkling eyes and quaint call. All forms of bird life are well worth while, and one will be greatly the gainer to cultivate the faculty of getting pleasure from every bird that crosses his pathway.

Von Berlepsch Experiment. The notable and classic 


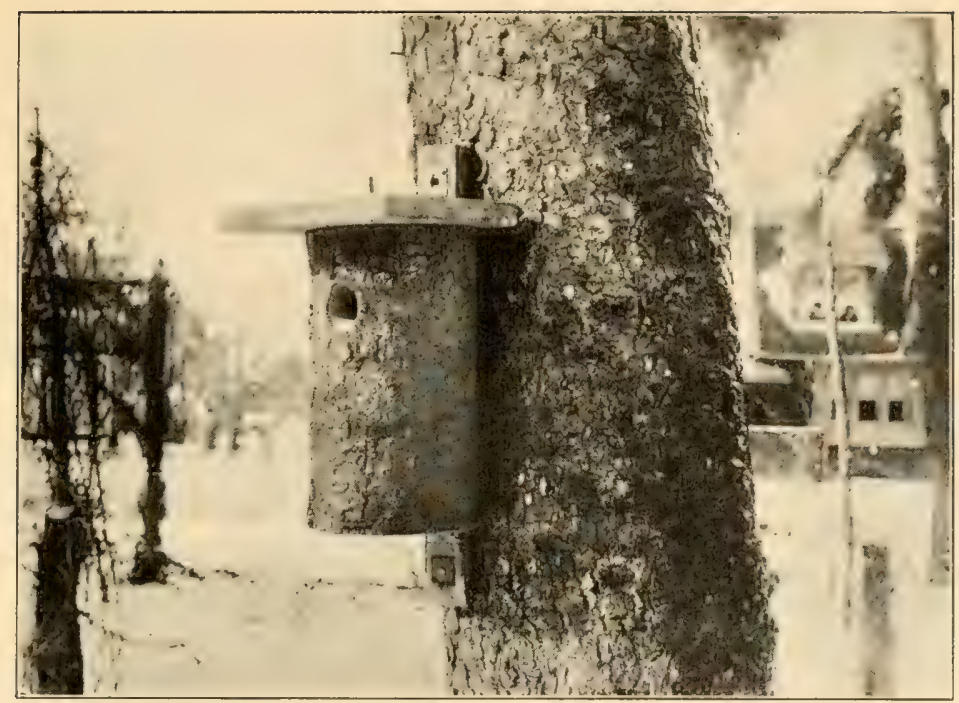

Von Berlepsch-model nesting-box

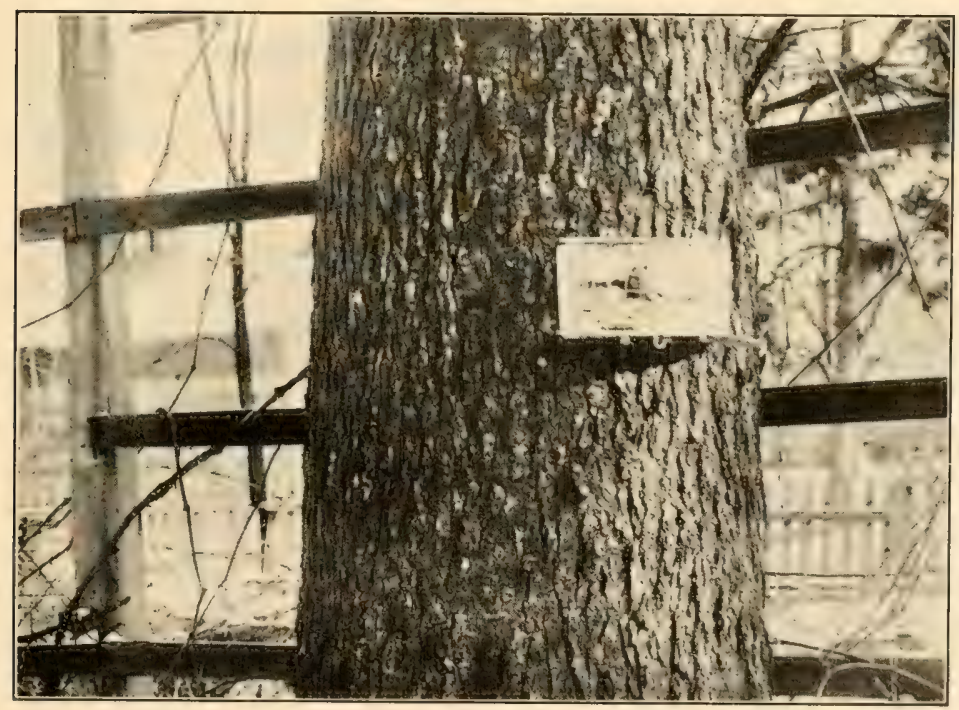

Suet basket in position 


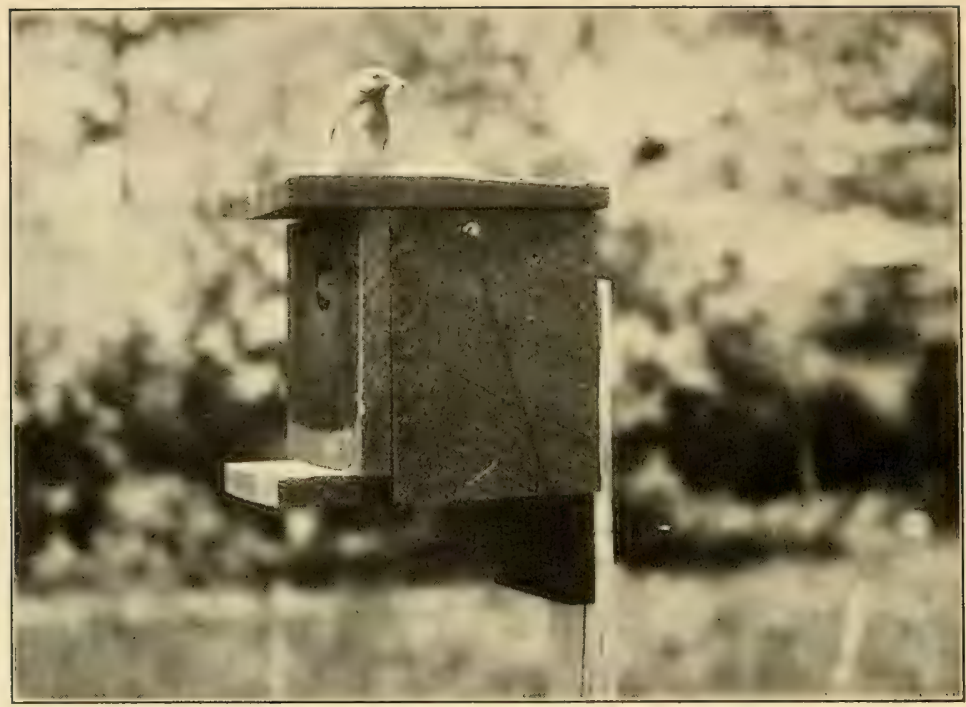

Photoraph by Li. H. Forbush

Ware-model nesting-box designed for tree swallows, occupied by bluebirds

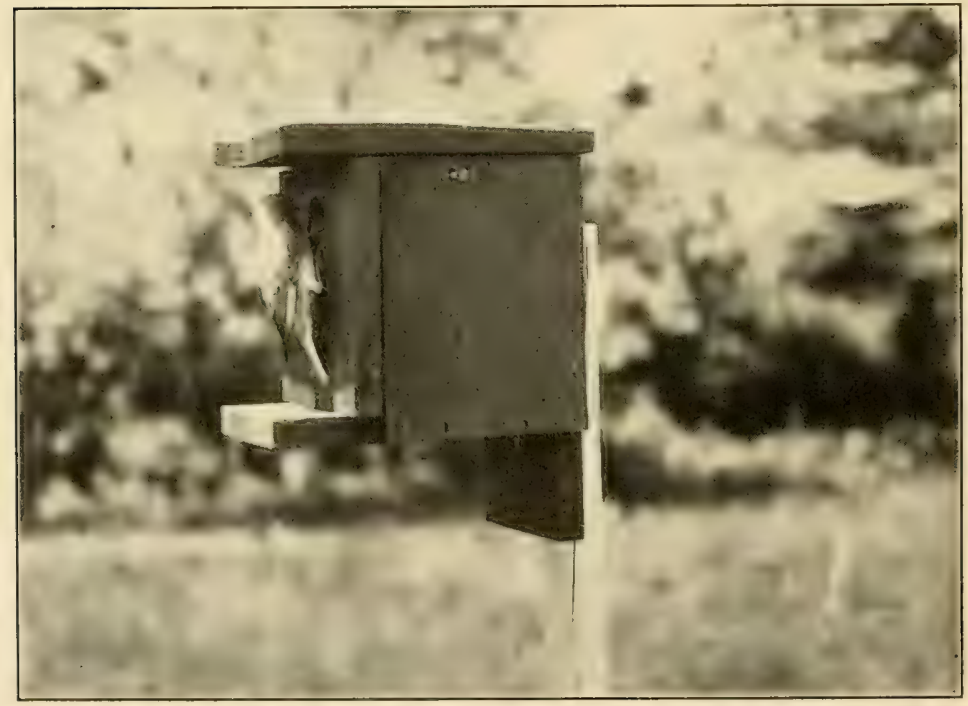

The same bluebird entering 
example of success in increasing the smaller land birds is that of Baron Von Berlepsch on his estates at Seebach, in Thuringia, Germany, which has become a matter of worldwide fame. Every one interested in the subject should secure the little book describing the details of his work, which is entitled "How to Attract and Protect Wild Birds," by M. Hiesemann, English translation, which can be secured at trifling cost from the National Association of Audubon Societies, New York City.

The story of the growth of this work is briefly as follows: Von Berlepsch when a boy noticed that the bird-houses then put up for birds were seldom occupied, and he began to inquire the reason and to make careful studies and experiments in methods of attracting birds. These studies led to journeys all over the world. For years he has been carrying on experiments on his estates with surprising results. Of about 500 acres, 19 are in a park, 60 are laid out in thickets, and 400 are woodland. There is also a lake which attracts water-birds. In an area of $\mathrm{I} 2$ or $\mathrm{I} 3$ acres of park upward of 500 pairs of birds regularly nest, not including a colony of over Ioo nests of house martins on a barn. About 300 nesting-boxes in the park are all occupied. In the woods there are about 2,000 boxes, of which about 90 per cent. regularly have tenants.

Lessons Therefrom. No one need expect to be able to go forth and immediately do likewise. This success represents many years of effort and an evolution in the habits of birds. Birds are considerably creatures of habit, great sticklers for custom, natural conservatives. The habits of a species can be changed only very gradually. Doubtless it took a long period of years for our "chimney" swift, which originally stuck its gummy nest to the inner walls of large hollow trees, to change to its present habit of nesting in 
chimneys, adopted since white men settled in America. A few individuals tried it, probably, and their young practised what they had learned. Chimney-nesting evidently proved safer than in hollow trees, where raccoons, squirrels, or other enemies ate the eggs or young, and the chimneyreared birds finally comprised practically the entire species, despite the fact that there are yet in some sections large hollow trees in which they could nest. Similarly have changed the habits of the cliff or eave swallow, barn swallow, phoebe, and various others, which could be enlarged upon. Thus, no doubt, the birds around Seebach, after a number of generations, have been led to alter their primeval habits, though along lines which have a similarity to nature, and are not altogether arbitrary.

Another corollary from this is that more and more species may be expected to change their regular habits through systematic popular efforts. Some species, of which now only an occasional individual happens to use a nest-box, may in time come to use them frequently or regularly. As the individuals raised in boxes increase in numbers year by year, the numbers of species and individuals using nesting-boxes should rapidly grow. Birds normally return from migration to the neighbourhood of their birthplace; hence in localities where birds are thus raised such habits will tend to spread rapidly.

Conditions in America. In this country we are in the infancy of attracting birds. Only about four species-the bluebird, house wren, purple martin, and tree swallow-had formerly become regularly accustomed to using artificial nests, and a number of other species have begun to do so. Including all parts of the country, twenty-seven species have been known to occupy artificial nest-boxes. If nationwide interest and effort can be developed, it is without 
question that in the course, say of even a decade, great advance will be made. Under reasonably favourable conditions, and with proper care and instruction, people can hope for some results even from the first, and the chances are that success will steadily increase. The pleasure and satisfaction found in such work will be great.

Cautions. At the same time it may be well to call attention to certain limitations, so that hopes may not be aroused which are unlikely to be realized. Children especially will be told how nice it is to attract birds as pets and how easy it is to put up a large number of boxes and have the garden full of birds. They begin with enthusiasm, but most of the boxes may be promptly taken by the English sparrow, and few or no native birds appear. Then they get discouraged and abandon the attempt. So there are some other points to bear in mind, aside from the obvious one of getting rid of the pests.

Dr. A. K. Fisher, of the U. S. Department of Agriculture, called my attention to the obvious fact that, owing to the limitations of the food supply, only about so many birds of a kind can live in a given area. Moreover, one pair of birds of some species are accustomed to preëmpt a certain area of ground as their own private hunting preserve, and drive off all others of their own kind. The frequent scarcity of birds below the normal is also a factor in making increase slow, since there is not enough stock to go around.

Hence people should not be disheartened if the results are small and slow at first, but should continue patiently. It is wise to begin on a small scale, and let the "business" have a normal growth. Yet, on the other hand, there are locations capable of considerable increase of bird life, though there are also conditions under which birds can never be attracted in numbers till these are made better. 
Importance of Attracting Birds. Whether or not there are any large number of birds in any particular garden or estate, there are various reasons why such efforts to attract birds are abundantly worth while. Even if only a normal number of birds were attracted to the grounds of a birdlover, these birds would be more likely to rear their young successfully under protection than under average conditions. In most cases, however, the number of birds on a tract made congenial to bird life will be larger than though no efforts were made to attract them. In every such case a number of birds are saved from enemies or are enabled to survive the winter, and one or more people gain a practical interest in the increase of bird life. Now, make this matter of attracting and feeding birds a nation-wide movement, as it is becoming, and the local good to a few birds or people is multiplied by thousands, and becomes an important factor. Not only are birds increased, but the public are interested in birds and their conservation, good legislation is more readily secured and maintained, and the laws are better enforced.

Coöperation from Game Preserves. The importance of coöperation in attracting and protecting birds by the owners of game preserves and by sportsmen's organizations is coming to be recognized. It is for the interest of all such to maintain and increase the supply of the species used as game. The methods used to protect and increase these have the same effect upon bird life in general. Most outdoor men and sportsmen worthy of the name, as distinguished from mere irresponsible pot-hunters, are glad to see the smaller birds about, and enjoy their presence. Ownership of land tends to arouse a sense of responsibility, and the owners of land used for hunting are apt to oppose wanton destruction. On well-regulated game preserves there is 


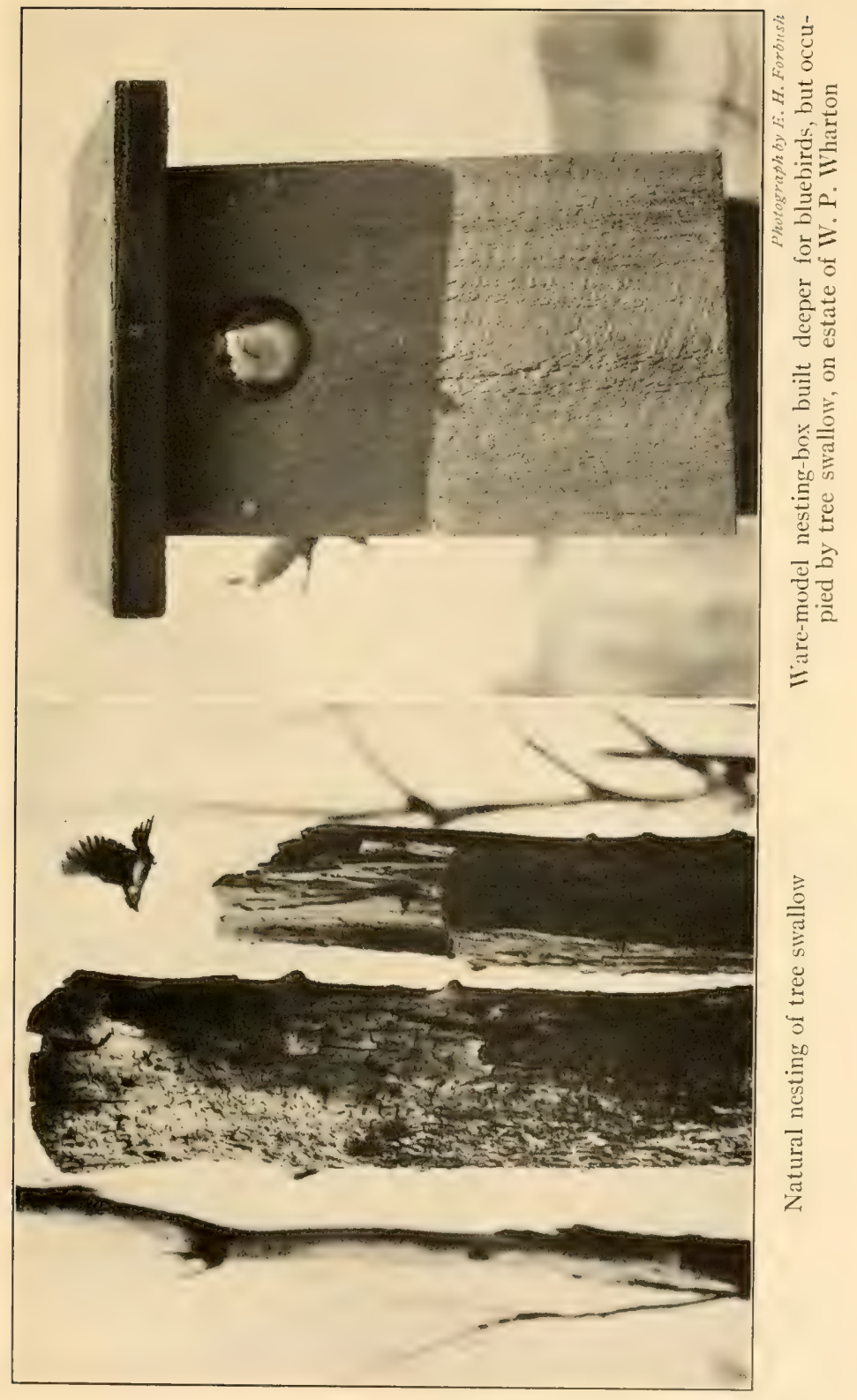




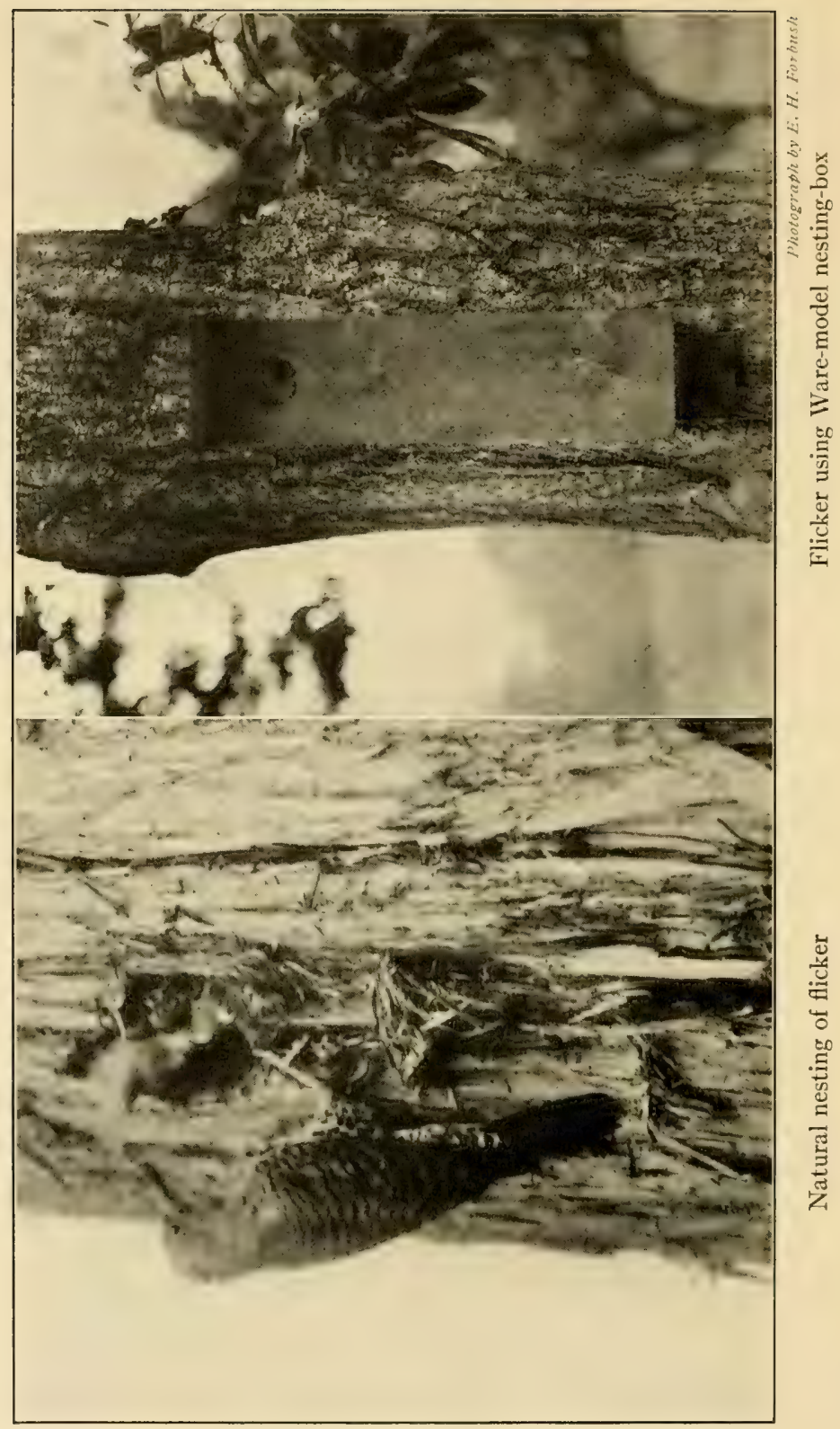


usually some effort to keep down the vermin. Hence many a shooting preserve really amounts to a bird sanctuary, with reference to the great majority of species of birds, and even as regards game-birds there may be more of these owing to methods employed than there would have been without. Coöperation in bird protection from sportsmen should thus be expected and encouraged.

Survey of Scope. Birds as we deal with them for these practical purposes may be classified as follows: (a) those that may be attracted to breed, (b) those attracted by food in winter, and (c) migrant transients. The scope of the work, then, will be to make surroundings attractive and safe from enemies, to assist birds in nesting, and to provide food and water as needed. The first two groups especially are amenable to practical methods, yet the transients will incidentally receive help and will furnish many delightful incidents. It is no small satisfaction to see a passing group of fox suarrows or white-throats eating the seeds we have thrown out, a hermit thrush enjoying our shrubbery, or brilliant warblers flitting through the foliage which we have planted. Migratory birds often linger in places which they find attractive and safe, but hurry past those that are undesirable.

Unity of Plan. Just as we have learned to increase the gallinaceous and waterfowl tribes, it has likewise been found possible to increase the smaller land-birds. The problems, of course, are quite different, yet there are certain similarities. Keeping such birds in confinement or under restraint is impracticable and unnecessary. The artificial methods which can be used to advantage are along the lines of providing facilities for nesting and of feeding in winter the few species that remain with us. Natural methods are kindred to those already described, consisting of furnishing 
attractive surroundings and making these safe from enemies. The main difference is that in the previous cases the matter of surroundings consisted largely of selecting suitable natural wild haunts, while in the present effort the environments of civilization must be restored to certain semblance of wild nature.

In trying to adopt a logical order of treatment the result depends somewhat upon the viewpoint. While the matter of furnishing attractive surroundings, as furnishing our stage-setting for the fascinating drama to be progressively enacted before us, is obviously fundamental, from the practical standpoint the public need not wait for years for trees and shrubs to grow before interesting themselves in useful practical ways with the birds, and really helping to increase them. While the surroundings are gradually improving so as to harbour more of them, we can help at least a few of them to nest and rear their young, and feed those that in severe winter weather are driven by necessity to our doors. Hence it may be practical logic to describe first the matters next to hand. These are the things which every one can do, and can begin on at once. Every little success becomes a triumph. The children are delighted, and learn to know and befriend the birds. This sort of thing is important to advance a nation-wide movement already begun for the restoration of bird life. Every intelligent person can do and ought to do something. Every household, unless in congested city areas, would do well to put up and care for at least one nest-box for the birds and a little lunchcounter for winter feeding. Reader, will you not do it?

The detailed plan of what may be undertaken follows. 


\section{CHAPTER XV \\ AIDS TO NESTING}

\section{a. Nesting-boxes}

Von Berlepsch Type. Many years ago Baron von Berlepsch began his careful experiments to ascertain what sort of artificial nesting-hollows, if any, would best attract birds. Examination of chambers dug by woodpeckers and others revealed the fact that they were all made on one plan. Beginning with an entrance barely large enough to admit the bird, the tunnel broadened out in the form of a pear, and narrowed again at the bottom, so that, while there was room for the parent to sit, the eggs tended to roll together in the centre. After further effort the Baron was able to have sections of natural branch excavated by machinery to reproduce exactly the tunnels of woodpeckers of different sizes. When he put them up in surroundings such as the feathered builders would have chosen, the birds did not perceive any difference from what they were accustomed to, and from the start took possession in good and increasing numbers.

Use in America. Here in America for a time these hollowlimb nest-boxes were imported from Germany. It proved expensive to do this, and various efforts were made to make machinery here which would do the work. This has now been accomplished, and such boxes, "made in America," are now on sale. They are made in six sizes, for wren, nut- 
hatch and chickadee, bluebird, flicker, screech owl, and wood duck, or species of corresponding sizes. The price for the present will probably average around one dollar, or a little more.

Von Berlepsch Model Not Essential. As experiments with nest-boxes in America progress, we are meeting with some surprises and having to revise somewhat our previous conceptions. The Von Berlepsch theory of the woodpecker model for nesting-boxes is being found not to be by any means of universal application in America. Perhaps the American birds are bristling with the spirit of independence, and refuse to follow precedent. At any rate they do not act just as the esteemed Baron finds that his birds do at Seebach. We are finding that our birds are quite indiscriminate, within certain limits, in the house-models which they will accept, and that there are fewer species here than in Europe which have yet learned to utilize these devices. It is certainly beyond question that bluebirds and house wrens will occupy practically any convenient model. Chickadees like the log-boxes, but they occupy other models apparently just as well. Woodpeckers ought to like log-boxes made in exact imitation of the apartments of their own manufacture, but how is it in fact? Most kinds in America still prefer their own workmanship. The flicker is the only woodpecker that uses boxes at all frequently, yet it often uses deep upright boxes made of boards, with the hole near the top. The purple martin prefers a compartment house, being gregarious, and the tree swallow will use a starch box as readily as a hollow log.

After all, if we want to attract birds, we must give them what they want, not what we think they ought to prefer. What we need now is a great mass of detailed data and experiments on these problems. E. H. Forbush and Wil- 
liam Brewster, for example, have put up side by side both hollow-log and board boxes, and find that more frequently the latter are chosen and the former are left unoccupied.

Following is the experience of Mr. Brewster on his summer place at Concord, Massachusetts, outlined to me in a letter. Several years ago he put up about ten Von Berlepsch boxes. Of these only one was ever occupied, by bluebirds. Latterly he has been having boxes made of boards, also cylinders of chestnut bark. All of such construction that he put up in I9I3 were occupied, nine by tree swallows, two by bluebirds, two by house wrens, also three pairs of flickers and one pair of crested flycatchers nested in sections of hollow apple-trunks, boarded up at both ends, with entrance holes cut in the sides.

Others, however, report considerable success with the Von Berlepsch boxes. What is needed now is a mass of detailed data from different localities and under varying conditions. It would be well if bird-lovers everywhere would make experiments, keep accurate record of them, and report in full detail to the Department of Applied Ornithology, National Association of Audubon Societies, New York. It may be found that certain species prefer a particular type of box. It will be well for all dealers to furnish several kinds, including the cheaper ones, of such models as have proved effective.

Mr. Forbush has found that the flicker, which would be supposed to prefer the hollow-log type as being the exact reproduction of its own nest, in cases where a log-box and a board-box were placed side by side, did not seem to show any decided preference, but used the board-box as readily as the other. Finding that most birds like the cheap boxes made from boards practically as well as the more expensive log-box, and in some cases better, he now uses the former. 
Apparatus for Sale. For those who do not care to make their own nesting-boxes, or other apparatus, the following list of manufacturers is offered: The Audubon Bird House Company, Meriden, N. H.; Philip E. Perry, 39 Clarke Street, Lexington, Mass.; E. C. Ware, Wareham, Mass.; The Simplex Bird Apparatus Company, Demarest, N. J.; Maplewood Biological Laboratory, Stamford, Conn.; Greenwich Bird Protective Society, Greenwich, Conn.; Winthrop Packard, Canton, Mass.; J. Warren Jacobs, Waynesburg, Pa.; Charles E.White, Kenilworth, Ill.; Joseph H. Dodson, Evanston, Ill. Besides nesting-boxes, these firms can mostly supply the various devices for feeding or protecting all birds.

Species to Expect. It will be of interest and importance to know what kinds of birds are to be considered possible occupants of nesting-boxes. This will vary, of course, with the locality, whether certain species are found there or not. The following twenty-seven species are listed in Farmers' Bulletin, No. 609, "Bird Houses and How to Build Them," issued by the U. S. Department of Agriculture. I will classify them as follows:

(a) Species regularly using nesting-boxes: house wren (the various sub-species), bluebird (Eastern and Western varieties), chickadee, purple martin, tree swallow, flicker, violet-green swallow (Western), house finch (Western), Bewick's wren (Western).

(b) Species occasionally using boxes: white-breasted nuthatch, downy woodpecker, hairy woodpecker (rarely), red-headed woodpecker, tufted titmouse, Carolina wren, crested flycatcher, screech owl, saw-whet owl, barn owl, sparrow hawk, wood duck, song sparrow (rarely), dipper (Western).

(c) Species using covered shelves, open on sides: robin, 
phoebe, barn swallow. Besides these, unfortunately, the imported English sparrow and European starling occupy boxes and drive away useful native birds. They should not be allowed to nest on the premises.

Standardizing Boxes. Knowing what kinds of birds there are which may accept our hospitality, the next thing is to make or secure boxes to meet their various preferences. A great variety of patterns have been used. Boxes for birds made by schools often show about every imaginable style. While it is true that birds of the various species do not insist upon any one particular model, they all evidently have certain lines of preference which it is important to follow. Hence in making each box it is well to have in mind at least some class or type of bird that it is intended for. To do this intelligently one should have some idea of what these various types prefer. It is safer to build on plans which birds are known to accept, rather than to try all sorts of new things. There would be a further advantage in standardizing boxes and having their appearance familiar to birds, that generations born in boxes of similar type might be expected to form the habit more strongly and recognize and adopt more regularly the nests prepared for them.

A Standard Type. After careful investigation and study of the subject, I would suggest as the most feasible type, all things considered, a simple rectangle of plain boards, with the roof sloping toward the front, or else level, and projecting out a little to shelter the entrance-hole. Gable roofs and various fancy fixings are not only unnecessary but unnatural in their surroundings, and would seem more likely than simple models to repel timid species, though it might not make any difference. While it is not necessary to paint them, painting will make them last much longer. A dull green colour is most generally used, or a brown stain. 
Proportions Not Important. The matter of the exact proportion of the box thus constructed does not appear to be important. The main requirement is that the cavity or chamber should be fairly deep, with a circular entrancehole just below the top. Only martins like the entrance near the floor level, though wrens also will use it thus if necessary. Most birds which use hollows for nests like to get out of sight, and perhaps also out of draughts.

Direction of Axis. The preponderance of practice is to make boxes with the long axis vertical, having them about twice as long as wide. This is the general shape of the hollow-log type of the Von Berlepsch model. In fact, a box made thus of weatherbeaten boards looks considerably like that type. Experience, however, shows that birds will use a square box, or even one slightly clongated horizontally. E. H. Forbush has of late been building his square. On the Henry Ford Farm, near Detroit, where a couple of hundred of boxes are put up and mostly occupied, a good many of them, especially those used by bluebirds, are nearly square, but slightly longer horizontally. My own theory is, from observation of hundreds of natural nesting-sites, that this class of birds usually select a cavity where their nest fills the entire space at the bottom. They also want to be well below the entrance-hole. Hence I would have the floor space of moderate size, preferably about square or round, and the upright dimension rather long.

Building a Box. As a typical case, here is a plan for making a nesting-box of the size for bluebirds: Saw out four pieces of $\frac{3}{4}$-inch board a foot long and 6 inches wide. In one of these cut out a circular hole, the top of which should come about 4 inches from the end of the board. This hole should be $\mathrm{I} \frac{1}{2}$ to $\mathrm{I} \frac{5}{8}$ inches in diameter, no more or no less, because if more the starling can get in, and if less the blue- 
bird will be shut out. Now nail these boards together to form a tunnel about five inches square inside. Then nail a piece of board flat on the end farthest from the entrance-hole to form the bottom, boring a small hole in this bottom to let out water that might beat in. Have the roof board a little wider than the box and set it either level or sloping slightly forward. It should project a couple of inches over the front, helping thus to shield the entrance from storms. It should be screwed down, or else, if desired, put on with hinges, so that access may be.had to throw out English sparrows' nests and clean it out in the fall. No perch should be placed in front, which would give only an easy lodgement for sparrows, and is not needed by the birds. Either nail to the back of the box a longer board to fasten to the tree, or, better, make the back board longer, and nail through the projecting ends. It can be painted outside, if desired, or left in the natural wood. In the latter case it is well to use weatherbeaten boards or else stain it. The inside of the boards should not have been planed, so that young birds can better climb out when the time comes. This model will be suitable for the majority of hole-nesting birds, varied only according to the size of the desired occupant.

Other Models. There are, however, other models preferred by certain species, as well as other devices acceptable to the generality of birds. These will be briefly suggested.

Tin Cans. After all, an old tin can with a small hole cut at one end will suit a pair of house wrens as well as any elaborate box. Bluebirds also sometimes occupy such receptacles, a tomato can being large enough for them. Since metal gets very hot in the sun and might suffocate young birds thus exposed, such nesting-sites should be placed where there will be shade when the foliage grows out. 
Gourds. These are very popular with wrens, and with martins in the South. Bluebirds also use them, and probably others would do so. In the South I have seen gourds tied in rows on crosspieces attached to poles, and occupied by colonies of martins. A suitable hole should be cut in the side of the gourd, and a small one underneath for drainage.

Starch Box. This is taken as the type of similar readymade boxes which can be utilized. Tree swallows use them readily if placed on poles. The crested flycatcher is as likely to appropriate them as any thing else. Bluebirds and wrens also occupy them. Always cut the whole near the top.

Earthenware. Some dealers have put on the market boxes of earthenware or crockery. While birds may sometimes use them, they are evidently not popular. It would seem as though the young might have trouble in climbing out, and that the material would be apt to absorb heat.

Bark Boxes. These can be made from strips of bark, in the form of a hollow log, with the ends fastened up and a hole cut. They will hardly last, though, more than one season, and the stronger board material is doubtless better. William Brewster, as noted above, has found these very effective, as also sections of hollow limbs boarded up at the ends, with a hole cut in the side.

Martin Houses. Purple martins prefer to nest in colonies, and like best of all houses built with compartments, although they will sometimes locate where there are a series of boxes or gourds. The compartments may each be 6 to 8 inches square. The hole should be near the floor level, say about an inch or two above it. Most birds prefer a hole just large enough for them to enter comfortably, but the martins seem afraid to enter an opening small enough to have their bodies shut out the light as they enter. Two and one half inches diameter is the aperture suggested in 
Farmer's Bulletin No. 609, quoted above, as admitting sufficient light while the martin enters. In view of the spread of the starling, which is likcly to make trouble for the martins, a good suggestion is made by Raymond $\mathrm{B}$. Thompson in Guide to Nature, January, 1915. It is that the diameter of the entrance-hole be made $1 \frac{5}{8}$ inches, which is a close fit for the martin, but will just exclude the starling, as elsewhere described in this chapter. To allow for the admission of light, another hole, about $\frac{1}{2}$ inch in diameter, is cut just above the entrance-hole. This looks like a clever scheme, and let us hope that the martins may not object to a tight fit! The experiment is well worth trying.

Location and Care. The house must be set on a pole out in the open, away from trees, and should be I 5 to 20 feet from the ground. A very convenient plan often adopted is to have the pole so that it can be lowered. It is set up between two short posts or bitts, with two long bolts reaching through all. When desired, the lower bolt can be taken out, and the pole swung over on the upper one as a pivot, thus bringing the house to the ground. It should be cleaned out every fall and all nests and rubbish removed. If left up, it is wise to stop up the entrances to keep out English sparrows, which would dirty it during winter and build nests before the martins returned. A better plan is to take it down and house it for the winter, putting it up again when the martins are due, which in the latitude of New York City would be about the middle of April.

Starting a Colony. Colonies once started usually coritinue year after year. The tendency is for the colony to grow larger and larger, doubtless from the return of the young. There is not much hope of enticing old birds from their chosen location, but the young birds are often crowded out, and may start a new colony if they find a site to their 
liking. It is a good plan to have at least a simple box with a few chambers ready for possible arrivals which otherwise might not linger on the premises.

An Instance. Arthur W. Brockway, of Hadlyme, Connecticut, after hearing a lecture by E. H. Forbush advising the putting up of boxes for martins, several days later saw a pair in his yard, and put up a single box on a pole. The pair took possession and raised a brood. Next spring several came. More boxes were put up and they all nested there. Each year there were more, and last season, about eight years from the beginning of the attempt, about one hundred were nesting, making, it is said, probably the largest colony in Connecticut. Unfortunately, about the first of July, I9r4, a long, cold rainstorm killed a considerable part of the colony, a calamity which with the martin, unhappily, is apt to occur, in Northern States, every few years, wiping out many a hard-earned colony. On the Henry Ford farm near Detroit the martins are splendidly started, and in I9I4 there were four large colony houses well occupied. The purple martins at Hadlyme feed their young chiefly on the larvæ of the dragonfly, taken from the meadows of the Connecticut River, going a couple of miles to and from their chief hunting-grounds. It may be that this species would give preference to locations in the vicinity of meadows and marshes.

Covered Shelves. Several species which have become accustomed to shelter their nests under buildings - the robin, phoebe, and barn swallow-sometimes will use a nesting-box of different construction from the others. This style consists merely of a shelf or a cup-shaped receptacle, with a roof over it, and open on one or more sides. The song sparrow has been known to use such a device open on all sides. It has been suggested that catbirds and 
other species nesting in shrubbery might use such a model as the latter, but this yet remains to be demonstrated. On the Henry Ford place robins and phoebes nest in these opensided boxes or roofed platforms. These can well be fastened to the eaves of buildings or to arbours, piazzas, or against trunks of trees as much protected against cats as possible.

Size of Entrance. In the matter of the size of the entrance-hole it is important to be very exact, especially in reference to protecting certain species using boxes from the entrance of the English sparrow and the European starling. These are pests to the native species, and some sizes of boxes can be made with reference to keeping them out. Here are the facts: The sparrow can enter a $1 \frac{1}{4}$-inch opening, but not the $\mathrm{I} \frac{1}{8}$-inch size. The starling can get through the $\mathrm{I}_{4} \frac{3}{4}$-inch size, but not the $\mathrm{I} \frac{5}{8}$-inch. T. Gilbert Pearson told me that this had been ascertained about the starling, and I verified it by further experiments. The bluebirds can just enter a hole $\mathrm{I} \frac{1}{2}$ inches in diameter. Hence, to protect it from the assaults of the starling, the diameter of the hole should be from $\mathrm{I} \frac{1}{2}$ to $\mathrm{I} \frac{5}{8}$ inches, no less or no more. Most species, however, cannot thus be protected from the sparrows, except the wrens and perhaps the chickadee. The wren can enter even a $\frac{7}{8}$-inch hole, but the opening may as well be $\mathrm{I} \frac{1}{8}$ inches, so that possibly the chickadee may also have a chance. However, while the chickadee can enter this, Mr. Forbush thinks that it prefers the $1 \frac{1}{4}$-inch, as he has seen one trying to enlarge a $\mathrm{I} \frac{1}{8}$-inch hole. In some localities, as in parts of eastern Massachusetts, the house wren is scarce or absent, and boxes with a very small aperture are apt to remain unused. In such case it is probably best to adopt the bluebird size as the general type for all the smaller birds, and make up one's mind to fight the English sparrow. 
Following is a list of species using boxes, classified as the proper sizes of the diameter of the entrance-hole which they require. Where two figures are given they represent the maximum and minimum sizes which are proper:

(a) I $\frac{1}{8}$-inch: house wren, Bewick's wren, Carolina wren, chickadee.

(b) $1 \frac{1}{4}$-inch: white-breasted nuthatch, tufted titmouse.

(c) $\mathrm{I} \frac{1}{2}$ to $\mathrm{I} \frac{5}{8}$-inch: bluebird, downy woodpecker, crested flycatcher, tree swallow, violet-green swallow.

(d) $\mathrm{I} \frac{3}{4}$ to 2 inches: red-headed woodpecker, hairy woodpecker.

(e) $2 \frac{1}{2}$ inches: flicker, saw-whet owl, purple martin.

(f) 3 inches: screech owl, sparrow hawk.

(g) $4 \frac{1}{2}$ inches: barn owl, wood duck.

On estates where other ducks are bred and the wood-duck boxes are accessible for pinioned stock, the opening should not be larger than $4 \frac{1}{2}$ inches to keep other larger ducks from interfering.

Size of Chamber. In deciding the size of the nestingchamber, the principle to go on is to make it just large enough to contain the nest that the species would normally build, or if, as with the woodpeckers, no nest is constructed, large enough for the bird to sit comfortably. For upright boxes the chamber will naturally be round or square. The height of the passage should be at least twice the diameter of the chamber. The following dimensions, taken from the Government Bulletin mentioned above, I should consider about right. In the list of species just cited in reference to size of aperture, for groups (a) and (b) the diameter of the chamber may be 4 inches; group (c) 5 inches; group (d), including also the purple martin and saw-whet owl 
from the next group, 6 inches; group (e), flicker, 7 inches; group (f) 8 inches; group (g) Io $\mathrm{x}$ i 8 inches.

Household Furnishings. For the most part the birds will furnish the apartment to suit themselves. There is just one simple thing, however, to be done. Woodpeckers always deposit their eggs on a layer of fine chips or rotted wood which they leave in the bottom of the cavity. They will not nest in a box with bare bottom. Even for other species a soft layer of this sort is well enough, as they find it in the natural cavities. Moreover, one cannot tell just which boxes woodpeckers might choose. Hence, it is well to put a moderate layer of sawdust in most nesting-boxes, except martin and wren houses.

Location of Boxes. Where to place the boxes is a most important matter, since mistakes here may bring all previous efforts to naught. In general the aim should be to select the locations with particular species in mind, and to place the boxes for them in just such situations as they would naturally select. Here is where a person who has studied birds and found their nests has an advantage. It is quite good fun to put yourself in the place of the bird. Just imagine you are this or that sort of bird, and you are looking for a site for a nest on this estate. Would you care to nest there at all and, if so, just where?

"Thinking Bird." All my life I have devoted considerable attention to the nesting habits of birds. In connection with species which are quite familiar, there comes to be a feeling almost of intimacy with their viewpoint. For instance, after finding hundreds of nests of hawks and owls, when I go into the woods now to hunt them out I have a sort of instinctive feeling of recognition when I see a place or site just adapted to this or that species. If I do not find it there, I merrily criticise, and say that if the bird knew as 
much as I do, it would certainly have nested right here!

Placing a Bluebird Box. A lady who had been very successful in attracting wrens, but had not secured any bluebirds, asked me to indicate some good places on her estate for boxes to attract the latter species. After looking about, I found a spot, off from the well-kept lawns, where there was a bit of natural New England pasture - a couple of old apple trees, a clump of sumachs nearby, some scattered bushes, and the grass not cut. On one of the apple trees a big hollow section had projected toward the south, about twelve feet from the ground, but had been sawed off. I should almost be willing to wager that at some time bluebirds had nested there. I suggested that a box of bluebird size be nailed to that flat surface. Many a bluebird's nest have I seen in exactly such surroundings. If it is not occupied by bluebirds next season, I am sure it will be because of scarcity of the species or other local conditions. This will serve to illustrate the principle on which I proceed. In case one is not familiar with the habits of birds, it will be well to consult some local ornithologist, or write to our Department of Applied Ornithology.

Surroundings for Different Species. In general, it is well to try to place the boxes in situations as nearly as possible representing the natural haunts of the species which may use them. It is true we are trying to induce the birds to change their habits to some extent, and with some degree of success. None the less, we shall make more progress by keeping as closely as possible to the ways of nature. Without taking time to describe the nesting-haunts of the various species, some generalizations as to the placing of boxes may be of interest. In general it is safe to assume that boxes placed in woods are less likely to be occupied. Wood- 


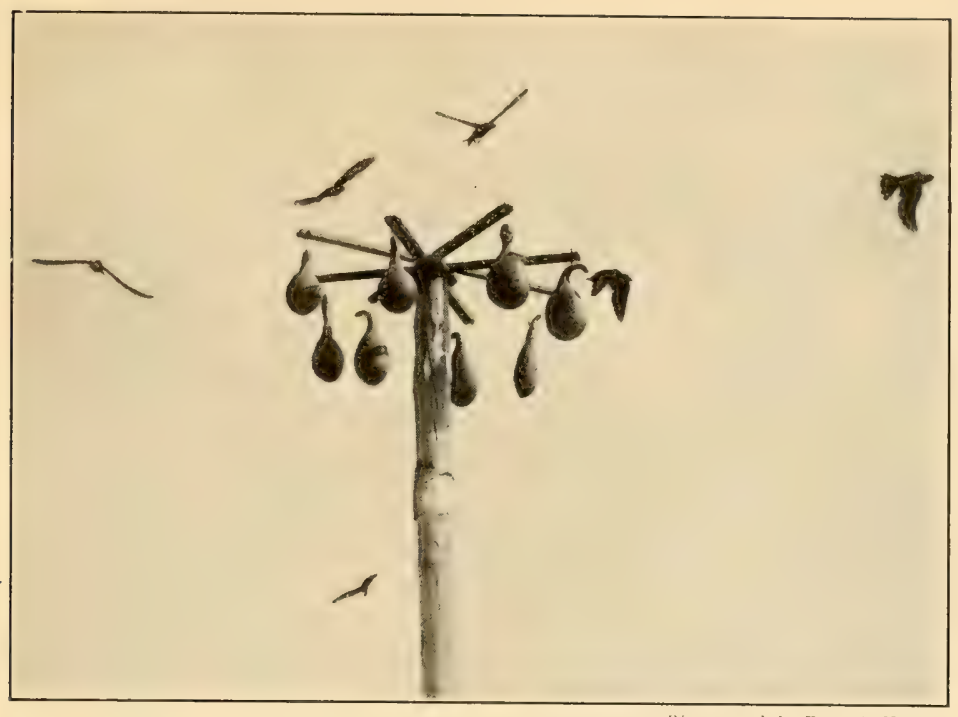

Whotograph hy Francis Hirpor.

Purple martins nesting in gourds

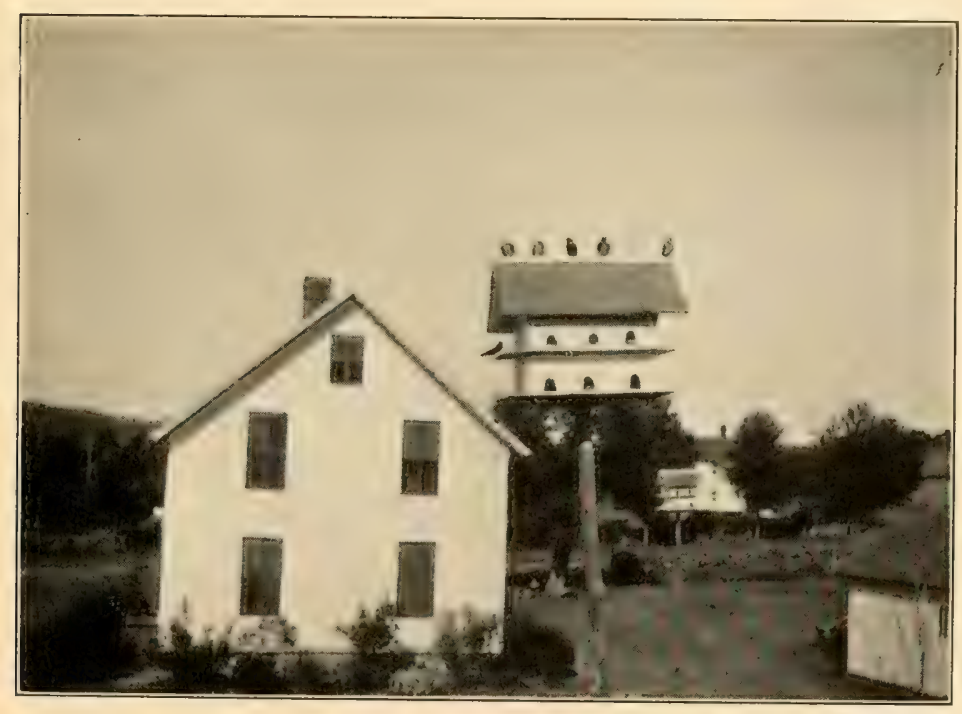

An occupied purple martin house. Note another in distance. About 1oo martins were breeding on the premises 


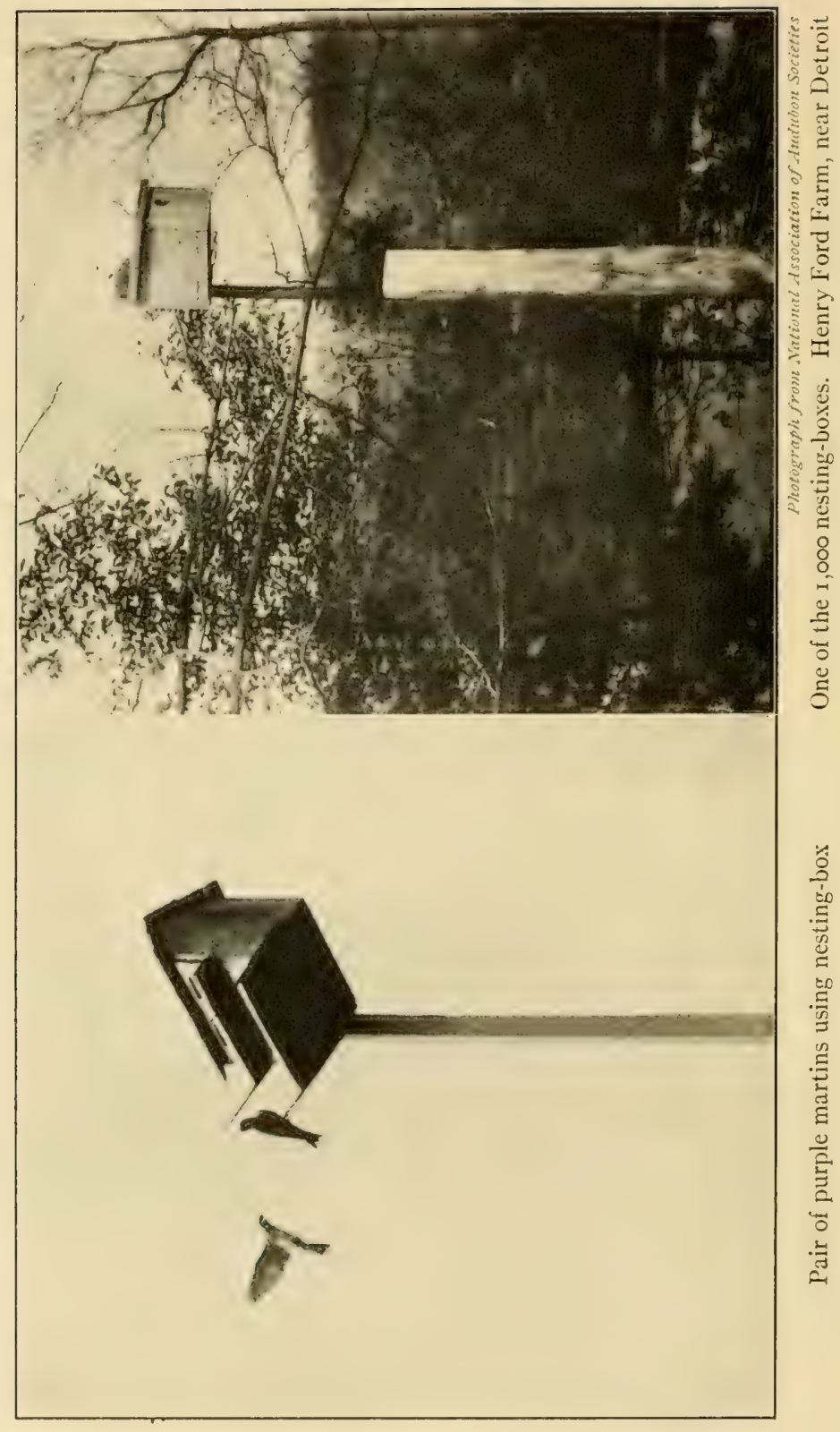


peckers would be the leading probability there, but the downy and hairy woodpeckers rarely use artificial nests, while the flicker and redhead are just as likely to nest in the open, especially in large isolated trees or in orchards. Sawwhet and screech owls are more likely to nest in woods, but the former is rare and the other not plenty. Wrens often take boxes fastened to the house, as do chickadees occasionally. Probably, though, the most likely location for the chickadee is the edge of a grove or in the orchard. The bluebird is especially partial to the orchard or an isolated group of trees in a pasture. The crested flycatcher likes an old orchard or a retired place at the edge of the woods. The robin and phoebe will nest almost anywhere under eaves of buildings or in the garden where a platform sheltered from above can be provided. For most birds a location is most attractive that is not too bare and open, but near shrubbery and foliage, where food can be found, though not directly amid these. Houses for martins, however, must be out in the open, away from foliage, so that the birds can readily fly in from all directions. Tree swallows also prefer boxes on poles in the open, but these may be somewhat more in among trees.

Height from Ground. Most species which use boxes prefer a location of moderate height. Eight to twelve feet represents a good average, not over fifteen. In one case, in the town of Brookline, Massachusetts, where over one hundred boxes of the Von Berlepsch type were put up by forestry men thirty-five to forty feet from the ground, the great majority were taken by gray, red, and flying squirrels and English sparrows, and only one by a native species, a pair of flickers. More than one element, of course, probably entered into this result. At any rate, it is best to follow the natural habits of the various species. Woodpeckers are 
more apt to build high, as are nuthatches and owls. But fifteen to twenty feet is high enough for any of them. Sometimes, however, individuals are known to nest higher up than ordinarily. E. H. Forbush has noted bluebirds using a box forty feet from the ground, and martins using houses raised on high cupolas or on top of city blocks. He once saw a pair of chickadees nesting seventy feet from the ground. The exception, however, does not disprove the rule. Birds apparently seek concealment and protection from above as well as from below.

Poles vs. Trees. The earlier experimenters with boxes placed them mostly on trees, when not on buildings. Now it begins to look as though location on poles or high posts was more attractive to birds. The experience of Mr. Forbush on his place at Wareham, Massachusetts, in I9I4, is instructive. Some seasons he has had boxes on buildings occupied, but this year the four so placed were not used. Of twelve in trees in various situations, such as by hedges and on the edge of woods, only one was occupied - by flickers, near the house. Nine others were mostly on poles, a few on telegraph poles or small trees trimmed off, leaving only branches at the top. Of these eight were occupied, the majority by tree swallows, the rest by bluebirds. They were put up too late for chickadees, which usually occupy boxes there.

Wharton Experiment. William P. Wharton has conducted on his estate at Groton, Massachusetts, extensive experiments along this line which are of great value, the results of which he has kindly written out for me. There are two farms several miles apart. One has an area of eighty acres, mostly open land; the other has about 370 acres, mainly woodland. The former he has owned for two years, most of the other considerably longer. I quote at length from his letter: 
"At the larger place I have put up twenty-four boxes of the Von Berlepsch model and of German manufacture. These have been in place several years, and on the average between five and six have been used by birds, mostly tree swallows and bluebirds. Some of these boxes, however, are too small in the entrance for birds larger than chickadees. The latter have never occupied but one box, and this was deserted. The last two years one of the boxes has been occupied by flickers. It should be remarked here that the use of creosote in treating the egg clusters of the gypsy moth inside the boxes may have had a repellent influence on the birds, since the number of these boxes used decreased after the first two years. F. H. Kennard is of the opinion that creosote does discourage the use of boxes. Two other types of boxes have been placed on this larger area-old hollow apple limbs with flat floors, and the ordinary board box. Without going into unnecessary detail, I will say that about the same proportion of these seem to have been occupied by birds from year to year as of the Von Berlepsch boxes - that is, about one fourth. Creosote has also been used in them.

"Although up to last spring only the Von Berlepsch boxes had been hung in part on posts, I thought I detected a preference on the part of the birds for these boxes so placed, and last spring I had eight new boxes of the plain board type made, and placed them on the posts of a fence surrounding a small made pond. These were stained on the outside to a weathered colour with a mixture of drop black and linseed oil. They had not been in position for an hour when the birds were going in and out of them and finally four of them were nested in, or $5 \circ$ per cent.

"On the eighty-acre farm where I live, I first placed twelve boxes of the Von Berlepsch model made by Mr. 
Bayne's Company, at Meriden, New Hampshire. The mistake was made by buying four or five with holes too small for the ordinary birds. These have never (two seasons) been occupied. Of the others, four were used the first year, and three the second, one of the larger ones having been occupied by flickers the past season. These boxes are all on trees. Last winter and spring I hung twenty-four board boxes, with entrance-holes from $\mathrm{x} \frac{1}{2}$ to 2 inches in diameter. These were painted dark green, and twenty-one of them were placed on poles, which in turn were fastened to fence posts in a cow pasture at intervals of 50 feet. Of these twenty-one boxes, twelve were certainly nested in, and in others unfinished nests were found. There were five or six families of tree swallows in these post boxes, and the other species were bluebirds and two English sparrows, the latter being broken up. Of the three other boxes of this type hung in trees, two were occupied by bluebirds. Of ten roofing-paper boxes made by Mr. Winthrop Packard three were occupied. My five hollow-limb boxes placed in trees were not used. None of the boxes used on this home farm has had any creosote put on or in them.

"I ought to say that I have had no success at all with boxes placed in the woods, and shall put up no more there. My experience agrees with Forbush's conclusion that boxes on poles or posts are more generally occupied than those on trees-elm generally. The more open and free from shade the situation the better have been the results. As far as I can see, the Von Berlepsch model has no advantage over the plain board box, except perhaps for flickers. I have had hairy woodpeckers bore into two Von Berlepsch boxes during the winter, when the regular entrance was plugged up to keep out squirrels and mice, but as far as I know, they did not nest in these boxes. They have not 


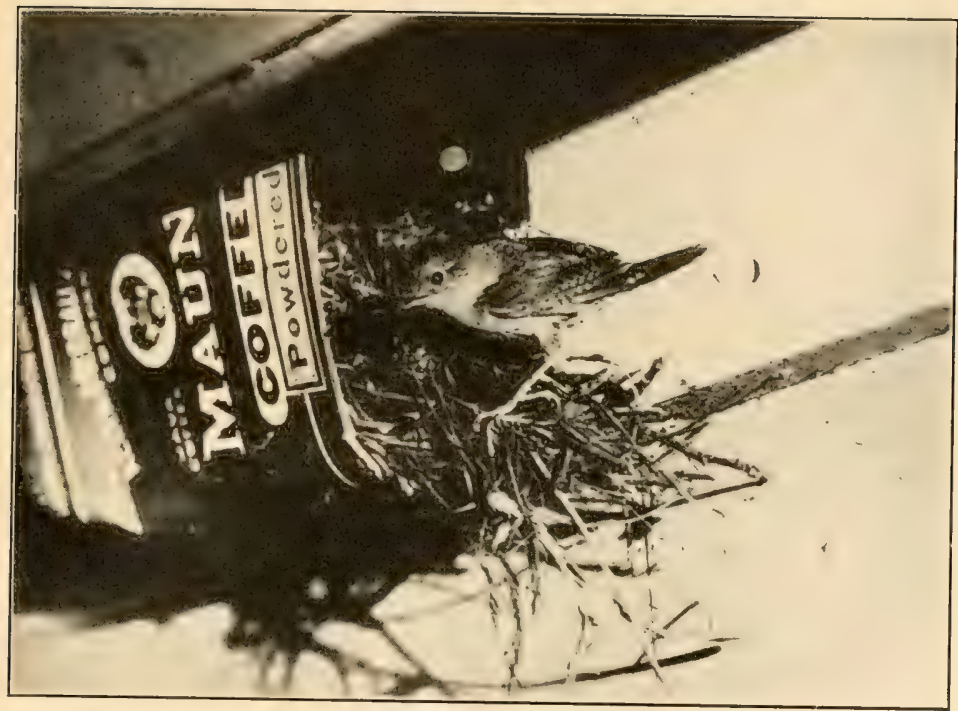

Hotse wren nesting in a tin can nailed up under the eares of a shed

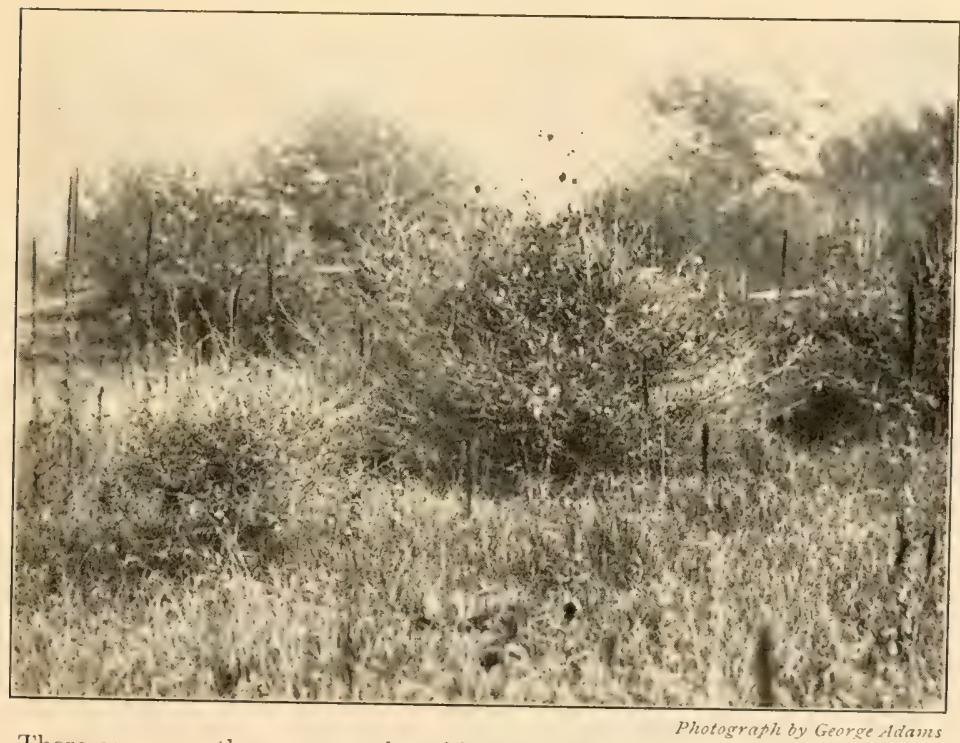

There are more than roo species of hawthorn on Ford Farm. They make splendid nesting places for song-birds 


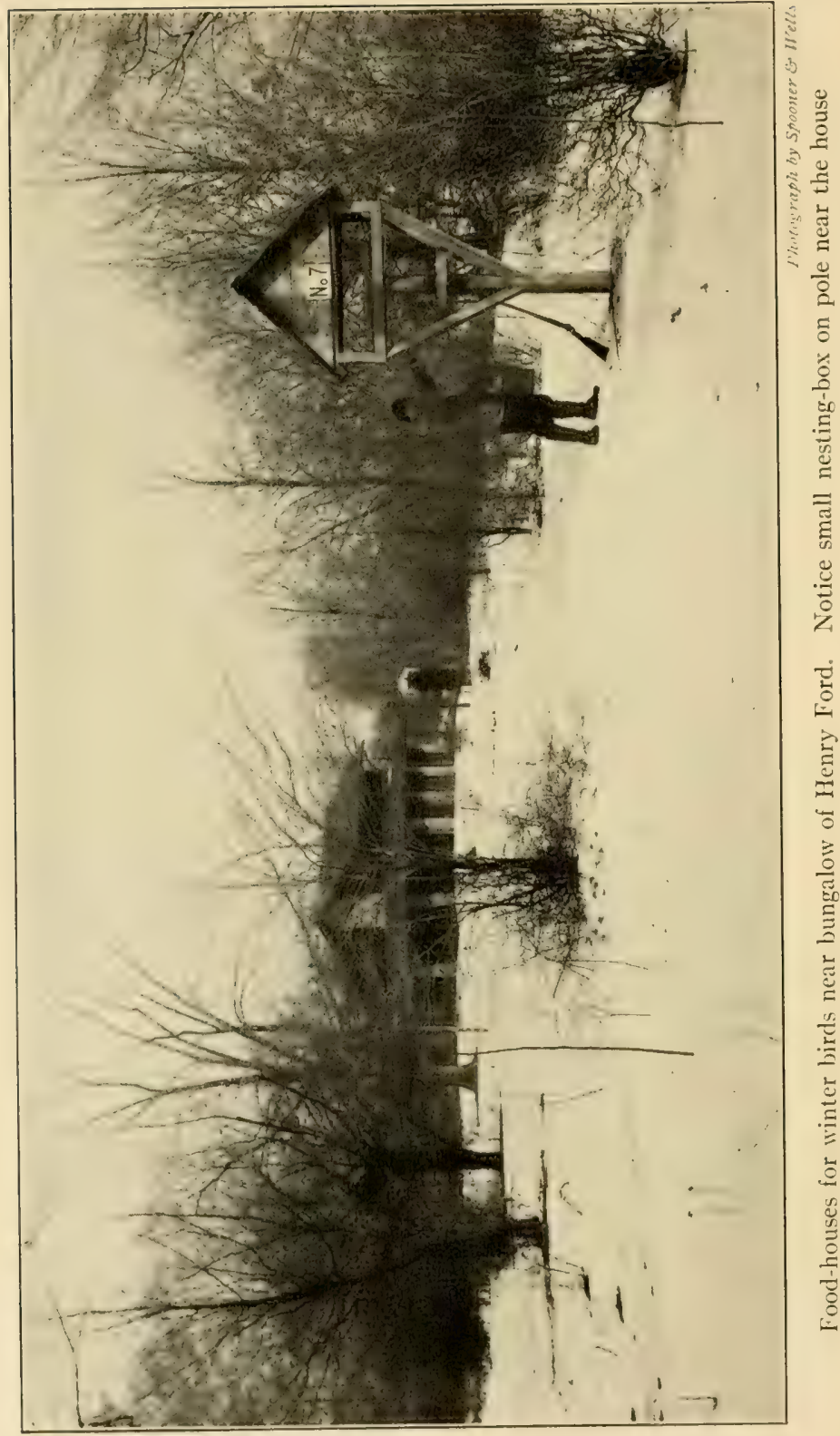


bored holes in the plain boxes. It is possible that future attempts to induce the more retiring woodland species to use man-made boxes may be more successful through the use of the German model. With the more easily attracted bluebirds and tree swallows, however, I feel reasonably sure that the plain board box is fully as effective as the more expensive type.

"As to the size of the entrance-hole, I feel it would be a mistake to put up any more boxes with holes having a diameter of less than $I_{2} \frac{1}{2}$ inches. Practically all my boxes with a diameter smaller than that are doing nothing. If people are urged to put up many of these, they are likely to be much disappointed, in this section, at any rate"where wrens are scarce.

Poles even without cat-guards make safer locations than trees, as animals do not climb them readily, especially if smooth or slender. Metal nailed around them higher than a cat can jump would assure safety. Mr. Forbush, however, has never had a cat climb to his boxes on poles. An especially secure device is one used on the Henry Ford farm. On 600 acres about 200 boxes had been put up, the majority of bluebird size. Most of these latter were on posts about 8 or 9 feet high, to which were bolted flat iron rods about a yard long, at the top of which the box was bolted. If an animal should climb the post, it could not get up the rod. The location chosen was where the nests would be inconspicuous, near trees or shrubbery, or among scattered trees. Sometimes they were on the east or northeast side of the trees, to get the afternoon shade, or, in case of tall trees, partly under them, but not near enough to branches for squirrels to jump to the boxes. Most of them were said to have been occupied. The man in charge had not climbed up to take any census, and, as Mr. Forbush has suggested, 
birds often roost in boxes and give the impression they are nesting there. The number occupied was doubtless considerable, mostly by bluebirds and wrens. Flickers and redheaded woodpeckers used the boxes on trees. In general woodpeckers are said to prefer the tree location so they can readily climb to the nest. The wrens nested almost anywhere, but the bluebirds, when there was a choice of boxes, one on a tree, the other on a post, regularly selected the latter.

The one pair of crested flycatchers which occupied a box on the place chose one at the top of the pole, I should say 20 feet from the ground. This was close to Mr. Ford's bungalow, which was well surrounded by groves. Here again the birds had a further choice - a board-made rectangular bluebird box at the top of the pole and a Von Berlepsch model just below it on the same pole. They chose the board box.

A good method of erecting a box on a pole is given by Mr. Forbush. A fence-post is used as a base. Holes are drilled, and the pole is bolted to the post by two lag-screws. To take down the box for cleaning, the lower screw or bolt can be withdrawn, and the other used as a pivot on which to lower pole and house, which is similar to the plan described for martin houses.

Direction of Entrance. The entrance should face away from the prevailing direction of storms. Most of the long, cold storms are from the northeast. The summer squalls and thunder showers blow from west and northwest. A generally southerly exposure is proper, say from southeast to southwest. Some prefer the former, to prevent the afternoon sun from beating in, if the box is not partly shaded from the westerly side. This latter is probably not important, but it does make a difference when it comes to 
northerly exposure. Birds do not like it so well, and might reject boxes thus placed, though Mr. Forbush has noticed that they sometimes take a box with northerly frontage if the cavity is deep. The young, however, are more liable to perish in storms.

Example from Martin Houses. The matter is well illustrated in the case of martin colonies. Mr. Forbush says that in a large compartment house they first occupy the rooms opening south and west, leaving those north and east to latecomers. In cold storms, when the young die, the casualties are first in the north and east compartments. As they require the holes to be near the floor level, they are more exposed than species using deep holes. Another item noticed by Mr. Forbush is that other species will occasionally use a box with the hole low down if it faces south and west, but not if in the other direction.

Not among Branches. People often put up boxes on the trunks of trees near the junction of one or more branches. Birds evidently dislike this. for such boxes are frequently not occupied, unless by wrens. Such branches make good perches for cats while they reach in and pull out the young. If on a tree at all, the box had better be fastened to the trunk away from limbs, and also not up among the foliage of the tree, where squirrels can jump to it easily.

Not Slanting Back. One of the points made by Baron Von Berlepsch in describing the proper placing of boxes is that these should not be set with the bottom projecting, causing the top to slope back, and leaving the entrance more exposed to the beating in of rain.

Cleaning House. In autumn, or certainly before spring, the nesting-boxes should be cleaned out. Old nests should always be removed, as most birds prefer to build their own, and seldom occupy a nest the second time. Squirrels and 
English sparrows often lug in a lot of stuff which should all be thrown out. Wasps or hornets sometimes take possession, and must be dispossessed - not an agreeable procedure before cold weather grips them. In localities where the gypsy moth is found, these pests are very apt to lay their eggs in nesting-boxes in July and August, so it is important to give them all an examination, even when they seem to be empty. Hence covers should always be made removable.

Housing Boxes in Winter. To avoid deterioration by the elements in winter it is often a good plan to store most of the boxes under shelter, and put them up again before their desired bird occupants arrive. Some boxes, however, should be left up for winter birds to use as shelters and roosting-places, in accordance with the number that are staying about.

Inducing Winter Birds to Nest. In at least some cases shelter and feeding in winter doubtless induce birds to remain and nest, notwithstanding the common theory that birds which remain in winter go North in summer and are replaced by some southerly individuals of the same sort. Rev. Wm. R. Lord is said by Mr. Forbush to have proved it in at least one case, where a chickadee which he could distinguish both wintered and nested, using the boxes for roosting during winter nights. Mr. Forbush is convinced that some individuals of this species, and perhaps others, are strictly resident, being found both in winter and in summer. At Wareham he fed a company of chickadees and believed he induced them to stay. They were very tame, and he wanted to see if he could make them accept his hospitality. So he cut down all the rotten limbs and stubs nearby and practically forced them to use his boxes, sometimes on the window-sill. Of course food, particularly suet, should be kept on hand for them. 


\section{b. Supplying Nesting Material}

Two Classes of Birds. While the matter of supplying nesting material to birds as a means of inducing them to nest on the premises has been suggested by some authors, this practice does not seem to have been emphasized as it deserves, and practically all attention has been given to nesting-boxes. The latter have a special element of the spectacular and of popular appeal, yet after all it is largely immaterial what sort of nests birds use, as long as we can attract them to nest with us and afford protection to them and their offspring during the critical period. Only a small minority of the species use or need the nesting-boxes, while a much larger number of kinds may be amenable to this other method. The two should be used in conjunction, else we may be open to the charge of partiality, as favouring hole-nesters as against weavers!

Early Lesson. My first lesson in the possibility of supplying nesting material to birds was when I was a small boy. Mother put out some choice pieces of lace to bleach on the window-sill at our home in Boston. At night they were missing, and we never knew what had become of them until next autumn the oriole's nest in the big elm near the window blew down in a gale, and there was the lace woven into the pretty structure. This gave me an idea, and I used to put out cotton, cloth, yarn, or string, and watch birds carry it off. In this way I could trace them to their nests, which otherwise might not have been built on the premises.

Recent Example. A recent concrete example of what can be accomplished in this way is given in the experience of W. G. Taylor of Derby, Connecticut, in the summer of I9I4 and previously. He has only a garden of two acres, but by feeding the birds in winter, and helping them to build their 
nests in spring, he always has unusualnumbersof birds about and a considerable number and variety of nests on the premises. Mr. Taylor is a real lover of birds, and has spent much time in studying the tastes of different species in reference to nesting material. He finds, for instance, that the robin likes best of all soft white cotton twine or strips of cotton cloth about a quarter of an inch wide, cut into lengths of 8 to ro inches to prevent the birds from becoming tangled and hanging themselves. There is some range of choice in colour between different species. For instance, the kingbird prefers red, blue, and green, or similar shades.

Studying Adaptation. Finding that the Baltimore oriole invariably started the nest with the outside fibrous bark of the last year's milkweed, Mr. Taylor decided it was because this bark is very soft and wraps readily around the twigs, staying where it is put, so he looked for a substitute. He found it in a ball of shoemaker's flax, such as they make their wax ends of, and cut it up into Io to I 2 inch lengths, putting it out on the trellis and bushes, as he did the other material. The orioles at once endorsed the judgment of their friend and adopted the new invention, even preferring it to the milkweed bark. The vireos also took it, using it to suspend their nests.

Other material which he puts out in quantity is horsehair and cotton batting. The horsehair he gets in quantity from livery stables and cuts into suitable lengths. No doubt cotton waste and all sorts of soft material would be acceptable to birds. Even bits of paper are often used, notably by vireos, and people with a sense of humour have amused themselves by furnishing printed legends or advertising matter of suitable proportions, which the birds displayed upon their nests. Orioles, chipping sparrows, and wrens, Mr. Taylor found, were fond of lining their nests with the 
horsehair. One pair of chippies built their nest entirely of horsehair, and another nest found last season after the leaves had come off was made of flax and horsehair. Vireos, wood pewee, least flycatcher, and kingbird liked to line their nests with the cotton batting.

Mud Pies. For the special benefit of the robins Mr. Taylor made a mud-puddle, stirred the mud to the right consistency, and also mixed in dried grass. The robins went nowhere else for material, and numbers of them nested on the premises or close by. Barn and eave swallows would use this if there were colonies in the vicinity. Robins are also greedy for lace, and it is not safe to leave any around.

Importance. Undoubtedly various birds which nest in shrubbery and on the ground would use such material and be attracted by it, besides other tree-nesting species not mentioned, such as the cedar-bird, purple finch, thrushes, thrasher, catbird, various warblers and sparrows, goldfinch, or others. I would emphasize this matter as in a class with the nesting-box for the pleasure it gives and the advantage to bird life. There is no question but that the supply of nesting material in a locality is an important factor in inducing birds to nest there. By all means try it out and report results. 


\section{CHAPTER XVI}

\section{MAKING SURROUNDINGS ATTRACTIVE}

Without surroundings which are pleasing to birds, efforts to attract them will be uphill work. The matter of vegetation is the prime factor, which furnishes food, shelter, and nesting-sites. Where there is congestion, traffic, noise, absence from vegetation and water, and a host of watchful cats, one cannot expect many birds. It is a wonder that birds come at all where they sometimes do, and it furnishes many a delightful surprise to find a bird responding to the least possible encouragement. Such a case was when George Eastman, in his garden, in the heart of the city of Rochester, New York, had a large thick shrub in a pot taken from his greenhouse and placed just outside his dining-room window. Along came a pair of catbirds and built their nest in it, and Mr. Eastman enjoyed watching them through the glass at close range when he came to breakfast. Once I had a pair of indigo-birds nest in my garden in Boston in a thick syringa bush, a species which would never have stayed there unless there had been quite a tangle. As already stated, one can begin with the artificial methods, to enjoy the presence of at least a few birds, and meanwhile be improving the surroundings, to make them as attractive as possible. Methods of doing the latter will now be suggested along several lines.

\section{a. AttractiveVegetation}

No bird prefers an arid desert. Even the birds of field or prairie, such as the bobolink and meadowlark, are de236 


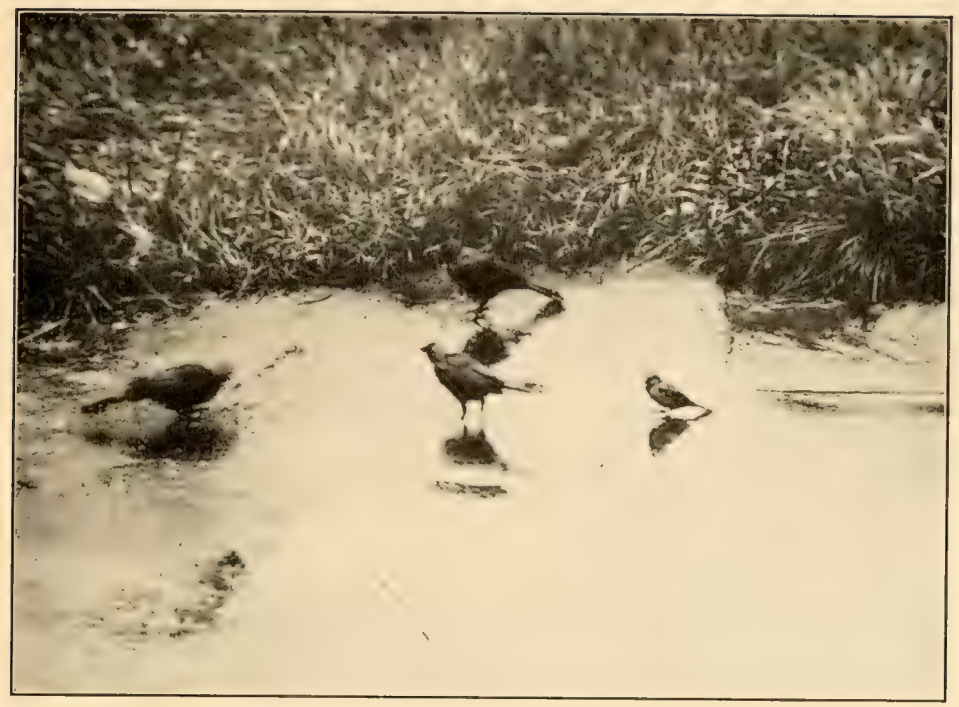

Grackles and English sparrow bathing in pool of rain-water on asphalt sidewalk, showing how presence of water attracts birds

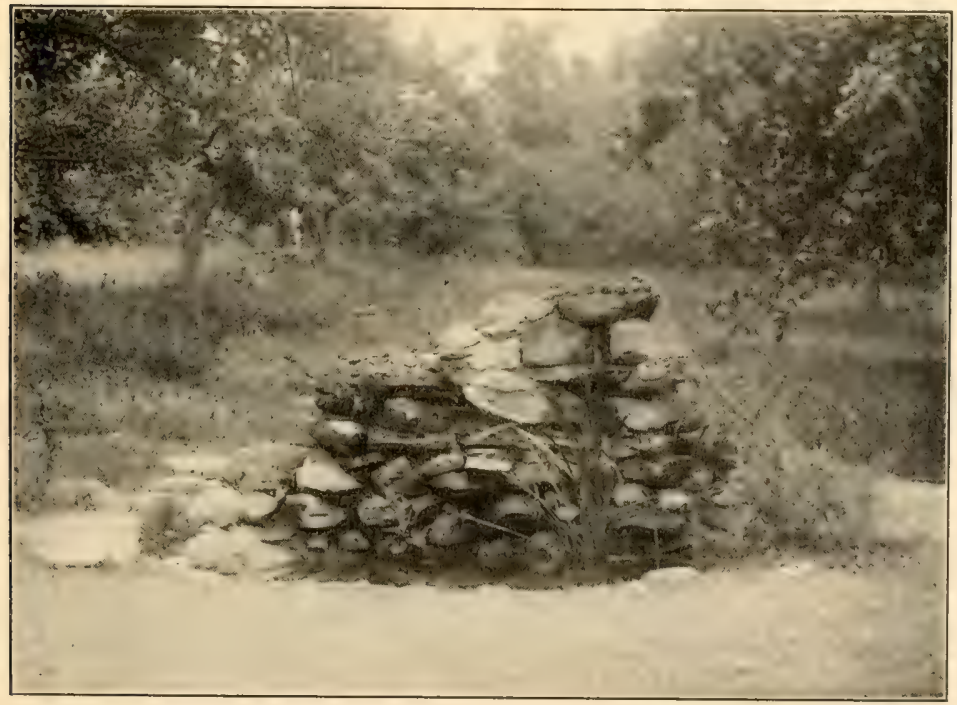

Birds' drinking fountain and bathing pool built by author for Connecticut Agricultural College 


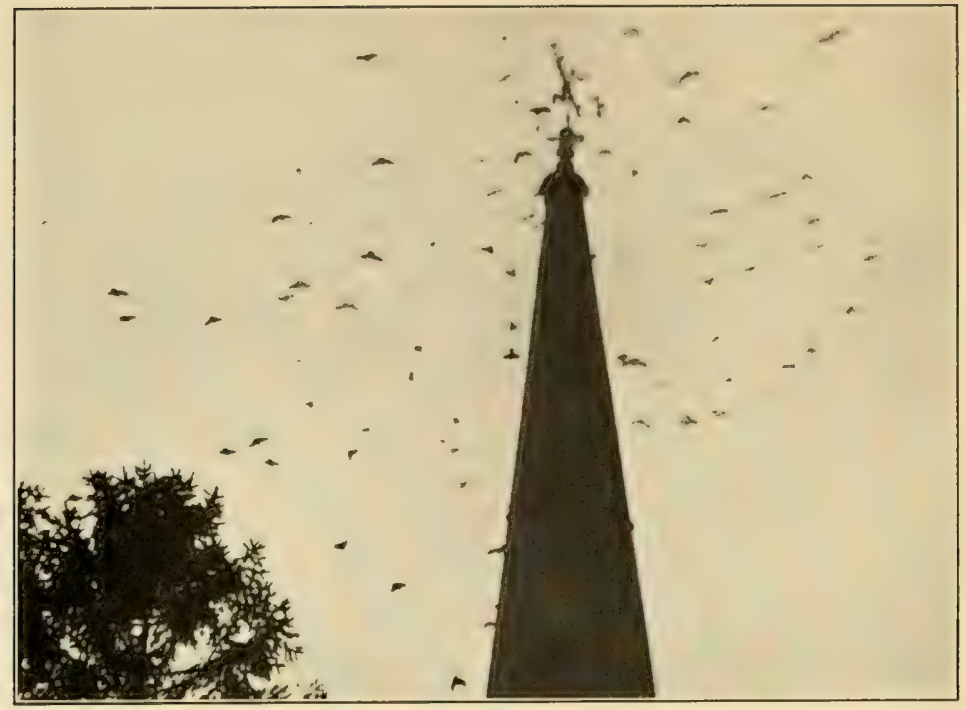

Starlings going to roost in steeple, showing how they congregate

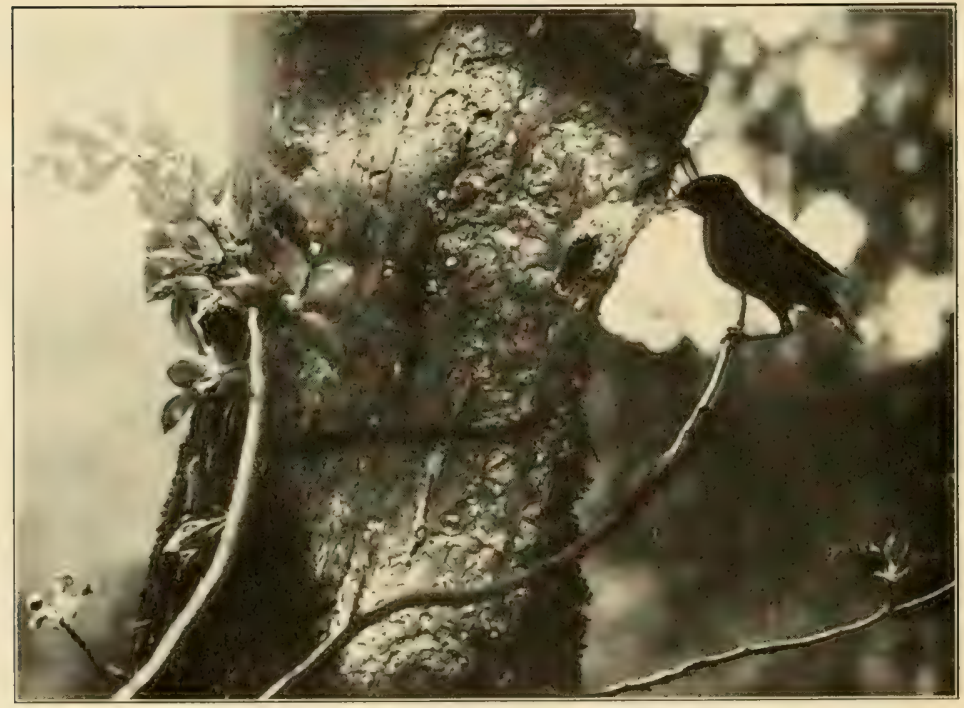

European starling entering nest of woodpecker which it has appropriated 
pendent upon the vegetation of their surroundings. The majority of small land-birds depend upon the supply of insects, seeds, and fruit, which in turn have plant-life as their basis. The problem of cover and shelter also has largely to do with vegetation. Hence abundant and diversified vegetation is the fundamental necessity, whether of trees, shrubbery, or smaller growths. These may serve for cover, food, or nesting.

Evergreen Cover. For purposes of cover it is not of first importance just what species of trees, shrubs, or plants are grown. The main thing is to have plenty of places where birds can get out of sight, and in winter be protected from cold winds. For all-round purposes of shelter nothing is better than evergreen of some sort. Hedges and clumps of evergreen, especially arbor vitæ and red and other cedar, should be planted if possible. Norway or other spruce is splendid, also pine or hemlock. A grove of white pine or hemlock is a treasure. Moreover, evergreens in winter are pleasing to human eyes as well as to birds. In my own small suburban yard are a few Norway spruces. Often do I find myself scanning them just for the pleasure of it, they are so restful and fragrant. They are a rendezvous for birds from the whole neighbourhood. In warbler time I can often discover one or more of these bird-gems among their foliage, and in nesting season grackles, blue-jays, robins, and chipping sparrows have recently nested in them. This winter, I9I5, four black-crowned night herons have roosted in them through January and February despite street traffic close by, houses surrounding, and the romping of children in the yard.

Shrubbery. A reasonable number of trees and frequent patches or hedges of shrubbery help to make ideal conditions the for largest number and variety of birds. Even 
from the human standpoint, the surroundings of home are made more attractive by the presence of trees and shrubs. In the prairie region of the West I have been impressed with this. On former trips to North Dakota to study bird life, the little homes stuck out on the bare prairie looked forlorn enough. Most of those early settlers planted "tree claims" and now these have grown up. Those formerly bleak homes now look cozy and attractive nestling among groves of trees and ornamental shrubbery. The financial value of property is enhanced by attractive appearance and surroundings. F. H. Kennard, the landscape architect, aptly notes how surroundings can just as well be made attractive as otherwise, and how windbreaks can almost always be planted somewhere with benefit. Lanes, he suggests, may be bordered with trees and walls covered with vines without any encroachments upon land needed for crops.

Food-bearing Species. In setting out shrubbery with a view to attracting birds, one will naturally give preference to those species which bear fruit or berries that birds are fond of. If there is already some shrubbery, note should be taken of what is lacking, in order to supply the need. Mr. Kennard aptly suggests the importance of planting so as to provide a continuous supply of food, and proposes as follows: for summer supply-cherry, mulberry, raspberry, blueberry, huckleberry, and the like; for autumn-elder and the various kinds of dogwood and viburnum; for winter, plants which hold their fruit longest-hawthorn, buckthorn, mountain ash, barberry, bayberry, sumach, and wild rose.

A Bulletin of the U. S. Department of Agriculture, by W. L. McAtee, on "Plants Useful to Attract Birds and Protect Fruit," gives a list of food-bearing trees and shrubs in what is thought to be the order of their attractiveness to the 
largest variety of birds: elder, raspberry and blackberry, mulberry, dogwood, sumach, wild cherry, blueberry, wild grape, pokeberry, Virginia creeper, bayberry, juniper, service berry, holly, strawberry, viburnum, hackberry, huckleberry, haw, spice bush, rose, sarsaparilla, sour gum, gooseberry, currants, snow-berry. As supplementary are given: manzanita, barberry, buffalo berry, silver berry, buckthorn, mountain ash, China berry, California Christmas berry, pepper tree, magnolia, nockaway, lote bush, and bluewood. The practice is very well known of planting fruits which birds prefer to keep them from eating fruits of commercial value. The white or the Russian mulberry are most in use for this purpose.

Various annuals are also of value. Note has already been made of planting patches of small grain which is left to stand for gallinaceous birds to feed upon, and will answer for smaller birds as well, and the mourning dove. Kinds most used are buckwheat, millet, and wheat. Sunflowers are also planted a good deal, as by Wallace Evans.

Gilbert H. Trafton, in his book on "Methods of Attracting Birds," has compiled a table of over thirty kinds of foodbearing trees, shrubs, and plants, in cross-reference columns, showing, from various authorities, what species of birds feed upon the fruits mentioned. He notes that the best allround fruit is the mulberry, either white or Russian. This corresponds with my own experience, for birds in considerable numbers constantly resort, nearly all summer, to a white mulberry tree in my yard, which, nevertheless, bears far more fruit than they can consume. He quotes E. H. Forbush as preferring the Charles Downing mulberry, and G. T. Powell as finding that a row of Governor Wood cherry trees along one side of his orchard so monopolized the attention of birds that they left the other fruit alone. Prof. 
H. A. Surface is also quoted as stating that the four fruits he finds most attractive to birds are an early sweet cherry, the service(June)berry, mulberry, and Virginia creeper.

Species Attractive to Birds. In an article in Bird-Lore, July-August, I9 2, F. H. Kennard gives a list of trees, vines, shrubs, and herbs bearing fruit or seeds attractive to birds, which he compiled as a provisional list from which to choose species for the further development of the bird sanctuary of the Meriden Bird Club at Meriden, New Hampshire. He omits from the list the larch or hackmatack and the Norway pine or spruce for want of direct data. E. H. Forbush, however, includes these, and I have had these species on my premises and found them quite attractive to birds. In the list which follows, taken from a reprint by the National Association of Audubon Societies, Mr. Kennard has marked with three asterisks, those plants which are particularly attractive to birds, while those with more than ordinary attractiveness are shown by two or one. Those species whose fruits seem to be eaten so seldom as to make their planting hardly worth while are marked with a cross.

\section{DECIDUOUS TREES}

*Acer negundo, Ash-leaved Maple, Box Elder.

**Acer saccharum, Sugar Maple; and doubtless other maples.

Betula populifolia, American Gray Birch.

Betula lutea, Yellow Birch; and probably other birches.

Celtis occidentalis, Hackberry.

Cercis canadensis, Redbud.
***Cormus florida, Flowering Dogwood.

†Corylus americana, American Hazel.

${ }^{* *}$ Crategus coccinea, White Thorn.

${ }^{* *}$ Cratagus corus-galli, Cockspur Thorn; and others of this genus.

$\nmid$ †agus americana, American Beech.

*Fraximus americana, American White Ash; and probably other species. 


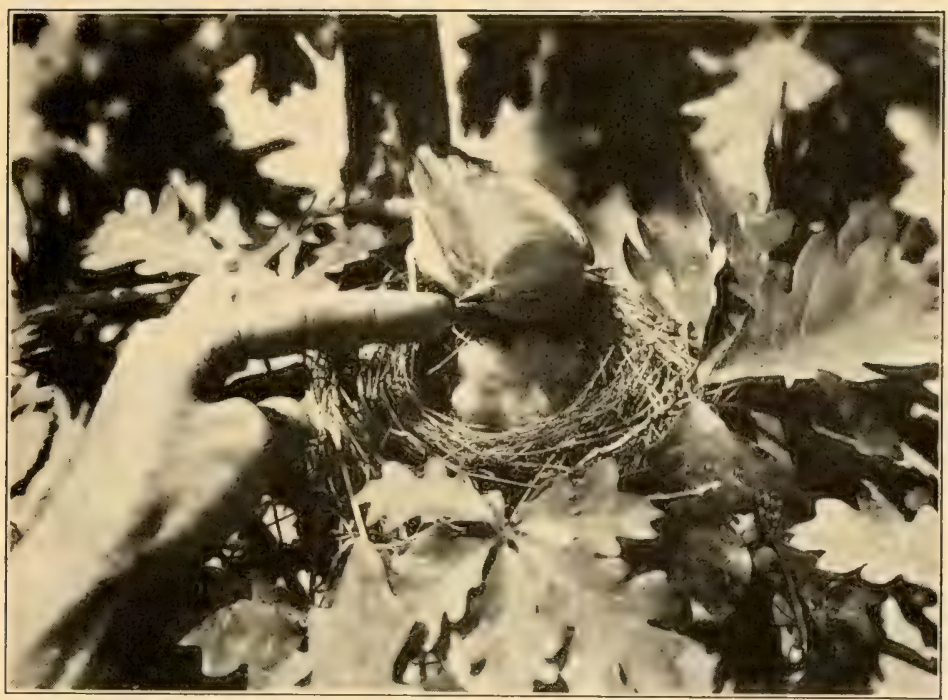

Female scarlet tanager being handled as she returned to nest with food

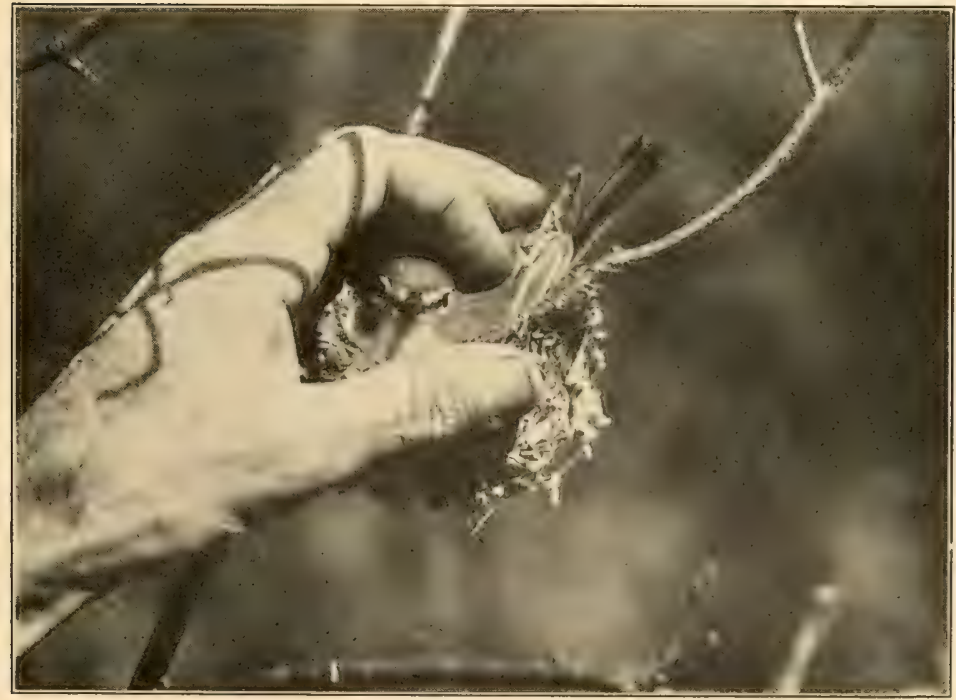

Blue-headed vireo being handled on nest by author 


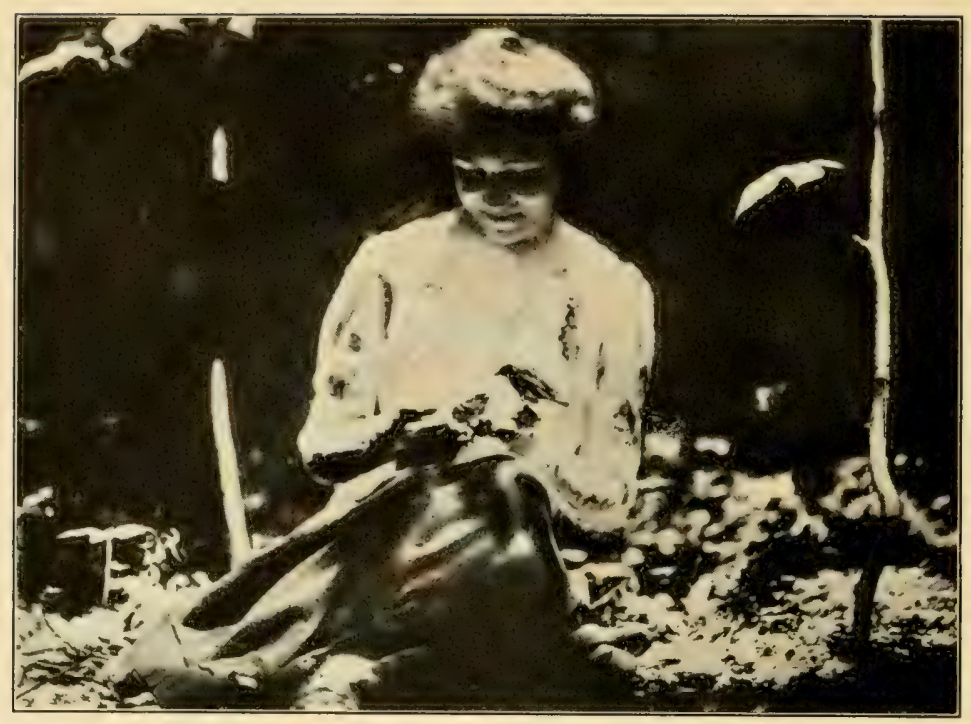

Black-throated green warbler feeding young in lap of girl

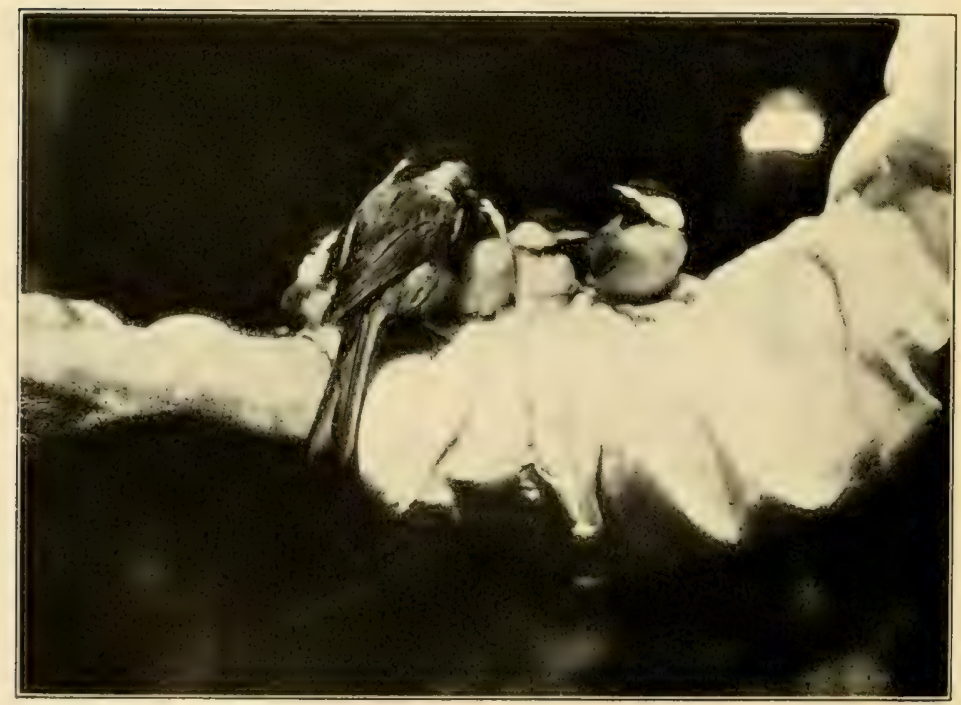

Chickadees feeding young on author's arm 
DECIDUOUS TREES-Continued

$\lceil$ Hicoria sp., Several kinds of Hickory.

Ilex opaca, American Holly.

$\dagger$ Liquidambar styraciflua, Sweet Gum.

$\dagger$ Liriodendron tulipifera, Tulip Tree.

***Morus rubra, Native Red Mulberry.

**N Nyssa sylvatica, Tupelo.

Ostrya virginiana, Hornbeam.

$\dagger$ Plantanus occidentalis, Sycamore.

$\nmid$ Populus sp. Various species of Poplars are sometimes fed upon.
***Prunus pennsylvanica, Bird Cherry.

***Prumus pumila, Sand Cherry.

***Prunus serotina, Black Cherry.

***Prunus virginiana, Choke Cherry.

**Pyrus americana, Mountain Ash.

†Quercus sp. Several species of oaks.

Sassaffras officinalis, Sassafras.

Ulmus americana, American Elm, and other species.

\section{EVERGREEN TREES}

**Juniperus virginiana, Red Cedar.

** Juniperus communis, Prostrate Juniper.

**Picea alba, White Spruce. ** " rubra, Red Spruce; and undoubtedly other species.

*Pinus rigida, Pitch Pine.

* " strobus, White Pine.

*Tsuga canadensis, Hemlock.

\section{SHRUBS}

**Amelanchier canadensis, Shad Bush.

**Benzion odoriferum, Spice Bush.

*Berberis vulgaris, Barberry.

Comptonia asplenifolia, Sweet Fern.

Corema conradii, Broom Crowberry.

***Cornus alternifolia, Blue Cornel.
***Cormus candidissima, Gray Cornel.

***Cormus sericea, Silky Cornel.

***Cormus stolonifera, Red Osier Cornel.

**Gaylussacia frondosa, Dangleberry.

**Gaylussacia resinosa, Huckleberry.

**Ilex glabra, Inkberry.

**. verticillata, Black 


\section{SHRUBS-Continued}

Alder; and probably Ilex lavigata, Winterberry Black Ilex.

Ligustrum vulgare, Privet. ** Myrica cerifera, Bayberry.

Prunus maritima, Beach Plum.

*Pyrus arbutifolia, Chokeberry.

Rhamnus catharticus, Buckthorn.

***Rhus copallina, Shining Sumach.

***Rhus glabra, Smooth Sumach.

***Rhus toxicodendron, Poison Ivy.

*** Rhus typhina, Staghorn Sumach.

***Rhus venenata, Poison Sumach.

** Ribes floridum, Large-flowering Currant.

**Ribeslacustre, Swamp Gooseberry; and other species.

**Rosa, sp. It is probable that the fruits of all the native wild roses are eaten largely by birds.

***Rubus occidentalis, Thimbleberry.

***Rubus strigosus, Red Raspberry.

***Rubus canadensis, Low Blackberry.

\section{VINES}

**Ampelopsis quinquefolia, Virginia Creeper.

Aretostaphylos uva-ursi, Bearberry.
*** Rubus villosus, High Blackberry.

***Sambucus canadensis, Common Elder.

***Sambucus pubens, Panicled Elder.

Shepherdia canadensis, Shepherdia.

**Symphoricarpos racemosus, Snowberry.

***Vaccinium caspitosum, Dwarf Bilberry.

***Vaccinium corymbosum, High-bush Blueberry.

***Vaccinium pennsylvanicum, Low-bush Blueberry; and doubtless other species, including Vaccinium vitisidaa, Cowberry.

**Viburnum, alnifolium, Hobble Bush.

**Viburmum dentatum, Arrow-wood.

**Viburnum lentago, Sheepberry.

**Viburnum nudum, Witherod.

**Viburmum opulus, Highbush Cranberry.

**Viburmum prunifolium, Black Haw; and doubtless $V$. acerifolium, $V$. cassinoides, and other species.
Celastrus scandens, False Bittersweet.

Menispermum candense, Moonseed. 


\section{VINES-Continued}

Mitchella repens, Partridgeberry.

Vaccinium macrocarpon, Cranberry.

Vaccinium oxycoccus, Dwarf Cranberry.
*Smilax rotundifolia, Bull Briar.

**Vitis cordifolia, Frost Grape.

**Vitis labrusca, Fox Grape. ** " vulpina, Riverside Grape.

HERBACEOUS PLANTS

**Aralia mudicaulis, Sarsaparilla.

Fagopyrum esculentum, Buckwheat.

**Fragaria virginiana, Strawberry.

Gaultieria procumbens, Checkerberry.
Helianthus annus, Sunflower.

**Phytolacca decandra, Pokeberry.

Smilacina racemosa, False Spikenard.

Solanum nigrum, Nightshade.

Concealment for Nests. Not only is thick foliage desirable for shelter and roosting, but also for nesting purposes. Most kinds of birds desire concealment for their nests in foliage or vegetation, and are more likely to take up their abode in surroundings where such concealment is provided. A number of species find thick evergreen just what they need. A good evergreen hedge is apt to be a popular place for birds to nest. Few things are more attractive to birds for nesting than good thickets or tangles. If one wants an artificial garden, that is one matter, and every nook and corner will be trimmed and garnished. But if birds are wanted, some spots should be left to Nature's way. Walks may be hoed, but it will not injure the real beauty of a garden to leave some masses of natural tangle, which Mrs. Mabel Osgood Wright has prettily nicknamed a "thrashery," from an incident of a pair of brown thrashers nesting in such a situation on her premises. Places of this sort are liable to attract interesting and unexpected bird 
neighbours, such as some unusual warbler. Just let everything grow up naturally, and, if necessary, plant vines or briars, and have a fine old tangle of everything that will grow.

Neatness Overdone. The fashion of cutting down shrubbery and of general trimming and cleaning up to secure open spaces has become quite common. It is considered a mark of neatness and thrift to cut off shrubbery and weeds along roads or drives. Every dead or hollow limb of a tree has to be removed. These, however, are the worst things that could be done from the standpoint of attracting birds. While a certain amount of cleaning up may be desirable as a concession to neatness, the more that natural conditions can be approximated the more birds there will be. Why should a bare roadside be considered more artistic than the wealth of Nature's planting? Dead limbs entice woodpeckers to build, and natural decayed hollows attract and shelter various birds.

Shelter Woods. One very prominent part of the Von Berlepsch plan is the proper planting and arrangement of vegetation of the various types to make natural nestingsites for the birds. One of his pet schemes is that of "shelter wood" for birds, based upon his observations of primitive conditions favourable to bird life in Africa and America. As it takes about ten years to develop his full plan of planting and pruning, modifications and suggestions from it will be more popularly used than the whole scheme in its entirety. In general, the idea is to plant a copse of thorn and other bushes to form a jungle impenetrable to enemies of birds, with occasional trees for partial shade. Details are fully described in the Hiesemann book.

Whorls by Pruning. In conjunction with this method, the shrubbery is for several seasons cut back, causing new 
branches or shoots to start in bunches or whorls, which make firm and secure foundations for nests. The birds on the estate which construct open nests usually choose these sites. This could be done readily on a small scale with bushes or clumps of shrubbery. The various thorn bushes are preferred for this purpose, because the thorns help to repel enemies of the birds, especially the white thorn, also hornbeam, beech, dog rose, various gooseberry bushes, privet, also red cedar and Norway spruce, and others.

Lopping Trees. Another similar plan followed is the lopping off of branches from the trunks of trees, and allowing clusters of shoots to grow out, which creates excellent sites for nests. On the estate are large rows or avenues of poplars treated in this fashion. I have myself noticed in our Western prairie regions, where there were strips of timber along streams, how fond the mourning doves, robins, grackies, and other species were of nesting where the sprouts grew out from the trunks of the box elders or other trees, usually 6 to 12 feet from the ground.

Tying Bushes. Still another device which is adopted, and one which is much more speedy, is the tying together of branches of a bush, so as to form above the point of junction a diverging cluster or whorl, making foundations for nests similar to those formed by pruning. The Baron used these only as a makeshift while the pruned whorls were growing. It is stated that out of fifty such tyings made the first year, forty-seven were occupied with nests that season.

Precautions. The following precautions were also observed: Fallen leaves must be left on the ground, as birds find food under them and are warned by rustling of hostile approach. Experiments showed that birds noticeably avoided places which were carefully raked. Working operations, wood cutting, and grazing of cattle should be dis- 
pensed with in the nesting season. Pruning and cutting of shrubbery must not be done in the breeding season, but early in spring and autumn.

\section{b. Water Supply}

Birds Crave Water. Under average trimmed-up urban or suburban conditions, or even in the typical neat village, land is all carefully drained, and there is apt to be no pool or stream where the birds can drink and bathe. A good water supply in summer is one of the conditions most attractive to birds. The providing of water will often cause numbers of them to locate on the estate to breed, and also attract as visitors many from the general surroundings.

The Main Requisites. The main requisites in providing water for birds are as follows: The water should be shallow, so that small birds can wade out in it and take their bath in bird fashion. The edges should not be steep, and there should be a gradual slope. It is well if the water is in a retired spot, somewhat sheltered by shrubbery, the sort of place naturally attractive to birds. At the same time shrubbery or herbage should not be so near the water that concealed cats can spring upon the birds. If it is near, keep the cats off.

Making a Bird Bath. The simplest devices will answer the purpose. Even a shallow dish of water out on the lawn, replenished regularly, is better than nothing, though birds prefer something which appears more natural. A wide flower-pot saucer, or something similar, will answer the purpose. If the affair is quite large, fill in with pebbles and small stones, having some of them project from the water for birds to stand upon. Another method, a step more elaborate, is to dig a slight hollow and make a small shallow cement basin, which can be filled by hand, by hose, 
or by water-pipe. Better have it at least partly in the shade. If there is no flow of water, it is well to scoop or sweep it out frequently and fill afresh, which will prevent the breeding of mosquitoes. If a water-pipe can be used, to provide a constantly changing supply, a hole several feet deep should be dug close by, filled up with loose rocks, a small drain-pipe run into this, and earth and turf put back to cover it. Such a cesspool will keep the surroundings dry and show no signs of its presence.

The Hodge Fountain. A more ambitious bird font, suggested first by Dr. C. F. Hodge, works very well. I made one on this plan for the Connecticut Agricultural College, which proves attractive both to birds and to visitors. The location is at the side of an orchard, facing a botanical garden. A trough of cement was made by masons, and irregular rocks were carted to the spot. These were piled up in a rustic design, and cement was used to hold them firm. The structure was made some 4 feet high. A water-pipe was run to the top, and by the cement a series of shallow pools was formed, arranged so that the water would trickle down from one to the other. At the base there was a cement pool made, about a yard long. Proper soil and water-plants were brought in, making a nice little aquarium in which small fish could have been kept. A vault made as just described kept the surroundings dry.

A Successful Bird Pool. What can be done in this line is suggested by the experience of Mrs. George H. Mellen at her home in Newton, Massachusetts. I quote the following from her, nearly word for word: The garden is on the corner of two residential streets in the city, and is about roo feet square, with trees and shrubbery. The first season large earthen receptacles were set on the lawn, but only three kinds of birds came to bathe. Next year a pool was 
made of irregular shape, and various ferns, vines, plants, and trees planted near gave it an air of seclusion and woodsiness evidently appreciated, as the first season sparrows, warblers, vireos, grackles, jays, robins, kingbirds, catbirds, thrashers, orioles, grosbeaks, chickadees, nuthatches, waxwings, humming-birds, and owls visited it. The pool was planned to give a background of ferns, tall growth at the head, a tree for perching at the foot, low growth on the houseside, and vines on the outer edges. The dimensions are 5 by 3 feet in widest part, 5 inches deep through the centre, and shelving to irregular border, with stones projecting into it at intervals. Grackles and jays do most of their bathing in the deep portions, and flickers invariably wade out into the centre and march across the 5 -inches-deep spaces.

Much Frequented. Some idea of the extent to which the pool is used may be gained from the following instances. One morning in August, between nine and ten, twenty-four baths were counted, by five species of birds. One afternoon, about two o'clock, five grackles, five blue-jays, four flickers, four orioles, two robins, and a sparrow were in the water or on the rocks about the edge at the same time. A nuthatch was calling from the trees nearby, and during the carnival a humming-bird perched on a branch over the pool and watched the sport.

Certainly there can be no question but that a pool with natural surroundings is better than a dish, and would be more readily recognized by birds as offering what they wanted.

\section{c. Suppression of Enemies}

Importance. No matter how attractive to birds a place may be, or how much is done for them, the presence of destructive enemies, particularly if abundant, will minimize 
or bring to naught much of what has been done. When surroundings are favourable and birds yet remain scarce, the probability is that it is overrun with silent yet destructive agencies. Careful attention and vigilance should be directed to the problem.

English Sparrow. It is almost hopeless to expect many birds to nest in boxes where this species is abundant. Though birds of other sorts may not be entirely prevented from nesting, their numbers will be materially lessened. On a certain estate $I$ was asked to ascertain why native birds did not come to occupy the boxes put up for them. Examination revealed the fact that English sparrows abounded on the place and had nests in all the boxes. The first thing I did was to instruct the gardener how to clean out the sparrows. Baron von Berlepsch fights them ceaselessly on his estate. His assertion is correct that "the increase of other kinds is in inverse ratio to the decrease of sparrows."

European Starling. The European starling, introduced about twenty-five years ago into New York City, has spread over most of the Eastern seaboard districts and is constantly extending its range. Probably in time starlings will be all over the country. They are about the size of the cowbird and not unlike it in appearance. Adults are black, with some brownish markings, and a yellow bill, the young being duller. When you see "a blackbird with a yellow bill" it is the advance guard of the host. In some localities, in fall and winter, they roam in flocks of hundreds and even thousands. As with the English sparrow, there seems to be no check upon their increasing hordes, for they are equally hardy amd pugnacious. They nest in hollow trees, holes in buildings, in towers and cupolas, or other such places. They appropriate all available holes, and drive 
native birds from those they have occupied, destroying their eggs or young. Even a bird as large as the flicker is seldom able to defend its nest-hole against them. Within two blocks of my home I saw one spring five new flickers' holes which were seized by starlings. I have been told of a starling being seen in the act of dragging out a young martin from a nest in a martin house.

Danger of Introducing Species. The case of the starling is a good illustration of the uncertainties and dangers involved in introducing species to new surroundings. In Europe the starling is usually liked, and Baron von Berlepsch encourages them to nest in the walls of his castle. But, introduced into Australia and New Zealand, it has become a pest, as it is already becoming in this country. In Europe conditions of bird life are somewhat different, and the valuable species are somehow able to hold their own; while here the few kinds which nest in hollows are not able to maintain themselves against this new invasion.

Method of Poisoning. The following method for poisoning English sparrows, which is also applicable to starlings, is described in Farmer's Bulletin 493, U. S. Department of Agriculture, "The English Sparrow as a Pest," by Ned Dearborn. Wheat is preferred as a bait and vehicle for administering the drug. Put one eighth ounce of pulverized strychnine into three fourths of a gill of hot water, add one and one half teaspoonful of starch or wheat flour moistened with a few drops of cold water, and heat, stirring constantly until the mixture thickens. Pour the hot poisoned starch over one quart of small kernelled wheat, and stir until every grain is coated. This will quickly dry and can be kept in a glass jar.

The best plan is to bait the birds in advance to a certain spot. With sparrows this is easy to do in cold weather, 
particularly when there is snow. Starlings are more shy and come less readily, but in severe winter weather they resort to backyards. Put out the poisoned grain on a dry morning, since moisture brings out the bitter taste of the strychnine. Allow about twenty kernels to each bird, as it takes six or seven to kill quickly. Watch out and kill the birds that become drowsy but would recover, as these are shy of poison in future, and seem to warn the others. Take care that the poison is not put out where native birds are accustomed to come.

Trapping. The starling seems rather shy to trap successfully, but the sparrow can be caught, cunning as it is, in large numbers, by certain methods and with proper precautions. The above-mentioned bulletin describes several devices, with diagrams, and it can be secured upon application to Washington. The "clover-leaf" trap, previously described, might be effective with sparrows. However, E. A. Quarles, vice-president of the American Game Protective Association, told me of trying a commercial sparrow trap, by which design the birds entered a small hole and were supposed to be unable to find their way out, but in this case they entered and left again with ease. The "feathered rat" is nobody's fool!

Barnes Trap. The following very effective device is in use by A. M. Barnes, on the estate of William Rockefeller, at Tarrytown, New York: An enclosure is made similar to a covered chicken-yard, with wire over the top. The wire throughout should be $\frac{3}{4}$-inch mesh, to keep sparrows from escaping. The pen should be high enough for a man to stand up in, and any convenient size, say 6 by ro feet, or larger if one cares to utilize it as a poultry-yard. Suspended from the overhead wire by the corners should be placed a board tray or lunch-counter on which small grain should be 
scattered. This should hang about one foot below the wire, and be made about 2 feet square, with a slight rim to keep the grain from blowing off, and should be located about the middle of the enclosure. Over the centre of this tray a few strands of the wire should be cut, and the ends bent down, leaving a hole just big enough to admit the sparrow. Especially in severe winter weather, though also at other times, the sparrows alight on the wire over the grain, enter the hole, but are unable to find their way out. Mr. Barnes has a smaller compartment at one end into which he drives the birds, to catch them more readily, though in a smaller trap this is unnecessary. Occasionally juncos, tree sparrows, and other native birds get in, but these are liberated without harm. The arrangement is so like an ordinary poultry-yard that even the shrewd sparrows do not suspect harm. Mr. Barnes has already caught several thousand of them. It is well to leave some sparrows in it always for decoys, and water should be provided for them. In case sparrows do not go in at first, it is well to catch a few otherwise and put them in. English sparrows are said to make good eating, and in this way they might be of use.

Cats. It is almost hopeless to have many birds if a place is overrun with cats. Notice how easily they scramble up the trunk of a tree when they really set out to. They can get almost any nest that is not out on slender branches. When young birds are learning to fly they are most likely to be captured. The average garden is a stalking-ground for cats. The English sparrow is able to increase largely through nesting in places inaccessible to cats, whereas various other species are not so fortunate. Robins and chipping sparrows are great sufferers, and many a nest in trellis or arbour, or in the orchard, is despoiled. In many places it is impracticable to shoot cats, besides being very unpleasant. 
The best plan is a box trap, such as the Evans trap, in which the cat pulls a trigger while eating the bait, and the door drops. A little chloroform will mercifully end a predatory career, and no one is the wiser.

Squirrels. Red squirrels are particularly destructive of birds' nests. Grays are ordinarily rather inoffensive, yet even they become destructive at times, when allowed so to increase that they overrun the food supply. Especially is this true in city parks, where they are hemmed in by traffic and cannot get away. If they are allowed to multiply unduly, they are forced to devour everything edible, and must be reduced in numbers. Squirrels of all sorts, including the pretty flying squirrel, are apt to occupy the nest-boxes put up for birds, often gnawing the openings to make them larger. Birds dislike a locality where squirrels are numerous and are apt to shun it.

Other Pests. Rats, the universal pest, must be fought ceaselessly. Get Farmer's Bulletin 369, "How to Destroy Rats." Weasels, minks, raccoons, skunks, and foxes are all after nests and young broods. For methods of trapping them see Part I, last section. Cooper's, sharp-shinned, and pigeon hawks, and the great horned owl are destructive of bird life. Other destructive hawks, usually rare, are the goshawk and duck hawk. The other kinds usually do more good than harm. Though all raptorial species probably kill some useful birds, the class as a whole fulfils an important function in keeping down snakes, rodents, and other vermin, which would destroy more birds by far than their captors take. Without them we should be overrun, and ground-nesting birds, including quails, grouse, and the like, could hardly survive. Even the great horned owl, destructive as it may be, is a notable destroyer of skunks. So often does it bear the skunk odour that woodsmen some- 
times consider this the natural odour of the bird. A good policy is to kill raptorial birds which we know seriously destroy birds but to give the rest of them the benefit of the doubt. Crows do some good, but they are great destroyers of eggs and young birds, and should not be allowed to become too numerous. Blue-jays are not guiltless, but they are so interesting and handsome that a moderate number of them may well be spared. 


\section{CHAPTER XVII}

\section{ARTIFICIAL FEEDING}

Why Feed the Birds. Though wild birds ordinarily prefer their own natural diet, there are often times, in severe winter weather, when a little artificial aid in obtaining food will save their lives. It is generally believed that wild birds, being very warm-blooded, seldom perish alone from cold, but succumb to the cold when their vitality is lowered by starvation. Nearly every winter there are spells of especial severity, when food is buried in snow or covered by a coating of ice. At such times the lives of many birds may be saved by a little care and forethought. It is a pleasure also to have the birds feeding at our doors and to be able to study them at close range, to have their enlivening company at a time when there is so little alive in the cold outdoor world. Certainly it becomes a means of education, particularly for the young. Further, it is even a sport to see what species can be attracted by our efforts, what ones can be induced to feed from the hand, and what photographs can be taken of the visitors. The practice both saves the lives of birds and greatly assists them, and also furnishes intense pleasure to the donor. It is becoming very frequent and even general in many parts of this country, and should become more so. Let every one feed the birds.

Concentrating Bird Life. During winter in any cold northern climate bird life is bound to be scarce at the best, 
both as to species and actual numbers of birds. The fact that individuals which find the food attractive are induced to locate in the vicinity, and to become frequent or even incessant visitors to the food supply, can serve to make bird life seem abundant and give a very cheerful aspect to the wintry surroundings. One very cold winter I had at my sheltered porch nearly all the time during daylight a flock of a dozen chickadees and several nuthatches and woodpeckers. There was always "something doing," and various happenings proved so interesting that it was often hard for me to stay away from the window and attend to my work.

Birds to Expect. The following list will give an idea of what kinds of birds may be possible guests of our hospitality. Reference is especially to the Northern and Eastern States unless otherwise specified. It may also be noted here that these divide themselves into two distinct classessuet-eaters and seed-eaters-though some species eat both. Those that eat suet at all are the easiest to attract within close range, and will sometimes eat on porch or window-sill, the others feeding mainly on the ground.

The chickadees, white-breasted nuthatch, and downy woodpecker are the three especial "stand-bys" of the average bird lunch-counter. The hairy woodpecker is often quite frequent, and the little red-breasted nuthatch not altogether a rarity. The brown creeper sometimes stops for a few bites, but quickly moves on, usually not caring to tarry. The blue-jay sometimes ventures, especially at a little distance from the house, though I have seen them come on a piazza roof. In severe weather crows will work at meat or bones hung up well back from the house, though I have seen them attracted thus to suburban gardens.

The usual seed-eaters most apt to be drawn are the tree 


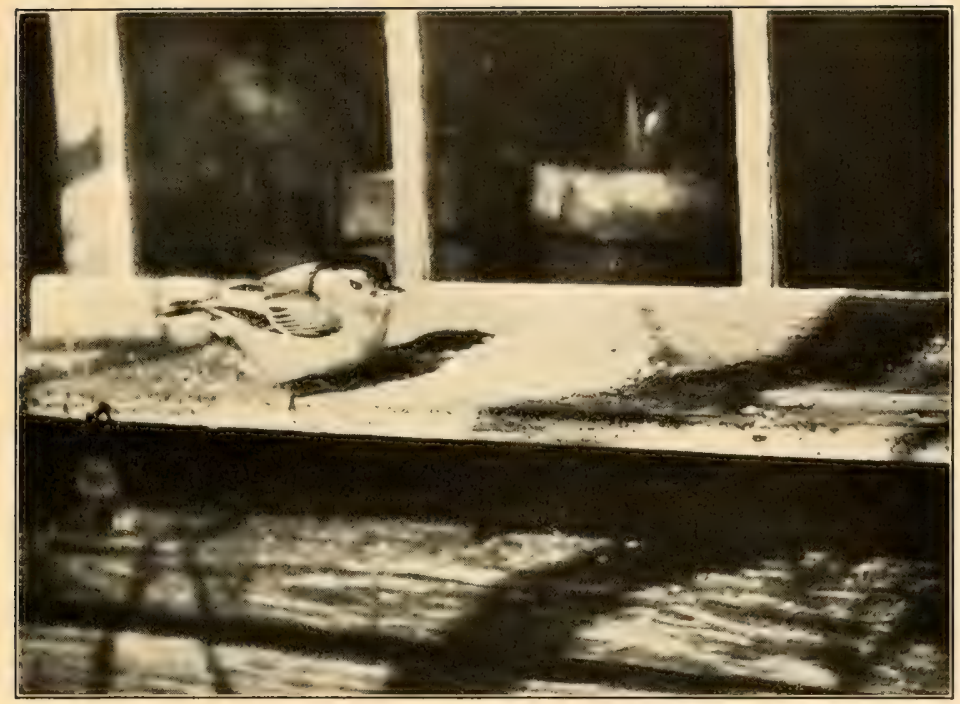

White-breasted nuthatch on window-sill, to get bread crumbs

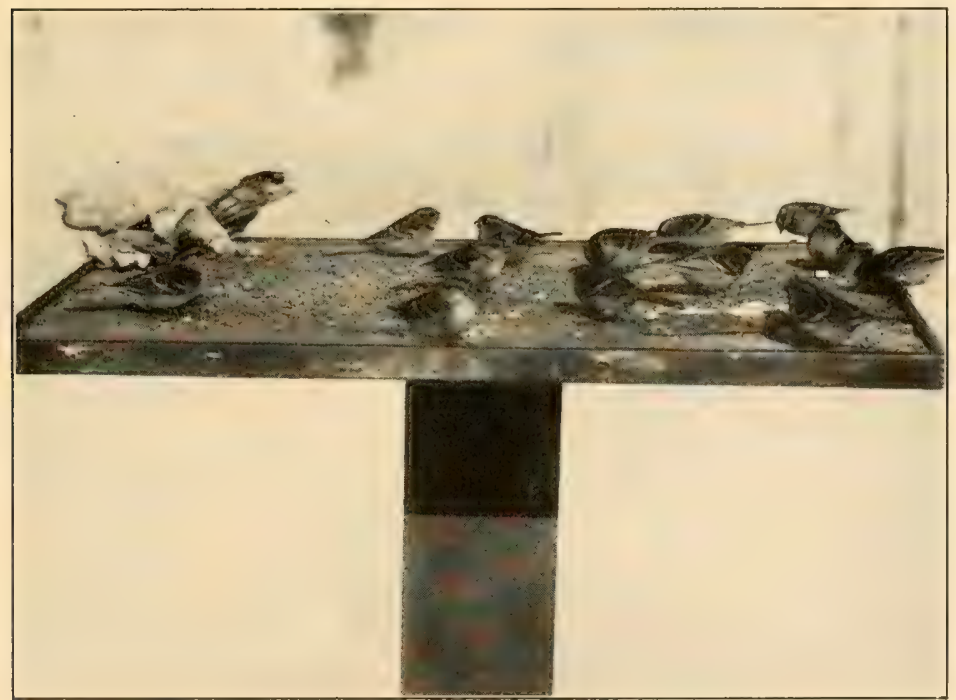

Tree sparrows at IV. G. Taylor's lunch-counter 


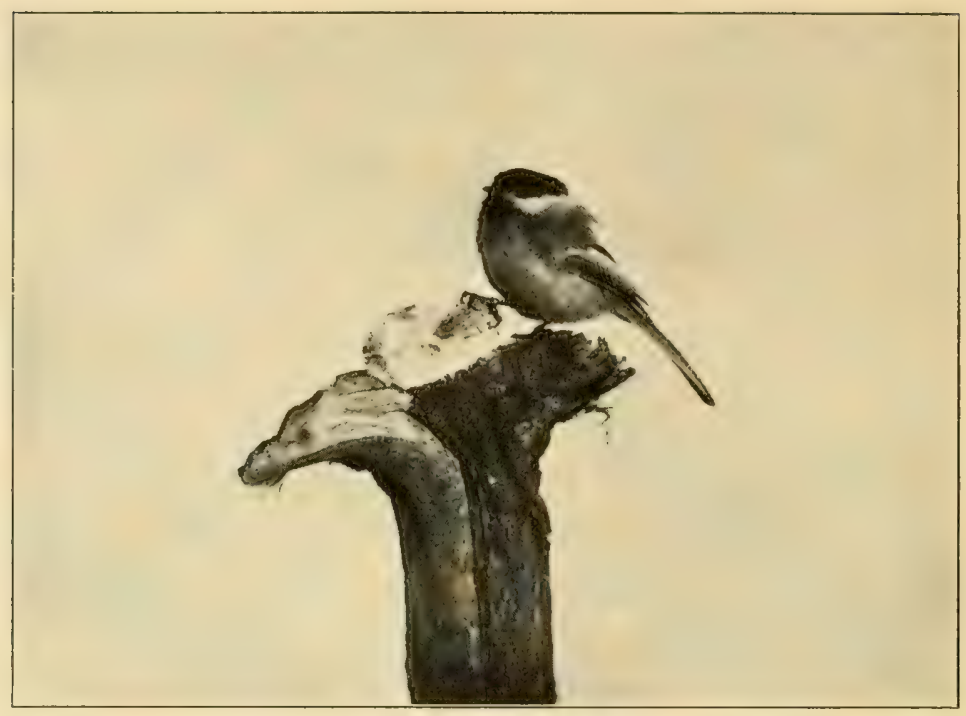

Chickadee feeding

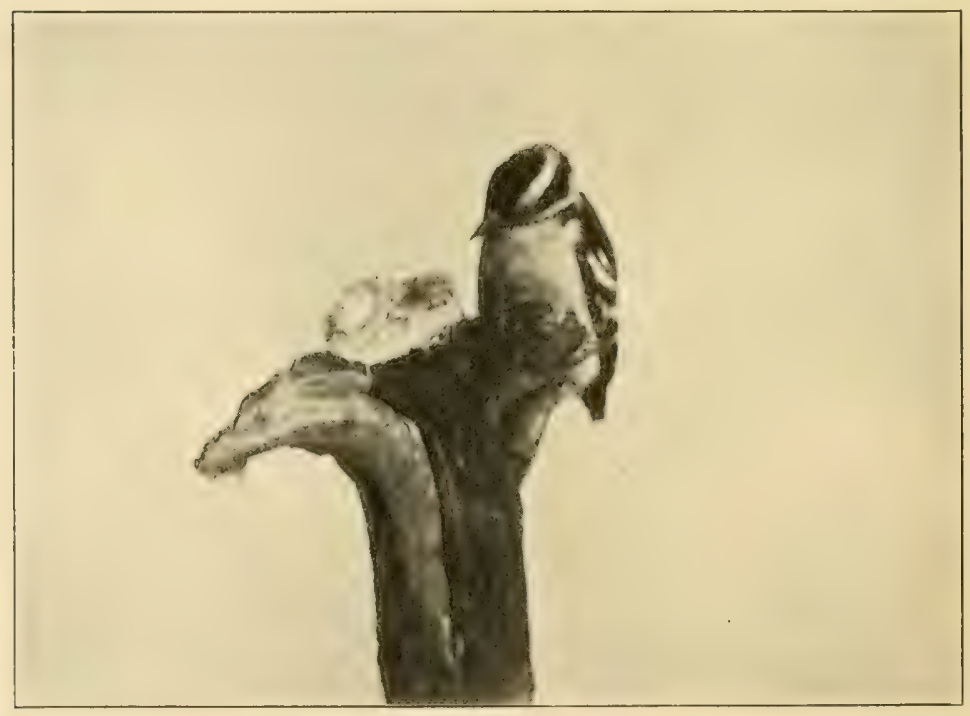

Downy woodpecker eating suct 
sparrow and junco. With these may come occasionally a song sparrow, fox sparrow, or white-throated sparrow. Well to the north, the common crossbill, white-winged crossbill, redpoll, pine grosbeak, evening grosbeak, Canada jay, and snow bunting have been fed. Ernest Harold Baynes, at Meriden, New Hampshire, has had most of these. Farther south, the cardinal, mockingbird, and tufted titmouse are more readily attracted. Just as I write this, Miss Frances H. Butler, of Woodstock, Connecticut, reports to me, under date of December 18 , a mockingbird which has stayed by the house for some days and eats berries from the woodbine, so one is always liable to get rarities.

In the category of the more unusual visitors to artificial feeding are the flicker and myrtle warbler, and Trafton in his book mentions the following casual records of species accepting artificial feeding: screech owl, white-crowned sparrow, rose-breasted grosbeak, pine siskin, red-bellied woodpecker, goldfinch, gold-crowned kinglet, horned lark, Lapland longspur, hermit thrush, winter wren, and also, from farther West, the yellow-headed blackbird, Clark's crow, Oregon jay, and gray-crowned rosy finch. In woods or fields we may also feed the quail, ruffed grouse, and pheasant, and on the edge of ice on ponds or streams, in severe cold snaps, various wild ducks.

Kinds of Food. For species which prefer animal food suet is the best and most attractive article that has been found. It does not freeze too hard and is easily taken by birds. The woodpeckers are probably the only ones that eat suet or meat exclusively. Nuthatches and titmice are practically omnivorous, as are most of the others. Birds of the sparrow and finch tribe are more fond of seeds, but they also eat suet to some extent, and a variety of other substances. Within certain broad lines it is not necessary to 
try to select certain particular foods for certain species. This artificial feeding is a makeshift at best, and birds when hungry are not particular, as long as they secure that which is capable of affording them nourishment.

Such birds as nuthatches and chickadees are particularly fond of ground-up nuts of any kinds, and broken squash and sunflower seeds, also ground-up dog biscuit, doughnuts, and bread crumbs. These are good also for all seed-eating birds, though seeds and small grains are easier and cheaper to provide for those which can use them. Barn sweepings are attractive to them, and certainly are cheap. Almost any small seeds will do, such as millet, hemp, rape, canary seed, and the like, also any ground grain. On the Henry Ford farm they have bags of (I) hemp, (2) canary and rape, (3) sunflower seed, (4) ground mixed-grain, with some beefscrap. The usual feeding had been equal parts of the first three, and one fourth as much of the last. It was found, however, that most birds greatly preferred the hemp and would eat that first, so the amount of this was increased, sometimes even to three quarters of the total supply. They' shell the hemp as they eat it.

Seasons for Feeding. Winter is, of course, the one time when the birds absolutely require food. Yet, while they can get it at other times, judicious use of it in a small way can sometimes be made in helping to attract more birds to one's own premises. For instance, suet kept up near the nesting-boxes may induce some individuals which remain in winter, such as chickadees and nuthatches, to occupy them for breeding. The presence of a feeding-tray, with a variety of attractive food, may induce spring arrivals to remain there to nest. Mr. Ford maintains such an arrangement on his estate, near his bungalow. It is a long, flat tray, made of boards, perhaps two feet wide and about 
a dozen in length, with a shallow rim around the edge to keep the food from blowing or washing off, and built upon posts about three feet high. Once a week the attendant puts out six or seven quarts of the mixture described above, in which time it is nearly all eaten. Robins use it very freely, also blue-jays and various species of the sparrows and finch tribe. Among others is the rose-breasted grosbeak, which many people are trying hard to attract. The grosbeak here devours the hemp seed with particular relish-a word to the wise. The large use to which this tray is put shows that summer feeding can be made of considerable account. It is pleasing to the owner of the premises to have so many more species brought under easy observation. The seed diet, of course, does not interest the strictly insectivorous birds like warblers or flycatchers, but orioles occasionally come. By the use of ants' eggs and such preparations as "mockingbird food" it might be possible to draw birds of this other type. Of course, though, we wish them to devote their energies largely to the insect pests on the premises.

Winter Feeding Methods. The various methods and devices for feeding birds in winter which have proved successful will now be described.

Suet Devices. Suet should be put up where the birds using it will be secure from cats as they eat. It can be fastened to a trunk or branch of a tree, and there is no need of any special perch, as the birds which use it are good hangers-on, whereas English sparrows will come more if there is a convenient perch. If merely nailed up it is liable to split off, so a better way is to tie it on, winding it around with twine. Still another method is to tack over it wire netting of rather small mesh, perhaps $\frac{1}{2}$-inch size. Through this the birds can reach in to eat, but cannot take off large pieces and waste it. Ready-made wire-mesh suet- 
holders are sold by several of the dealers listed in Chapter $\mathrm{XV}$. It is best to place the suet on the south side of the tree, preferably in a sheltered place. Otherwise suet can be placed on a shelf or platform, or as further described.

Feeding Seed. A simple shelf or platform is as good a place as any on which to place seed and small grain or a variety of foods for small birds. This is easier to keep free from snow, and is safer from attacks of enemies. This can be put in any convenient place, preferably where it is somewhat sheltered from cold winds. It is a matter of pleasure and interest to place it conveniently near a window, where the birds can be watched and enjoyed on the coldest and stormiest days. Just a simple platform, say a couple of feet square, on a post of convenient height, will suffice. The tray or platform should have around it a slight rim to keep the food from blowing off. Only a little food at a time is needed, replenishing it as is required. After snowstorms the snow can be swept off and more food supplied.

Taylor's Lunch-counter. Such an arrangement is used by W. G. Taylor, previously mentioned. Mr. Taylor has the lunch-counter near the kitchen window, and all winter has a constant procession of hungry birds, thankful for his hospitality. Nearly every day this kind friend of birds shells and pounds up fine about a quart of peanuts, which are gone by night, also various other nuts, seeds, crumbs, and suet. There are nearly always a crowd of tree sparrows and juncos, also numerous chickadees, white-breasted nuthatches, and downy woodpeckers, as well as some hairy woodpeckers and jays, and others casually. One winter there was a mockingbird which took possession of the establishment and was so selfish in keeping the other birds at a distance that Mr. Taylor reluctantly drove it off. Even 


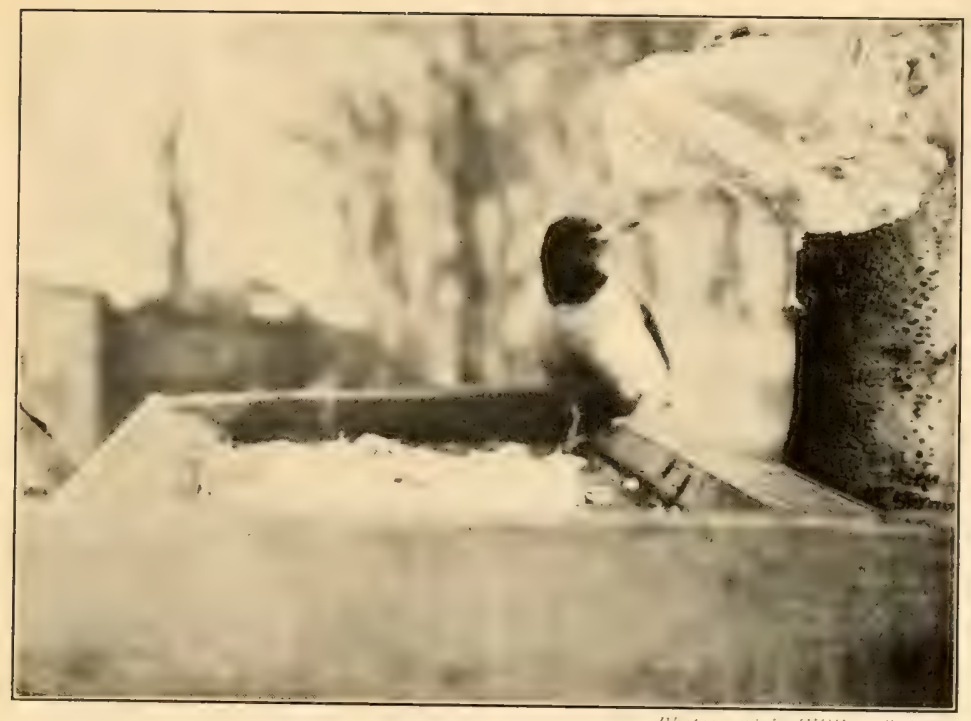

Red-headed woodpecker at lunch-counter

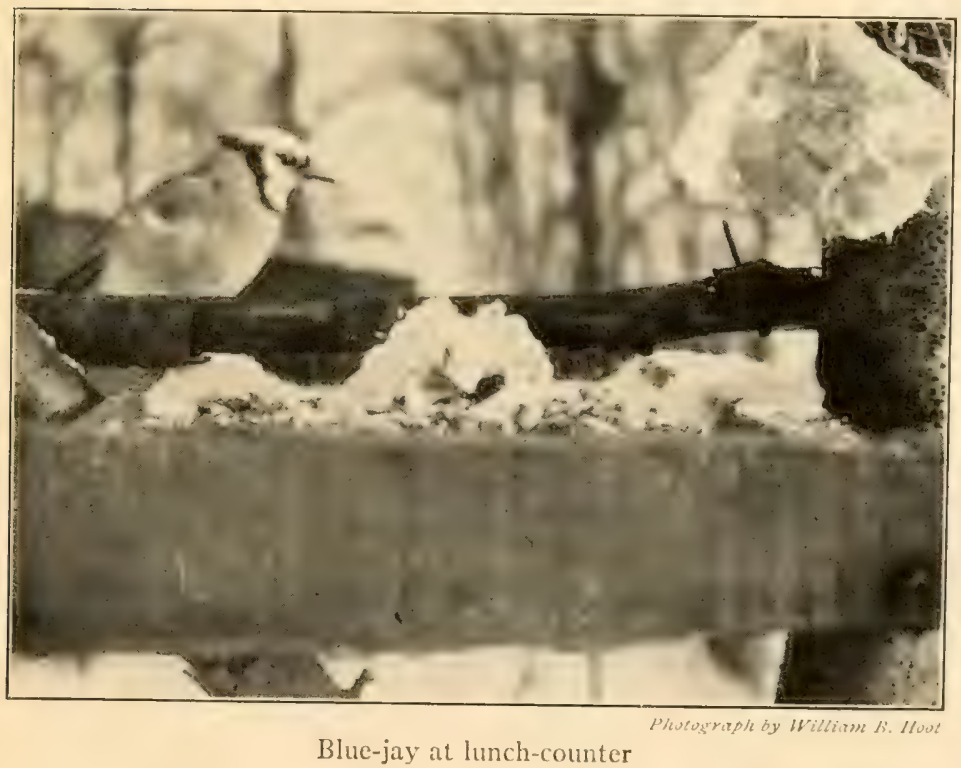




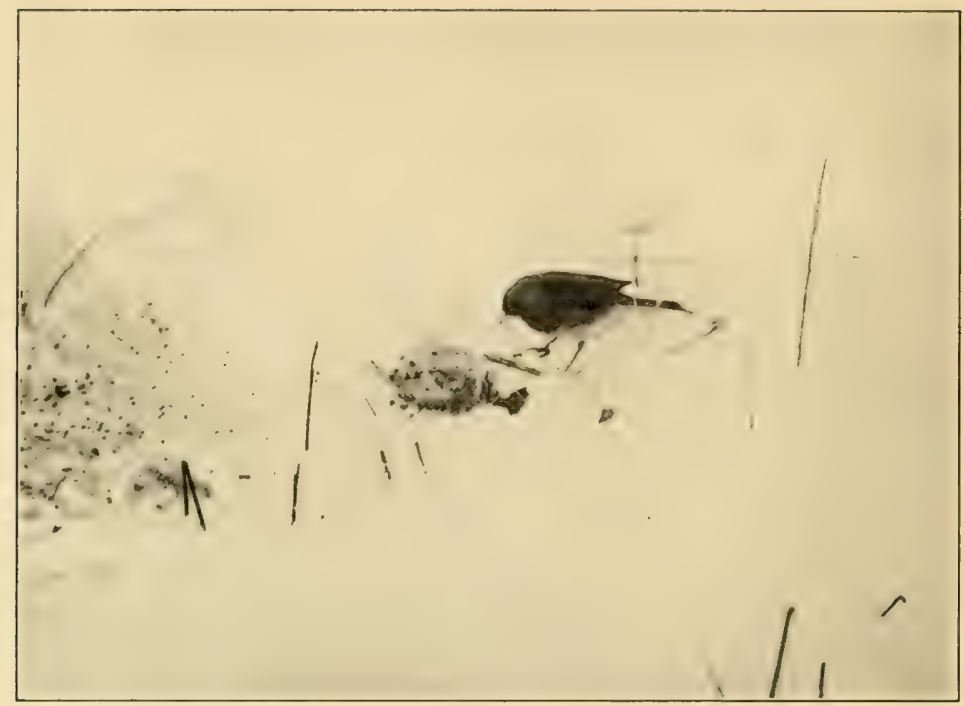

Junco or snow-bird eating seed sprinkled on snow

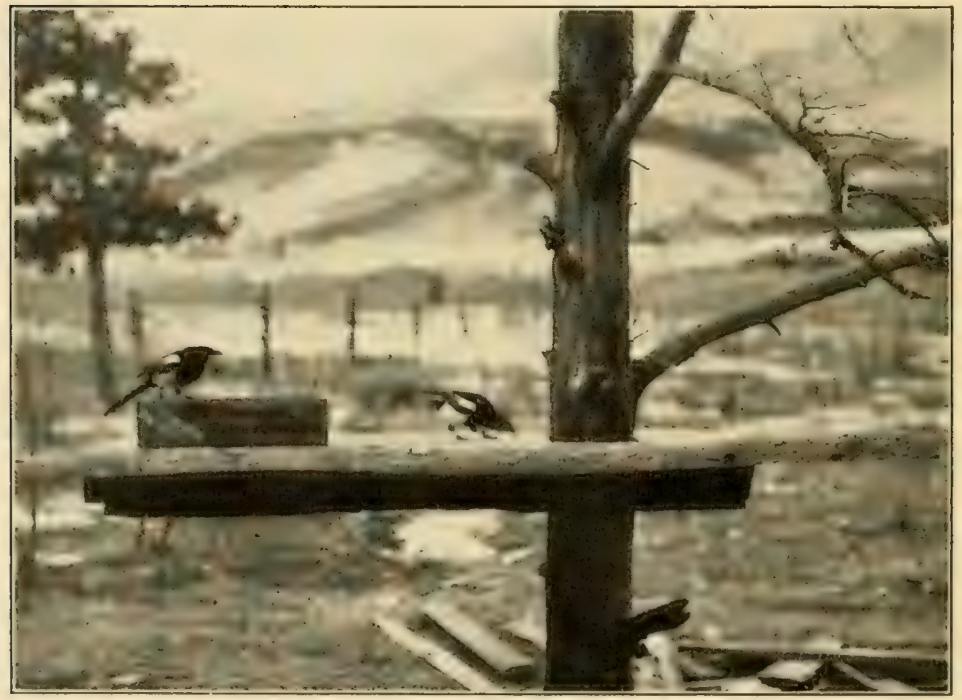

Magpies on food-shelf 
crows came into the garden in severe weather and picked the bones hung up in trees.

Movable Tray. When there is a tree handy to a window, some bird-lovers enjoy having a feeding-tray or lunchcounter that can be drawn back and forth on some sort of trolley arrangement between the tree and the window. If birds which come are at first a little shy, they can learn to get their meals out at the tree, and the tray can gradually be brought nearer, until it is right at the window.

Window Arrangements. Where birds will come to feed at the window some further plans for their entertainment and that of the pleased observers may be tried. The simplest thing, of course, is a little shelf or tray to hold the food. Some go further and build what might be called a windowbox. It is made of glass in a frame, and fits snugly into the partly-open window, so that no cold can enter, setting back from the window into the room. The floor of this is the food-shelf, and the birds feeding are thus brought practically into the room, separated from the observer only by the thickness of the glass, to which nearness they soon become accustomed. It affords fine opportunity to secure photographs if the window is in direct sunshine on the south side.

Birds' Christmas Tree. On the window-ledge a small evergreen may be placed, with food secured to the branches, as by the melting process described farther on. This exhibits the food plainly, and sometimes works very well. The children are especially pleased, and call this "the birds' Christmas tree." Any such little detail which serves to interest children in the birds is well worth while, as children thus trained are apt to gain lifelong interest in birds and their protection.

Tree Shelf. Small shelves for feeding can be put up 
against the trunks of trees. A simple way is to break off the front and part of the sides of a small box, drive in a few more nails to strengthen, if needed, and nail the upright part to the tree. Any other device will do just as well.

Ground Feeding. Seeds and small grain scattered on the ground in certain spots will attract birds of the class which use such food. Barn sweepings are enjoyed, and in the country are easily utilized. Such species as the junco are rather timid, and sometimes will feed better when the food is away from buildings in natural surroundings.

Drawing Pests. Of course putting food around is liable to draw pests. If rats are brought in by it, the best plan may be to feed up from the ground. English sparrows are apt to come, whatever methods are employed. They do not so readily eat suet hung on a perpendicular trunk, though they do it to some extent. About all one can do is to shoot them judiciously and also trap or poison them, as described above.

Von Berlepsch Designs. The philosophy of Baron von Berlepsch regarding feeding of birds is that ( $\mathrm{I}$ ) the methods must be readily accepted by those for which it is intended, (2) that they can be carried out in all weathers, and (3) they must be cheap and economical of material. With these requirements in view he devised the food-tree, the foodstick, the food-house, and the food-bell.

Food-tree. This represents a tree abounding with insects and larvæ, but through artificial means. It is made by taking a small evergreen, or part of one, and pouring on the twigs a mixture of various foods in melted suet, which is allowed to harden. As this destroys the foliage touched, it is well not to use ornamental trees near houses. "Christmas" trees which have been in warm rooms soon shed their leaves, and are not so good as those directly from the woods. 
Food Mixture. The following receipt is suggested in Hiesemann's book with the proportions in ounces, and is intended to serve only as a guide, not to be slavishly followed: white bread (dried and ground), $4 \frac{1}{2}$; ground meatscrap, 3; hemp, 6; crushed hemp, 3; maw, 3; poppy flour, $\mathrm{I} \frac{1}{2}$; white millet, 3 ; oats (ground), $\mathrm{I} \frac{1}{2}$; dried elderberries, $\mathrm{I} \frac{1}{2}$; sunflower seeds, $I \frac{1}{2}$; ants' eggs, $I \frac{1}{2}$. About one and a half times the amount of beef or mutton suet should be melted and the food stirred in. This can be kept when hardened, and heated again upon occasion. After several heatings more fat should be put in to replace the considerable loss by evaporation when heating. In applying, it is important to have it boiling hot and to let it settle down among the needles clear to the branches, to hold it well. Cakes of this, called "food stone," were said to be on sale in Germany, and they are also sold by dealers in this country listed above.

Food-stick. A modification of the above is the "foodstick." The plan, as described, is to cut a branch about 2 inches thick and some 8 inches long, bore in it, on one side, holes $\frac{3}{4}$-inch wide and of about that depth. Fill these holes with the melted preparation, and nail the stick to the tree, with the holes nearly downward to protect them from ice.

Food-house. The idea of this is simply that of the feeding-tray or lunch-counter already mentioned, but protected from the weather by a roof. It has been tried often in this country, and works well. The device consists of a central post which supports the pinnacle of the quadrilateral roof, and also holds the food-tray. Four other posts support the corners of the roof, which slopes down on each side from the point in the centre. The tray is a platform, about 2 feet square, through the middle of which the post runs, 
placed well up to the height of the eaves. In some models a rather narrow strip of glass runs entirely around the house just below the edge of the roof. This makes it possible to place the tray lower down, in better light, and yet protected from the weather. Lower down on the post is another smaller tray, which serves to attract the birds to the structure, though it is not so well protected. After feeding there they readily find their way up higher. It should be located in a warm, sheltered spot, where birds will like to come.

Weather-vane Food-box. Another covered feedingplace is a box of any rectangular shape with one end open. This is made to revolve on a rod on a post, with arms or "wings" extended on each side of the open end. This acts as a weather-vane, the wings turning the entrance to the box always away from the wind, so that snow does not drive in, and birds can always find food.

Food-bell. Still another device is the food-bell, which is an automatic device somewhat on the principle of the poultry self-feeders. Seeds and other foods are in a jar above, and drop down as fast as the birds eat it below. The exact mechanism is fully described in the Hiesemann book. It does not appear to be much in use in this country, as the few birds which we have in winter seem better served by the other simpler devices. Other curious and ingenious contrivances are also described in the above work.

Other Birds to Feed. Methods for feeding such birds as quails and grouse in winter have been described in Part I. In bitterly cold spells when nearly all water surface becomes frozen except air holes or small openings, and wild ducks congregate in these, it is a great boon to them to put out corn on the edge of the ice. This is often done by gamewardens and others, and many valuable wildfowl have thus been saved. 
Coöperation and Education. Public coöperation in these practical methods of all sorts described in this volume for increasing, propagating, attracting, feeding, or protecting birds goes hand in hand with the education of the public to the interest and value of bird life. It is important to get people to do things such as these. They will then become more interested and will do more and more. Get school children to make and put up nesting-boxes, or have them provide nesting-material and watch what the birds do with it. Organize school squads to feed the birds in winter. Let bird-lovers see that at least the rudiments of bird-study and bird-conservation are taught in the public schools. It is to be hoped that all who read these pages may realize more fully the great possibilities in many aspects of applied ornithology. These things are no sentimental fad, but have come to stay.

It seems as though the inventive ingenuity of man had reached the limit in the invention of murderous devices to exterminate the birds, but it is well that now so many are following the worthy example of Baron von Berlepsch, and are becoming ingenious and earnest in planning for their welfare instead of their destruction. The foundations laid by such organizations as the National Association of Audubon Societies and other organizations and individuals in this splendid endeavour have not been in vain. Let the good work go on. 



\section{ADDENDA}

(To be read at end of Chapter II, page 54.)

Miscellaneous Diseases. Wild gallinaceous birds are liable to the same troubles to which domesticated species are subject. I would refer readers to any of the numerous works on the care of poultry, turkeys, and ducks, and also to the excellent "Farmer's Bulletin Number 390," "Pheasant Raising in the United States," by Henry Oldys, which has a considerable section on diseases of pheasants.

\section{(To be read at end of Chapter XVI, page 254.)}

Tree-guards. Wire arrangements to prevent cats or other vermin from climbing trees to rob the nests of birds are sold by some dealers. It is easy, however, to make suitable contrivances. Two general plans are usually followed: one is to tack a sheet of metal around the tree. This should be at least six feet from the ground, and from one to two feet wide; the other way is to fasten a strip of wire netting around the tree, like a flaring collar, hornshaped, the wider end downward. If there could be a vermin-proof fence around the premises, these would not be needed.

\section{(To be read after section on "Food-bell," page 264.)}

Hanging Feeder. A popular and simple feeding device is to suspend by a wire-so that animals cannot reach it -some receptacle, covered on top, such as a hollowed cocoanut, a tin can, or other object, with a hole in the side, filled with suet or some food mixture. 



\section{INDEX}

Acid, boric, 127

tannic, I 26

Agricultural College, Connecticut, 247

Agriculture, Massachusetts State Board of, rog

U. S. Department of, 54, 109, 2I4, 238

Alternation of ground, 8, 23-24, 83$84,85,87$

American Game Protective \& Propagation Association, Intro, 63 , $25 \mathrm{I}$

Appeal of birds, 203

Applied Ornithology, Department of, Pref., Intro., 200, 205, 240, 265

Artificial method, 3,8

Attracting birds, $6,70,147-8,181-3$, I $99,203-265$

Aubry, E., I 22, I30

Audubon Societies, National Association of, Pref., Intro., 200, 205, 240,265

Austin, E. H., I30, I43

O. R., I43

Authorities, coöperation from, 20

Aviary pheasants, 76,86

Bantam, 29, 33, 5I-2, 98, I33, I47, I56, I66, I76

Barnes, A. M., 25I

Barley meal, I 7I

Bartlett, Captain, I86

Helen, 12

Bath, bird, 246-8

Baynes, Ernest Harold, 228, 257

Beebe, C. William, I88

Bent, A. C., II9

Berlepsch, Baron von, 133, 204-5, 2I I , 23I $244,255,262,265$

Berlepsch, Baron von, boxes, see Nesting-boxes

Blackbird, yellow-headed, 257

Bluebird, I46, 206, 21 2, 2I4, 216, $222,224,225,228,230$
Bobolink, 236

Bob-white, see Quail

Bog, 118

Box, see Nesting-box

Breeding, difficult, 95

intermitted, 140

preparation for, 79

retarded, I40

Brewster, William, 213

Bridges, H. P., 59, 7I, 73-4

Brockway, Arthur W., 220

Brooders, 8-9, 60, I62-3, I67, 194

Browse, 6 I

Brush, provide, 24,30

Buckwood pheasantries, I 2

Bunting, snow, 257

Bushes, tying, 245

Butler, Miss Frances H., 257

Calomel, I 27

Can, tin, 217,264

Capercailzie, $9 \mathrm{I}$

Captured ducklings, $173-4$

Cardinal, 257

Cat, domestic, 5, 43, 44, I08-9, I 28 , I38, 228, 231, 236, 254-5

-guard, 228, 254

wild, 5

Catbird, 220, 235, 236, 248

Catching stock, $30,48,84,85,88$, I 23,126

Cedar-bird, 235

Celery, wild, I48, I 70, I8I

Chamber, size, 222

Change of ground $8,23-4,83-4,85$, 87

Charcoal, 27, 37, 167

Chickadee, 204, 212, 214, 221, 222, $225,227,232,248,256,260$

Chicken, prairie, $16,55,65$

Chick-grain, 25, 4I-2

Children, 265

Childs-Walcott estate, see Walcott

Chill, I64

China, 75 
Christmas-tree, birds', 26r

Clark, Neil, 86-8, I 29, I3I, I 7I system, 86-8

Cleaning plumage, $125^{-6}$

Cleanliness, important, 25, 38, I28, I66

Clipping wing, 24, 46, 126, I84

Clover-leaf trap, 49

Clove Valley Club, 45, 86, I29, I62

Cocoanut feeder, 264

Colonies, protected, 200

Confinement, see Crowding

Connecticut State Game Farm, 14, 40

Construction, light, 24

Control, methods, $84,85,87-8$, I $45^{-7}$

Converse, Edmund C., I 22, I3O

Cook, Henry, I23, 125, I 29, I36, I 57, I 7 I, I 72, I95

Coop, 3I, 42, 82, 86, I6I, I67

Coot, or mud-hen, I54, I94-5

Covies, breeding in, 28

Cox, John A., I36, I38, I 54, I66, I 72

Crab, horse-shoe, I36, I 72-3

Crandall, L. S., I96

Crane, $196-7$ demoiselle, 197 Soudan crowned, 197

Creeper, brown, 256

Creosote repels birds, 227

Crissel, 26, 42

Critical period, 46

Crossbill, common, 257 white-winged, 257

Crow, $5,254,256,260$ Clarke's crow, or nutcracker, 257

Crowding, $45,77,8 \mathrm{r}$

Crustacea, $\mathrm{I}_{42}$

Curd, milk, 37

Custard, 36-8, 40-2

Dealers in apparatus, 2I4 in stock, $I I-12$ regulations for, 19-20

Dearborn, Ned, 250

Dipper, 2I 4

Disease, 54

duck, 122

grouse, 18-19

pheasant, $54,76-7$

precautions, $19^{-20}$

quail, $15-20,46$

turkey, 68-9, 74
Dogs, 43,97, I10, 190

Dove, ground, Ior mourning, 100-I, 245

Drumming, 65

Ducks, control free, I45 diving, sea, or marine, $116-7,118$, I35, I $4 \mathrm{I}-3, \mathrm{I} 63, \mathrm{I} 75$

edible, II 7

river, pond, fresh-water, marsh, I I 6-7, I35, I 74

wild, II 5-I80, 257, 264

young, or ducklings, I59-1 79

young in pond with adults, 144

Ducks, species:

Australian duck, I39

Bahama duck, I39

baldpate, II 7, II9, I20, I37, I $53-4$, I 67

black duck, II 7, I 24, I33, I37, I 39, I 43, I 44, I46-8, I 53, I 57 , I67

blue-bill, or broad-bill, see Scaup Duck

bufflehead, or butter-ball, II7, I 80

canvasback, or canvas-back, II 7 9, I $22, \mathrm{I}_{35}-7, \mathrm{I} 42, \mathrm{I} 53, \mathrm{I} 63$, I67, I $76-7$

coot, or sea-coot, see Scoter

eider, $\mathrm{II}_{7}, \mathrm{I} 35, \mathrm{I}_{4} 2, \mathrm{I} 76$

king, II 7

northern, II 7

fish duck, see Merganser

Florida duck, II 7

gadwall, II7, II9-20, I 23, I37, I 39, I $50, I_{53}, I_{57}, I_{67}, I_{77}$

golden-eye, II7, I63, I 73, I75, I77178

Barrow's, II 7

harlequin duck, II 7

Labrador duck, I $8 \circ$

mallard, II7. II9, I24-6, I3I, I33, I37, I39, I 45-7, I 49, I 5-5, I 57, I60, I6 $3,167,177-8$

mandarin duck, I37, I39, I54, $\mathbf{I} 56-7, \mathbf{1 6 3}, \mathbf{1 6 6}$

merganser, II 7, II $9, I_{4} 2$

old-squaw, II 7

Pekin duck, 122, 157

pintail, I17, II9-20, I24, I33, I37, I39, I 50, I53-5, I67, I77

pochard, I35, I5०

redhead, II7-9, I36-7, I39-40, I42, I53-4, I57, I67, I76 
Ducks, species-Continued

ring-necked duck, II 7

rosy-billed duck, 139

ruddy duck, I $17,153,174,176$

scaup duck, I 42, I 43, I 53

greater, II 7 , II9

lesser, I17, I19, 136-7, I55, I 67, I 73, I 76,178

scoter, 142,163

surf, II 7

velvet, II 7

white-winged, II7, II9, I53, I $73,175^{-6}, 178$

sheldrake, see Merganser

shoveller, I1 $, 119-20,137,139$, I 50, I $53-4$, I 56-7, I67, I 77

spotted-billed duck, I39

teal, I20, I37, I39, I50, I53-4, 156-7

blue-winged, II 7, II9, I23, I37, I $53,155,167, I_{77}$

cinnamon, II7, II9, I39, I67

garganey, 139

green-winged, II7, II9, I37, I39, I4I, I55, I67, I77

Pampas, I39

tree duck, I23, I39, I78

fulvous, 139, I 57

red-billed, 139,157

tufted duck, I35, I 50

widgeon, see Baldpate

European, I39, I 50, I 57

Dynamiting, $\mathrm{I} 38$

Eastman, George, 236

Education, 265

Egg-eating, 79

Egg, ants', 37

boiled, $36,38,40-2$

distributed, 82

keeping, 33, I55

laying, or production, $32-3,59$, $72-3,8 \mathrm{I}, \mathrm{I} 32, \mathrm{I} 52-4,196$

setting, 33

taking, 33,155

thin-shelled, I4I

transporting, 155

Egret, $197-8$

Enclosure for ducks, I37-8, I64, 167

Enemies, see Vermin

English system, ducks, I49-5I

Enteritis, 46

Entrance-hole, size, 219, 22I-2
Escape, 47

Evans, Wallace, II, I4, I6, 27, 40, $44,46,65,109,136,140,147$, I $57,164-5$, I 7 I

system, 84-6

Evergreens, see Vegetation

Exercise important, 25

Failures, reasons for, $\mathrm{I}_{5} \mathrm{I}-2$

Farmer's Bulletins, 54, Io9

Farming, goose, I 88-9 I

Feather-plucking, 79

Feeder, automatic, 264

hanging, 264

Feeding wild birds, 6, 70, 95, I8I-3, $236-46,255-65$

on ground, 262

seasons for, $25^{8}-9$

stations, 6

Fencing, 2I-4, 43-4, 7I-2, 83-4, 87, I20, I38, I60, 166

Fertility, 158

Fields, fenced, 43

rearing, 43, I6 I

Fighting, 57, 78, 96, 187, 192

Finch, 259

gray-crowned rosy, 257

house, 214

purple, 235

Finley, William L., 99

Fish, I18, 127, I42, I 54

heads, I39

live, 136

minnows, $136,138-9$

raw, 196

scrap, 127

shell-, I42, I 76

Flicker, 21 2-13, 222, 225, 227-8, 230, 248,257

Flies, 39, 4I

Flycatcher, 259

crested, 214, 222, 225, 230

least, 235

Food, animal, 26, 39, 42, 127-8, 130, I 43, I68-70, I 7 I, I 74-5

-bell, 264

-box, 264

browse, $6 \mathrm{r}, 64,185,192$

for adults, $24-7,64-5,72,125$, I $27-31,136,138-43$

for young, $35^{-42,}, 167-177$

forcing, $26-7,127,130$

grain, 25, 38, 40, 6I, I 27-30, I42, I 52 , I 70-I, I85, I92-3, I96, 259 


\section{Food-Continued}

green, 26, 39, 6r, 64, 72, I28, I39, I $70,185,192$

-house, 263

insect, $39,61,64,97,139,174-5$, I 96

lack of natural, 93

mixture, 263

plants, see Planting

sea, $142,{ }^{7} 6$

-stick, 263

-tree, 262

Fonts, drinking, 168

Forbush, E. H., 109, II2-13, 216, $220,228-9,232,239,240$

Ford, Henry, 216, 220, 221, 229-30, 258

Fountain, see Bath

Fox, 5, 44, 71, 106, I 22

Free range, $43,84-5,145-7,189-90$

French system, 96

Frey, A. N., 125

Gallinaceous birds, 3-99, I3I

Gallinule, r95

Game Breeder, The, Intro., 94

Game Breeders' Association, I7

Game, dealers in, II-I2

Game-warden, Intro., 264

George, Amos E., 6I

German systems, 97-8, 158-9, 204206,2 I I-I 2

Going-light disease, 178

Goldfinch, 235, 257

Goose, brant, 184

Canada, 184-9 I

Egyptian, 144

snow, 184, I90

white-fronted, I 84

wild, I $84-19$ I

Gourds, 218

Grackle, 237, 245, 248

Grain, see Food

Grant, W. W., I 75

Grass, diet, 185

Grebe, I 54

Grit, 27, 37, 167

Grosbeak, evening, 257

pine, 257

rose-breasted, $248,257,259$

Ground, change, 42

Grouse, 253, 264

black, 9I

blue, 55
Grouse-Continued

dusky, 55

pinnated, 55

ruffed, $6,16,55-65,257$

sage, 55

sand, $9 \mathrm{r}$

sharp-tailed, 55

Guide to Nature, 219

Guinea-fowl, 92

Harem, 8o

Hatching, 8, 72-3, 82, 87, I 59 -houses, 34, 87, I 57

Hawk, 5, I03, 253

Cooper's, 253

duck, 253

gos (goshawk), 253

pigeon, 253

sharp-shinned, 253

sparrow, 2I4, 222

-trap, 103-4

Heat, artificial, I 24

Hen, heath-, 55

Hens, $8,43,47-8,60,87, \mathbf{1 5 6}, \mathbf{1 5 9}$, I6I, I66

Heron, I $97-8$

black-crowned night, 237

Heywood, John, I 2

Hiesemann, 205, 244

Hodge, Dr. C. F., 14 , 56, 57, 247

Hogs, 74

Holding-pen, 21

Holding stock on land, 48, 69

Homing instinct, 145,206

Hookworm, 18

Hopkins, Frank, 40

Horne, I. S., II, I6

Howell, T. A., 54, 64, 108, 145

Humming-bird, 248

Hunting, 88

Incubate, failure to, 9

Incubation, 8-9, 34, I 54, I 56-9

Incubator, 34, 60, 97, 157-9, 162, I95

Indigo-bird, 236

Industry, birds by, Intro., 89

Insect, see Food

Islands, I I9, 133, I36, 137, I38, 192

Jay, blue-, 237, 248, 254, 256, 259, 260

Canada, 257

Oregon, 257 


\section{INDEX}

Jekyl Island, Ga., 74

Junco, or snowbird, 257, 260

Kennard, F. H., 68, 227, 238, 240

Kingbird, 234, 235, 248

Kinglet, golden-crowned, 257

Klein, George J., I 2

Lanier, Charles D., I47

Lark, horned, 257

Larsen, 94

Law, IO, I9-2I, I02, 135

Laying, see Eggs

second, 59

Leaves, fallen, 245

Liberating stock, $7,94-5$

Liming, I6I

Lockwood, Wilton, I36, I38, I40

Longspur, Lapland, 257

Lopping trees, 245

Lord, Rev. William R., 232

Lunch-counter, 259

Mackensen, W. J., II

MacVicar, A. G., I4, 28, 40, 63, II I 29, I 50, I 5 I, I 76, I 86

Donald, 63, I 76

Maggots, 39, I75

Manross, F. N., I5, 56, I16, I65

Martin, European, 205

purple, 206, 21 4, 218-20, 222, 225, 231

Martin-house, 205, 218-I9, 23I

Massachusetts Game Commission, I4

Mating, 29, 30, 95-6, I 84, I86-7, I9O, I92

McAtee, W. L., I8I, 238

McIlhenny, E. A., I53, I77, I97-8, I99

McLean, Hon. Geo. P., I4, 48, 5 I, 60

Meadowlark, 236

Meat, dried, 39

Mellen, Mrs. Geo. H., 247-8

Mental state, I34-5

Meriden Bird Club, 240

Mexican stock, 4 , II, I6

Mice, 228

Milk, 37, 6r

Mink, 71 , 106, I38, I54, I85, I90

Mockingbird, 257,260

Moderation, in feeding, 25, 35, I68

Modified methods, 163
Moisture, for nests, 235. Also see Incubation

Monogamy, 20, 27, I 24

Moth, gypsy, 227

Mud-hen, see Coot

Muskrat, 5

Native birds, I 3

Natural methods, 3-6, 209-10

Neatness, overdone, 244

Nesting, 32, 96, 97, I 20, I37, I52, I87, I93, I95

Nesting-boxes, I33, 2 I I-232

bark, 2 I 8

care for winter, 232

cleaning, 23I

earthenware, 2 I 8

furnishings, 223

height, $225-6$

hollow limb, 227

location, 223-3I

making, 2II, 2I5-I 7

placing, 205

roofing-paper, 228

standardizing, 2I 5

starch-box, 2 I 8

used in winter, 232

Von Berlepsch, 2I3, 2I6, 225, 227, 228

Nesting material, supplying, 233-5

Nests, cleaning, $87,23 \mathrm{I}$ concealment for, $243-4$ sites for, 244-5

New Jersey Game Commission, r $_{4}$

New York Zoölogical Park, I 28

Nuthatch, 204, 248, 256

white-breasted, 21 I, 214, 222, 256 , 260

red-breasted, 256

Oates, Capt., I $_{57}$

Oiling, I6o

Oklahoma, I6

Oldys, Henry, 54

Oregon, 75-6, 99

Oriole, Baltimore, 234, 248, 259

Owl, 5, 103, 248

barn, 214,222

great horned, 253-4

saw-whet, 214, 222, 235

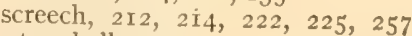

Oyster-shells, 27 
Packard, Winthrop, 228

Pairing, 29, 30, 95-6, 190

Pan, bathing, I63, I65, I67, I70, I 74, I 76

Partridge, chukar, oI gray or Hungarian, 4, 92, 99 red-legged, or French, 91 spruce, 55

Pastime, 88

Pearson, T. Gilbert, Pref., Intro., I97, 22 I

Pens, 2I-4, 58, 79, 8I, 96

Pensioners, see Wounded

Percy, Lord William, I49

Personalia, Introduction

Pewee, wood, 235

Phasianidæ, 75

Pheasant, 45, 75-90, 91, 257

English, 75

golden, 76

Lady Amherst, 76

Manchurian, 76

meal, $38,4 \mathrm{I}$

Mongolian, 76

Oregon, 76

Reeves, 76

ring-necked, $75-90$

silver, 76

Phillips, Dr. John C., I46, I54

Phoebe, 21 5, 220, 221, 225

Pickerel, I 54

Pigeon, passenger, roo band-tailed, ror wood, IOI

Pike, I 54

Pinioned, 138 , I96

Pinioning, $82,86,126-7,185$

Planting grain or food, $6,70,72,95$, I $81-3,185,236-46$. Also see Vegetation

Plucking geese, I9I

Pneumonia, I22

Poisoning, 70-I, I IO-II, 250-I, 262

Pole, 219, 227-230

erecting, 330

Polygamy, 27, 57, 58, 65, 78, 124-5

Pond, I 15-1 18, I 29, I36, I37, I47-8, I 80, I $85-6$, I 95

Portal, Maurice, 196

Poultry, dangerous, 18

Powell, G. T., 239

Preserves, game, 208-9
Prices, 78, 89

Privacy, important, 28, 59, I52

Problems of breeding, I3I, I34

Profession, new, Intro.

Profit, financial, Intro., 89,180

Propagation, value of, 64

Ptarmigan, 55

Pugnacity, 57

Pulling quills, $149-51$

Quail,

bob-white, 4, 13-52, 93

blue, see Scaled

California, 8, 50, 52-54

European, 92

Gambel's, 5o, 52

Messina, 4, 9r

monogamous, 20

mountain, 50

scaled, 50, 5 I

valley, see California

Quails, 9, 98, 253, 257, 264

Quarantine, useless, I9

Quarles, E. A., 25 I

Quarters, winter, 2 I for wildfowl, II $7-124,185$

Raccoon, 4, 74, 106, 206

Rats, 43, I09-I10, I33, I38, 253

Rearing-fields, 35

Receiving stock, 24

Redpoll, 257

Reservations, protected, 4-5, 199

Responsibility, public, 180

Restocking, 7, 74

Results, immediate, 210

Rettger, Dr. L. F., 15, 18, 37

Rice,

constipates, $4 \mathrm{r}$

wild, 181,183

Robin, 214, 220, 221, 225, 234, 235, $237,245,248,252,259$

Rockefeller Foundation, 199

Rockefeller, William, 4, I r, 9I-2, roI, 251

Rogers, Harry T., I4, I6, 27, 38, 49, $5 \mathrm{I}, 54,62,65,77,79,80,82,93$, I10, 17 I, 186

system, $83-4$

Sage, Mrs. Russell, 199

Salt, I43

Saskatchewan, II9

Savage, C. H., 93 
Schools, bird-study in, 265

Scott, Adam, I3I, I6I

Seidler, Ludwig, 4I, I 58, I 7 I, I72

Selden, B. H., I4

Separate, $185,192-3$

Setting

eggs, 33

hens, 34

Shade 22, 27, 43, 60, 138, 160, I62

Shaw, C. H., 8, 53

Shelf, feeding, 259, 260

window, $26 \mathrm{I}$

tree, $26 I-2$

Shelter, 6, 2I, 22-3, 72, 77, I20-4, $130,185,196$

woods, 244

Shelves, nesting, 220

Shooting, protection for, 4-5

Shore birds, 194

Shrubbery, see Vegetation

Silkies, 33, 176

Siskin pine, 257

Size, unimportant, 204

Skunk, 5, 106, 108, 253

Snakes, 74, I 1 8, 154, 253

Soil, composition of, good, 83

Song-birds, 203

Souring, bad, 25,38, I 28

Sparrow, 235, 248, 259

chipping, 234, 235, 237, 252

English, 215, 22I, 225, 228, 23I, $250,254,259$

fox, 209,257

song, 2I 4,257

tree, 256,260

white-crowned, 257

white-throated, 209, 257

Sportsman, true, Intro.

Spratt, 4O, 4I

Squirrel,

flying, 206, 225, 228, 23I, 253

red, $5,225,253$

gray, 225, 253

Starling, 2I 5, 2I6, 22 I, 254-5

Starting, I0, 77, I43

States, method for, 84

Staying with hens, $47-8$

Stock, receiving, 125 securing, 9-10,20,56, 77, I 24 southern, II

Storrs Agri. Experimental Station, I5

Connecticut, I6
Strongylus, I8

Strutting, 62, 65

Suet devices, 259-60

Sulpher, 27

Surroundings, making attractive, 236,254

Swallow, barn, 206, 21 5, 220, 235

eave, or cliff, 206,235

tree, 206, 21 4, 222, 225, 228

violet-green, 2 I4, 222

Swan, 192-3

trumpeter, 192

mute, 192

black, 192

Swimming, I60, I63-7

Talbott, J. W., I2

Tameness, 59, 68

Taylor, W.G., 233--5, 259

Terrell, Clyde B., 18I-3

Thinking bird, 223

Thompson, Mrs. F. F., I00-I

Thompson, Raymond B., 219

Thrasher, brown, 235, 243, 248

Thrush, 235

hermit, 209, 257

Tilley, Geo. D., 1 2, 92

Time to acquire, 2 I

Tinamou, 9I-2

Titcomb, J. W., I8I

Titmouse, tufted, 2I 4, 222

Tooting, 65

Trafton, Gilbert H., 239

Tragopan, 9I

Trap, 49

Barnes, 25I

box, 104-5

clover-leaf, I05

Evans, 104-5

hawk, I03-4

hole-in-fence, 107

mink, 106

pitfall, ro5

stone-pile, Io7

weasel, I06

Trapping, 5, IO3, III, I 27, 25I-2, 262

Treaty, International, 200

Tree-guard, 254

Troughs, I62

Turkey, Florida, 67

Merriam's, 67

Mexican, 67

mongrel, 68 
276

Turkey-Continued

Rio Grande, 67

wild, $67-74$

Turtle, I I 8, I38, I44, I54

Value, economic, 204

Vegetation, aquatic, II8

attractive, $236-46$

deciduous trees, $240-1$

evergreen, 237, 24I, 243

food-bearing, $238-43$

herbaceous, 243

shrubbery, 237-9, 24I-2

vines, $242-3$

Vermicelli, 175

Vermin, $5,7,43,74,98$, IO3-II, I33, I $44,185,248-54,262$

methods of destroying, 70-1, $\mathrm{IO}^{-}$

III, 250-4

-proof fence; 23

Vices, 79

Vireo, 234, 235, 248

Wachtel, 97

Wading birds, 194-8

Walcott, Frederic C, I25, I35, I38, I 45, I 49, I 50, I 5 I, I 7 I, I 72, I 75 , 190

estate, or preserve, I06, I2I-2,

I 29, I $46-8$, I 79

Wapato, I82

Warbler, 204, 209, 235; 237, 248, 259

myrtle, 257

Warren, Dr. A. F., I4I
INDEX

Water, drinking, $27,4 \mathrm{x}-2, \mathrm{I} 43, \mathrm{I} 6 \mathrm{r}$, I $66, I 68,236,246-8$

-plants, I8I-3

Waterfowl, II 5-200

Watts, Ernest A., I00

Waxwing, 248

Weasel, 5, 71, 106-7, 1 10

Weather-vane feeder, 264

Wharton, William P., 226-9

Whealton, J. W., I2, I44, I87-9I

Whisker, William, ro8

Whorls, by pruning, 244-5

Wildcat, 5

Wildness, I 54, I77, I84

Wind-break, 238

Window-shelf, 26 I

Wintering, 6, 2I, 50, 54, 72, 77, I $2 \mathrm{I}-4$, I37, I4I, 259-62

Wire, see Fencing

Woodcock, I 94

Woodpecker, 2I I, 2I 2, 225, 230, 256 downy, 2I4, 222, 225, 256, 260 hairy, $214,222,225,256,260$ red-bellied, 257

red-headed, 2I4, 222, 225, 230

Woodmont Club system, 69

Worms, I4I

Worthington, C. C., $7 \mathrm{I}$

Wounded birds, 56 , I 43, I $50-1$

Wren, I46, 2I I, 22 I, 225

Bewick's, 2I4, 222

Carolina, 214, 222

house, 206, 2I4, 222, 230, 234

winter, 257

Wright, Mrs. Mabel Osgood, 243

Yards, uncovered, 22 



SMITHSONIAN INSTITUTION LIBRARIES 